\title{
„Ex vivo“ Replikation des pathogenen Prion Proteins
}

\author{
Dissertation \\ zur Erlangung des Doktorgrades \\ der Mathematisch-Naturwissenschaftlichen Fakultäten \\ der Georg-August-Universität zu Göttingen \\ Vorgelegt von \\ Dipl. Biochem. Lars Heinig \\ geb. 29.4.1978 in Karl-Marx-Stadt, jetzt Chemnitz
}


D7

Referent :

Koreferent:

Prof. Dr. Oliver Einsle

Tag der mündlichen Prüfung:

Prof. Dr. Frauke Melchior

2.11.2006 


\section{Inhaltsverzeichnis:}

1

1.1

1.2

1.3

1.4

1.5

1.6

1.6.1

1.6 .2

1.7

1.8

1.9

2

2.1

2.1.1

2.1.2

2.1 .3

2.1.4

2.1 .5

2.1.6

2.1.7

2.1 .8

2.1.9

2.1.10

2.1.11

2.1.12

2.1.12.1

2.1.12.2

2.1.12.3

2.1.12.4

2.1.13

2.1.14

2.2

2.2.1

2.2.2

2.2 .3

2.2.3.1

2.2.3.2

2.2.3.3

2.2.3.4

2.3

2.3.1

2.3.2

2.3 .3

2.3.4

2.3 .5
Einleitung

Die Prion Hypothese

TSE-Erkrankungen

Die Molekularbiologie des Prion Proteins

Der zelluläre Zyklus des PrP

Mögliche Funktionen des $\operatorname{PrP}^{\mathrm{C}}$

Modelle zur TSE-Detektierung

Tiermodelle zur Detektion von TSE-Erkrankungen

Zellkulturmodelle zur Detektion von TSE-Infektionen

Retroviren

Tetracyclin regulierte Proteinexpression

Aufgabenstellung

Materialen und Methoden

Molekulargenetische Methoden

DNA-Isolierung aus Blut

DNA-Isolierung aus Zellkulturen

DNA-Isolierung aus Gewebe

Plasmidisolierung aus transformierten Zellen

DNA-Amplifikation mittels Polymerase Kettenreaktion (PCR)

Reinigung von PCR-Produkten

Agarose-Gelelektrophorese

DNA-Spaltung durch Restriktionsendonukleasen

Isolierung von DNA-Fragmenten aus Agarosegelen

Photometrische Konzentrationsbestimmung von DNA

Dialyse von salzhaltigen Lösungen

Klonierung von DNA-Fragmenten

Dephosphorylierung von DNA-Fragmenten

Ligation von DNA-Fragmenten über Restriktionsschnittstellen

TA-Klonierung von DNA-Fragmenten

Adenylierung von DNA-Fragmenten

Restriktionsfragment-Kartierung

DNA-Sequenzierung

Prokaryontische Techniken

Bakterienkultivierung

Bestimmung der optischen Dichte von Bakterienkulturen

Transformation von E. coli

Herstellung elektro-kompetenter E. coli

Herstellung chemisch-kompetenter E. coli

Transformation elektro-kompetenter E. coli

Transformation chemisch-kompetenter E. coli

Eukaryontische Techniken

Kultivierung von eukaryontischen Zellen

Lebendzellzahlbestimmung von eukaryontischen Zellen

Herstellung transienter Zellen durch Micellen

Herstellung stabiler eukaryontischer Zellen durch Elektroporation

Retrovirale Transfektion eukaryontischer Zellen 
Bestimmung der Transfektionseffektivität anhand der Luziferaseaktivität 36 monoklonalen Antikörpern (mAK) (CD)-Spektroskopie (MALDI-MS)

Material 51

Antibiotika $\quad 51$

Antikörper 51

Proteaseinhibitoren $\quad 52$

Kulturmedien $\quad 52$

Chemikalien $\quad 52$

Medien $\quad 53$

Lösungen $\quad 54$

$\begin{array}{ll}\text { Ausgangsvektoren } & 57\end{array}$ 
3.5.1 Detektionsminimum der $\operatorname{PrP}^{\mathrm{C}}$ Expression im WB 83

4.2.1 Herstellung stabil tTA exprimierender Zelllinien 102

4.2.2 Herstellung doppelt stabiler $\operatorname{PrP}^{\mathrm{C}}$ exprimierender Zellen 103

$\begin{array}{lll}4.3 & \operatorname{PrP}^{\mathrm{C}} \text { Expressionsanalysen } & 103\end{array}$

4.3.1 $\quad \operatorname{PrP}^{\mathrm{C}}$ Expressionsanalyse durch den WB 104

4.3.2 Immunfluoreszenzmikroskopie zur Detektion der $\operatorname{PrP}^{\mathrm{C}}$ Expression 105

4.3.3 $\quad \operatorname{PrP}^{\mathrm{C}}$ Expressionsanalyse mit Hilfe der Durchflusszytometrie 105

4.3.4 Sekundärstrukturanalyse mit Hilfe der CD-Spektroskopie 106

4.4 Ko- und Überexpression von Proteinen während der $\operatorname{PrP}^{\mathrm{C}}$ Expression 107

4.5 Infektion von reguliert $\operatorname{PrP}^{\mathrm{C}}$ exprimierenden Zellklonen 109

4.5.1 $\quad \operatorname{PrP}^{\text {res }}$ Nachweis durch den Western Blot 109

4.5.2 $\quad \operatorname{PrP}^{\mathrm{Sc}}$ Nachweis mit Hilfe der Durchflusszytometrie 110

4.6 Mögliche Erweiterung des neu geschaffenen Systems 112

\section{Anhang}

Danksagung

Lebenslauf 


\section{Abbildungsverzeichnis:}

Abb. 1 Replikationsmodell des $\operatorname{PrP}^{\mathrm{Sc}} \quad 1$

Abb. 2 Histologischer Schnitt durch ein CJD geschädigtes Gehirn 2

Abb. 3 Epidemiologischer Zusammenhang von BSE und vCJD in England 4

Abb. 4 Auftreten von CWD in Nordamerika während der letzten 5 Jahre 5

Abb. 5 Zellmembran mit gebundenen $\operatorname{PrP}^{\mathrm{C}} \quad 6$

Abb. 6 Aufbau des murinen prnp Gens $\quad 7$

Abb. 7 Aufbau des humanen prnp Gens $\quad 7$

Abb. 8 Durch NMR Analyse bestätigte $\operatorname{PrP}^{\mathrm{C}}$ Sekundärstruktur 8

Abb. 9 Zwei vermutete $\operatorname{PrP}^{\mathrm{Sc}}$ Sekundärstrukturen, die noch nicht durch NMR 8 Analyse bestätigt wurden

Abb. 10 Zellulärer Zyklus des PrP 9

Abb. 11 Schematischer Aufbau eines Retrovirus 14

Abb. 12 Genomstruktur der LTR-Region eines Retrovirus 14

Abb. 13 Replikationsmodell eines Retrovirus in der Zelle 15

Abb. 14 Strukturformel des Tetracyclins 16

Abb. 15 Regulation einer Proteinexpression durch das Tet-Off System am 17 Beispiel des PrP

Abb. 16 pGEM-T Vektor $\quad 57$

Abb. 17 pCMV/Bsd Vektor $\quad 58$

Abb. 18 pTet-Off Vektor 58

Abb. 19 pTRE-FU Vektor $\quad 59$

Abb. 20 pBI-EGFP Vektor $\quad 59$

Abb. 21 pRev-TRE Vektor $\quad 60$

Abb. 22 pUC19 Vektor $\quad 60$

Abb. 23 pGL3 Vektor $\quad 61$

Abb. 24 PCR-Amplifikate der verschiedenen prnp Fragmente auf einem 63 1\%igen (w/v) Agarosegel

Abb. 25 BSA-Eichkurve in $\mathrm{H}_{2} \mathrm{O}$

Abb. 26 Expression der verschiedenen rPrP in E. coli 67

Abb. 27 Verschiedene Methoden der IB Reinigung des rfPrP aus E. coli 68

Abb. 28 Modifizierte Aufreinigung des rfPrP durch Ultraschall 68

Abb. 29 Klonierungschema des pCMV/Bsd Tet-Off Vektors 70

Abb. 30 Strukturformel des Blasticidins $\quad 70$

Abb. 31 Blasticidinresistenzkurven der verschiedenen Zelllinien $\quad 71$

Abb. 32 Optimierung der Transfektionseffizienz 73

Abb. 33 Fluoreszenzmikroskopische Aufnahmen der verschiedenen Zelllinien $\quad 74$

Abb. 34 Mycoplasmentest-PCR

Abb. 35 Strukturformel des Hygromycins $\quad 76$ 
Abb. 36 Hygromycinresistenz der verschiedenen Zellklone 76

$\begin{array}{ll}\text { Abb. } 37 \text { Klonierung des pTRE-FU Vektors mit Insert } & 78\end{array}$

Abb. 38 Stabile Transfektion durch Elektroporation 78

Abb. 39 Klonierung des retroviralen Expressionsvektors $\quad 79$

Abb. 40 Stabile Transfektion durch Retroviren $\quad 80$

Abb. 41 Proteinbestimmung von BSA im E1A-Lysepuffer 82

Abb. 42 WB Klonselektion der $\operatorname{PrP}^{0 / 0}$ Zelllinie $\quad 82$

Abb. $43 \operatorname{PrP}^{\mathrm{C}}$ Detektionsminimum des C1 Klons 83

Abb. 44 Tet-Abhängigkeit des C1 Klons $\quad 84$

Abb. 45 Zeitabhängige $\operatorname{PrP}^{\mathrm{C}}$ Expression des C1 Klons 84

Abb. 46 WB des selektierten Klons der 3T3 Zelllinie 85

Abb. 47 WB des selektierten Klons der N2a Zelllinie 85

Abb. 48 Immunfluoreszenzmikroskopie der verschiedenen $\operatorname{PrP}^{\mathrm{C}} \quad$ 86/87 exprimierenden Zellklone

Abb. 49 FACS Analyse der $\operatorname{PrP}^{\mathrm{C}}$ Expression 88

Abb. 50 WB der IMAC des nicht infizierten C1 Klons 90

$\begin{array}{lr}\text { Abb. } 51 \text { CD-Spektren der IMAC-Proben } & \text { 91/92 }\end{array}$

Abb. 52 2D-Gel der $\operatorname{PrP}^{0 / 0}$ Zellklone 93

Abb. 53 Infektion einer Zelllinie mit TSE 95

Abb. 54 Detektion von $\operatorname{PrP}^{\text {res }}$ im PK abhängigen Verdau 96

Abb. 55 Detektion von PrP ${ }^{\text {res }}$ im zeitabhängigen PK Verdau 97

Abb. 56 PK Verdau der verschiedenen Zellklone nach BSE-Infektion 98

Abb. 57 FACS Analyse der Zellklone 99

Abb. 58 Detektionsmöglichkeiten des Prion Proteins 103

Abb. 59 Schema der Erweiterung des bisher etablierten Zellmodells 113

\section{Tabellenverzeichnis:}

Tab. 1 TSE-Erkrankungen in verschiedenen Organismen 3

Tab. 2 Verwendete Restriktionsendonukleasen 24

Tab. 3 Eigenschaften des Bakterienstamms 30

Tab. 4 Verwendete Zelllinien 33

Tab. 5 Negativkontrollen der FACS Messung 48

Tab. 6 Primer zur Amplifikation des prnp Gens 62

Tab. 7 Sequenzprimer für den pGEM-T Vektor $\quad 64$

Tab. 8 Aminosäuresequenzvergleich der speziesspezifischen Prion Proteine 65

Tab. 9 Verhältnis der DNA zu den Transfektions-Agenzien 72

Tab. 10 Hergestellte stabile regulierbare $\operatorname{PrP}^{\mathrm{C}}$ exprimierende Zellklone 81

Tab. 11 Zusammenfassung der identifizierten Proteine in der Massenspektrometrie 94 


\section{Abkürzungsverzeichnis:}

$\begin{array}{ll}\% & \text { Prozent } \\ \Omega & \text { Ohm } \\ { }^{\circ} \mathrm{C} & \text { Grad Celsius } \\ \mu & \text { Mikro } \\ \mu \mathrm{F} & \text { Mikrofarad } \\ \mu \mathrm{l} & \text { Mikroliter }\end{array}$

Abb. Abbildung

ad „adjust“

APS Ammoniumpersulfat

ATP Adenosintriphosphat

bp Basenpaare

BSA Rinderserumalbumin

bzw. beziehungsweise

ca. circa

CD Circulardichroismus

cfu „colony forming units“

CJD Creutzfeldt-Jakob-Krankheit

cm Zentimeter

DMSO Dimethylsulfoxid

DOC Natriumdeoxycholat

DPZ Deutsches Primatenzentrum

DTT Dithiothreitol

E. coli Escherichia coli

ECL „enhanced chemiluminescence“

EDTA Ethylendiamintetraessigsäure

EGFP „enhanced green fluorescent protein“

ER endoplasmatisches Reticulum

et al. „et alii“

EtOH Ethanol

FCS fötales Kälberserum

g Fallbeschleunigung

GPI Glykosylphosphatidylinositol

gr. große

GSS Gerstmann-Sträusler-Scheinker Syndrom

h Stunden

$\mathrm{H}_{2} \mathrm{O}_{\text {bid }} \quad$ Bidestilliertes Wasser

HRP Meerrettichperoxidase 


\begin{tabular}{|c|c|}
\hline $\mathrm{Hz}$ & Hertz \\
\hline IB & „inclusion bodies“ \\
\hline IEF & isoelektrische Fokussierung \\
\hline IgG & Immunglobulin G \\
\hline $\mathrm{kb}$ & Kilobasen \\
\hline $\mathrm{kV}$ & Kilovolt \\
\hline 1 & Liter \\
\hline LB & Luria Bertani \\
\hline Lsg. & Lösung \\
\hline M & Mol \\
\hline $\mathrm{mg}$ & Milligramm \\
\hline $\min$ & Minuten \\
\hline $\mathrm{ml}$ & Milliliter \\
\hline $\mathrm{mm}$ & Millimeter \\
\hline $\mathrm{mM}$ & Millimol \\
\hline MOI & „multiplicity of infection“ \\
\hline MPBST & $5 \%$ (w/v) Milchpulver in PBST \\
\hline ng & Nanogramm \\
\hline NZM & Nitrozellulosemembran \\
\hline OD & optische Dichte \\
\hline ORF & offenes Leseraster \\
\hline PAGE & Polyacrylamid-Gelelektrophorese \\
\hline PBS & phosphatgepufferte Kochsalzlösung \\
\hline PBST & 0,1 \% (v/v) Tween 20 in PBS \\
\hline $\mathrm{pH}$ & $\mathrm{pH}-$ Wert \\
\hline PK & Proteinase K \\
\hline PMSF & Phenylmethylsulfonylfluorid \\
\hline POD & Peroxidase \\
\hline $\operatorname{PrP}^{\mathrm{C}}$ & zelluläres Prion Protein \\
\hline $\operatorname{PrP}^{\text {res }}$ & degradiertes $\operatorname{PrP}^{\mathrm{Sc}}$ \\
\hline $\operatorname{PrP}^{\mathrm{Sc}}$ & pathogenes Prion Protein \\
\hline rpm & Umdrehungen pro Minute \\
\hline $\mathrm{RT}$ & Raumtemperatur \\
\hline Rt & reverse Transkriptase \\
\hline $\mathrm{s}$ & Sekunden \\
\hline SDS & Natriumdodecylsulfat \\
\hline $\mathrm{T}$ & Temperatur \\
\hline Tab. & Tabelle \\
\hline TAE & Tris-Acetat-EDTA \\
\hline TEMED & N,N,N,N - Tetramethylethylenediami \\
\hline
\end{tabular}




$\begin{array}{ll}\text { Tris } & \text { Trishydroxymethylaminomethan } \\ \text { TSE } & \text { Transmissible Spongiforme Enzephalopathie } \\ \text { U } & \text { Unit } \\ \text { V } & \text { Volt } \\ \text { v/v } & \text { Volumenprozent } \\ \text { Vh } & \text { Voltstunden } \\ \text { w/v } & \text { Massenprozent } \\ \text { WB } & \text { Western Blot } \\ \text { Wdh. } & \text { Wiederholung } \\ \text { z. B. } & \text { zum Beispiel } \\ \text { ZNS } & \text { zentrales Nervensystem }\end{array}$

\section{Aminosäurenabkürzungen}

$\begin{array}{ll}\text { A } & \text { Alanin } \\ \text { C } & \text { Cystein } \\ \text { D } & \text { Asparaginsäure } \\ \text { E } & \text { Glutaminsäure } \\ \text { F } & \text { Phenylalanin } \\ \text { G } & \text { Glycin } \\ \text { H } & \text { Histidin } \\ \text { I } & \text { Isoleucin } \\ \text { K } & \text { Lysin } \\ \text { L } & \text { Leucin } \\ \text { M } & \text { Methionin } \\ \text { N } & \text { Asparagin } \\ \text { P } & \text { Prolin } \\ \text { Q } & \text { Glutamin } \\ \text { R } & \text { Arginin } \\ \text { S } & \text { Serin } \\ \text { T } & \text { Threonin } \\ \text { V } & \text { Valin } \\ \text { W } & \text { Tryptophan } \\ \text { Y } & \text { Tyrosin }\end{array}$

\section{Nukleinsäurenabkürzungen}
A Adenin
C Cytosin
G Guanin 


$\begin{array}{ll}\text { T } & \text { Thymin } \\ \text { dATP } & \text { Desoxyriboadenosintriphosphat } \\ \text { dNTP } & \text { Desoxyribonukleosidtriphosphate } \\ \text { ddNTP } & \text { Didesoxynukleotidtriphosphate } \\ \text { dsDNA } & \text { doppelsträngige Desoxyribonukleinsäure } \\ \text { ssRNA } & \text { einzelsträngige Ribonukleinsäure } \\ \text { RNA } & \text { Ribonukleinsäure } \\ \text { DNA } & \text { Desoxyribonukleinsäure }\end{array}$




\section{$1 \quad$ Einleitung}

\subsection{Die Prion Hypothese}

Prion steht für „proteinaceous infections particle“ und ist laut der „protein-only hypothesis“ (Prusiner, 1982) das infektiöse Agens der Transmissiblen Spongiformen Enzephalopathien (TSE). Die TSE-Erkrankungen werden durch eine Konformationsänderung einer apathogenen zellulären Isoform $\left(\mathrm{PrP}^{\mathrm{C}}\right)$ in eine pathogene Isoform $\left(\mathrm{PrP}^{\mathrm{Sc}}\right)$ verursacht. Sc steht dabei für Scrapie, da eine TSE-Erkrankung zuerst bei Schafen beobachtet wurde (Deslys et al., 2001). Diese Konformationsänderung kann entweder spontan oder induziert durch exogenes $\operatorname{PrP}^{\mathrm{Sc}}$ erfolgen. Dabei kommt es zur Anlagerung von $\operatorname{PrP}^{\mathrm{Sc}}$ an $\operatorname{PrP}^{\mathrm{C}}$ (McKinley et al., 1983; Eigen, 1996). Ein Modell der induzierten Konformationsänderung ist in der Abb. 1 dargestellt.

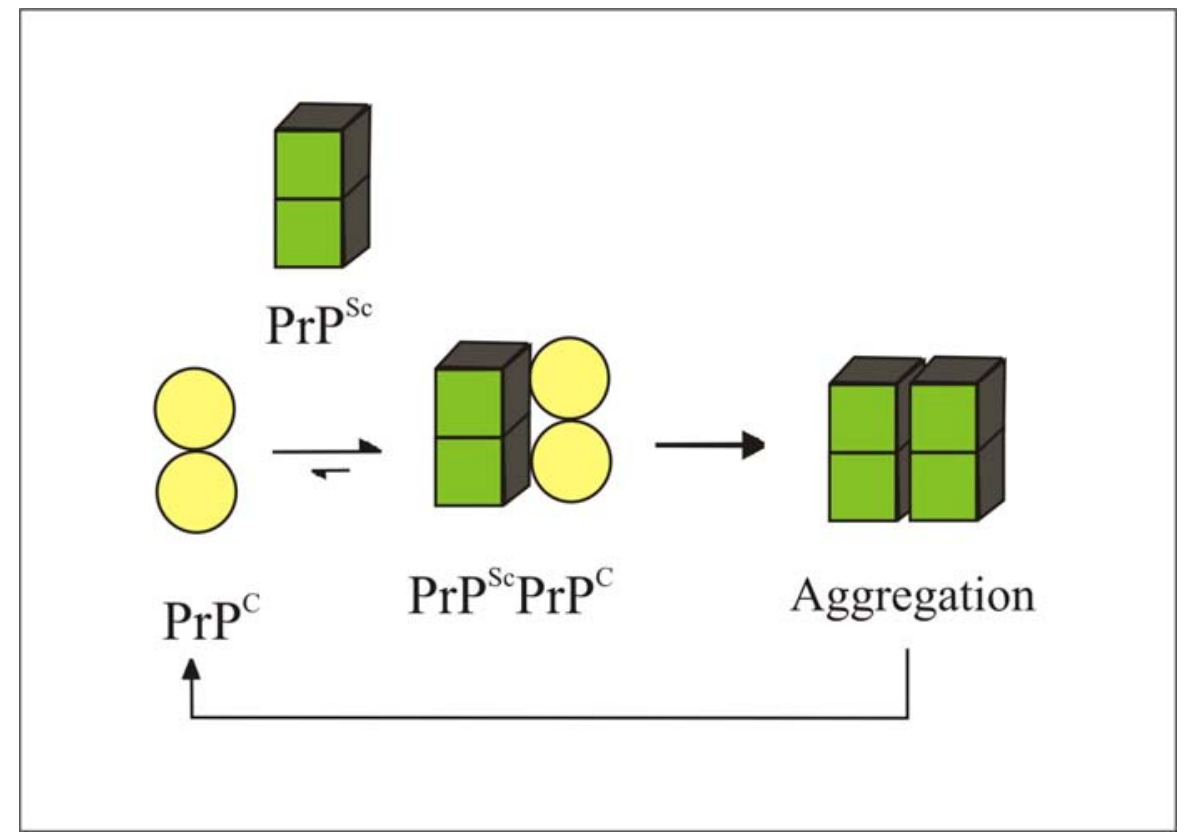

Abb. 1 Replikationsmodell des $\operatorname{PrP}^{\mathrm{Sc}}$ Durch Bindung des $\operatorname{PrP}^{\mathrm{Sc}}$ an das $\operatorname{PrP}^{\mathrm{C}}$ wird ein $\mathrm{PrP}^{\mathrm{C}}-\mathrm{PrP}^{\mathrm{Sc}}$ Intermediat gebildet, dieses bewirkt eine Konformationsänderung des $\operatorname{PrP}^{\mathrm{C}}$. Dadurch entsteht ein neues $\mathrm{PrP}^{\mathrm{Sc}}$, das zur Aggregation mit anderen $\operatorname{PrP}^{\mathrm{Sc}}$ neigt (nach Jarrett et al., 1993).

Durch die partielle Resistenz von $\operatorname{PrP}^{\mathrm{Sc}}$ gegenüber zellulären Proteasen (Mitsuiki et al., 2006) reichert sich die pathogene Isoform im Gewebe an. Besonders häufig tritt dies im zentralen Nervensystem auf, wo es zu einer Akkumulation kommt, die dann zur Bildung von Plaques führt, dargestellt in der Abb. 2. Ein Faktor $\mathrm{X}$ ist nach einigen Theorien eventuell mit an der Bildung von Plaques beteiligt (Telling et al., 1995; Kaneko et al., 1997). Allerdings wird diese Theorie nicht von allen Wissenschaftlern geteilt. 
Andere Forscher sind der Überzeugung, dass Nukleinsäuren (Akowitz et al., 1994) oder Viren (Diringer et al., 1988; Narang, 1996) für die TSE-Erkrankungen verantwortlich sind. Dagegen spricht aber, dass das infektiöse Agens gegen UV (Safar et al., 2005), ionisierende Strahlung (Gibbs et al., 1978), hohe Temperaturen (Brown et al., 2000) sowie gegen chemische und physikalische Einflüsse (Bellinger-Kawahara et al., 1987) resistent ist.

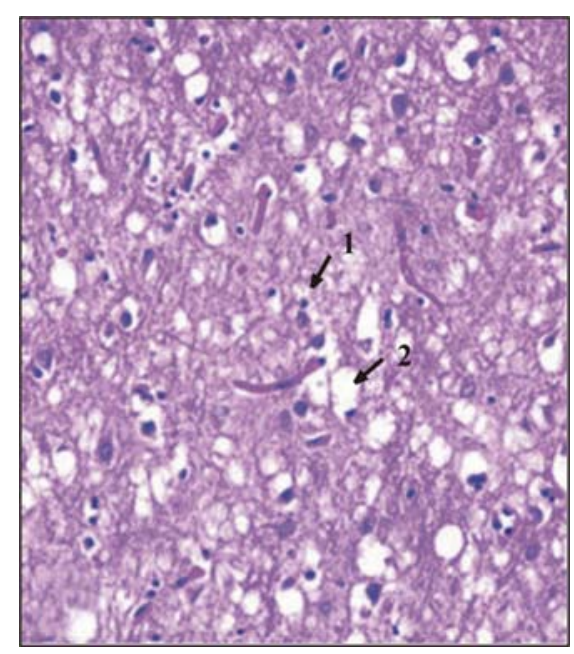

Abb. 2 Histologischer Schnitt durch ein CJD geschädigtes Gehirn Mit 1) Plaques und 2) Löcher im Hirngewebe (nach Safar et al., 2005).

\section{$1.2 \quad$ TSE-Erkrankungen}

Die TSE-Erkrankungen wirken sich vor allem im Gehirn der betroffenen Organismen aus. Dabei kommt es zur Ausbildung eines durchlöcherten schwammartigen Zellgewebes mit amyloiden Proteinablagerungen, den Plaques. Diese sind allerdings erst nach einer histologischen „post mortem“ Analyse zu beobachten. So können TSE-Erkrankungen beim Menschen gegenüber anderen neurodegenerativen Erkrankungen, wie z. B. der amyotrophischen Lateralsklerose (ALS), abgegrenzt werden (Dupuis et al., 2002). Bei einer „ante mortem“ Differentialdiagnose, die auf Verhaltensauffälligkeiten und Bewegungsataxien beruht (Wilesmith et al., 1988), ist dies nicht möglich. Die verschiedenen bekannten TSE-Erkrankungen sind in der Tab. 1 dargestellt. 
Tab. 1 TSE-Erkrankungen in verschiedenen Organismen

\begin{tabular}{lll}
\hline TSE-Erkrankung & Auftreten & Literatur \\
\hline Creutzfeldt-Jakob Erkrankung (CJD) & Mensch & Creutzfeldt, 1920; Jakob, \\
& & 1921 \\
Neue Variante von CJD (vCJD) & Mensch & Britton et al., 1995 \\
Fatale Familiäre Insomnia (FFI) & Mensch & Lugaresi et al., 1986 \\
Gerstmann-Sträusler-Scheinker Syndrom & Mensch & Gerstmann et al., 1928 \\
(GSS) & & \\
Kuru & Mensch & Gajdusek et al., 1957 \\
Bovine Spongiforme Enzephalopathie & Rind & Wells et al., 1987 \\
(BSE) & & \\
Chronic Wasting disease (CWD) & Elch, Weiss- & Williams et al., 1980 und \\
& wedelhirsch & 1982 \\
Exotic Ungulate Encephalopathie (EUE) & Kudu & Cunningham et al., 1993 \\
Feline Spongiforme Encephalopathie (FSE) & Katze & Wyatt et al., 1991 \\
Traberkrankheit / Scrapie & Schaf, Ziege & Parry et al., 1983 \\
Transmissible Mink Encephalopathie & Nerz & Hartsough et al., 1965 \\
(TME) & & \\
\hline
\end{tabular}

Das große Interesse an TSE-Erkrankungen begann Mitte der 90-ziger Jahre des letzten Jahrhunderts, als eine neue Variante von CJD (vCJD) auftrat. Diese Variante unterscheidet sich von CJD durch die geringe Inkubationszeit von nur einigen Monaten bis zu wenigen Jahren (Zeidler et al., 1997). Ansonsten zeigten sie typische Ablagerungserscheinungen wie sie nur selten in CJD vorkommen, sie hatten aber untereinander ein fast identisches histopatologisches Muster. Deshalb führte man ein „strain typing“ ein, um diese Variante vom bekannten CJD Krankheitsablauf abzugrenzen. Die ersten Fälle von vCJD traten in England und später auch im restlichen Europa auf. Das Auftreten dieser Variante ist in Verbindung mit dem Verzehr von BSE infiziertem Rindfleisch zu sehen. In der Abb. 3 ist der epidemiologische Zusammenhang von BSE mit dem Auftreten von vCJD in England dargestellt. 


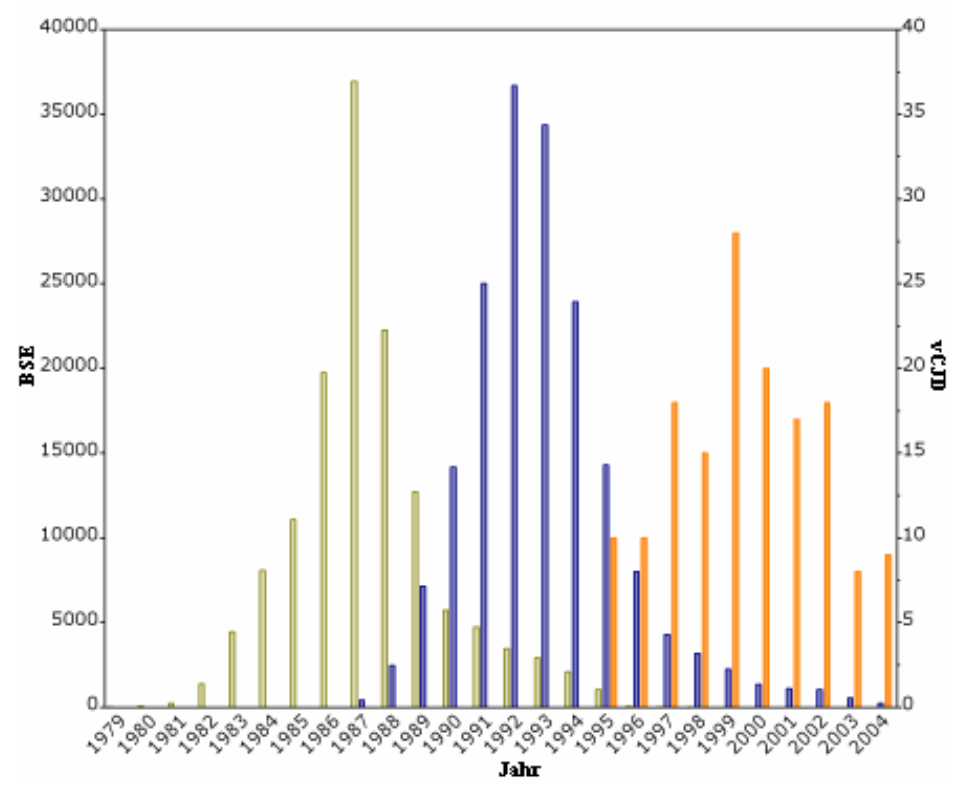

Abb. 3 Epidemiologischer Zusammenhang von BSE und vCJD in England Dargestellt ist ( ) das Geburtsjahr der BSE-Tiere, ( $\mathbf{\square})$ die BSE-Fälle in Rindern und $(\square)$ die aufgetretenen Fälle von vCJD im Menschen (nach Public Health Agency of Canada, 2006).

Die Abb. 3 zeigt, dass die ersten Fälle von vCJD 1995, also 8 Jahre nach der Identifizierung von BSE in Rindern auftraten. Außerdem, dass die Rinder nicht einmal 8 Jahre alt waren, als sie Anzeichen der Krankheit zeigten. Weiterhin ist zu erkennen, dass seit 1992 die Anzahl der Rinder mit BSE-Infektionen deutlich abgenommen hat. Dementsprechend ist auch die Anzahl der erkrankten Personen mit einem zeitlichen Abstand von 8 Jahren danach ebenfalls gesunken. Dies ist vermutlich auf strengere Kontrollen von Rinderprodukten seit dem Erkennen von BSE und seinen Auswirkungen zurückzuführen.

Seit Beginn des 21. Jahrhunderts gibt es einen neuen, durch Prionen hervorgerufenen TSEAusbruch. Dieses Mal allerdings nicht von BSE in Europa, sondern von CWD in Nordamerika. Von CWD sind sowohl Wild- als auch Zuchtpopulationen der Cerviden betroffen. Da noch nicht zweifelsfrei bewiesen ist, dass CWD auf den Menschen übertragbar ist, sind mögliche Folgeerscheinungen noch nicht abzuschätzen. Im Besonderen gilt dies für die nordamerikanischen Ureinwohner in den betroffenen Regionen durch ihren höheren Wildfleischverzehr. Die Abb. 4 zeigt die epidemieartige Vermehrung von CWD in Nordamerika seit 2002. 


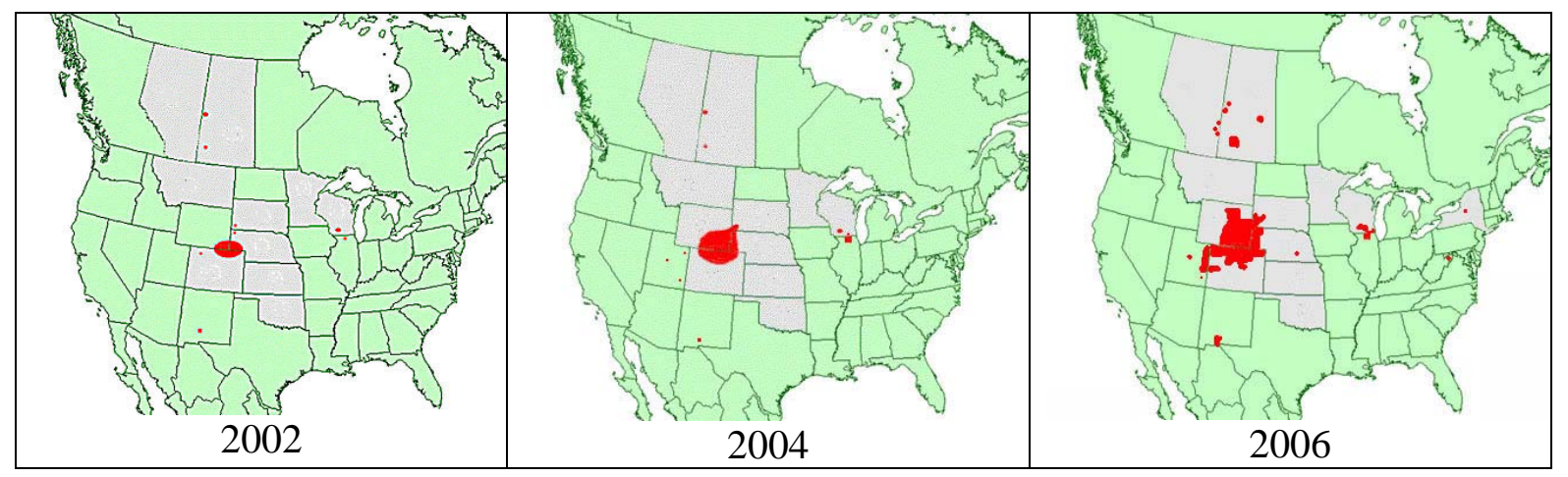

Abb. 4 Auftreten von CWD in Nordamerika während der letzten 5 Jahre Dargestellt sind (•) die infizierten Wildpopulationen und ( $\square$ ) die infizierten Zuchtpopulationen (nach CWD Alliance, 2006).

Aus der Abb. 4 ist zu erkennen, dass sich CWD von wenigen Fällen im Herzen Nordamerikas, zu einer Epidemie auf dem Kontinent entwickelt hat. Dabei hat sowohl die Zahl der infizierten Wild- als auch die der Zuchtpopulationen zugenommen. Zurückzuführen ist dies wahrscheinlich darauf, dass im Gegensatz zu BSE diese Krankheit vor allem durch den Speichel übertragen wird (Miller et al., 2004; Belay et al., 2004).

\subsection{Die Molekularbiologie des Prion Proteins}

Das $\operatorname{PrP}^{\mathrm{C}}$ ist ein extrazelluläres Glykoprotein. Es besitzt eine Disulfidbrücke zwischen den Cysteinen an Position 179 und 214 (Safar et al., 1990). An den Positionen 51 bis 90 befinden sich fünf hintereinander liegende hoch konservierte glycin- und prolinreiche Oktapeptidsequenzen (Oktarepeats). Diese sind in der Lage zweiwertige Ionen, besonders Kupferionen, zu binden (Thompsett et al., 2005; Choi et al., 2006). Von diesen Oktarepeats sind aber nur vier zur Komplexbildung fähig, da am fünften Oktarepeat ein Histidin fehlt (Burns et al., 2005). Vor diesen Sequenzen befindet sich die Signalsequenz des $\operatorname{PrP}^{\mathrm{C}}$. Über einen Serinrest ist es an der Position 231 an der Zellmembran durch einen GlykosylphosphatidylinositolAnker (GPI-Anker) gebunden (Stahl et al., 1987). Dort wird es in drei verschiedenen Glykosylierungsformen präsentiert (Endo et al., 1989). Das membrangebundene $\operatorname{PrP}^{\mathrm{C}}$ ist in der Abb. 5 dargestellt. 


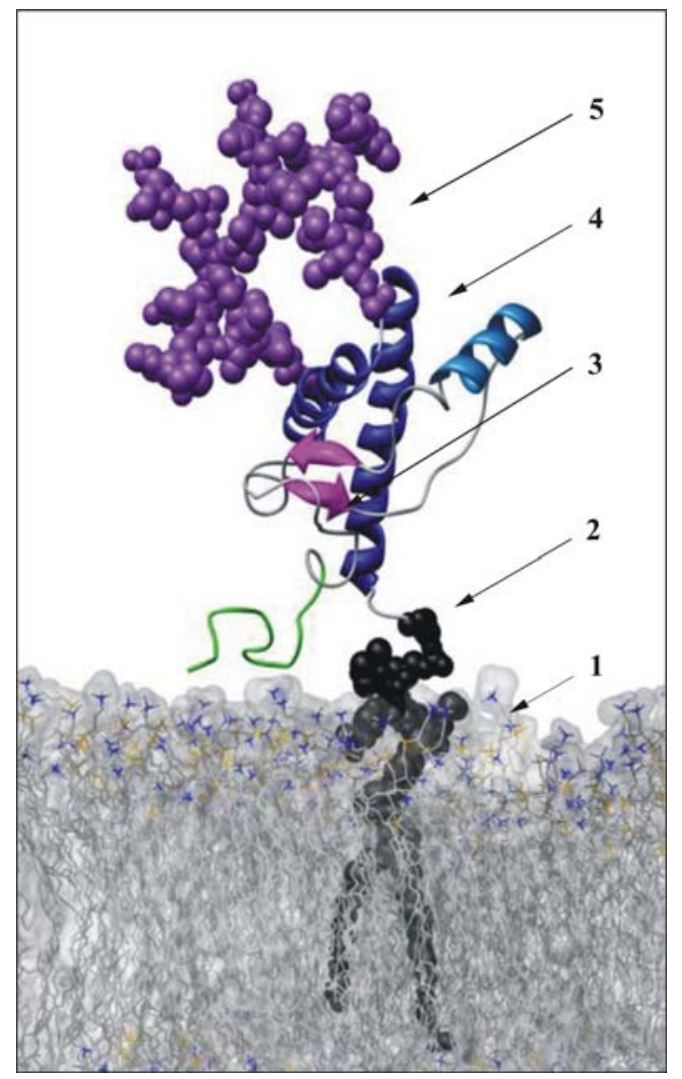

Abb. 5 Zellmembran mit gebundenen $\operatorname{PrP}^{\mathrm{C}}$ Dargestellt ist das $\operatorname{PrP}^{\mathrm{C}}$ mit 1) Zellmembran, 2) einem GPI-Anker, 3) zwei antiparallelen $\beta$ Faltblättern, 4) drei $\alpha$-Helices und 5) zwei Glykosylierungen (nach DeMarco et al., 2005).

Mit Hilfe des Western Blots (WB) kann die un-, mono- und diglykosylierte Form nachgewiesen werden. Das Molekulargewicht des $\operatorname{PrP}^{\mathrm{C}}$ variiert zwischen $25 \mathrm{kDa}$ und $37 \mathrm{kDa}$, in Abhängigkeit von der jeweiligen Spezies und deren Glykosylierungsstufe (Caughey et al., 1989; Bolton et al., 1985; Endo et al., 1989). Ansonsten unterscheidet sich das $\operatorname{PrP}^{\mathrm{C}}$ vieler Spezies in nur wenigen Aminosäuren voneinander. Die Homologie beträgt bei Säugern zwischen 85 \% und 97 \% (Gabriel et al., 1992). Zwischen Primaten und dem Menschen betragen die Gemeinsamkeiten sogar 92,9 \% bis 99,6 \% (Schatzl et al., 1995). Das $\operatorname{PrP}^{\mathrm{C}}$ kommt bei Säugetieren (Wu et al., 2006; Windl et al., 1995), Vögeln (Gabriel et al., 1992), Reptilien (Simonic et al., 2000), Fischen (Oidtmann et al., 2003; Cotto et al., 2005) und sogar in der Hefe (S. cerevisiae; Scheibel, 2004) vor. Daher kann man sagen, dass es ein evolutionäres hochkonserviertes Protein ist. Das Gen des PrP wird als prnp bezeichnet, wobei das für das Protein kodierende offene Leseraster („open reading frame“, ORF) in nur einem Exon lokalisiert ist (Basler et al., 1986; Prusiner, 1991). Das prnp Gen besteht bei vielen Organismen, wie z. B. der Maus, der Ratte, dem Schaf und dem Rind, aus drei Exons und zwei Introns (Basler et al., 1986), dargestellt in der Abb. 6. Die Länge des prnp ORF ist dabei 
speziesspezifisch und variiert zwischen 759 bp und 789 bp. Beim Menschen befindet sich das prnp Gen auf dem Chromosom Nr. 20 und besteht aus zwei Exons, dargestellt in der Abb. 7 (Chesebro et al., 1985; Oesch et al., 1985). Die Expression des $\operatorname{PrP}^{\mathrm{C}}$ konnte beim Menschen besonders in den Zellen des Nerven- (Moudjou et al., 2001; Ford et al., 2002) und des Immunsystems (Prinz et al., 2003) nachgewiesen werden.

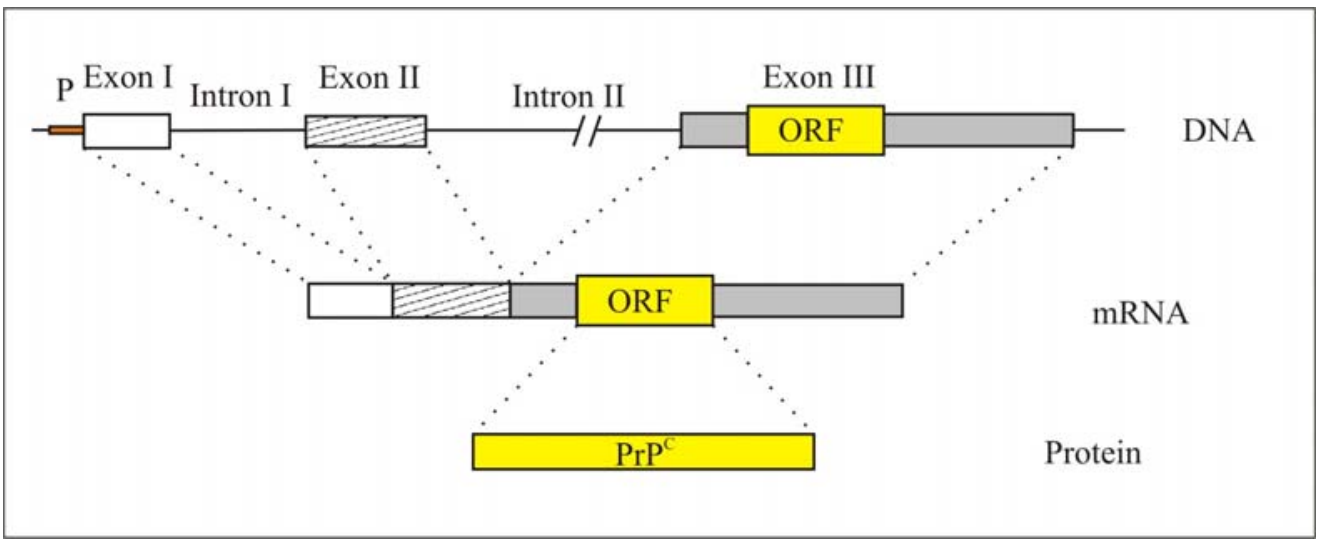

Abb. 6 Aufbau des murinen prnp Gens Das murine prnp Gen enthält drei Exons und zwei Introns. Der Promotor (P) befindet sich vor dem ersten Exon und das ORF im dritten Exon.

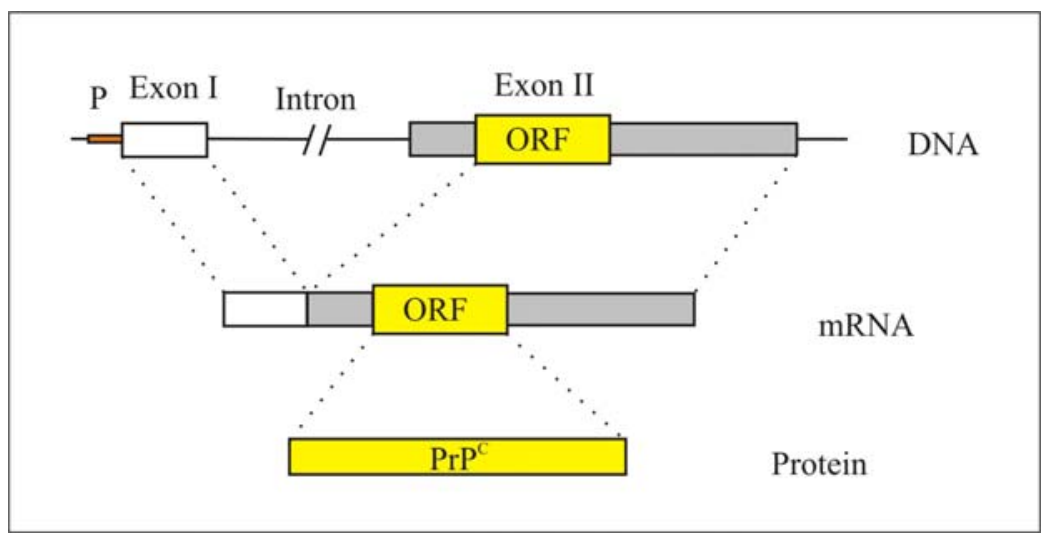

Abb. 7 Aufbau des humanen prnp Gens Das humane prnp Gen enthält zwei Exons und ein Intron. Der Promotor (P) befindet sich vor dem ersten Exon und das ORF im zweiten Exon.

Das $\operatorname{PrP}^{\mathrm{C}}$ besteht aus drei $\alpha$-Helices und zwei antiparallelen $\beta$-Faltblättern (Riek et al., 1996), dargestellt in der Abb. 8. Diese Isoform bindet Kupfer, ist nicht Proteinase K (PK) resistent und nicht pathogen. Dagegen besitzt das $\operatorname{PrP}^{\mathrm{Sc}}$ einen erhöhten $\beta$-Faltblattanteil, bindet kein Kupfer, ist pathogen und PK resistent. Das $\mathrm{PrP}^{\mathrm{Sc}}$ neigt zur Aggregation und bildet Fibrillen, die so genannten „scrapie associated fibirlls“ (SAF). Die 3D Struktur des $\operatorname{PrP}^{\mathrm{C}}$ ist durch NMR Analyse bestätigt worden. Vom $\operatorname{PrP}^{\mathrm{Sc}}$ dagegen, gibt es bisher keine bestätigte NMR Struktur, sondern nur verschiedene Computermodelle, diese sind dargestellt in der Abb. 9. 




Abb. 8 Durch NMR Analyse bestätigte $\operatorname{PrP}^{\mathrm{C}}$ Sekundärstruktur (nach Riek et al., 1996)
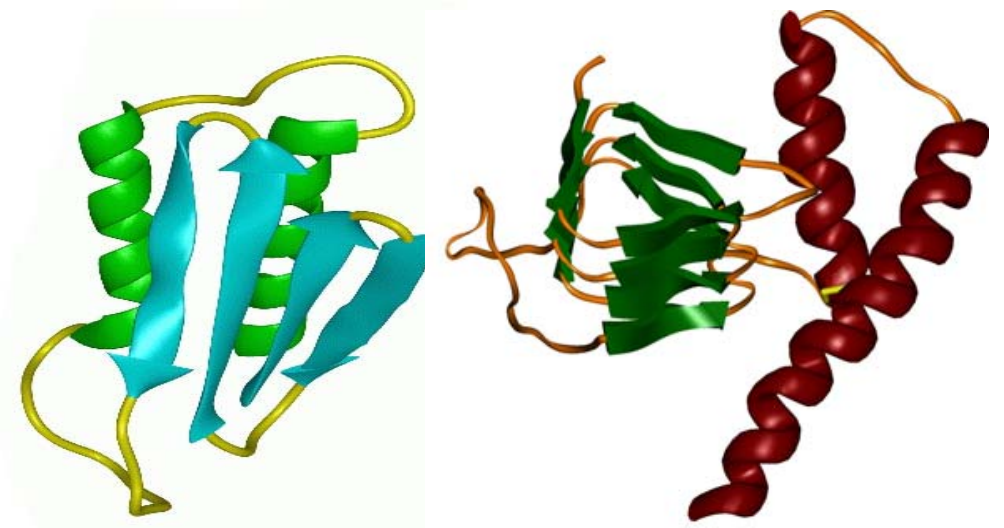

Abb. 9 Zwei vermutete noch nicht durch NMR Analyse bestätigte PrP $^{\mathrm{Sc}}$ Sekundärstrukturen (nach Riek et al., 1996 (links); Cohen, 2006 (rechts))

Aufgrund der unterschiedlichen molekularen Eigenschaften ist eine Unterscheidung der beiden Isoformen anhand einer Sekundärstrukturanalyse durch eine CD-Spektroskopie möglich (Ziegler et al., 2003; Leffers et al., 2004). Ebenso durch einen WB, bei dem die beiden Isoformen vor und nach dem PK Verdau miteinander verglichen werden können. Denn nach dem PK Verdau ist kein $\operatorname{PrP}^{\mathrm{C}}$ mehr zu detektieren, dagegen ist die degradierte Form des $\operatorname{PrP}^{\mathrm{Sc}}$ als $\operatorname{PrP}^{\text {res }}$ erkennbar. Diese liegt wie das $\operatorname{PrP}^{\mathrm{C}}$ in drei verschiedenen Glykosylierungsformen vor, besitzt aber aufgrund des partiellen Verdaus durch die PK ein geringeres Molekulargewicht, da nur die ersten 60 Aminosäuren abgebaut werden (Jendroska et al., 1991).

\subsection{Der zelluläre Zyklus des PrP}

Das $\operatorname{PrP}^{\mathrm{C}}$ durchläuft in der Zelle einen Zyklus, nachdem es am Endoplasmischen Reticulum (ER) gebildet wird. Zuerst erfolgen einige posttranslationale Modifikationen am rauen ER und im Golgi-Apparat. Das sind die Glykosylierungen, die Anheftung des Sialinsäurerestes und die Ausbildung der Disulfidbrücke. Danach gelangt das $\operatorname{PrP}^{\mathrm{C}}$ an die Zelloberfläche, wo es über den Serinrest mit einem GPI-Anker verbunden und in allen drei Glykosylierungsstufen präsentiert wird. Durch den Membranfluss bleibt es allerdings nicht dauerhaft an der Membranoberfläche. Besonders angereichert findet man das $\operatorname{PrP}^{\mathrm{C}}$ in den so genannten Rafts (Vey et al., 1996; Taraboulos et al., 1995), diese sind sphingolipid- und cholesterolreiche Membrandomänen und sind mitverantwortlich für die Endozytose, die hier besonders häufig stattfindet. Wahrscheinlich haben die Rafts ebenfalls einen Anteil an der 
Konformationsänderung des $\operatorname{PrP}^{\mathrm{C}}$ (Rogers et al., 1993; Lehmann et al., 1997). Sowohl das $\operatorname{PrP}^{\mathrm{C}}$ als auch das $\operatorname{PrP}^{\mathrm{Sc}}$ wandert zu den Endosomen und den Lysosomen, wo nur das $\operatorname{PrP}^{\mathrm{C}}$ abgebaut wird (Nuziante et al., 2003). In der Abb. 10 ist der zelluläre Zyklus des PrP dargestellt.

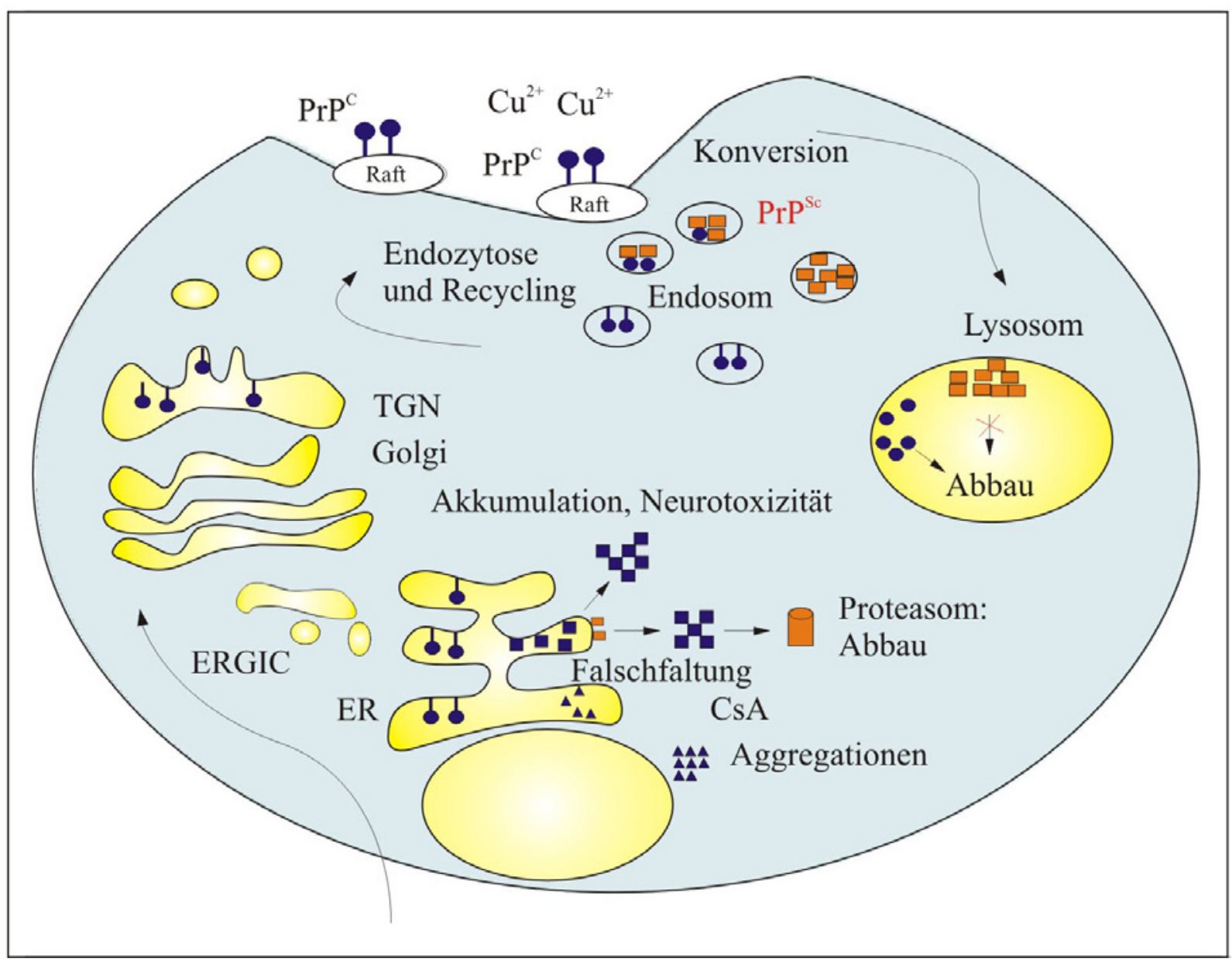

Abb. 10 Zellulärer Zyklus des PrP Die Synthese des zellulären PrP (•) erfolgt am Endoplasmischen Reticulum (ER). Nach weiteren Modifikationen am ER-Golgi-Intermediate-Kompartment (ERGIC) und dem Trans-Golgi-Netzwerk (TGN) wird das $\mathrm{PrP}^{\mathrm{C}}$ an der Zelloberfläche präsentiert. Durch Endozytose an den Rafts wird das $\operatorname{PrP}$ aufgenommen und in die pathogene Isoform $\operatorname{PrP}^{\mathrm{Sc}}(\square)$ umgewandelt. Über die Endosomen gelangen die PrP Isoformen in die Lysosomen, wo das $\operatorname{PrP}^{\mathrm{C}}$, nicht aber das $\operatorname{PrP}^{\mathrm{Sc}}$ abgebaut wird. Andere nicht pathogene PrP Isoformen können durch Fehlfaltungen entstehen (ם), diese werden aber abgebaut. Ebenso können sich $\operatorname{PrP}^{\mathrm{C}}$ Aggregate ( $\boldsymbol{\Delta}$ ) durch Zugabe von Cyclosporin A (CsA) bilden (nach Nuziante et al., 2003).

\subsection{Mögliche Funktionen des $\operatorname{PrP}^{\mathrm{C}}$}

Die Funktion des zellulären $\operatorname{PrP}^{\mathrm{C}}$ ist, trotz intensiver Bemühungen verschiedener Arbeitsgruppen bis heute noch nicht geklärt. Das Prion Protein ist ein hoch konserviertes Protein. Das deutet darauf hin, dass seine Funktion zu einem frühen evolutionären Zeitpunkt festgelegt wurde (Lupi et al., 2006). Zur Klärung der Funktion des $\operatorname{PrP}^{\mathrm{C}}$ wurden $\operatorname{PrP}$ „knockout “ Mäuse hergestellt, diese zeigten keine atypischen Verhaltensweisen oder 
Funktionsstörungen (Bueler et al., 1992). Die Lebensdauer der Purkinje Zellen im Hirn war, im Gegensatz zu ihren Wildtyp Artverwandten, in diesen Mäusen etwas verringert (Sakaguchi et al., 1996; Flechsig et al., 2003).

Dem $\operatorname{PrP}^{\mathrm{C}}$ werden verschiedene Funktionen zugeschrieben, unter anderem soll es bei den Schlafzyklen der Maus eine Rolle spielen (Tobler et al., 1996). Eine Beteiligung an der Beseitigung von oxidativem Stress (Brown et al., 1998) und damit zusammenhängenden Alterungsprozessen wird dem $\operatorname{PrP}^{\mathrm{C}}$ ebenfalls zugedacht. Da $\operatorname{PrP}^{\mathrm{C}}$ in der Lage ist, Kupferionen zu binden, wird ihm eine Rolle im Kupfermetabolismus zugeschrieben (Kramer et al., 2001). Außerdem wird ein Zusammenhang mit Viren, wie z.B. dem HIV, nicht ausgeschlossen (Gabus et al., 2001; Leblanc et al., 2004). Das $\operatorname{PrP}^{\mathrm{C}}$ spielt laut neusten Erkenntnissen ebenso eine Rolle bei der Immunabwehr (Heppner et al., 2004; Aguzzi, 2006).

Durch die Art der $\operatorname{PrP}^{\mathrm{Sc}}$ Akkumulation wird ein Zusammenhang mit anderen amyloiden Proteinablagerungen nicht ausgeschlossen (Stewart et al., 2005). Dazu gehören vor allem die neurodegenerativen Erkrankungen wie Alzheimer (Brown et al., 2004), Chorea Huntington (Bertram et al., 2005) und Parkinson (Bonifati et al., 2006).

\subsection{Modelle zur TSE-Detektierung}

Seit ca. 50 Jahren werden Tiermodelle zur Untersuchung und Charakterisierung von TSEErkrankungen genutzt. Erst in den letzten 5 Jahren wurden verstärkt Zellkulturmodelle zur Untersuchung dieser Erkrankungen entwickelt.

\subsubsection{Tiermodelle zur Detektion von TSE-Erkrankungen}

Zur Untersuchung von Krankheiten wird in der Medizin häufig auf ein Tiermodell zurückgegriffen. Erst nachdem im Tiermodell Medikamente gegen Krankheiten getestet wurden, können diese auf den Menschen angewendet werden. Allerdings bieten diese Tiermodelle viele Fehlerquellen. Nur durch die Erprobung am Menschen in klinischen Studien können diese erkannt bzw. festgestellt werden. So erkrankten Probanden erst kürzlich bei Medikamententests der Firma Parexel (Rosenthal, 2006) in England.

Angewandte Tiermodelle in der Prionenforschung sind das Schaf-, Schweine-, und Rindermodell, diese ergaben sich aus den historischen Zusammenhängen des Auftretens der TSE-Erkrankungen. Allerdings sind die Modelle vom Affen, der Maus, der Ratte und des Hamsters, die heute am häufigsten angewandten. Als Affenmodelle werden dabei heute nur noch die nicht-humanen Primaten verwendet. Vertreter dieser Gruppe sind die Javaneraffen 
(Macaca mulatta, Marcos et al., 2005), die Totenkopfaffen (Saimiri sciureus, March et al., 2005) und die Weißbüschelaffen (Callithrix jacchus, Baker et al., 1998). Im Moment werden Javaneraffen, am DPZ, im Rahmen eines EU-Verbundprojektes für eine Übertragungsstudie von BSE auf Primaten und einer damit zusammenhängenden Risikoabschätzung der Übertragbarkeit auf den Menschen genutzt (Lasmezas et al., 2005).

Ebenso werden nicht humane Primaten (Marsh et al., 2005) und transgene Mäuse für CWD Transfektionsexperimente benutzt (Browing et al., 2004). Weitere Übertragungsexperimente wurden mit Schimpansen durchgeführt. Dabei wurde Kuru (Gajdusek et al., 1966) genauso wie CJD (Gibbs et al., 1968), durch die Ähnlichkeit der Auswirkungen von Kuru und Scrapie (Hadlow, 1959), auf Schimpansen übertragen. Dieses Modell wird heute aus ethischen Gründen aufgrund der Artverwandtschaft der Menschenaffen zum Menschen nicht mehr angewandt.

Die Übertragbarkeit von TSE-Erkrankungen wurde zuerst bei Schafen beobachtet. Dabei wurde festgestellt, dass Scrapie in Schafen auftritt und auf andere Schafe übertragen werden konnte (Cuillé et al., 1936). Danach wurde entdeckt, dass es auch auf Mäuse übertragbar war (Chandler, 1961). Im Mausmodell wurde ebenfalls die Übertragbarkeit von Scrapie aus Schaf (Hadlow et al., 1982; Foster et al., 1993) und Ziege gezeigt (Hadlow et al., 1980). Da in England Mitte der 80-ziger Jahre des letzten Jahrhunderts Übertragungen von BSE bei Rindern auftraten, wurden diese ebenfalls im Wildtyp-Mausmodell untersucht (Wilesmith et al., 1991; Weissmann et al., 1994). Auch wurde eine Übertragbarkeit auf Schweine gezeigt (Dawson et al., 1990; Wells et al., 2003).

Das Hamstermodell hingegen wurde vor allem zur Bestimmung der infektiösen Dosis des TSE-Agens benutzt (Prusiner et al., 1980; Dawson et al., 1991). Zur Klärung der Funktion des $\operatorname{PrP}^{\mathrm{C}}$ werden heute aber vor allem transgene Mausmodelle eingesetzt (Weissmann et al., 1993; Kretzschmar et al., 1997; Biasimi et al., 2006).

Die durch den hohen Pflegeaufwand teuren Tiermodelle haben alle den Nachteil, dass die Resultate von Infektionsexperimenten erst nach langer Inkubationszeit zur Verfügung stehen. Dabei bleibt unklar, ob die experimentellen Bedingungen denen einer natürlichen Infektion entsprechen. Da es zum einen die Möglichkeit der intracerebralen Infektion gibt (Foster et al., 1994; Wells et al., 2004) und zum anderen die der Oralen (Wells et al., 1994; Foster et al., 2001). Der Nachteil dieser beiden Infektionsmöglichkeiten ist, dass das Tier bei der intracerebralen Inokulation den chirurgischen Eingriff eventuell nicht überlebt und bei der oralen Infektion, dass das infektiöse Agens oft nur unvollständig aufgenommen wird. 


\subsubsection{Zellkulturmodelle zur Detektion von TSE-Infektionen}

Der Vorteil des Zellkulturmodells gegenüber dem Tiermodell liegt vor allem in der schnelleren $\operatorname{PrP}^{\mathrm{Sc}}$ Detektion durch kürzere Inkubationszeiten. Die $\mathrm{PrP}^{\mathrm{Sc}}$ Detektion ist in diesen Modellen um ein bis zwei Zehnerpotenzen sensitiver und ist durch unbegrenzte Verfügbarkeit an Zellmaterial schnell zu wiederholen.

Bei den verwendeten Zelllinien wird entweder das zelleigene $\operatorname{PrP}^{\mathrm{C}}$ oder ein durch Transfektion eingeschleustes exogenes $\operatorname{PrP}^{\mathrm{C}}$ stabil überexprimiert. Eine Überexpression des $\operatorname{PrP}^{\mathrm{C}}$ ist notwendig, da durch $\operatorname{PrP}^{\mathrm{Sc}}$ nur ein geringer Teil des $\operatorname{PrP}^{\mathrm{C}}$ zu einer Konformationsänderung angeregt wird (Brandner et al., 1996; Blattler et al., 1997). Die so entstehende $\mathrm{PrP}^{\mathrm{Sc}}$ Konzentration ist in nicht modifizierten Zellen zu gering, um durch einen PK Verdau nachgewiesen werden zu können. Durch eine erhöhte $\operatorname{PrP}^{\mathrm{C}}$ Konzentration allerdings, wird das Reaktionsgleichgewicht in Richtung $\operatorname{PrP}^{\mathrm{Sc}}$ verschoben (Come et al., 1993).

$$
\operatorname{PrP}^{\mathrm{C}}+\operatorname{PrP}^{\mathrm{Sc}} \rightleftharpoons \operatorname{PrP}^{\mathrm{C}} \operatorname{PrP}^{\mathrm{Sc}} \text { (Intermediat) } \rightarrow \operatorname{PrP}^{\mathrm{Sc}}
$$

$\mathrm{Zu}$ den verwendeten Zelllinien, die das endogene $\operatorname{PrP}^{\mathrm{C}}$ überexprimieren, gehören die N2a Zellen (Bosque et al., 2000; Enari et al., 2001), die Smb Zellen (Birkettl et al., 2001; Kanu et al., 2002), die Rov Zellen (Sabuncu et al., 2003; Paquet et al., 2004), die 3T3 L1 Tet-Off Zellen (Stuke et al., 2005), die Astrocyten (Cronier et al., 2004), die HEK293 Zellen (Satoh et al., 2004) und die Glioblastoma Zelllinie T98G (Kikuchi et al., 2004). Besonders häufig für Experimente werden die N2a und die Rov Zellen verwendet. Diese sowie die anderen hier genannten Zellen haben allerdings einen entscheidenden Nachteil, sie alle besitzen ein endogenes $\mathrm{PrP}^{\mathrm{C}}$, das nach einer Infektion mit TSE ebenfalls reagiert.

Aus diesem Grund wurde in dieser Arbeit mit PrP „knock-out“ Zellen gearbeitet. Diese besitzen kein endogenes $\operatorname{PrP}^{\mathrm{C}}$, weshalb nach einer Transfektion mit dem prnp Gen auch nur das exprimierte $\operatorname{PrP}^{\mathrm{C}}$ nachgewiesen wird und nach einer $\operatorname{PrP}^{\mathrm{Sc}}$ Infektion interagieren kann. Die Ergebnisse sind aus diesem Grund im Gegensatz zu den anderen Zelllinien eindeutig. An dieser Zelllinie kann die Regulation der $\operatorname{PrP}^{\mathrm{C}}$ Expression genau bestimmt werden. Reagiert das $\operatorname{PrP}^{\mathrm{C}}$ in diesen Zellen auf eine TSE-Infektion, kann außerdem genauer auf die Spezies des Erregers und die des eingeschleusten $\operatorname{PrP}^{\mathrm{C}}$ eingegangen werden. Durch Variation von Erreger und endogenem $\operatorname{PrP}^{\mathrm{C}}$ können so Rückschlüsse auf die Übertragbarkeit von TSEErkrankungen über die Speziesbarriere hinweg gewonnen werden. Durch die Bestimmung der minimalen infektiösen Dosis kann eine Risikoabschätzung für verschiedene Spezies getroffen werden. Kombiniert man ein PrP „knock-out“ Zellmodell mit anderen Zellmodellen, so 
können Informationen über das Zusammenspiel verschiedener Zelltypen bei der TSEInfektion erhalten werden.

Die Arbeit mit den Zellkulturmodellen hat neben der genauen Definierbarkeit des Systems den Vorteil, dass das Risiko einer TSE-Infektion für das Laborpersonal geringer ist als mit den Tiermodellen. Auch ist der Umgang mit Zellkulturen ethisch unbedenklich. Durch all diese Faktoren kann das Zellkulturmodell das Tiermodell fast ersetzen. Trotzdem kann auf Tierexperimente nicht vollständig verzichtet werden, da derzeit eine Medikamentenzulassung erst nach Tierversuchen erfolgt und ein Vergleich der beiden Modelle den größten Erkenntnisgewinn liefert.

\subsection{Retroviren}

Da in dieser Arbeit Zellkulturen nicht nur mit TSE infiziert wurden, sondern auch mit Retroviren, um verschiedene Gene in ein Wirtsgenom zu integrieren, wird hier auf diese Virenfamilie eingegangen.

Viren sind infektiöse Einheiten mit einer Größe von wenigen nm bis hin zu wenigen $\mu \mathrm{m}$. Sie besitzen keinen eigenen Stoffwechsel. Daher vermehren Viren sich nicht wie Pro- und Eukaryonten sondern dadurch, dass sie in diese eindringen und deren Reproduktionsmechanismen nutzen. Dies geschieht, indem sie ihr Genom in die Wirtszelle einbringen und den wirtseigenen Replikationsapparat verwenden, um neue Virenbestandteile zu produzieren. Viren werden anhand der Symmetrieform, der Capside, der Membranhülle und nach der Art ihrer Erbinformation unterschieden. Als Erbinformation kann dabei DNA oder RNA dienen, die als Einzel- oder Doppelstrang im Virus vorliegen kann.

Das besondere an Retroviren ist, dass sie für eine eigene „reverse transkriptase“ (Rt) kodieren. Diese Rt wird dazu verwendet, vireneigene ssRNA in dsDNA umzuschreiben. Nach Integration der proviralen DNA in das Wirtsgenom, werden die viralen Proteine von dieser Matrize synthetisiert. Ansonsten besitzen Retroviren ein Capsid, das von einer Hüllmembran mit Glykoproteinen umgeben ist. Die Glykoproteine dienen der Erkennung der Wirtszelle und der Virus-Zell-Interaktion. Der schematische Aufbau eines Retrovirus ist in der Abb. 11 dargestellt. 


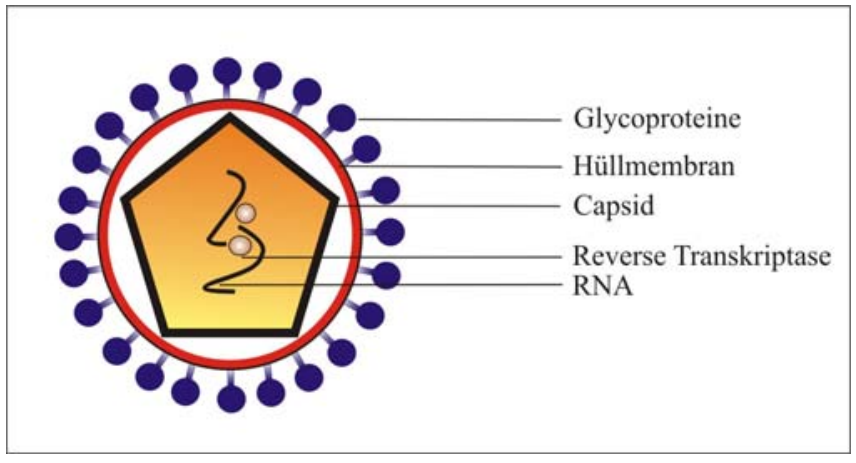

Abb. 11 Schematischer Aufbau eines Retrovirus

In das retrovirale Genom können verschiedene heterologe Gene eingebracht werden. Allerdings sollte dies zwischen den „long terminal repeats“ (LTR)-Regionen geschehen, dargestellt in der Abb. 12, damit die Integration in das Wirtsgenom mit hoher Frequenz erfolgen kann. Diese Eigenschaft wurde in dieser Arbeit ausgenutzt, um verschiedene Zelllinien mit prnp Genen zu transfizieren. Für die Transfektion der Zellen wurde ein Lentivirussystem verwendet. Zur selben Virenfamilie gehört auch das HIV. Diese Virenfamilie ist besonders effizient, da es zu einer fast 100\%igen Expression des Transgens in den infizierten Zellen kommt. Der Replikationszyklus eines Retrovirus ist in der Abb. 13 dargestellt.



Abb. 12 Genomstruktur der LTR-Region eines Retrovirus Die DNA-Replikation erfolgt in Richtung 5'-3', dazwischen liegen die für das Virus wichtigen Proteine gag, pol und env.

In dieser Arbeit wurden prnp Gene eingeschleust und zusammen mit dem Wirtsgenom repliziert. Durch Ausnutzung des Replikationsapparates des Wirts konnte das gewünschte Prion Protein exprimiert werden. 


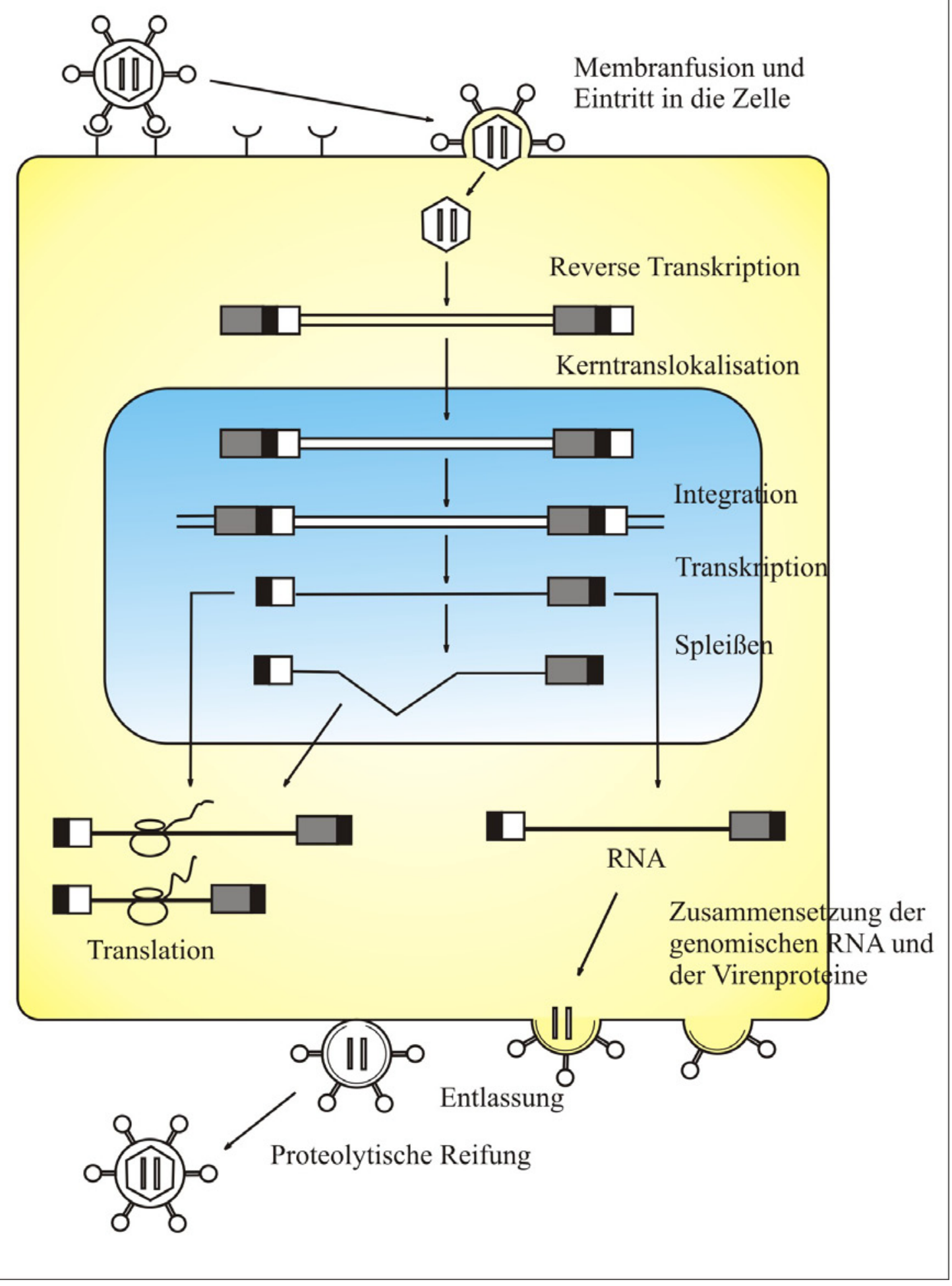

Abb. 13 Replikationsmodell eines Retrovirus in der Zelle Nach dem Eintritt des Virus in die Wirtszelle wird seine RNA durch die reverse Transkriptase in DNA umgeschrieben. Die DNA wird in den Zellkern eingeschleust und in das Wirtsgenom integriert. Anschließend folgt die Transkription der Virusgene. Die hier entstandene RNA wird entweder gespleißt und dient als Matrize für die Synthese der Virusproteine oder wird unmodifiziert als Genom für neue Virenpartikel verwendet. Aus den Virenproteinen und dem Genom werden neue Viruspartikel gebildet und ohne die Zellmembran zu zerstören, ausgeschleust (nach Coffin et al., 1997). 


\subsection{Tetracyclin regulierte Proteinexpression}

Da die in dieser Arbeit verwendeten Zellen das $\operatorname{PrP}^{\mathrm{C}}$ induzierbar exprimieren sollen, ist ein regulierbarer Promotor erforderlich. Dafür wurde das Tetracyclin (Tet)-System verwendet. Bei diesem System gibt es zwei Möglichkeiten der Regulation. Entweder das Tet-Off System, bei dem die Zellen das gewünschte Protein exprimieren, bis sie ein Signal zur Abschaltung der Expression erhalten oder das Tet-On System, bei dem die Zellen so lange kein Protein exprimieren, bis sie ein Signal erhalten. Die Expression wird durch das Antibiotikum Tetracyclin (dargestellt in der Abb. 14) oder dessen Derivat Doxycyclin (Dox) an- oder abgeschaltet. Das zytotoxischere Doxycyclin wirkt dabei 100-fach stärker als Tetracyclin (Gossen et al., 1995).<smiles>CN(C)C1C(O)=C(C(N)=O)C(=O)C2(O)C(O)=C3C(=O)c4c(O)cccc4C(C)(O)C3CC12</smiles>

Abb. 14 Strukturformel des Tetracyclins

Das Tet-System wurde von Gossen und Bujard 1992 entwickelt und ist heute neben dem FlpIn oder dem Cre/Lox-System eines der meist genutzten Systeme zur Regulation von Proteinexpressionen.

Der Vorteil des Tet-Systems besteht darin, dass die Sequenz für den regulierbaren Promotor nicht in Eukaryonten vorkommt und damit nicht ungewollt angeschaltet werden kann. In der vorliegenden Arbeit wurde das Tet-Off System verwendet, da dieses eine geringere Basisexpression als das Tet-On System aufweist (Gossen et al., 1995). Außerdem ist das TetOff System sowohl durch Tet als auch Dox regulierbar, was bei dem nur Dox regulierbaren Tet-On System nicht möglich ist. Die Funktionsweise des Tet-Off Systems für die Regulation der prnp Transkription ist in der Abb. 15 dargestellt. 




Abb. 15 Regulation einer Proteinexpression durch das Tet-Off System am Beispiel des PrP Das tTAElement setzt sich an das TRE-Element. Deshalb kann das prnp Gen transkribiert und das $\operatorname{PrP}^{\mathrm{C}}$ synthetisiert werden. Sobald sich Doxycyclin (Dox) an das tTA-Element bindet, wird die Bindung mit dem TRE-Element unterbunden und die Transkription wird verhindert. Durch diese reversible Inhibierung, kann die Transkription erneut unter der Voraussetzung beginnen, dass das Dox vom tTA-Element entfernt wird.

Da die Aktivierung nur in trans und nicht in cis Stellung erfolgen kann, spricht man von einer Transaktivierung. Dabei müssen die beiden regulatorischen Elemente auf verschiedenen Plasmiden lokalisiert sein und in die Zelle separat transfiziert werden. Bei dem Tet-Off System bindet sich das tTA-Element, welches im pCMV/Bsd Tet-Off Vektor lokalisiert ist, an das „tetracycline responsive element“ (TRE), welches sich im pTRE-FU Vektor mit dem zu transkribierenden Gen befindet. So kann das gewünschte Protein exprimiert werden. Wird aber Dox oder Tet zugegeben, bindet das Antibiotikum an das tTA-Element. 
Dieses kann sich dann nicht mehr an das TRE-Element binden und die Proteinexpression wird verhindert. Erst wenn diese Inhibierung durch das Antibiotikum aufgehoben wird, kann eine erneute Proteinexpression erfolgen. Somit bildet das Antibiotikum Tet oder Dox die Grundlage für das Funktionieren dieses Systems zur reversiblen Inhibierung der Transkription des Zielgens. Durch diese Antibiotika ist das System an- oder abstellbar. 


\subsection{Aufgabenstellung}

Prionen sind infektiöse Proteine, die aufgrund fehlender Nukleinsäuren nicht mit den üblichen Methoden zu detektieren sind. Der nur in Sicherheitslabors anwendbare „Bioassay“, der durch die intracerebrale Inokulation von infektiösem Material erfolgt, bietet bisher die einzige Möglichkeit Prionen zu vermehren und Infektiösität sicher nachzuweisen. Eine „ex vivo“ Replikation von infektiösen Prionen in Zellkultur wäre daher eine deutliche Vereinfachung. Außerdem kann ein solches System zum Verständnis der molekularen Vorgänge der bis heute kaum untersuchten ersten Infektionsschritte führen. Auch zur Aufklärung der immer noch fraglichen biologischen Funktionen des zellulären Prion Proteins $\left(\operatorname{PrP}^{\mathrm{C}}\right)$ könnte es beitragen. Bisher wurden nur Zellkulturmodelle mit endogener $\operatorname{PrP}^{\mathrm{C}}$ Expression zur Replikation von infektiösem $\operatorname{PrP}^{\mathrm{Sc}}$ beschrieben. Die Schwierigkeiten der Replikation in verschiedenen Zelltypen beruhen vermutlich auf einer zu geringen Basisexpression des $\operatorname{PrP}^{\mathrm{C}}$. Daher soll versucht werden, eine „ex vivo“ Replikation von $\mathrm{PrP}^{\mathrm{Sc}}$ in verschiedenen Zelltypen in einem neuen Zellkultursystem zu erreichen. Ein solches Zellkulturmodell könnte sowohl zur Diagnose von TSE-Erkrankungen als auch zur Untersuchung von molekularwissenschaftlichen Fragestellungen dienen.

Um eine Überexpression des $\operatorname{PrP}^{\mathrm{C}}$ zu erhalten, sollen $\operatorname{PrP}$ „knock-out“ ( $\mathrm{PrP}^{0 / 0}$ ) Zellen mit einem speziell konstruierten PrP Expressionsvektor stabil transfiziert werden. Diese Überexpression ist für die Detektion des $\operatorname{PrP}^{\mathrm{Sc}}$ nötig, da sich nur ein geringer Teil des $\operatorname{PrP}^{\mathrm{C}}$ in diese pathogene Isoform umfaltet. Der Expressionsvektor wurde als Kassette konstruiert damit ein prnp Gen eingebaut und gegen andere ausgetauscht werden kann. Dadurch sollen neue stabile regulierbare $\operatorname{PrP}^{\mathrm{C}}$ exprimierende Zelllinien am DPZ, neben der 3T3 Tet-Off hFFI Zelllinie, einer stabil exprimierenden murinen Zelllinie für das humane PrP, etabliert werden. Diese Zellen müssen genauer in Bezug auf die Art der Regulierbarkeit sowie die An- und Abschaltung der $\operatorname{PrP}^{\mathrm{C}}$ Expression mit Hilfe des Western Blots und der Immunfluoreszenz charakterisiert werden.

Können sich diese Zellen regulieren lassen, sollte versucht werden die Zellen mit BSE zu infizieren. Dazu müssten sie mit infektiösem Rinderhirnhomogenat inkubiert werden, um eine Infektion der Zelllinie und der Replikation des $\operatorname{PrP}^{\mathrm{Sc}}$ herbeizuführen. Die Vermehrung könnte anschließend mit Hilfe des Proteinase K Verdaus beobachtet werden. 


\section{$2 \quad$ Materialien und Methoden}

Im Folgenden werden die verwendeten Techniken aus den Bereichen der Molekulargenetik, Zellbiologie, Bakteriologie, Proteinbiochemie sowie Bioanalytik beschrieben.

\subsection{Molekulargenetische Methoden}

\subsubsection{DNA-Isolierung aus Blut}

$1 \mathrm{ml}$ frisch abgenommenes Vollblut wurde mit $1 \mathrm{ml}$ eiskaltem Puffer $\mathrm{C} 1$ und $3 \mathrm{ml} \mathrm{H}_{2} \mathrm{O}_{\text {bid }}$ gemischt. Anschließend folgte eine Inkubation auf Eis für $10 \mathrm{~min}$, in der die Probe aller 2 min invertiert wurde. Diese Probe wurde dann für 15 min mit $1300 \mathrm{~g}$ bei $4{ }^{\circ} \mathrm{C}$ zentrifugiert. Der Überstand wurde verworfen und das Pellet in 0,25 ml eiskaltem Puffer C1 und 0,75 ml $\mathrm{H}_{2} \mathrm{O}_{\text {bid }}$ suspendiert. Nach 15 min Zentrifugation mit 1300 g bei $4{ }^{\circ} \mathrm{C}$ (Centrifuge $5415 \mathrm{C}$, Eppendorf) wurde das Pellet in $1 \mathrm{ml}$ Puffer G2 resuspendiert und der Überstand verworfen. Zur Suspension wurden $25 \mu \mathrm{l}$ PK Lösung zugegeben und für 60 min bei $50{ }^{\circ} \mathrm{C}$ inkubiert. Diese Suspension wurde auf eine mit $1 \mathrm{ml}$ QBT Puffer equilibrierte Säule gegeben. Durch die Gravitation lief die Suspension selbständig durch die Säule. Die Säule wurde danach dreimal mit $1 \mathrm{ml}$ Puffer PE gewaschen. Durch Zugabe von 2 ml Puffer QF wurde die DNA eluiert. Anschließend wurde die genomische DNA gefällt.

\subsubsection{DNA-Isolierung aus Zellkulturen}

Auf geerntete $1 \times 10^{6}$ Zellen wurden 0,5 ml eiskalter Puffer C1 und 1,5 ml $\mathrm{H}_{2} \mathrm{O}_{\text {bid }}$ gegeben. Anschließend wurde weiter wie bei 2.1.1 verfahren.

\subsubsection{DNA-Isolierung aus Gewebe}

20 mg Gewebe wurden mit flüssigem Stickstoff in einem Potter durch einen Mörser zerkleinert. Danach wurde 0,1 ml einer PK Lösung zugegeben und für 2 h bei $50{ }^{\circ} \mathrm{C}$ inkubiert. Anschließend wurde weiter wie bei 2.1.1 verfahren. 


\subsubsection{Plasmidisolierung aus transformierten Zellen}

Die hier beschriebene Methode ist zur Isolierung von Plasmiden aus 1 bis $5 \mathrm{ml}$ Übernachtkulturen von Bakterien mit Hilfe des Plasmidisolierungs Kits von Qiagen (QIAprep Spin Miniprep Kit) geeignet. Die Übernachtkultur wurde für $10 \mathrm{~min}$ mit $13000 \mathrm{~g}$ zentrifugiert. Das Pellet wurde in $250 \mu$ l Puffer P1, der mit 2,5 $\mu$ l RNaseA (100 mg/ml) versetzt war, resuspendiert. Die Zellen wurden durch die Zugabe von $250 \mu$ l Puffer P2 lysiert und durch vier- bis sechsmaliges Invertieren gemischt. Diese Lysisreaktion wurde durch die Zugabe von $350 \mu$ l des Puffers N3 gestoppt. Die Zellfragmente wurden danach durch Zentrifugation für 10 min mit 13000 g pelletiert und der Überstand wurde auf eine Qiagen Säule überführt. Es folgte eine Zentrifugation von 1 min mit 13000 g. Anschließend wurde die Säule mit $750 \mu$ l des Puffers PE gewaschen und zweimal wie zuvor beschrieben zentrifugiert. Das an die Säulenmatrix gebundene Plasmid wurde mit $50 \mu \mathrm{H}_{2} \mathrm{O}_{\text {bid }}$ durch Zentrifugation wie beschrieben eluiert. Das so eluierte Plasmid wurde bei $-20{ }^{\circ} \mathrm{C}$ gelagert.

\subsubsection{DNA-Amplifikation mittels Polymerase Kettenreaktion (PCR)}

Die PCR-Technik (Saiki et al., 1985; Mullis et al., 1987) ist eine enzymatische Methode für die Amplifikation spezifischer dsDNA-Fragmente. Durch zwei an den komplementären Strängen in entgegengesetzte Richtungen orientierte gebundene Oligonukleotide (Primer), wurde das zu amplifizierende DNA-Fragment synthetisiert. Durch das Einbauen verschiedener Nukleotide in den Primer konnten zusätzlich spezifische Schnittstellen an das Fragment angefügt werden. Durch wiederholte Zyklen von Denaturierung, Annealing und Elongation wurden die DNA-Fragmente exponenziell vermehrt. Die Amplifikationsreaktionen wurden in einem Thermocycler (Mastercycler gradient, Eppendorf) durchgeführt.

$\begin{array}{rrl}\text { PCR-Reaktionsansatz: } & 1,0 \mu \mathrm{l} & \text { Primer } 1(100 \mu \mathrm{M}) \\ 1,0 \mu \mathrm{l} & \text { Primer } 2(100 \mu \mathrm{M}) \\ 1,0 \mu \mathrm{l} & \text { dNTP-Mix (je } 10 \mathrm{mM}) \\ 5,0 \mu \mathrm{l} & 10 \text { x Taq Polymerasepuffer } \\ 0,5 \mu \mathrm{l} & \text { Taq Polymerase }(2,5 \mathrm{U} / \mu \mathrm{l}) \\ 2,0 \mu \mathrm{l} & 25 \mathrm{mM} \mathrm{MgCl}_{2} \\ & <100,0 \mathrm{ng} & \text { dsDNA } \\ & \text { ad. } 50,0 \mu \mathrm{l} & \mathrm{H}_{2} \mathrm{O}_{\text {bid }}\end{array}$

Die optimale Annealingtemperatur für das prnp Gen musste zuvor durch einen Temperaturgradienten bestimmt werden. Alle anderen Bedingungen sollten dabei konstant sein. Einen Anhaltspunkt für diese Annealingtemperatur erhielt man aus der 
Schmelztemperatur $\left(\mathrm{T}_{\mathrm{m}}\right)$ der entsprechenden Primer. Diese ergab sich aus deren Basenzusammensetzung. Die einfachste Gleichung zur Berechnung der theoretischen Schmelztemperatur war folgende:

$$
T_{m}=4 \cdot(\text { Anzahl an G bzw. C) }+2 \cdot(\text { Anzahl A bzw. T) }
$$

Diese Gleichung eignete sich allerdings nur für Primer bis zu einer Länge von 20 Nukleotiden. Für längere Primer musste diese Gleichung modifiziert werden. Die Anzahl der Zyklen ist ein Maß für die Menge am entstehenden Produkt, da theoretisch in jedem Zyklus die Anzahl der DNA-Templates verdoppelt wurde. Für die verschiedenen DNA-Fragmente wurden verschieden angepasste PCR-Programme verwendet, die in a) bis d) aufgelistet sind.

a) Amplifikation von des prnp Gens aus genomischer DNA

Schritt 1: $\quad \mathrm{T}=95,0^{\circ} \mathrm{C} \quad 5,00 \mathrm{~min}$

Schritt 2: $\quad \mathrm{T}=94,0^{\circ} \mathrm{C} \quad 0,50 \mathrm{~min}$

Schritt 3: $\quad \mathrm{T}=59,1^{\circ} \mathrm{C} \quad 1,00 \mathrm{~min}$

Schritt 4: $\quad \mathrm{T}=72,0^{\circ} \mathrm{C} \quad 0,75 \mathrm{~min}$

35 Wdh. der Schritte 2 bis 4

Schritt 5: $\quad \mathrm{T}=72,0^{\circ} \mathrm{C} \quad 4,00 \mathrm{~min}$

Schritt 6: $\mathrm{T}=4,0^{\circ} \mathrm{C} \quad \infty \quad \mathrm{min}$

b) Amplifikation des prnp Gens aus Vektoren

Diese Methode ist für die Verwendung eines Plasmids oder eines Bakterienklons geeignet.

Schritt 1: $\quad \mathrm{T}=95,0^{\circ} \mathrm{C} \quad 5,00 \mathrm{~min}$

Schritt 2: $\quad \mathrm{T}=94,0^{\circ} \mathrm{C} \quad 0,50 \mathrm{~min}$

Schritt 3: $\quad \mathrm{T}=52,0^{\circ} \mathrm{C} \quad 1,50 \mathrm{~min}$

Schritt 4: $\mathrm{T}=72,0^{\circ} \mathrm{C} \quad 1,00 \mathrm{~min}$

25 Wdh. der Schritte 2 bis 4

Schritt 5: $\quad \mathrm{T}=72,0^{\circ} \mathrm{C} \quad 4,00 \mathrm{~min}$

Schritt 6: $\quad \mathrm{T}=4,0^{\circ} \mathrm{C} \quad \infty \quad \mathrm{min}$

c) Amplifikation des tTA-Elements

Schritt 1: $\quad \mathrm{T}=95,0^{\circ} \mathrm{C} \quad 5,00 \mathrm{~min}$

Schritt 2: $\quad \mathrm{T}=94,0^{\circ} \mathrm{C} \quad 0,75 \mathrm{~min}$

Schritt 3: $\quad \mathrm{T}=54,0^{\circ} \mathrm{C} \quad 1,00 \mathrm{~min}$

Schritt 4: $\quad \mathrm{T}=72,0^{\circ} \mathrm{C} \quad 1,00 \mathrm{~min}$

32 Wdh. der Schritte 2 bis 4

Schritt 5: $\quad \mathrm{T}=72,0^{\circ} \mathrm{C} \quad 5,00 \mathrm{~min}$

Schritt 6: $\quad \mathrm{T}=4,0^{\circ} \mathrm{C} \quad \infty \quad \mathrm{min}$ 
d) Mycoplasmentest in der Zellkultur

$\begin{array}{lr}\text { Schritt 1: } \mathrm{T}=94,0{ }^{\circ} \mathrm{C} & 2,00 \mathrm{~min} \\ \text { Schritt 2: } \mathrm{T}=94,0{ }^{\circ} \mathrm{C} & 0,50 \mathrm{~min} \\ \text { Schritt 3: } \mathrm{T}=55,0{ }^{\circ} \mathrm{C} & 0,50 \mathrm{~min} \\ \text { Schritt 4: } \mathrm{T}=72,0{ }^{\circ} \mathrm{C} & 0,50 \mathrm{~min} \\ \text { 35 Wdh. der Schritte } 2 \text { bis } 4 \\ \text { Schritt 5: } \mathrm{T}=4,0^{\circ} \mathrm{C} \quad \infty \quad \mathrm{min}\end{array}$

\subsubsection{Reinigung von PCR-Produkten}

Um Oligonukleotiden und andere Verunreinigungen zu entfernen, musste die PCR-Probe gereinigt werden. Die Reinigung von DNA-Fragmenten erfolgte mit dem QIAquick PCR Purification Kit (Qiagen). Das 5-fache Volumen der PCR-Probe an Puffer PB wurde zugegeben und gemischt. Anschließend wurde die Suspension in eine Säule gegeben und für 1 min mit 13000 g zentrifugiert. Der Durchlauf wurde verworfen. Danach wurde die Säule mit $750 \mu$ Puffer PE und durch Zentrifugation für 1 min mit 13000 g gewaschen. Nach dem Verwerfen des Durchlaufs wurde die Säule nochmals unter den gleichen Bedingungen wie zuvor zentrifugiert. Anschließend wurde die Säule mit $50 \mu \mathrm{l} 70{ }^{\circ} \mathrm{C}$ warmen $0,1 \mathrm{M}$ Tris/ $\mathrm{HCl}$, pH 8,0 durch Zentrifugation für 1 min mit 13000 g eluiert und das Eluat bei $-20{ }^{\circ} \mathrm{C}$ gelagert.

\subsubsection{Agarose-Gelelektrophorese}

Zur Auftrennung von DNA-Fragmenten mit anschließender Reinigung und Identifizierung wurden Agarose-Gelelektrophoresen durchgeführt. Für die zu erwartende Größe der Fragmente von 0,2 kb bis $12 \mathrm{~kb}$ wurden Horizontalgele verwendet. Diese enthielten je nach berechneter Fragmentgröße 0,5 \% bis 2,5 \% (w/v) Agarose (Sambrook et al., 1989; Takahashi et al., 1969) in TAE-Puffer (0,01 M EDTA, 0,2 M Essigsäure, 0,4 M Tris mit pH 8,0). Der Nachweis der DNA-Banden erfolgte mit Ethidiumbromid, welches in die DNA interkaliert und unter UV-Licht fluoresziert. Dabei wurden jeweils $100 \mathrm{ml}$ Gelvolumen mit 0,1 \% (w/v) Ethidiumbromidlösung versetzt. Die Proben wurden mit 1/10 ihres Volumens an Probenpuffer (6 x Loading Dye Solution, Fermentas) versetzt und aufgetragen. Als Längenstandard diente, je nach der zu erwartenden Fragmentgröße, $1 \mu \mathrm{g}$ des „100 bp-DNA Ladder“ oder „1 kb-DNA Ladder“ (GeneRuler, Fermentas). Die Auftrennung der DNAFragmente erfolgte bei $120 \mathrm{~V}$ in 1 x TAE als Laufpuffer. Anschließend wurde das Bandenmuster im Gel mit einem Geldokumentationssystem (Gel Jet Imager, Intas) dokumentiert. 


\subsubsection{DNA-Spaltung durch Restriktionsendonukleasen}

Um dsDNA-Fragmente in einem Vektor zu klonieren, wurden diese durch bestimmte Restriktionsendonukleasen gespalten. Die Enzymkonzentrationen und Pufferbedingungen wurden dabei nach Herstellerangaben gewählt. Bei Verwendung von mehreren Restriktionsenzymen mit unterschiedlichen Pufferbedingungen wurde zuerst das Enzym mit dem Optimum bei einer niedrigeren Salzkonzentration verwendet. Anschließend wurde die Salzkonzentration erhöht und mit dem zweiten Enzym geschnitten. Der Verdau wurde für 2 h mit der für das jeweilige Enzym optimalen Temperatur durchgeführt. Die verwendeten Restriktionsenzyme mit den eingesetzten Pufferkonzentrationen sowie deren Erkennungssequenzen sind in der Tab. 2 aufgelistet. Die entstandenen Fragmente wurden anschließend durch eine Agarose-Gelelektrophorese analysiert und dokumentiert.

Tab. 2 Verwendete Restriktionsendonukleasen

\begin{tabular}{lll}
\hline Enzym & Pufferkonzentration & \\
\hline BamHI & $1 \mathrm{x}$ & Erkennungssequenz \\
HindIII & $2 \mathrm{x}$ & $\mathrm{G}^{\mathbf{\nabla}}$ GATCC \\
ScaI & $2 \mathrm{x}$ & $\mathrm{A}^{\boldsymbol{\nabla}}$ AGCTT \\
SspI & $1 \mathrm{x}$ & $\mathrm{AGT}^{\mathbf{\nabla}} \mathrm{ACT}$ \\
XhoI & $2 \mathrm{x}$ & $\mathrm{AAT}^{\mathbf{\nabla}} \mathrm{ATT}$ \\
XmnI & $1 \mathrm{x}$ & $\mathrm{C}^{\mathbf{\nabla}} \mathrm{TCGAG}$ \\
\hline
\end{tabular}

${ }^{1} 1$ x Multi-Core ${ }^{\mathrm{TM}}$ Puffer (Promega, 25 mM Tris/Acetat, pH 7,5, $100 \mathrm{mM}$ Natriumacetat, $10 \mathrm{mM}$ Magnesiumacetat, $1 \mathrm{mM}$ DTT)

Für einen Restriktionsverdau wurde folgender Ansatz verwendet:

$\begin{aligned} 1 \mu \mathrm{l} & \text { Enzym (5 U) } \\ 1 \mu \mathrm{l} & \text { Puffer } \\ \mathrm{x} \mu \mathrm{l} & \text { DNA oder Vektor } \\ \text { ad. } 30 \mu \mathrm{l} & \mathrm{H}_{2} \mathrm{O}_{\text {bid }}\end{aligned}$

Das eingesetzte Volumen $\mathrm{x}$ an DNA-Lösung, wurde so gewählt, dass 2 bis $3 \mu \mathrm{g}$ im Restriktionsansatz enthalten waren. 


\subsubsection{Isolierung von DNA-Fragmenten aus Agarosegelen}

Die zu isolierenden DNA-Fragmente wurden aus dem Agarosegel geschnitten und mit dem QIAquick Gel Extraktions-Kit (Qiagen) gereinigt. Das ausgeschnittene Gelstück wurde in ein 1,5 ml Eppendorfgefäß gegeben, mit dem 3-fachen Volumen (w/v) an QG Puffer versetzt und bei $50{ }^{\circ} \mathrm{C}$ für $10 \mathrm{~min}$ aufgelöst (Thermomixer 5446, Eppendorf). Anschließend wurde die Lösung auf eine QIAquick-Säule gegeben und für $1 \mathrm{~min}$ in der Tischzentrifuge mit $13000 \mathrm{~g}$ zentrifugiert. Dieser Durchlauf wurde verworfen. Anschließend wurde die Säule mit $750 \mu l$ PE Puffer durch Zentrifugation für 1 min mit 13000 g gewaschen und erneut zentrifugiert wie bereits beschrieben. Danach wurde zur Elution der DNA-Fragmente die Säule mit $30 \mu \mathrm{l}$ $\mathrm{H}_{2} \mathrm{O}_{\text {bid }}$ für 1 min mit 13000 g zentrifugiert.

\subsubsection{Photometrische Konzentrationsbestimmung von DNA}

Zur Bestimmung einer Nukleinsäurekonzentration in einer Lösung wurde deren optische Dichte bei $260 \mathrm{~nm}$ gemessen. Dazu wurden die Proben im Verhältnis 1:100 mit $\mathrm{H}_{2} \mathrm{O}_{\text {bid }}$ verdünnt und in eine Quarzglasküvette mit $1 \mathrm{~cm}$ Schichtdicke überführt. Die Messung erfolgte in einem Spektralphotometer (GeneQuant, Pharmacia Biotech). Die Konzentrationsberechnung ließ sich mit folgender Gleichung durchführen:

$$
c[n g / \mu l]=O D_{260} \cdot \Sigma \cdot V_{F}
$$

mit

$$
\begin{array}{ll}
\mathrm{C} & =\text { Konzentration } \\
\mathrm{OD}_{260} & =\text { Extinktion der optischen Dichte bei } 260 \mathrm{~nm} \\
\Sigma & =\text { Extinktionskoeffizient } \\
\mathrm{V}_{\mathrm{F}} & =\text { Verdünnungsfaktor } \\
\Sigma & =0,05 \text { für dsDNA }
\end{array}
$$

Um die Reinheit der jeweiligen DNA zu ermitteln, wurde zusätzlich der Quotient von $\mathrm{OD}_{260} / \mathrm{OD}_{280}$ bestimmt. Bei einem Wert von 1,6 bis 2,0 wurde mit der Aufarbeitung fortgefahren, da der ideale Wert für wässrige dsDNA-Lösungen bei 2,0 liegt. 


\subsubsection{Dialyse von salzhaltigen Lösungen}

Da sich Salze in den verschiedenen molekularbiologischen Techniken, wie z. B. der Transformation oder Ligation störend auswirken, mussten diese entfernt werden. Dazu wurden die salzhaltigen DNA- oder Proteinlösungen auf die Oberseite einer Dialysemembran (0,025 $\mu \mathrm{m}$ Porendurchmesser, Millipore) pipettiert. Dabei befand sich die raue Unterseite über einer 10\%igen Glycerinlösung. Diese Membran wurde für 2 h bei RT inkubiert. Das Volumen der DNA-haltigen Lösung musste mind. $20 \mu$ l betragen, da ansonsten das Volumen nach der Dialyse zu gering war, um von der Membran abgenommen werden zu können.

\subsubsection{Klonierung von DNA-Fragmenten}

Unter Klonierung versteht man die Verknüpfung von Vektor- und Insert-DNA mittels Ligation (Weiss et al., 1968; Scharf et al., 1986). Für eine erfolgreiche Ligation mussten allerdings bestimmte Bedingungen erfüllt sein, die nachfolgend beschrieben werden.

\subsubsection{Dephosphorylierung von DNA-Fragmenten}

Um eine Religation des geschnittenen Vektors $\mathrm{zu}$ vermeiden, wurde dieser zuvor dephosphoryliert. Dabei wurden am 5'-Ende des linearen Vektors die Phosphatreste unter zu Hilfenahme des folgenden Dephosphorylierungsansatzes abgespalten:

$10 \mu \mathrm{l} 200 \mu \mathrm{g}$ lineare Plasmid DNA

$1 \mu \mathrm{l}$ alkalische Phosphatase $(1 \mathrm{U} / \mu \mathrm{l})$

$3 \mu \mathrm{l} 10 \mathrm{x}$ alkalischer Phosphatase Puffer ad. $30 \mu \mathrm{l} \mathrm{H} \mathrm{O}_{\text {bid }}$

Die Inkubation des Dephosphorylierungsansatzes erfolgte für $1 \mathrm{~h}$ bei $37{ }^{\circ} \mathrm{C}$ mit anschließender Inaktivierung des Enzyms bei $85^{\circ} \mathrm{C}$ für $10 \mathrm{~min}$.

\subsubsection{Ligation von DNA-Fragmenten über Restriktionsschnittstellen}

Für die Ligation von Vektor und Insert über Restriktionsschnittstellen wurden Insert und Vektor mit einem oder zwei kompatiblen Enzymen geschnitten. Wenn zwei verschiedene Restriktionsenzyme verwendet wurden, wurde die Richtung in der das Insert in den Vektor ligiert, festgelegt. Wurde dagegen nur ein Enzym verwendet, konnte das Insert in 
unterschiedlichen Orientierungen im Vektor vorliegen. In der vorliegenden Arbeit wurden beide Methoden angewandt. Folgender Ligationsansatz wurde dabei verwendet:

100 ng linearer Vektor-DNA

3-facher molarer Überschuss an Insert-DNA

$2 \mu \mathrm{l} 10 \mathrm{x}$ T4 Ligationspuffer

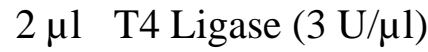

ad. $20 \mu \mathrm{l} \quad \mathrm{H}_{2} \mathrm{O}_{\text {bid }}$

Der Ligationsansatz wurde über Nacht bei $16{ }^{\circ} \mathrm{C}$ im Wasserbad inkubiert. Die Berechnung der verwendeten optimalen Mengen an Vektor und Insert am Beispiel eines 12 kb Vektors und eines 0,8 kb Inserts ist in der nachfolgender Gleichung dargestellt:

[(50 ng Vektor $\cdot 0,8 \mathrm{~kb}-$ Insert $) /(12 \mathrm{~kb}$ Vektor $)] \cdot 3($ Überschuss Insert $)=10 \mathrm{ng}$ Insert

\subsubsection{TA-Klonierung von DNA-Fragmenten}

Da normalerweise die Taq Polymerase ein Adenin an das 3'-Ende des DNA-Stranges nach der PCR synthetisiert, konnten gereinigte PCR-Produkte direkt in einen Vektor kloniert werden. Diese Methode konnte nur angewandt werden, weil ein überhängendes Thymin Bestandteil des verwendeten pGEM-T Vektors (Promega) war. Verfügte das Insert nicht über ein Adenin am 3'-Ende, musste dieses noch adenyliert werden. Ansonsten erfolgte die Ligation des Vektors mit dem Insert direkt über Nacht bei $16{ }^{\circ} \mathrm{C}$ mit dem folgenden TAKlonierungsansatz:

$$
\begin{aligned}
& \text { 0,5 } \mu \text { l pGEM-T Vektor (50 ng) } \\
& 5,0 \mu \mathrm{l} 10 \mathrm{x} \text { Ligationspuffer } \\
& 0,8 \mu \mathrm{l} 2 \mathrm{x} \text { T4 Ligase }(1 \mathrm{U} / \mu \mathrm{l}) \\
& 50,0 \text { ng DNA-Fragment } \\
& \text { ad. } 10,0 \mu \mathrm{l} \quad \mathrm{H}_{2} \mathrm{O}_{\text {bid }}
\end{aligned}
$$

Aufgrund dessen, dass der pGEM-T Vektor für die $\alpha$-Komplementation ausgelegt ist, wurden die positiven Klone auf IPTG-XGal LB Amp Platten identifiziert, da ein Fragment, zwischen das lacZ-Gen kloniert wurde. Deshalb konnte die durch das lacZ-Gen codierende $\beta$-Galactosidase nicht gebildet werden, die sonst das X-Gal spaltete, wodurch ein blauer Indolfarbstoff gebildet würde. Aus diesem Grund erschienen die Klone mit Insert weiß. Daher wird die $\alpha$-Komplementation auch als blau/weiß Selektion bezeichnet (Horwitz et al., 1964; Ullmann et al., 1967). 


\title{
2.1.12.4 Adenylierung von DNA-Fragmenten
}

Durch Adenylierung wurde ein Adenin an ein DNA-Fragment angefügt, dabei wurde das Fragment durch Inkubation mit dATP und einer Polymerase adenyliert. Die Reaktion erfolgte für $2 \mathrm{~h}$ bei $70{ }^{\circ} \mathrm{C}$ mit folgendem Adenylierungsansatz:

\author{
$1,0 \mu \mathrm{l} 1 \mathrm{mM}$ dATP

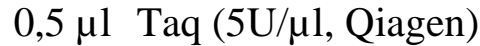 \\ $1,0 \mu \mathrm{l} 10 \mathrm{x}$ Puffer \\ $0,2 \mu \mathrm{l} 25 \mathrm{mM} \mathrm{MgCl}_{2}$ \\ $5,0 \mu$ DNA-Fragment \\ ad. $10,0 \mu \mathrm{l} \quad \mathrm{H}_{2} \mathrm{O}_{\text {bid }}$
}

\subsubsection{Restriktionsfragment-Kartierung}

Durch den Einsatz mehrerer Restriktionsenzyme wurde das Plasmid in verschiedene Fragmente, mit unterschiedlichen Längen, geschnitten. Dieser Restriktionsverdau wurde anschließend auf ein Agarosegel aufgetragen und dokumentiert. War das gewünschte Fragment im Vektor vorhanden, konnte so gleichzeitig die Orientierung des Fragmentes bestimmt werden.

\subsubsection{DNA-Sequenzierung}

Um genaue Kenntnisse über die Sequenz von Genen zu erhalten, wurden diese sequenziert. Die Sequenzierung beruht auf der Kettenabbruchmethode nach Sanger, 1977. Allerdings wurden fluoreszenzmarkierte Didesoxynukleotidtriphosphate (ddNTPs) statt radioaktiver verwendet. Dabei wurde jedem der vier ddNTPs eine andere Fluoreszenzmarkierung zugeordnet. Neben den ddNTPs befanden sich auch Desoxyribonukleotide (dNTPs) in einem Sequenzieransatz, die während der Sequenzreaktion eingebaut wurden. Wurde aber ein Didesoxynukleotid eingebaut, stoppte die Synthese, da sie keine Hydroxylgruppe am 3'-Ende besaß, diese aber für eine Folgereaktion notwendig wäre. Da dieser Einbau zufällig erfolgte, entstanden DNA-Stränge mit unterschiedlichen Längen, diese konnten durch eine Kapillarelektrophorese bestimmt werden. Diese DNA-Stränge wurden entsprechend ihrer Größe aufgetrennt. Danach wurde die Fluoreszenzmarkierung durch einen Laserstrahl detektiert. Durch die Größenbestimmung wurden die um eine Base unterschiedlichen Stränge erkannt und ihr Fluoreszenzsignal entsprechend dem Nukleotid sortiert. Durch eine Software wurde die Sequenz der DNA-Templates anschließend als Elektropherogramm ausgegeben. 
Für die Bestimmung der Gensequenz aus einem Plasmid wurden 300 ng DNA benötigt oder 30 ng, wenn die Sequenz eines PCR-Fragments bestimmt werden sollte. Die Sequenz-PCR erfolgte mit folgendem Ansatz:

Sequenz-PCR Ansatz:

$$
\begin{aligned}
& 1,0 \mu \mathrm{l} \text { Big Dye } \\
& 1,5 \mu \mathrm{l} 5 \mathrm{x} \text { Puffer } \\
& 1,0 \mu \mathrm{l} \text { 3,3 pmol/ } \mu \mathrm{l} \text { Primer } \\
& \mathrm{x} \mu \mathrm{l} \text { DNA } \\
& \text { ad.10,0 } \mu \mathrm{l} \mathrm{H}_{2} \mathrm{O}_{\text {bid }}
\end{aligned}
$$

Sequenz-PCR:

Schritt 1: $\mathrm{T}=95^{\circ} \mathrm{C} \quad 5,00 \mathrm{~min}$

Schritt 2: $\mathrm{T}=96{ }^{\circ} \mathrm{C} \quad 0,50 \mathrm{~min}$

Schritt 3: $\mathrm{T}=50^{\circ} \mathrm{C} \quad 0,25 \mathrm{~min}$

Schritt 4: $\mathrm{T}=60^{\circ} \mathrm{C} \quad 4,00 \mathrm{~min}$

25 Wdh. der Schritte 2 bis 4

Schritt 5: $\mathrm{T}=72{ }^{\circ} \mathrm{C} \quad 5,00 \mathrm{~min}$

Schritt 6: $\mathrm{T}=4^{\circ} \mathrm{C} \quad \infty \quad \min$

Anschließend musste das Sequenz PCR-Produkt mit folgendem Ansatz gefällt werden:

$$
\begin{array}{rl}
10 \mu \mathrm{l} & 3 \mathrm{M} \mathrm{NaN}_{3}, \mathrm{pH} 5,5 \\
250 \mu \mathrm{l} & 96 \% \text { iger EtOH } \\
90 \mu \mathrm{l} & \mathrm{H}_{2} \mathrm{O}_{\text {bid }}
\end{array}
$$

Dieser Ansatz wurde für 15 min bei RT mit 13000 g zentrifugiert. Der Überstand wurde verworfen und das Pellet mit $250 \mu$ l 70\%igem EtOH gewaschen und anschließend für 5 min mit 13000 g zentrifugiert. Das Pellet wurde getrocknet und durch Dr. Christian Roos von der Arbeitsgruppe Primatengenetik am Deutschen Primatenzentrum sequenziert. Die Sequenzierung erfolgte mittels eines 3100-Avant Genetic Analyzers (Applied Biosystems). Die erhaltenen Daten wurden anschließend mit den Sequenzanalyseprogrammen BioEdit und Chromas ausgewertet. 


\subsection{Prokaryontische Techniken}

\subsubsection{Bakterienkultivierung}

Für ein optimales Wachstum der Bakterien sind Temperaturen von $37{ }^{\circ} \mathrm{C}$ und ein entsprechendes Nährmedium erforderlich. Der in dieser Arbeit verwendete Bakterienstamm ist in der Tab. 3 dargestellt.

Tab. 3 Eigenschaften des Bakterienstamms

\begin{tabular}{lcl}
\hline Bakterienstamm & Medium & Genotyp \\
\hline E. coli DH5 $\alpha$ & Luria-Bertani & F- supE44 hsdR17 recA1 gyrA96 endA1 thi-1 relA1 \\
& (LB) & deoR lambda- \\
\end{tabular}

Damit auf Bakterienkulturen über einen längeren Zeitraum als Referenz zurückgegriffen werden konnte, wurden Glycerinkulturen angelegt. Dazu wurden die Bakterien bei einer OD $_{595}$ von 0,8 im Verhältnis von 4:1 mit Glycerin gemischt und sofort in flüssigen Stickstoff eingefroren. Die so hergestellten Kryokulturen waren bei $-80^{\circ} \mathrm{C}$ beliebig haltbar.

\subsubsection{Bestimmung der optischen Dichte von Bakterienkulturen}

Die optische Dichte (OD) von Bakterienkulturen wurde in einem Spektralphotometer (Uvikon 810, Kontron) bestimmt. Bei einer Wellenlänge von $595 \mathrm{~nm}\left(\mathrm{OD}_{595}\right)$ wurde gegen das Medium als Leerwert, in einer $1 \mathrm{ml}$ Küvette mit einer Schichtdicke von $1 \mathrm{~cm}$ (Halbmikro Einmalküvetten, Ratiolab), gemessen.

\subsubsection{Transformation von $E$. coli}

Für eine elektrische oder chemische Transformation von DNA wurden kompetente E. coli Zellen benötigt. Die Zellen mussten kompetent sein, da sie nur so Fremd-DNA aufnehmen konnten. 


\subsubsection{Herstellung elektro-kompetenter $E$. coli}

Zur Herstellung elektro-kompetenter Zellen wurden $5 \mathrm{ml}$ LB-Medium mit dem entsprechenden E. coli Stamm angeimpft und über Nacht bei $37{ }^{\circ} \mathrm{C}$ mit $200 \mathrm{rpm}$ im Rundschüttler inkubiert. Mit dieser Vorkultur wurden am nächsten Tag 200 ml LB-Medium angeimpft und unter gleichen Bedingungen wie am Vortag im Rundschüttler inkubiert. Beim Erreichen einer $\mathrm{OD}_{595}$ von 0,8 bis 1,0 wurden die Zellen für 30 min auf Eis inkubiert und anschließend zu $50 \mathrm{ml}$ aliquotiert und $10 \mathrm{~min}$ bei $4{ }^{\circ} \mathrm{C}$ mit $1100 \mathrm{~g}$ zentrifugiert (Minifuge GL, Heraeus Christ). Der Überstand wurde verworfen und das Zellpellet in $50 \mathrm{ml}$ eiskaltem $\mathrm{H}_{2} \mathrm{O}_{\text {bid }}$ resuspendiert. Nach 10 min Inkubation auf Eis wurden die Zellen für 10 min bei $4{ }^{\circ} \mathrm{C}$ mit 1100 g sedimentiert. Anschließend wurde das Pellet in $25 \mathrm{ml}$ eiskaltem $\mathrm{H}_{2} \mathrm{O}_{\text {bid }}$ resuspendiert und 10 min auf Eis inkubiert. Nach der erneuten Zentrifugation unter gleichen Bedingungen wurde das Pellet in $10 \mathrm{ml}$ einer eiskalten 10\%igen (v/v) Glycerinlösung mit 0,1 $\mathrm{M} \mathrm{CaCl}_{2}$ resuspendiert und zu $200 \mu \mathrm{l}$ in vorgekühlte sterile Eppendorfgefäße aliquotiert und bis zur Verwendung bei $-80{ }^{\circ} \mathrm{C}$ gelagert. Die so hergestellten elektro-kompetenten E. coli Zellen behielten ihre Transformationskompetenz für 2 Monate. Danach wurden neue kompetente Zellen hergestellt.

\subsubsection{Herstellung chemisch-kompetenter $E$. coli}

LB-Medium wurde mit einer Übernachtkultur angeimpft, wie bei 2.2.3.1 beschrieben. Bei Erreichen einer $\mathrm{OD}_{595}$ von 0,6 bis 0,8 wurden die Zellen für 15 min auf Eis inkubiert und anschließend zu $50 \mathrm{ml}$ aliquotiert und $5 \mathrm{~min}$ mit $1100 \mathrm{~g}$ und $4{ }^{\circ} \mathrm{C}$ zentrifugiert. Das Pellet wurde in $25 \mathrm{ml}$ eiskalter 0,1 $\mathrm{M} \mathrm{CaCl}_{2}$-Lösung resuspendiert und $30 \mathrm{~min}$ auf Eis inkubiert. Anschließend wurde wie beschrieben zentrifugiert. Die erhaltenen Pellets wurden in je $5 \mathrm{ml}$ eiskalter 20\%iger (v/v) Glycerinlösung mit 0,1 $\mathrm{M} \mathrm{CaCl}_{2}$ aufgenommen und in vorgekühlte Eppendorfgefäße aliquotiert. Diese wurden in flüssigem Stickstoff schockgefroren und bei $-80{ }^{\circ} \mathrm{C}$ bis zur weiteren Verwendung gelagert.

\subsubsection{Transformation elektro-kompetenter $\boldsymbol{E}$. coli}

Für die Elektroporation wurden $100 \mu$ l elektro-kompetenter Zellen eingesetzt. Die Zellsuspension wurde unmittelbar vor der Transformation auf Eis aufgetaut. Nach dem Auftauen wurden die Zellen in eine mit Eis vorgekühlte Elektroporationsküvette überführt. Anschließend wurden $10 \mu \mathrm{l}$ salzfreie DNA-Lösung zugegeben. Die DNA-Menge für eine 
optimale Transformationseffizienz lag bei 50 ng. Die Elektroporation wurde bei einer Spannung von $2,5 \mathrm{kV}$, einer Kapazität von $25 \mu \mathrm{F}$ und einem Widerstand von $200 \Omega$ durchgeführt (GENE PULSER II, Bio-Rad). Nach der Elektroporation wurden die Zellen mit $1 \mathrm{ml}$ LB-Medium versetzt. Danach wurde die Zellsuspension in ein steriles Eppendorfgefäß überführt und bei $37^{\circ} \mathrm{C}$ mit $200 \mathrm{rpm}$ für $1 \mathrm{~h}$ auf dem Rundschüttler inkubiert. In dieser Zeit normalisierte sich der Zellstoffwechsel und das verantwortliche Gen für die Antibiotikaresistenz wurde translatiert. Danach wurden unterschiedliche Bakterienverdünnungen auf LBAmp Platten ausplattiert und bei $37{ }^{\circ} \mathrm{C}$ über Nacht inkubiert, damit am nächsten Tag die Bakterienklone selektiert werden konnten

\subsubsection{Transformation chemisch-kompetenter $E$. coli}

Die chemisch kompetenten E. coli wurden auf Eis aufgetaut. $50 \mu$ l dieser Zellen wurden mit dem zu transfizierenden Plasmid für 20 min auf Eis inkubiert. Diese Suspension wurde anschließend für $90 \mathrm{~s}$ im Wasserbad bei $42{ }^{\circ} \mathrm{C}$ erhitzt und danach für 2 min auf Eis gekühlt. Damit sich die Antibiotikaresistenz ausbilden konnte, wurden $950 \mu$ l LB-Medium zugegeben und bei $37^{\circ} \mathrm{C}$ und 200 rpm für $1 \mathrm{~h}$ auf einem Rundschüttler inkubiert. Danach wurde der Ansatz wie bei der Transformation elektro-kompetenter E. coli Zellen ausplattiert.

\subsection{Eukaryontische Techniken}

\subsubsection{Kultivierung von eukaryontischen Zellen}

Für die Zellkulturarbeiten wurden die Empfehlungen für den Umgang mit eukaryontischen Zellen befolgt (Lindl, 2000). Die verwendeten Zelllinien sind in der Tab. 4 dargestellt. In flüssigem Stickstoff $\left(-196{ }^{\circ} \mathrm{C}\right)$ eingelagerte Zellen wurden in einem Wasserbad bei $37{ }^{\circ} \mathrm{C}$ aufgetaut und für 5 min mit 100 g zentrifugiert (Centrifuge 5810, Eppendorf). Der Überstand wurde verworfen, das Zellpellet in dem entsprechenden Medium resuspendiert und in eine Zellkulturflasche überführt. 
Tab. 4 Verwendete Zelllinien

\begin{tabular}{|c|c|c|c|}
\hline Zellstämme & Gewebe & Medium & Referenz \\
\hline \multirow[t]{3}{*}{$\operatorname{PrP}^{0 / 0}$} & murine neuronale $\operatorname{Pr} \mathrm{P}^{0 / 0}$ & $\mathrm{DMEM}+10 \%(\mathrm{v} / \mathrm{v}) \mathrm{FCS}$ & Kretzschmar et \\
\hline & Zellen & $+1 \%(\mathrm{v} / \mathrm{v})$ & al., 1997 \\
\hline & & Penicillin/Streptomycin & \\
\hline \multirow[t]{3}{*}{ N2a } & Maus Neuroblastoma & RPMI $1640+10 \%(v / v)$ FCS & Klebe et al., \\
\hline & Zellen & $+1 \%(\mathrm{v} / \mathrm{v})$ & 1969 \\
\hline & & Penicillin/Streptomycin & \\
\hline \multirow[t]{3}{*}{ ЗТЗ } & Swiss albino Maus & $\mathrm{DMEM}+10 \%(\mathrm{v} / \mathrm{v}) \mathrm{FCS}$ & Todaro et al., \\
\hline & Fibroblasten Zellen & $+1 \%(\mathrm{v} / \mathrm{v})$ & 1963 \\
\hline & & Penicillin/Streptomycin & \\
\hline \multirow[t]{3}{*}{ 3T3 L1 Tet-Off } & modifizierte 3T3 Zellen & DMEM + $10 \%(\mathrm{v} / \mathrm{v}) \mathrm{FCS}$ & Buschmann et \\
\hline & & $+1 \%(\mathrm{v} / \mathrm{v})$ & al. \\
\hline & & Penicillin/Streptomycin & \\
\hline \multirow[t]{5}{*}{ PT67 } & modifizierte 3T3 Zellen & DMEM + $10 \%(\mathrm{v} / \mathrm{v}) \mathrm{FCS}$ & Miller et al., \\
\hline & & $+1 \%(\mathrm{v} / \mathrm{v})$ & 1996 \\
\hline & & Penicillin/Streptomycin & \\
\hline & & + 4 mM L-Glutamine & \\
\hline & & $+4,5 \mathrm{~g} / \mathrm{l}$ Glucose & \\
\hline
\end{tabular}

Wenn nicht anders beschrieben, wurden die adherent wachsenden Zellen in dem entsprechenden Zellkulturmedium unter sterilen Bedingungen bei $37{ }^{\circ} \mathrm{C}$ und $5 \% \mathrm{CO}_{2}$ kultiviert. Nach Erreichen von 70 \% bis 90 \% Konfluenz wurden die Zellen zweimal mit PBS gewaschen und mit 1 x Trypsin/EDTA bei $37{ }^{\circ} \mathrm{C}$ vom Zellkulturflaschenboden durch Schwenken gelöst. Dies wurde im Mikroskop kontrolliert. Danach wurde die Trypsinreaktion mit 4 Volumen Kulturmedium gestoppt. Anschließend wurden die Zellen für 5 min mit $100 \mathrm{~g}$ abzentrifugiert. Der Überstand wurde verworfen und das Pellet in frischem Medium resuspendiert. Diese Suspension wurde je nach Zelltyp mit einer Verdünnung von 1:3 bis 1:20 in neue Kulturflaschen passagiert. Experimentelle Daten wurden mit Hilfe von Transfektionsexperimenten erst nach mind. drei Passagen und einer Woche in Kultur erhoben. Zur Lagerung von Zellen und Verifizierung experimenteller Daten wurden Kryokulturen der Zellen angelegt. Zum Einfrieren der Zellen wurden jeweils 1 x $10^{6}$ Zellen im Einfriermedium (10 \% DMSO + 25 \% FCS + 65 \% Medium) resuspendiert und in ein Kryoröhrchen (Nalgene) überführt. Diese Kryoröhrchen wurden in eine Kryobox (Cryo $1{ }^{\circ} \mathrm{C}$ Freezing Container, 
Nalgene) überführt und mit Isopropanol langsam über Nacht im Gefrierschrank auf $-80{ }^{\circ} \mathrm{C}$ abgekühlt. Am nächsten Tag wurden die Kryoröhrchen in flüssigen Stickstoff überführt und bis zur weiteren Verwendung aufbewahrt.

\subsubsection{Lebendzellzahlbestimmung von eukaryontischen Zellen}

Die Bestimmung der Lebendzellzahl erfolgte mit Hilfe einer Neubauer Zählkammer. Dabei wurde die Eigenschaft toter Zellen benutzt, sich durch Trypanblau färben zu lassen. Im Gegensatz dazu besaßen lebende Zellen diese Eigenschaft nicht. Dafür wurden die Zellen abtrypsiniert und mit 100 g für 5 min abzentrifugiert. Das Zellpellet wurde in einer definierten Menge Medium resuspendiert. $20 \mu \mathrm{l}$ dieser Suspension wurden mit $20 \mu \mathrm{l}$ 0,5 \% Trypanblau gemischt und in eine Neubauerkammer zwischen Objektträger und Deckgläschen gebracht. Unter dem Mikroskop wurden dann die lebenden Zellen ausgezählt, deren Gesamtzellzahl sich nach folgender Gleichung berechnen lässt:

$$
\text { Lebendgesamtzellzahl = gezählte Zellzahl }\left[\mathrm{ml}^{-1} \cdot 2 \cdot 10^{4} \cdot V[\mathrm{ml}]\right.
$$

\subsubsection{Herstellung transienter Zellen durch Micellen}

Zur transienten Transfektion von eukaryontischen Zellen wurde das Effectene- und das SuperFect Transfektionsreagenz (Qiagen) verwendet. Das SuperFect Reagenz legt sich um die DNA, wodurch ihre Stabilität erhöht wurde und diese über Endozytose in die Zellen eingeschleust werden konnten. Das Effectene benötigt dazu noch ein kondensierendes Agens (Enhancer). Dieser DNA-Transfektions-Komplex wurde dann in Micellen verpackt und in die Zelle eingeschleust (Tang et al., 1996). Die eigentliche Transfektion erfolgte durch eine Fusion der Micellen mit den Lipiden der Zellmembran, wodurch die zu transfizierende DNA in das Zytoplasma der Zellen eingeschleust wurde.

Dazu wurden 1 x $10^{5}$ Zellen auf einer 12 Well Platte ausplattiert. Am nächsten Tag wurden zur Bestimmung der optimalen Transfektionseffizienz verschiedene Konzentrationen DNA und Transfektionsreagenzien zugegeben. Dafür wurden die Zellen mit Medium ohne Serum für $1 \mathrm{~h}$ inkubiert. Anschließend wurden die Zellen dreimal mit PBS gewaschen. Auf diese Zellen wurde der DNA-Transfektions-Komplex gegeben und für 30 min bei RT inkubiert. Anschließend wurden die Zellen für $2 \mathrm{~h}$ im Brutschrank bei $37{ }^{\circ} \mathrm{C}$ und $5 \% \mathrm{CO}_{2}$ inkubiert. Danach wurden die Zellen gewaschen und mit Vollmedium weiter inkubiert. 
Zur Bestimmung der optimalen Transfektionseffizienz wurden Zellen mit dem pGL3 Vektor transfiziert. Am nächsten Tag wurden die Zellen lysiert und die Luziferaseaktivität gemessen.

\subsubsection{Herstellung stabiler eukaryontischer Zellen durch Elektroporation}

Mit einem Enzym wurden $100 \mu$ g eines Vektors linearisiert. Dieser wurde anschließend durch 0,25 kV und 0,975 F in $5 \times 10^{6}$ abtrypsinierte Zellen mit dem Gene Pulser II (Bio-Rad) elektroporiert. Anschließend wurden zur Etablierung stabil transfizierter Zellen diese in eine 6 cm Zellkulturschale (Greiner) überführt. 24 h später wurde durch Zugabe eines Antibiotikums die Selektion gestartet. Das dabei verwendete Antibiotikum war abhängig vom Selektionsmarker auf dem Vektor mit dem die eukaryontischen Zellen transfiziert wurden. Zur Entfernung abgestorbener Zellen wurde das Medium alle zwei Tage abgenommen und die Zellkulturschale gründlich mit PBS gewaschen. Das Wechseln des Mediums erfolgte so lange, bis nur noch einzelne Zellklone im Mikroskop zu erkennen waren. Die Selektionsdauer war abhängig von der verwendeten Antibiotikakonzentration, die zuvor anhand der Antibiotikaresistenz nicht transfizierter Zellen ermittelt wurde.

\subsubsection{Retrovirale Transfektion eukaryontischer Zellen}

Für die Retrovirale Infektion von Eukaryonten wurde der Vector pRevTRE verwendet. Da dieser Vektor allein keine Zellen infizieren kann, wurde dieser zunächst in die PT67 Zelllinie mit 0,25 kV und 0,975 $\mu \mathrm{F}$ elektroporiert. Diese Zelllinie exprimierte die Virushüllproteine, verpackte den Vektor in ein Capsid mit Virushülle und gab ihn über die Zellmembran in das Zellmedium ab, ohne dass die Zellen dabei zerstört wurden. Dieses Medium wurde anschließend durch einen 0,45 $\mu \mathrm{m}$ Zelluloseacetatfilter filtriert, so dass nur Medium mit Viren im Durchlauf übrig blieben. Um eine Infektion zu erreichen, wurde ein „multiplicity of infection“ (MOI) von 0,5 bis 3 „colony forming units“ (cfu) pro Zelle benötigt. Die zu infizierende Zelllinie musste für eine retrovirale Transfektion zu $60 \%$ konfluent in einer Zellkulturflasche gewachsen sein. Zu dieser Kultur wurden $4 \mu \mathrm{g} / \mathrm{ml}$ Polybrene gegeben, damit sich die Virenpartikel besser an die Zellen binden und eindringen konnten (Davis et al., 2002; Lee et al., 2005; Landazuri et al., 2006). Anschließend wurde diese Zelllinie mit dem Durchlauf der Filtration für 24 h inkubiert. Danach wurde das Medium abgenommen und durch normales Zellkulturmedium ersetzt. Nach 2 Tagen wurde mit der Selektion stabil transfizierter Zellen durch die Zugabe eines Antibiotikums begonnen. Da sich in der zu 
infizierenden Zelllinie und auf dem retroviralen Vektor verschiedene Resistenzgene befanden, blieben nach der Selektion nur die Zellen übrig, die beide Resistenzen ausgeprägt hatten.

\subsection{Proteinbiochemische Methoden}

\subsubsection{Bestimmung der Transfektionseffektivität anhand der Luziferaseaktivität}

Zur Bestimmung der optimalen Transfektionseffektivität wurde die Luziferaseaktivität in den transient transfizierten Zellen gemessen. Dazu wurden die Zellen 24 h nach der Transfektion mit $50 \mu$ l Lysepuffer lysiert. Um die Zelltrümmer zu entfernen, wurde die Zellsuspension abgenommen und für 2 min mit 13000 g zentrifugiert. $50 \mu$ des Überstandes wurden im Luminometer (Lumat LB 9507, Berthold) mit $100 \mu$ l Luziferasereagenz resuspendiert und das dabei emittierte Licht nach 5 s gemessen. Nach einer statistischen Auswertung konnte die optimale Effektivität bestimmt werden.

\subsubsection{Proteinextraktion aus „inclusion bodies“ (IB)}

Proteine können in E. coli angereichert und mit Ausbeuten von bis zu 100 mg/l extrahiert werden. Bei hoher Überexpression rekombinanter Proteine kommt es häufig zur Aggregation von Proteinen in „inclusion bodies“ (IB). Zur Gewinnung des nativen Proteins wurden die IB isoliert. Unter geeigneten Anreicherungs- und Präparationsbedingungen beträgt die Reinheit des Proteins in den IB $\approx 90 \%$. Da die IB als Proteinaggregate eine hohe Dichte aufweisen, ist eine Isolierung durch einfache Zentrifugation möglich. Für diese Aufreinigung wurden verschiedene Methoden angewandt.

\subsubsection{Aufschluss der E. coli Zellen durch Ultraschall}

Eine Übernachtkultur von E. coli Zellen, die ein rekombinantes Protein exprimieren, wurde angeimpft. 12 h später wurden $5 \mathrm{ml}$ dieser Kultur für 5 min mit 1100 g zentrifugiert. Der Überstand wurde verworfen und das Pellet mit 5 ml Puffer I (1 mM EDTA, 0,1 M Tris/HCl, $\mathrm{pH}$ 7) resuspendiert. 1,5 mg Lysozym wurden zugegeben, mit dem Ultraturrax (Labsonic 2000, Braun) gemischt und anschließend für 30 min bei $4{ }^{\circ} \mathrm{C}$ inkubiert. Während der Ultraschallbehandlung musste die Probe im Eisbad gekühlt werden, da durch die hohe lokale Energie der Scherkräfte Wärme freigesetzt wurde. Die Proben wurden in verschiedenen Zeitintervallen dem Ultraschall ausgesetzt, 1 x 30 s, 1 x 1 min und 3 x 1 min. Dabei wurde 
nach jeder Minute die Probe für 1 min auf Eis gekühlt. Nach Abschluss der Ultraschallbehandlung wurde $\mathrm{MgCl}_{2}$ (3 $\mathrm{mM}$ Endkonzentration) und DNase $(10 \mu \mathrm{g} / \mathrm{ml}$ Endkonzentration) zugegeben. Die Lösungen wurden anschließend für 30 min bei RT inkubiert. Es folgte eine Zugabe von 0,5 Volumen an Puffer II (60 mM EDTA, 6 \% Trition X 100, 1,5 M NaCl, pH 7) mit einer erneuten Inkubation von $30 \mathrm{~min}$. Danach wurde die Probe für 20 min mit $13000 \mathrm{~g}$ bei $4{ }^{\circ} \mathrm{C}$ zentrifugiert. Der Überstand wurde verworfen und das Pellet mit Hilfe eines Ultraturrax in $1 \mathrm{ml}$ Puffer III (20 mM EDTA, 0,1 M Tris/HCl, pH 7) gelöst. Diese Probe wurde solange zentrifugiert wie beschrieben und mit dem Ultraturrax gelöst, bis eine Schaumbildung nicht mehr auftrat. Wurde dieser Punkt erreicht, war das Detergens vollständig ausgewaschen. Danach wurde die Probe aliquotiert und ein Teil auf ein SDS-PAGE-Gel zur Kontrolle aufgetragen.

\subsubsection{Aufschluss der E. coli Zellen durch eine Retsch-Mühle}

Im Gegensatz zur Ultrazentrifugation beruht der Zellaufschluss mit Hilfe der Retsch-Mühle auf rein mechanischen Kräften. Es wurde eine Übernachtkultur wie bei 2.4.2.1 angelegt und aufgearbeitet sowie mit Puffer inkubiert. Danach wurden $500 \mu \mathrm{l}$ dieser Probenlösung in $2 \mathrm{ml}$ Eppendorfgefäße mit je 0,5 g Glasperlen gegeben. Diese Proben wurden anschließend unterschiedlichen Zeitintervallen mit der Retsch-Mühle (Tissuelyser, Qiagen) mit $25 \mathrm{~Hz}$ behandelt, 1 x 1 min, 1 x 5 min und 1 x 10 min. Anschließend wurden die Proben im Eisbad gekühlt. Nach Zugabe von $450 \mu$ l Puffer I wurden die Proben mit 13000 g für 3 min bei $4{ }^{\circ} \mathrm{C}$ zentrifugiert. Danach wurde $\mathrm{MgCl}_{2}$ (3 $\mathrm{mM}$ Endkonzentration) und DNase $(10 \mu \mathrm{g} / \mathrm{ml}$ Endkonzentration) zugegeben. Es folgte eine Inkubation von 30 min bei RT. Nach Zugabe von $370 \mu \mathrm{l}$ von Puffer II folgte eine Inkubation für $30 \mathrm{~min}$. Anschließend wurden diese Proben für 10 min mit $13000 \mathrm{~g}$ und $4{ }^{\circ} \mathrm{C}$ zentrifugiert. Der Überstand wurde verworfen und das Pellet in $1 \mathrm{ml}$ Puffer III aufgenommen und zentrifugiert. Das Pellet wurde anschließend in Puffer III resuspendiert und ein Teil zur Analyse auf ein SDS-PAGE-Gel aufgetragen.

\subsubsection{Proteinextraktion aus einer eukaryontischen Zelllinie durch Zelllyse}

Abtrypsinierte Zellen wurden für 5 min mit 100 g abzentrifugiert und das Pellet in $500 \mu \mathrm{l}$ E1A-Puffer (50 mM Hepes, $150 \mathrm{mM} \mathrm{NaCl,} \mathrm{0,1} \mathrm{\%} \mathrm{(v/v)} \mathrm{Igepal)} \mathrm{resuspendiert} \mathrm{und}$ anschließend für 30 min auf Eis inkubiert und im Abstand von jeweils 5 min invertiert. Pro $100 \mu$ l enthält dieser Puffer je $1 \mu$ l DNase, $1 \mu$ l RNase und je $1 \mu$ l der Proteaseinhibitoren 
Phenylmethylsulfonylfluorid (PMSF, gegen Serin- und Cysteinproteasen), Leupeptin (gegen Thiolproteasen), Pepstatin A (gegen saure Proteasen) und Aprotenin (gegen Serinproteasen). Anschließend wurde die Zellsuspension für 5 min mit $13000 \mathrm{~g}$ und bei $4{ }^{\circ} \mathrm{C}$ zentrifugiert. Der Überstand wurde abgenommen und das Zellpellet in $100 \mu$ E1A-Puffer resuspendiert. Für eine weitere optionale Auftrennung wurde die Pelletsuspension dreimal für $20 \mathrm{~s}$ sonifiziert. Anschließend wurde die Suspension für 5 min mit $13000 \mathrm{~g}$ und $4{ }^{\circ} \mathrm{C}$ zentrifugiert. Der Überstand wurde mit Pr1 und das Zellpellet, dass in $100 \mu$ E1A-Puffer resuspendiert wurde, mit Pr2 gekennzeichnet.

\subsubsection{Proteinbestimmung nach Bradford}

Die Proteinbestimmung nach Bradford beruht auf einer Verschiebung des Absorptionsmaximums einer Proteinlösung von 465 nm nach 595 nm. Diese Verschiebung wurde durch die Bindung des Farbstoffes Coomassie-Brilliantblau an Proteine hervorgerufen (Bradford, 1976). Diese Proteinbestimmung wurde mit Hilfe eines Protein Assays (Bio-Rad) durchgeführt. Die Extinktion einer proteinhaltigen Probenlösung wurde nach 10 min Inkubation bei $595 \mathrm{~nm}$ gegen eine proteinlose Probenlösung als Referenzwert mit einem Absorbtionsmessgerät (GENios, TECAN) bestimmt. Die Probenlösung besteht aus $150 \mu \mathrm{l}$ $\mathrm{H}_{2} \mathrm{O}_{\text {bid, }} 40 \mu \mathrm{l}$ Bradfordreagenz und $10 \mu \mathrm{l}$ Probe. Die Proteinextinktion wurde aus dem statistischen Mittel von drei Messungen bestimmt. Zur Bestimmung der Konzentration einer unbekannten Proteinlösung wurde diese gegen eine Rinderserumalbumin (BSA)-Eichreihe gemessen und durch lineare Regression ermittelt.

\subsubsection{Proteinkonzentrierung durch Ethanolfällung}

Für verschiedene Methoden, wie z. B. der WB, wurde eine definierte Proteinkonzentration benötigt. War sie zu gering, wurde die Probenlösung mit EtOH gefällt. Die Proteinlösung wurde mit dem 2,2-fachen Volumen an 96\%igen EtOH resuspendiert und für $1 \mathrm{~h}$ bei $-80{ }^{\circ} \mathrm{C}$ inkubiert. Danach wurde die Suspension für 20 min mit 13000 g und $4{ }^{\circ} \mathrm{C}$ zentrifugiert. Der Überstand wurde verworfen und das Pellet mit 70\%igen EtOH gewaschen und unter den gleichen Bedingungen wie zuvor zentrifugiert. Der Überstand wurde wieder verworfen und die restliche Lösung bei RT durch eine Speed Vac (Speed Vac Concentrator, Intas) getrocknet. Anschließend wurde die Probe in einem geeigneten Puffervolumen resuspendiert. 


\subsubsection{Proteinkonzentrierung durch Trichloressigsäure (TCA)}

Zu einer Proteinlösung wurde TCA zu einer Endkonzentration von $10 \%$ (v/v) gegeben und für 30 min bei $4{ }^{\circ} \mathrm{C}$ inkubiert (Bennet, 1967). Im Anschluss wurde die Lösung mit $13000 \mathrm{~g}$ bei $4{ }^{\circ} \mathrm{C}$ für 10 min zentrifugiert. Der Überstand wurde verworfen und das Pellet in Wasser zu einer definierten Endkonzentration resuspendiert.

\subsubsection{Zweidimensionale (2D)-Gelelektrophorese}

Proteingemische können mit der 2D-Gelelektrophorese in zwei Dimensionen aufgetrennt werden (Klose, 1975). Dabei werden die Proteine in der ersten Dimension nach ihrem isoelektrischen Punkt in der Zweiten dagegen nach ihrem Molekulargewicht in einem Natriumdodecylsulfat (SDS)-Gel aufgetrennt. Dadurch ist es möglich, das Proteom einer Zelle zu charakterisieren. Die Proteine wanderten in der ersten Dimension auf einem $\mathrm{pH}-$ Gradienten im elektrischen Feld so lange, bis sie ihren isoelektrischen Punkt erreicht hatten, das heißt, ihre Nettoladung gleich Null war. Der Ladungszustand der Proteine wurde dabei durch alle positiven und negativen Ladungen der Aminosäureseitenketten, die dreidimensionale Struktur, die Phosphorylierungen und die Glykosylierungen bestimmt. In dieser Arbeit wurde ein pH-Gradient in Form eines Hydrofilms (GE Healthcare) verwendet. Der verwendete Gradient war dabei von der zu untersuchenden Probe abhängig. Ein pHGradient von 3 bis 10 wurde für die erste Einstufung der zu erwartenden Proteine aus dem Zelllysat verwendet. Die gesuchten Proteine wurden später durch eine Einengung des $\mathrm{pH}$ Bereiches genauer aufgetrennt. Als Proteingemische wurden nur zuvor gereinigte und fraktionierte Proben eingesetzt. Da das Zelllysat durch einen salzreichen Puffer aufgearbeitet wurde, mussten die Salze wieder entfernt werden, da sie verhinderten, dass die benötigte Spannung für die 2D-Gelelektrophorese aufgebaut werden konnte. Die Salze wurden durch eine Dialyse (siehe 2.1.11) entfernt. Anschließend wurden die Proteine in $120 \mu \mathrm{l}$ Rehydrationspuffer (8 M Harnstoff, 2 \% (w/v) CHAPS, 0,002 \% Bromphenolblau, 0,5 \% (v/v) IPG Puffer, 0,2 \% (w/v) DTT) aufgenommen und für 10 min bei RT unter Schwenken inkubiert. Die IPG Strips (Immobiline DryStrip pH 3-10, GE Healthcare) wurden anschließend mit dieser Lösung beladen. Über Nacht erfolgte dann eine aktive Rehydrierung bei 50 V. Im Anschluss daran wurde ein Spannungsgradient aufgebaut. Dieser lief mit einer Gesamtlaufzeit von 9250 Voltstunden (Vh) im Ettan IPGphor II (Amersham Biosciences). Dazu wurde das folgende Programm verwendet: 


$\begin{array}{lrr}\text { 1. Schritt } & 50 \mathrm{~V} & 10 \mathrm{~h} \\ \text { 2. Schritt } & 200 \mathrm{~V} & 1 \mathrm{~h} \\ \text { 3. Schritt } & 2000 \mathrm{~V} & 1 \mathrm{~h} \\ \text { 4. Schritt } & 3000 \mathrm{~V} & 7000 \mathrm{Vh} \\ \text { 5. Schritt } & 10 \mathrm{~V} & 5 \mathrm{~h}\end{array}$

Der 5. Schritt diente dazu, dass die Proteine nicht ungewollt bis zur weiteren Verwendung diffundierten. Die Strips wurden jetzt entweder bei $-80{ }^{\circ} \mathrm{C}$ eingefroren oder sofort für ein SDS-PAGE-Gel aufgearbeitet. Dazu wurden die Strips mit $10 \mathrm{ml}$ Equilibrierungspuffer (6 M Harnstoff, 2 \% SDS, 30 \% Glycerin, 0,002 \% Bromphenolblau, $50 \mathrm{ml}$ Tris/HCl, pH 8,8) und mit $1 \%$ (w/v) DTT versetzt und für 30 min und 100 rpm im Schwenkschüttler equilibriert. Anschließend wurde der Equilibrierungspuffer mit 2,5 \% (w/v) Jodacetatamid versetzt und die Strips für $30 \mathrm{~min}$ und $100 \mathrm{rpm}$ alkyliert. Danach wurden die Strips in ein SDS-Gel eingelegt und die Proteine nach ihrem Molekulargewicht aufgetrennt. Damit keine Luftblasen die Gelelektrophorese störten, wurde die Geltasche vor dem Beladen mit dem Gelstrip mit einer 0,4\%igen (w/v) Agaroselösung in SDS-Laufpuffer überschichtet.

\subsubsection{Sodiumdodecylsulfat-Polyacrylamid-Gelelektrophorese (SDS-PAGE)}

Die SDS-PAGE ist ein diskontinuierliches Proteintrennungsverfahren im elektrischen Feld (Laemmli, 1970). Die Proteine werden, wie zuvor beschrieben, dabei nach ihrem Molekulargewicht aufgetrennt. Proteinproben die nicht fokussiert wurden, mussten nach ihrer Aufarbeitung mit Dithiothreitol (DTT) und SDS im Probenpuffer versetzt werden, so dass diese anionischen Detergenzien nach dem Erhitzen der Probe auf $85{ }^{\circ} \mathrm{C}$ die Proteine umschließen und diese negativ beladen. Die entstehende Nettoladung ist bei allen so behandelten Proteinen gleich, so dass die Proteine nur nach ihrer Größe aufgetrennt werden. Die negativ geladenen SDS-Protein-Komplexe wandern im elektrischen Feld zur Anode, wobei die jeweilige relative Laufstrecke umgekehrt proportional zum Logarithmus des Molekulargewichtes ist.

Für die Trennung von Proteinen wurde das Mini-PROTEAN 3 System (Bio-Rad) genutzt. Dieses System ermöglichte die Trennung der Proteine auf einer $1 \mathrm{~mm}$ dicken und $7 \mathrm{~cm}$ langen Gellaufstrecke. Die verwendeten Gele bestanden dabei aus zwei Teilen mit verschiedenen Acrylamidkonzentrationen, einem 12\%igem Trenngel mit darüber liegendem 4\%igem Sammelgel. Zur Polymerisation der Gele wurde N,N,N,N-Tetramethylendiamin (TEMED) und Ammoniumpersulfat (APS) verwendet. Die Anzahl der Probetaschen im Sammelgel wurde durch die aufgetragene Proteinkonzentration bestimmt. Die Proteine wurden in 
Lithiumdodecylsulfat (LDS)-Probenpuffer (141 mM Tris Base, 2 \% LDS, 10 \% Glycerin, 0,51 mM EDTA, 0,22 mM SERVA Blue G250, 0,175 mM Phenol Rot, 106 mM Tris/HCl, pH 8,5) aufgenommen und für 15 min bei $95{ }^{\circ} \mathrm{C}$ inkubiert. Als Laufpuffer wurde ein MOPSPuffer (1 M MOPS, 1 M Tris Base, 0,0205 M EDTA) verwendet. Für das Sammelgel wurde eine konstante Spannung von $100 \mathrm{~V}$ und für das Trenngel $200 \mathrm{~V}$ angelegt. Nach $1 \mathrm{~h}$ wurde die Elektrophorese beendet. Die aufgetrennten Proteine wurden nun entweder auf eine Membran transferiert und über einen ECL-Blot detektiert oder aber mit Coomassie-Brilliantblau im Gel angefärbt. Bestimmte Spots wurden bei der 2D-Gelelektrophorese ausgeschnitten und durch die Massenspektrometrie bestimmt.

\subsubsection{Western Blot durch Elektrotransfer}

Zum Blotten eines SDS-Gels wurde das Invitrogen XCell II Blot Modul verwendet. Alle verwendeten Materialen wurden im Blotpuffer getränkt. Auf zwei Lagen eines Schaumstoffes wurden drei Lagen 3 mm dickes Filterpapier (Whatman) gelegt. Darüber wurde das SDSPAGE-Gel luftblasenfrei aufgelegt. Auf dieses Gel wurde eine entsprechend der Gelgröße zurechtgeschnittene Nitrozellulosemembran (NZM) mit einer Porengröße von 0,2 $\mu \mathrm{m}$ (Schleicher \& Schuell) luftblasenfrei auflegt. Dann wurde eine Lage $3 \mathrm{~mm}$ dickes Filterpapier darüber gelegt und von der Mitte des Blots alle eventuellen Luftblasen mit einer Stripette zum Rand herausgedrückt. Im Anschluss daran wurden wiederum zwei Lagen 3 mm dickes Filterpapier und zwei Lagen Schaumstofftuch aufgelegt. Dieses so genannte „Sandwich“ wurde in eine Blotkammer eingeklemmt und diese mit $5 \%$ Transferpuffer (0,5 M Bicine, 0,0205 M EDTA, 0,5 M Tris/HCl), 20 \% Methanol und $75 \%$ Wasser aufgefüllt. Da die Proteine in dem Gel durch das SDS negativ geladen waren, musste die NZM an der Anode liegen. Der Transfer der gebundenen Proteine erfolgte anschließend von der Kathode zur Anode. Für den Transfer wurden $30 \mathrm{~V}$ für $1 \mathrm{~h}$ angelegt. Um den vollständigen Transfer zu prüfen, wurde anschließend das SDS-PAGE-Gel mit Coomassie-Blau angefärbt.

\subsubsection{Immundetektierung mit dem ECL-System}

Die NZM wurde nach dem Blotten für 1 h mit 5 \% (w/v) Milchpulver in PBST (MPBST) bei $37^{\circ} \mathrm{C}$ inkubiert und anschließend dreimal für 5 min mit einem 0,1 \% (v/v) Tween 20 in PBS Puffer (PBST) gewaschen. Anschließend wurde die NZM mit einem 1:2000 verdünnten murinen anti-PrP Antikörpermix (mAk-mix) in MPBST für $2 \mathrm{~h}$ inkubiert. Der anti-PrP mAk- 
mix bestand aus einer Mischung aus 6 gegen das PrP gerichtete Maus-IgG mAks, diese waren das 3B5, 4F2, 8G8, 11C6, 12F10 und das 14D3 (Krasemann et al., 1996; Krasemann et al., 1999). Danach wurde die NZM dreimal für 5 min mit 0,1 \% PBST Puffer gewaschen. Anschließend wurde die Membran für 1 h mit einem 1:10000 verdünntem Meerrettichperoxidase (HRP) konjugierten Ziege anti-Maus IgG Ak in MPBST inkubiert. Danach wurde die NZM fünfmal für 5 min mit 0,1 \% PBST Puffer und zweimal für 7 min mit PBS Puffer gewaschen. Zum Entwickeln der NZM wurde sie in eine ECL-Folientasche gelegt und im Dunkeln mit $2 \mathrm{ml}$ einer 1:1 Mischung zweier Substratlösungen inkubiert. Die Substratlösung 1 (2,5 M Luminol, 0,4 M p-Cumarinsäure, 0,1 M Tris/HCl, pH 8,0) und Substratlösung 2 $\left(0,09 \%(\mathrm{v} / \mathrm{v}) \mathrm{H}_{2} \mathrm{O}_{2}, 0,1 \mathrm{M}\right.$ Tris/HCl, $\mathrm{pH}$ 8,0) wurden direkt vor der Anwendung miteinander gemischt. Diese Lösung wurde 1 min auf der NZM inkubiert, bevor die überschüssige Lösung mit einer Stripette durch Rollen weggedrückt wurde. Ein Detektionsfilm (Hyperfilm, Amersham Biosciences) wurde anschließend für $10 \mathrm{~s}$ bis 5 min belichtet und mit dem Filmentwicklungsgerät Kodak Elite Chrome 400 entwickelt. Wenn mit dem bloßen Auge schon eine Lumineszenz beobachtet werden konnte, reichte ein kurzes Auflegen des Films auf die NZM. Reichte diese Belichtungszeit nicht aus, so wurde der Film über Nacht belichtet und am nächsten Tag entwickelt. Konnten immer noch keine Banden erkannt werden, wurde die Membran mit einer 0,1 M Glycinlösung, $\mathrm{pH}$ 2,9 abgestrippt und die Immundetektierung mit erhöhten Antikörperkonzentrationen und längeren Inkubationszeiten wiederholt.

\subsubsection{Coomassie-Blaufärbung von SDS Gelen}

Proteine in SDS-Gelen wurden mit der Coomassie-Blaufärbung nachgewiesen. Dabei bindet sich der Farbstoff an die Proteine, nicht aber an die Gelmatrix. Für die Färbung wurde kolloidales Brilliantblau G (Sigma) verwendet. Das Gel wurde nach der Elektrophorese für 60 min mit 40 \% (v/v) EtOH und 10 \% (v/v) Essigsäure in $\mathrm{H}_{2} \mathrm{O}_{\text {bid }}$ fixiert. Danach wurde das Gel zweimal mit $100 \mathrm{ml} \mathrm{H} \mathrm{O}_{\text {bid }}$ gewaschen und für $12 \mathrm{~h}$ in der Färbelösung inkubiert. Diese bestand aus $20 \mathrm{ml}$ des kolloidalen Brilliantblau, $20 \mathrm{ml}$ Methanol und $60 \mathrm{ml} \mathrm{H}_{2} \mathrm{O}_{\text {bid. }}$ Nach der Inkubation wurde das Gel so lange mit 1\%iger (v/v) Essigsäure gewaschen, bis nur noch die blaugefärbten Proteine und keine unspezifischen Banden zu erkennen waren (Neuhoff, 1985). Das entfärbte Gel wurde anschließend eingeschweißt und bis zur weiteren Verwendung bei $4{ }^{\circ} \mathrm{C}$ gelagert. Die so angefärbten Proteine konnten für eine massenspektrometrische Analyse verwendet werden, da der Farbstoff diese Analysemethode nicht beeinträchtigt und die Detektionsgrenze der Färbemethode bei 30 ng liegt. 


\subsubsection{Ponceau-Rotfärbung von Nitrozellulosemembranen}

Die Ponceau-Rotfärbung ist eine reversible Proteinfärbemethode auf Nitrozellulose- und Zellulosemembranen, die nachfolgende Nachweismethoden wie den WB nicht beeinträchtigt. Die Membran wurde in der Ponceau-Rotlösung (2 \% (w/v) Ponceaurot in $3 \%(v / v)$ TCA) für 3 min bei RT inkubiert und dann viermal mit $100 \mathrm{ml} \mathrm{H}_{2} \mathrm{O}_{\text {bid }}$ so lange gewaschen, bis nur noch die Proteinbanden rot gefärbt waren. Die Nachweisgrenze dieser Färbemethode liegt bei 50 ng (Li et al., 1989). Die gefärbten Banden auf der Membran wurden eingescannt und mit dem Ergebnis des WB verglichen. Damit die Membran erneut verwendet werden konnte, wurde sie bis zur vollständigen Entfärbung mit $\mathrm{H}_{2} \mathrm{O}$ gewaschen.

\subsubsection{Aufarbeitung von Gewebematerial}

Von einem zu untersuchenden Gewebematerial wurde das Gewicht bestimmt und mit Hilfe eines Zellschredders (Qiagen) durch schrittweise Zugabe von Tris-Puffer (100 mM KCl, 320 mM Saccharose, 10 mM Tris/HCl, $\mathrm{pH}$ 7,5) zu einem 10\%igem (w/v) Homogenat verarbeitet. Da es während der Homogenisierung zu Wärmeentwicklung und Autolyse kam, wurden alle Arbeiten bei $4{ }^{\circ} \mathrm{C}$ durchgeführt.

\subsubsection{TSE-Infektion von eukaryontischen Zellen}

Da mit TSE-Erregern nur im S3 Labor gearbeitet werden darf, wurden alle Arbeiten in diesem Bereich durchgeführt. Ansonsten wurden die Zellen unter den gleichen Bedingungen gehalten wie die nicht infizierten. Sobald eine Zellkulturflasche zu 80 \% bewachsen war, konnte sie infiziert werden. Dazu wurde ein 10\%iges (w/v) Hirnhomogenat für 20 min bei $80{ }^{\circ} \mathrm{C}$ erhitzt und anschließend durch gründliches Vortexen gemischt (Lehmann et al., 2005). Danach wurde das Medium der Zellen entfernt und die Zellen mit 1 \% (w/v) BSE-Hirnhomogenat in Bezug auf das uninfizierte Zellkulturmedium für $5 \mathrm{~h}$ im Brutschrank bei $37^{\circ} \mathrm{C}$ inkubiert. Nach 5 h wurde dieses Medium entfernt und in uninfiziertem Zellkulturmedium weiter kultiviert. Nach 2 Tagen weiterer Kultivierung wurden die Zellen getestet, ob eine BSEInfektion vorlag. Für eine WB Analyse wurden die Zellen geerntet und entweder sofort aufgearbeitet oder bei $-80{ }^{\circ} \mathrm{C}$ gelagert. Alle anderen PrP Detektionsmöglichkeiten, wie z. B. die FACS Analyse, erforderten, dass die Zellen sofort verwendet werden mussten. Zur Untersuchung der Infektionsstabilität wurden die Zellen passagiert, indem sie bei einer 
erreichten Konfluenz von 80 \% im Verhältnis 1:5 gesplittet wurden. Das Pellet wurde eingefroren und mit den späteren Passagen verglichen.

\subsubsection{Proteinase K (PK) Verdau von infizierten Proben}

Da das $\operatorname{PrP}^{\mathrm{C}}$ PK sensitiv und das $\operatorname{PrP}^{\mathrm{Sc}} \mathrm{PK}$ resistent ist, wurde der PK Verdau zum Nachweis von $\operatorname{PrP}^{\text {res }}$ verwendet. Die $\mathrm{PK}$ Resistenz des $\mathrm{PrP}^{\mathrm{Sc}}$ variierte dabei in Abhängigkeit von der verwendeten $\mathrm{PK}$ und des $\operatorname{PrP}^{\mathrm{Sc}}$ Materials. Aus diesem Grund wurden verschiedene Konzentrationen und Inkubationszeiten untersucht. Dazu wurden $20 \mu \mathrm{g}$ bis $50 \mu \mathrm{g}$ Protein mit PK Puffer (1 mM CaCl $2,0,5$ \% (w/v) SDS, Tris/HCl, pH 7,8) versetzt und für 5, 10, 20, 30, 45 und $60 \mathrm{~min}$ bei $37^{\circ} \mathrm{C}$ verdaut. Die eingesetzten PK Mengen variierten dabei von $0,01 \mu \mathrm{g} / \mathrm{ml}$ bis $500 \mu \mathrm{g} / \mathrm{ml}$. Der PK Verdau wurde mit 0,1 M PMSF in Isopropanol gestoppt. Anschließend wurden die Proben im LDS-Probenpuffer aufgenommen und auf ein SDSPAGE-Gel aufgetragen

\subsubsection{Trennung von $\operatorname{PrP}^{\mathrm{C}}$ und $\operatorname{PrP}^{\mathrm{Sc}}$ durch „immobilised metall affinity chromatography“ (IMAC)}

Da sich die beiden PrP Isoformen in der Fähigkeit Kupfer zu binden unterscheiden, wurde eine Affinitätschromatographie benutzt, um sie zu trennen. Die dabei verwendete Form war die IMAC. In der IMAC-Säule binden aromatische Aminosäuren, hauptsächlich Histidin, zweiwertige Metallionen durch Chelatkomplexierung. Die Ablösung dieses Komplexes hängt dabei von der Dissoziationskonstante ab. Diese ist abhängig von der Ladungszahl des Metallions und vom aromatischen Charakter der Aminosäure. Die Elution der gebundenen Proteine erfolgte dann durch eine Absenkung des $\mathrm{pH}$-Wertes und durch eine Komplexbindung mit einem anderen Chelator, wie z. B. EDTA.

Für die Trennung der PrP Isoformen wurden 5 ml Säulen (Amersham Biosciences) mit „fast flow chelating sepharose“ als Säulenmatrix verwendet. Diese wurden mit $15 \mathrm{ml} \mathrm{H}_{2} \mathrm{O}_{\text {bid }}$ gewaschen und mit Kupferionen durch $5 \mathrm{ml}$ einer 0,1 $\mathrm{M} \mathrm{CuSO}_{4}$-Lösung beladen. Um nicht gebundene Ionen zu entfernen, wurde die Säule mit $50 \mathrm{ml} \mathrm{H}_{2} \mathrm{O}_{\text {bid }}$ gewaschen. Anschließend erfolgte die Equilibrierung durch 25 ml Waschpuffer (500 mM KCl, 1 mM Imidazol, 20 mM Tris/HCl, pH 8,0) und danach mit 50 ml Equilibrierungspuffer (1 \% Octylglykopyranosid in Waschpuffer). Im Anschluss wurde der Überstand von in Tris-Puffer solubilisierten (siehe 2.4.17) und zentrifugierten Proteinen auf die Säule aufgetragen. Anschließend wurde die 
Säule für 1 min mit 13000 g zentrifugiert. Danach wurde zur Entfernung unspezifischer gebundener Proteine die Säule mit 15 ml Waschpuffer gewaschen. Gefolgt von der Elution der spezifisch gebundenen Proteine durch $15 \mathrm{ml}$ Elutionspuffer $(0,1 \mathrm{M}$ EDTA in Waschpuffer). Zur Entfernung noch nicht verdrängter Proteine von der Säule, wurden diese mit 0,5 M EDTA in Waschpuffer gewaschen. Die Säule wurde anschließend regeneriert und konnte erneut verwendet werden. Wasch-, Durchlauf- und Elutionsfraktionen wurden in jeweils 2 ml Fraktionen gesammelt und analysiert. Der Proteingehalt der einzelnen Fraktionen wurde anschließend bestimmt und jeweils $30 \mu \mathrm{g}$ auf ein SDS-Gel aufgetragen.

\subsubsection{Solubilisierung von Proteinen}

Für die IMAC konnten nur gelöste Proteine verwendet werden, da sonst die Poren des Säulenmaterials verstopfen würden. Aus diesem Grund mussten diese Proteine solubilisiert werden. Die Proteine wurden dabei entweder aus der Zellkultur, aus E. coli oder aus Hirnmaterial gewonnen. Dabei lag das Probenmaterial infiziert oder uninfiziert vor. Zur Solubilisierung wurde das Material bei $4{ }^{\circ} \mathrm{C}$ aufgetaut und anschließend für 15 min mit $700 \mathrm{~g}$ und $4{ }^{\circ} \mathrm{C}$ zentrifugiert. Die Angaben der Mengen beziehen sich hier jeweils auf $1 \mathrm{Gramm}$ Material. Wurde weniger Material eingesetzt, wurde entsprechend weniger Puffer verwendet. Der Überstand wurde bei $-80{ }^{\circ} \mathrm{C}$ eingefroren und das Pellet mit $3 \mathrm{ml} 10$ \% (w/v) Octylglykopyranosid resuspendiert. Anschließend wurde die Suspension durch Zugabe von $15 \mathrm{ml}$ TrisPuffer auf 2 \% (w/v) Octylglykopyranosid verdünnt. Zu dieser Suspension wurden je $10 \mu \mathrm{l}$ der Proteinaseinhibitoren Pepstatin A, Leupeptin und PMSF mit je einer Konzentration von 1 $\mu \mathrm{g} / \mu \mathrm{l}$ zugegeben und über Nacht bei $4{ }^{\circ} \mathrm{C}$ inkubiert. Die Suspension wurde am nächsten Tag für 2 min mit 10000 g bei RT zentrifugiert. Der Überstand wurde abgenommen und wie bereits beschrieben zentrifugiert. Dieser Überstand wurde jetzt für die IMAC eingesetzt. Zur Überprüfung wurde nach jedem Zwischenschritt eine Probe entnommen und auf ein SDSPAGE-Gel aufgetragen.

\subsubsection{Fluoreszenzmikroskopie}

Zur Darstellung fluoreszierender Proteine in Zellen wurde die Fluoreszenzmikroskopie verwendet. Die zu untersuchende Zellkultur wuchs auf einem $15 \mathrm{~mm}$ x $15 \mathrm{~mm}$ großen Deckgläschen an, das auf dem Boden einer Zellkulturplatte lag. Nach Erreichen einer Konfluenz von 90 \%, wurde die Zellkultur zur Entfernung abgestorbener Zellen dreimal mit PBS gewaschen. Anschließend wurde das Deckgläschen verkehrt herum mit einer 
Konservierungslösung aus 10 \% Glycerin und 90 \% PBS auf einem Objektträger an den Rändern mit Klarlack fixiert. Dieser Objektträger wurde anschließend im Fluoreszenzmikroskop (Olympus IX70) betrachtet und mit dem Kamerasystem Zeiss Axioskop Visitron Systems dokumentiert. Damit eine Fluoreszenz beobachtet werden konnte, wurden die Zellen mit einer Wellenlänge von $488 \mathrm{~nm}$ angeregt, dabei konnte eine Emission bei $530 \mathrm{~nm}$ für grün fluoreszierende Chromophore beobachtet werden. Anschließend wurden die Bilder mit dem Programm Spot (Diagnoctic Instrument) ausgewertet.

\subsubsection{Immunfluoreszenzmikroskopie von $\operatorname{PrP}^{\mathrm{C}}$ exprimierenden Zelllinien mit monoklonalen Antikörpern (mAK)}

Zur Detektion von PrP in Zellkulturen wurde die Immunfluoreszenz eingesetzt. Dafür wurde eine Zellkonfluenz von 90 \% benötigt. Nach Erreichen der Konfluenz wurde das Medium abgenommen und die Zellen dreimal mit PBS gewaschen. Anschließend wurden sie durch Inkubation mit Aceton/Methanol im Verhältnis 1:1 (v/v) für $30 \mathrm{~s}$ permeabilisiert und fixiert. Die Lösung wurde abgenommen und zweimal mit PBS für 5 min gewaschen. Danach wurde mit dem murinen anti-PrP mAk-mix in einer Verdünnung von 1:1000 in PBS für $1 \mathrm{~h}$ bei $37^{\circ} \mathrm{C}$ unter Schwenken inkubiert. Anschließend wurde der Ak abgenommen und zweimal mit 3 \% FCS (v/v) in PBS gewaschen. Der sekundäre Ak, ein Fluoresceinisothiocyanat (FITC) konjugierter Ziege anti-Maus IgG2 in einer Verdünnung von 1:2000 wurde zugegeben und für $1 \mathrm{~h}$ im Dunkeln bei $37{ }^{\circ} \mathrm{C}$ unter Schwenken inkubiert. Nach der Inkubation wurde der Ak abgenommen und zweimal mit 3 \% FCS (v/v) in PBS gewaschen. Anschließend wurden die Zellen unter dem Fluoreszenzmikroskop beobachtet und dokumentiert.

\subsubsection{Durchflusszytometrie zur Detektion von $\operatorname{PrP}^{\mathrm{C}}$ und $\operatorname{PrP}^{\mathrm{Sc}}$}

Mit Hilfe der Durchflusszytometrie („fluorescence activated cell sorting“, FACS) können Zellen ohne Markierungen auf Eigenschaften wie Größe und Granularität analysiert werden. Dies geschieht durch einen Detektor und einen Laserstrahl. Werden die Zellen oder aber Teile von ihnen mit einem Fluoreszenzfarbstoff wie FITC, DAPI oder Alexa markiert, können ihre Fluoreszenzeigenschaften gemessen werden. In dieser Arbeit wurde die FACS Analyse zur Detektion von $\operatorname{PrP}^{\mathrm{C}}$ und $\operatorname{PrP}^{\mathrm{Sc}}$ in verschiedenen Zelllinien mit Hilfe von FITC markierten anti-Maus Sekundärantikörpern verwendet. Der FITC Farbstoff wird mit einer Wellenlänge von 488 nm angeregt und emittiert bei einer Wellenlänge von 530 nm grünes Licht. Die dabei 
entstandenen Emissionskurven wurden zur Analyse der PrP Expression in der Zellkultur verwendet.

Sollte die Expression im Zellkern mit betrachtet werden, wurde 0,3\%iges (v/v) Trition X 100 zur Permeabilisierung der Zellmembran und des Zellkerns verwendet. Wurden die Zellen nur intrazellulär betrachtet, wurde Saponinpuffer (0,5 \% (w/v) Saponin in PBS) statt Trition X 100 verwendet, da Saponin nur die Zellmembran permeabilisiert und nicht die Zellkerne. Wurde nur die Oberfläche der Zellen untersucht, wurde keine dieser beiden Permeabilisierungsreagenzien eingesetzt.

Für die FACS Analyse wurden 1 x $10^{6}$ Zellen verwendet, diese wurden von der Zellkulturflasche abtrypsiniert und zentrifugiert. Der Überstand wurde verworfen und das Pellet durch Resuspension in $200 \mu$ Formaldehydpuffer (4 \% (v/v) in PBS) fixiert und für 8 min bei $37^{\circ} \mathrm{C}$ inkubiert. Anschließend wurden die Zellen für 5 min mit 100 g zentrifugiert. Der Überstand wurde entfernt und das Pellet weiter verwendet. Zu dem Pellet wurden $200 \mu \mathrm{l}$ Saponinpuffer zugegeben und für $5 \mathrm{~min}$ bei $37^{\circ} \mathrm{C}$ inkubiert und anschließend wiederum für 5 min mit 100 g zentrifugiert. Der Überstand wurde verworfen und zu dem Pellet wurden 100 $\mu \mathrm{l}$ Primärantikörperlösung, ein Maus anti-PrP mAk-mix zugegeben und für $1 \mathrm{~h}$ bei $37^{\circ} \mathrm{C}$ inkubiert. Danach wurde die Suspension wie beschrieben zentrifugiert, der Überstand verworfen und das Pellet anschließend zur Entfernung des restlichen ungebundenen Ak mit $500 \mu \mathrm{l}$ PBS gewaschen und zentrifugiert. Zum Pellet wurden $100 \mu \mathrm{l}$ Sekundärantikörperlösung, eine FITC konjugierter Ziege anti-Maus Ak-Lösung, zugegeben und im Dunkeln für $1 \mathrm{~h}$ bei $37^{\circ} \mathrm{C}$ inkubiert. Nach der Inkubation wurde die Suspension wie bereits beschrieben zentrifugiert, der Überstand verworfen und das Pellet anschließend zur Entfernung des restlichen nicht gebundenen Ak noch zweimal mit $500 \mu \mathrm{l}$ PBS gewaschen und zentrifugiert. Das Pellet wurde danach in $100 \mu \mathrm{l}$ 0,5 \% (w/v) BSA in PBS resuspendiert und im FACS gemessen.

Vorversuche wurden mit uninfizierten Proben in einem LSR II Durchflusszytometer (BD Bioscience) am Deutschen Primatenzentrum durchgeführt und infizierte Proben wurden mit einem FACS Calibur (Becton Dickinson) am Primatenzentrum des Paul-Ehrlich-Institutes, der Bundesbehörde für Seren und Vakzine in Langen gemessen. Mit den Programmen CellQuest 3.3 und FlowJo (Tree Star) wurden die Daten ausgewertet. Zur Vermeidung von Fehlinterpretationen bei der Auswertung mussten die in der Tab. 5 angegebenen Negativkontrollen mitbestimmt werden. 


\section{Tab. 5 Negativkontrollen der FACS Messung}

\begin{tabular}{cccc}
\hline Nr. & Zellen & prim. AK & sek. AK \\
\hline 1 & + & - & - \\
2 & + & - & + \\
3 & + & + & Isotyp \\
4 & + & + & anti-Kaninchen \\
5 & + & + & + \\
\hline
\end{tabular}

Die Probe 1 wurde zur Ermittlung der Eigenfluoreszenz der Kontrollzelllinie benötigt, die Probe 2 zur Bestimmung unspezifischer Bindungen des zweiten Ak an diese Zellen. Zur Analyse der Spezifität der Bindung des zweiten Ak an den ersten Ak wurden die Proben 3 und 4 benötigt. Als Vergleich zur untersuchenden Zellkultur wurde die Probe 5 verwendet.

\subsubsection{Sekundärstrukturanalyse von Proteinen durch Circulardichroismus (CD)- Spektroskopie}

Mittels der CD-Spektroskopie können Wechselwirkungen chiraler Substanzen mit zirkular polarisiertem Licht in Abwesenheit eines magnetischen Feldes detektiert werden. Im Gegensatz zu linear oder planar polarisiertem Licht, bestehend aus links- und rechtszirkular polarisiertem Licht gleicher Intensität, besteht ein zirkular polarisierter Lichtstrahl aus zwei planaren, senkrecht zueinander polarisierten und um $90^{\circ}$ phasenverschobenen Lichtstrahlen. Je nach Polarisation, links- oder rechtszirkular, rotiert der elektrische Vektor dabei um die Richtungsachse. Der CD ist dabei als die Differenz der Absorption $\Delta A$ von links- $\left(A_{\mathrm{lcp}}\right)$ und rechtszirkular $\left(A_{\text {rсp }}\right)$ polarisiertem Licht definiert (Fasman, 1996):

$$
\Delta A=A_{\mathrm{lcp}}-A_{\mathrm{rcp}}=\varepsilon_{\mathrm{lcp}} c \cdot l-\varepsilon_{\mathrm{rcp}} c \cdot l=\Delta \varepsilon c \cdot l
$$

Hierbei bezeichnen $\varepsilon$ die jeweiligen dekadischen molaren Extinktionskoeffizienten, $c$ die Molarität des Analyten und $l$ die optische Weglänge. Für den dekadischen molaren CD $\Delta \varepsilon$ gilt somit:

$$
\Delta \varepsilon=\varepsilon_{1}-\varepsilon_{\mathrm{r}}
$$

Moderne, kommerziell erhältliche CD-Spektrometer bestimmen die allgemein sehr niedrigen Werte von $\Delta A$ mittels einer Modulationstechnik und können zuverlässige Werte von $\Delta \varepsilon$ liefern. Besonders in der biochemischen Literatur wird jedoch eine traditionellere Methode verwendet. Diese basiert auf der Tatsache, dass planar polarisiertes Licht beim Durchgang durch ein zirkulardichroisches Medium aufgrund der unterschiedlichen Absorption der beiden 
zirkularen Komponenten in elliptisch polarisiertes Licht konvertiert wird. Dabei beschreibt die Spitze des elektrischen Vektors weder eine oszillierende noch zirkular rotierende Bahn um die Richtungsachse. Von dieser „elliptischen“ Form des elektrischen Vektors wurde die Bezeichnung „Elliptizität“ $(\theta)$ abgeleitet. Diese ist anhand der jeweiligen Ausrichtung und Amplitude ihrer beiden zirkularen Komponenten beschreibbar. Es gilt dabei:

$$
\theta(\operatorname{deg})=180 \ln 10 \Delta A / 4 \pi=32,98 \Delta A
$$

Somit ist $\theta$ linear abhängig vom CD. Um die Abhängigkeit von Pfadlänge und Konzentration zu eliminieren und so zu standardisierten Werten zu gelangen, wird die molare Elliptizität [ $\theta]$ definiert:

$$
[\theta]=100 \theta / c l=3298 \Delta \varepsilon
$$

CD-Spektren von Proteinen werden auch als „Aminosäurereste bezogene Elliptizität“ $\left([\Theta]_{\mathrm{MRW}}\right)$ angegeben:

$$
[\Theta]_{\mathrm{MRW}}\left(\operatorname{deg} \mathrm{cm}^{2} \mathrm{dmol}^{-1}\right)=\left(\Theta \mathrm{M}_{\mathrm{r}}\right) /\left(10 c l \mathrm{~N}_{\mathrm{A}}\right)
$$

mit:

$\Theta$ - gemessenes Signal (mdeg)

$\mathrm{M}_{\mathrm{r}}$ - Molare Masse des Proteins

$\mathrm{N}_{\mathrm{A}}$ - Anzahl der Aminosäuren des Proteins

Hierbei ist zwischen Nah- und Fern-UV-CD-Spektren zu unterscheiden. Bei ersterem (250300 nm) wird die Chiralität der Umgebung aromatischer Aminosäuren detektiert, die im Allgemeinen mit der nativen Tertiärstruktur von Proteinen verbunden ist.

Für die Analyse der Proteinsekundärstruktur wird das Fern-UV-CD-Spektrum von 180 bis $250 \mathrm{~nm}$ benötigt, da in diesem Bereich die $\mathrm{n} \rightarrow \pi^{*}$ und die $\pi \rightarrow \pi^{*}$ Übergänge der Carbonylgruppe der Säureamidbindung liegen. Aufgrund der Chiralität der Peptidbindungen ist daher das CD-Spektrum eine Möglichkeit der Sekundärstrukturanalyse. Für die Strukturanalyse eines unbekannten Peptides/Proteins wird das CD-Spektrum gemessen und anschließend mit einer mathematischen Linearkombination der CD-Spektren von Proteinen mit bekanntem Anteil ungeordneter, $\alpha$-helikaler und ß-Faltblattstrukturen angepasst. Aus der Anpassung der Sekundärstrukturkomponenten erhält man dann die jeweiligen Anteile für das unbekannte Protein und kann so Rückschlüsse auf dessen Sekundärstruktur ziehen. 
Für die CD-Spektroskopie wurde jeweils $1 \mathrm{mg}$ einer Proteinprobe untersucht. Die Probe wurde in CD-Puffer gelöst (10 mM Tris, 100 mM KCl, 320 mM Saccharose, 10 \% Glycerin, 0,01 \% NP40, pH 7,5) und bei $10{ }^{\circ} \mathrm{C}$ mit einer $1 \mathrm{~mm}$ Küvette im J-810 Spektropolarimeter (Jasco) gemessen. Die CD-Spektroskopie wurde in der Abteilung Enzymologie der Biochemischen Fakultät der Martin-Luther-Universität Halle-Wittenberg durch Herrn Dipl. Biochem. Knut Kölbel durchgeführt.

\subsubsection{Matrix-unterstützte Laserdesorptions-Ionisations-Massenspektrometrie (MALDI-MS)}

Unter Massenspektrometrie (MS) versteht man die Bestimmung der Molekülmasse freier Ionen im Hochvakuum. Ein Massenspektrometer besteht aus einer Ionenquelle, die einen Strahl gasförmiger Ionen erzeugt. Diese werden durch einen Massenanalysator nach ihrem Masse/Ladungs Quotient, der an einem Detektor abgelesen werden kann, aufgetrennt. Um ein Proteingemisch zu analysieren, musste es dazu auf einer Matrix zur Kristallisation gebracht werden. Dieses wird anschließend im Vakuum einem intensiven Laserimpuls ausgesetzt. Dabei kommt es zur Freisetzung der Energie wobei ein Teil der Matrix mit der Probe schlagartig verdampft und ionisiert wird. Im elektrischen Feld werden die geladenen Ionen nach ihrer Flugzeit in einem Messrohr in Verbindung mit einer gepulserten Ionenerzeugung („time-of-flight“, TOF) detektiert. So können Proteine mit verschiedenen Molekulargewichten auf Grund ihrer zeitversetzten Detektion durch ihr spezifisches Masse/Ladungsverhältnis bestimmt werden.

Verschiedene Zelllinien mit und ohne $\mathrm{PrP}^{\mathrm{C}}$ Expression wurden für ein 2D-SDS-PAGE-Gel aufgearbeitet. Das entstandene 2D-Gel wurde mit einer Coomassie-Blaufärbung angefärbt und bestimmte Proteine nach dem Vergleich der Gelbilder ausgestanzt und analysiert durch eine MALDI-TOF-MS von Dr. Olaf Jahn in der Arbeitsgruppe Proteomics am MPI für experimentelle Medizin in Göttingen. Dort wurden die Proteinproben zuerst mit Trypsin in Peptidfragmente gespalten, dies geschah durch einen In-Gelverdau im Genesis ProTeam 150 Advanced Digest (Tecan) automatisch. Anschließend wurden die Proben auf eine $\alpha$-Cyano-4Hydroxyzimzsäure-Matrix beladen (Jahn et al., 2006). Diese Proben wurden anschließend mit einer Laserintensität bei einem Masse/Ladungsverhältnis von 500 bis 4000 ionisert. Von jeder Probe wurden jeweils 25 Messpunkte analysiert. Diese wurden im Ultraflex I MALDITOF/TOF Massenspektrometer (Bruker Daltonics) bestimmt. Die erhaltenen Fragmente wurden mit dem Programm BioTools 3.0 (Bruker Daltonics) identifiziert. Dabei wurden die Peptidmassen mit den theoretischen Massenlisten aus der Proteindatenbank verglichen. Es 
handelte sich dabei um Daten, die bei einem theoretischen Verdau „in silico“ mit den verwendeten Proteasen aller bekannten Proteine ermittelt werden konnten. Durch einen Vergleich mit der Entrez NCBI Proteindatenbank wurden diese verifiziert.

\subsection{Materialien}

\subsubsection{Material}

Material

0,025 $\mu \mathrm{m}$ Dialysemembran

$0,2 \mu \mathrm{m}$ Protran NZM

12 Well Platte

$6 \mathrm{~cm}$ Zellkulturschale

6 x Loading Dye

$75 \mathrm{~cm}^{2}$ Zellkulturflasche

Bio-Rad Protein Assay

Filterpapier

GeneRuler 1 kb-Ladder

GeneRuler 100 bp-Ladder

Halbmikro Einmalküvetten

Hyperfilm

Kryobox

Kryoröhrchen

pH Strips 3-10

SeeBlue Plus2

\subsubsection{Antibiotika}

Amphothericin B

Ampicillin

Blasticidin S HCl

Doxycyclin

Hygromycin B

Neomycin

Penicillin/Streptomycin

Tetracyclin
Firma

Millipore

Schleicher \& Schuell

Greiner

Greiner

Fermentas

Greiner

Bio-Rad

Whatman

Fermentas

Fermentas

Ratiolab

Amersham Biosciences

Nalgene

Nalgene

GE Healthcare

Invitrogen
Kat. Nr.

VSWP01300

FD0262-1

665180

628160

R0611

658170

500-0006

3030-6185

SM0311/2/3

SM0321/2/3

Nr. 2712010

RPN 3103K

5100

5000

17-6001-11

LC5925

\subsubsection{Antikörper}

POD/Ziege anti-Maus IgG Dianova

FITC/Ziege anti-Maus IgG2 Dianova

mAk anti-Maus IgG
Sigma

Boehringer Mannheim

Invitrogen

Sigma

Sigma

Serva

PAN Biotech GmbH

Sigma
A-2411

835269

46-1120

D-9891

H-0654

30250

P06-07100

$\mathrm{T}-3383$
115-035-003

115-095-003

aus Hybridomakulturen 


\subsubsection{Proteaseinhibitoren}

Pepstatin A

Leupetin

Aprotenin

PMSF

\subsubsection{Kulturmedien}

Sigma

P4265

Sigma

L0649

Sigma

Carl Roth GmbH
A3428

6367.1

$\begin{array}{lll}\text { Agar } & \text { Difco Laboratories } & 0140-07-4 \\ \text { DMEM } & \text { PAN Biotech GmbH } & \text { P04-02500 } \\ \text { RPMI 1640 } & \text { PAN Biotech GmbH } & \text { P04-18500 } \\ \text { FCS } & \text { PAN Biotech GmbH } & 3302-P 250316 \\ \text { L-Glytamin } & \text { PAA Laboratories GmbH } & \text { M11-004 } \\ \text { Trypsi/EDTA } & \text { PAN Biotech GmbH } & \text { P10-023100 } \\ \text { Hefe-Extrakt } & \text { Carl Roth GmbH } & 2363.2 \\ \text { Bacto-Trypton } & \text { Carl Roth GmbH } & 8952.2\end{array}$

\subsubsection{Chemikalien}

\begin{tabular}{|c|c|c|}
\hline 2-Mercaptoethanol & Merck & 8.05740 .0250 \\
\hline $30 \%$ ige $\mathrm{H}_{2} \mathrm{O}_{2}$ Lösung & Merck & 822287 \\
\hline Acrylamid & Sigma & A-3553 \\
\hline Agarose & Carl Roth GmbH & 3367.3 \\
\hline APS & Sigma & A3678 \\
\hline ATP & Sigma & A6419 \\
\hline Bicine & Sigma & B3876-2509 \\
\hline Bis-Tris & Sigma & В 9754 \\
\hline Bromphenolblau & Merck & 1.08122 .0025 \\
\hline $\mathrm{CaCl}_{2}$ & Merck & A428388 \\
\hline DMSO & Merck & 1.02952 .1000 \\
\hline DNase & Sigma & D-4138 \\
\hline DOC & Merck & 1.06504 .0100 \\
\hline DTT & AppliChem & A2948.0025 \\
\hline EDTA & Carl Roth GmbH & 8040.2 \\
\hline Essigsäure & Merck & 1.00063 .1000 \\
\hline Ethanol & Carl Roth GmbH & 9065.2 \\
\hline Ethidiumbromid & Applichem & A1152.0025 \\
\hline Formaldehyd & Sigma & $25.254-9$ \\
\hline Glycerin & Carl Roth GmbH & 3783.1 \\
\hline Glycin & Carl Roth GmbH & 3908.3 \\
\hline Guanidin $\mathrm{HCl}$ & Carl Roth GmbH & 0037.1 \\
\hline $\mathrm{HCl}$ & Merck & 1.00317 .100 \\
\hline Hepes & Carl Roth GmbH & 9105.3 \\
\hline Isopropanol & Merck & 1.09634 .2500 \\
\hline $\mathrm{KCl}$ & Merck & 4936-1000 \\
\hline Kolloidales Brilliant Blau G & Sigma & B-2025 \\
\hline LDS & Invitrogen & NP0008 \\
\hline Luminol & Sigma & A8511 \\
\hline Lysozym & Eurogentec & ME-0510-10 \\
\hline Methanol & Carl Roth GmbH & 4627.2 \\
\hline
\end{tabular}




\begin{tabular}{lll} 
Methylenblau & Riedel De Haën AG & 28514 \\
$\mathrm{MgCl}_{2}$ & Merck & 8.14733 .0500 \\
Milchpulver & Carl Roth GmbH & T145.1 \\
MOPS & Carl Roth GmbH & 6979.3 \\
N,N,-Methylenbisacrylamid & Gibco & $15516-016$ \\
$\mathrm{Na}_{2}$ EDTA & Merck & 1.08418 .1000 \\
$\mathrm{Na}_{2} \mathrm{HPO}_{4}$ & Merck & 1.06585 .5000 \\
$\mathrm{Na}_{\text {Acetat }}$ & Merck & TA644068 \\
$\mathrm{NaCl}_{\text {NaH}} \mathrm{PO}_{4}$ & Carl Roth GmbH & 3957.1 \\
NaOH & Merck & 1.06346 .1000 \\
Natriumacetat & Carl Roth GmbH & 6771.2 \\
Noniden P40 & Merck & T-644068 \\
o-Phosphorsäure & Sigma & I3021 \\
p-Cumarinsäure & Merck & 1.00565 .0500 \\
Phenol Rot & Merck & 8.00237 .0010 \\
Polybren & Sigma & P3532 \\
Proteinase K & Aldrich & $10-768-9$ \\
RNase A & Roche & 03115879001 \\
Saccharose & Qiagen & 1018048 \\
Saponin & Merck & K31517487 \\
SDS & Sigma & $024 \mathrm{~K} 2505$ \\
TCA & Merck & 8.22050 .1000 \\
TEMED & Carl Roth GmbH & 8789 \\
Tricine & Carl Roth GmbH & 2367.3 \\
Tris Base & Carl Roth GmbH & 6977.1 \\
Tris & Sigma & T1503 \\
Trition X 100 & Carl Roth GmbH & 4855.3 \\
Trypanblau & Merck & 1.08603 .1000 \\
Tween-20 & Merck & K13268032 \\
Xylencyanol & Merck & 8.17072 .1000 \\
& Merck & 1.10590 .0005 \\
\hline
\end{tabular}

\subsubsection{Medien}

LB-Medium: Das Medium musste nach der Herstellung autoklaviert werden, danach wurde das Medium bei RT bis zur Verwendung gelagert.

$\begin{array}{rl}10,00 \mathrm{~g} & \text { Bacto - Trypton } \\ 5,00 \mathrm{~g} & \text { Hefe - Extrakt } \\ 10,00 \mathrm{~g} & \mathrm{NaCl} \\ \text { ad. } 1,00 \mathrm{l} & \mathrm{H}_{2} \mathrm{O}\end{array}$

LB-Platten: Das Medium wurde autoklaviert und danach auf eine Temperatur von $56{ }^{\circ} \mathrm{C}$ abgekühlt. Anschließend wurden die Platten gegossen. Danach folgte eine Lagerung der Platten bei $4{ }^{\circ} \mathrm{C}$ bis zur ihrer weiteren Verwendung. Für LB-Amp Platten wurde zusätzlich noch $1 \mathrm{ml}$ Ampicillin $(100 \mathrm{mg} / \mathrm{ml})$ zugegeben, allerdings erst nach dem Abkühlvorgang. 


\begin{tabular}{|c|c|c|c|}
\hline & $\begin{array}{r}10,00 \\
5,00 \\
10,00 \\
15,00 \\
\text { ad. } 1,00\end{array}$ & $\begin{array}{l}\mathrm{g} \\
\mathrm{g} \\
\mathrm{g} \\
\mathrm{g} \\
\mathrm{l}\end{array}$ & $\begin{array}{l}\text { Bacto-Trypton } \\
\text { Hefe-Extrakt } \\
\mathrm{NaCl} \\
\text { Agar } \\
\mathrm{H}_{2} \mathrm{O}\end{array}$ \\
\hline Zellkulturmedium: & $\begin{array}{r}500,00 \\
10,00 \\
1,00\end{array}$ & $\begin{array}{l}\mathrm{ml} \\
\%(\mathrm{v} / \mathrm{v}) \\
\%(\mathrm{v} / \mathrm{v})\end{array}$ & $\begin{array}{l}\text { DMEM oder RPMI } 1640 \\
\text { FCS } \\
\text { Penicillin/Streptomycin } 100 \mu \mathrm{g} / \mathrm{ml}\end{array}$ \\
\hline Zelleinfriermedium: & $\begin{array}{l}65,00 \\
25,00 \\
10,00\end{array}$ & $\begin{array}{l}\%(\mathrm{v} / \mathrm{v}) \\
\%(\mathrm{v} / \mathrm{v}) \\
\%(\mathrm{v} / \mathrm{v})\end{array}$ & $\begin{array}{l}\text { Medium entsprechend der Zelllinie } \\
\text { FCS } \\
\text { DMSO }\end{array}$ \\
\hline Gewebehomogenat: & 10,00 & $\%(\mathrm{w} / \mathrm{v})$ & Gewebe in $100 \mathrm{mM}$ Tris-Puffer \\
\hline
\end{tabular}

\subsubsection{Lösungen}

Proteinase K Stammlösung: 10,00 \% (v/v) Glycerin $40,00 \mathrm{mg} / \mathrm{ml} \quad$ Proteinase $\mathrm{K}$ 100,00 mM Tris/HCI, pH 8,0 25,00 $\mathrm{mM} \quad \mathrm{CaCl}_{2}$

mAk-mix: $\quad$ Eine Mischung aus 6 (3B5, 4F2, 8G8, 11C6, $12 \mathrm{~F} 10$ und 14D3) im gleichen Verhältnis gegen das PrP gerichteten mAks, aus Hybridomakulturen, am DPZ gewonnen.

CD-Puffer:

$$
\begin{array}{rl}
10,00 & \mathrm{mM} \\
100,00 & \mathrm{mM} \\
320,00 & \mathrm{mM} \\
10,00 & \%(\mathrm{v} / \mathrm{v}) \\
0,01 & \%(\mathrm{v} / \mathrm{v})
\end{array}
$$

Tris

$\mathrm{KCl}$

Saccharose

Glycerin

NP40, pH 7,5

Tris-Puffer:

$$
\begin{array}{rc}
100,00 & \mathrm{mM} \\
320,00 & \mathrm{mM} \\
10,00 & \mathrm{mM}
\end{array}
$$

$\mathrm{KCl}$

Saccharose

Tris/HCl, pH 7,5

Lysis-Puffer für PK Verdau: 100,00 mM

$\begin{array}{rl}100,00 \mathrm{mM} & \mathrm{NaCl} \\ 10,00 \mathrm{mM} & \text { EDTA } \\ 0,50 \%(\mathrm{v} / \mathrm{v}) & \text { NP } 40 \\ 0,50 \%(\mathrm{w} / \mathrm{v}) & \text { DOC }\end{array}$

ad. $100,00 \mathrm{ml}$

$\mathrm{H}_{2} \mathrm{O}$

Rehydratrationspuffer:

$\begin{array}{lll}8,00 & \mathrm{M} & \text { Harnstoff } \\ 2,00 \%(\mathrm{w} / \mathrm{v}) & \text { CHAPS } \\ 0,50 \%(\mathrm{v} / \mathrm{v}) & \text { IPG Puffer } \\ 0,20 \%(\mathrm{w} / \mathrm{v}) & \text { DTT } \\ 0,02 \%(\mathrm{w} / \mathrm{v}) & \text { Bromphenolbau }\end{array}$




\begin{tabular}{|c|c|c|c|}
\hline Equilibrierungspuffer: & $\begin{array}{r}6,00 \\
2,00 \\
50,00 \\
30,00 \\
0,02\end{array}$ & $\begin{array}{l}\mathrm{M} \\
\%(\mathrm{w} / \mathrm{v}) \\
\mathrm{ml} \\
\%(\mathrm{v} / \mathrm{v}) \\
\%(\mathrm{w} / \mathrm{v})\end{array}$ & $\begin{array}{l}\text { Harnstoff } \\
\text { SDS } \\
\text { Tris/HCl, pH 8,8 } \\
\text { Glycerin } \\
\text { Bromphenolbau }\end{array}$ \\
\hline Saponinpuffer: & 0,50 & $\%(\mathrm{w} / \mathrm{v})$ & Saponin in PBS \\
\hline 10 x Probenpuffer: & $\begin{array}{r}50,00 \\
0,25 \\
0,25\end{array}$ & $\begin{array}{l}\%(\mathrm{v} / \mathrm{v}) \\
\%(\mathrm{w} / \mathrm{v}) \\
\%(\mathrm{w} / \mathrm{v})\end{array}$ & $\begin{array}{l}\text { Glycerin } \\
\text { Bromphenolblau } \\
\text { Xylencyanol }\end{array}$ \\
\hline 10 x TAE-Laufpuffer: & $\begin{array}{l}0,40 \\
0,01 \\
0,20\end{array}$ & $\begin{array}{l}\mathrm{M} \\
\mathrm{M} \\
\mathrm{M}\end{array}$ & $\begin{array}{l}\text { Tris, pH 8,0 } \\
\text { EDTA } \\
\text { Essigsäure }\end{array}$ \\
\hline 1 x T4-Ligationspuffer: & $\begin{array}{r}30,00 \\
10,00 \\
10,00 \\
0,10\end{array}$ & $\begin{array}{l}\mathrm{mM} \\
\mathrm{mM} \\
\mathrm{mM} \\
\mathrm{mM}\end{array}$ & $\begin{array}{l}\text { Tris/HCl, pH 7,8 } \\
\mathrm{MgCl}_{2} \\
\text { DTT } \\
\text { ATP }\end{array}$ \\
\hline Puffer I: & $\begin{array}{r}1,00 \\
100,00\end{array}$ & $\begin{array}{l}\mathrm{mM} \\
\mathrm{mM}\end{array}$ & $\begin{array}{l}\text { EDTA } \\
\text { Tris/HCl, pH 7,0 }\end{array}$ \\
\hline Puffer II: & $\begin{array}{r}60,00 \\
6,00 \\
1,50\end{array}$ & $\begin{array}{l}\mathrm{mM} \\
\%(\mathrm{v} / \mathrm{v}) \\
\mathrm{M}\end{array}$ & $\begin{array}{l}\text { EDTA } \\
\text { Trition X } 100 \\
\text { NaCl, pH 7,0 }\end{array}$ \\
\hline Puffer III: & $\begin{array}{r}20,00 \\
0,10\end{array}$ & $\begin{array}{l}\mathrm{mM} \\
\mathrm{M}\end{array}$ & $\begin{array}{l}\text { EDTA } \\
\text { Tris/HCl, pH 7,0 }\end{array}$ \\
\hline LDS-Probenpuffer: & $\begin{array}{r}106,00 \\
141,00 \\
2,00 \\
10,00 \\
0,51 \\
0,22 \\
0,17\end{array}$ & $\begin{array}{l}\mathrm{mM} \\
\mathrm{mM} \\
\%(\mathrm{w} / \mathrm{v}) \\
\%(\mathrm{v} / \mathrm{v}) \\
\mathrm{mM} \\
\mathrm{mM} \\
\mathrm{mM}\end{array}$ & $\begin{array}{l}\text { Tris/HCl, pH 8,5 } \\
\text { Tris Base } \\
\text { LDS } \\
\text { Glycerin } \\
\text { EDTA } \\
\text { SERVA Blue G } 250 \\
\text { Phenol Rot }\end{array}$ \\
\hline SDS-Trenngel: & $\begin{array}{r}4,00 \\
3,35 \\
2,50 \\
0,10 \\
50,00 \\
5,00\end{array}$ & $\begin{array}{c}\mathrm{ml} \\
\mathrm{ml} \\
\mathrm{ml} \\
\% \\
\mu \mathrm{l} \\
\mu \mathrm{l}\end{array}$ & $\begin{array}{l}\text { Acryl-/Bisacrylamid }(37,5: 1) \\
\mathrm{H}_{2} \mathrm{O} \\
375 \text { mM Tris/HCl, pH 8,8 } \\
\text { SDS } \\
10 \% \text { iges APS } \\
\text { TEMED }\end{array}$ \\
\hline
\end{tabular}




\begin{tabular}{|c|c|c|c|}
\hline SDS-Sammelgel (4 \%): & 1,70 & $\mathrm{ml}$ & Acryl-/BisAcrylamid (37,5:1) \\
\hline & 10,20 & $\mathrm{ml}$ & $\mathrm{H}_{2} \mathrm{O}$ \\
\hline & 125,00 & $\mathrm{mM}$ & Tris/HCI, pH 6,8 \\
\hline & 0,10 & $\mathrm{ml}$ & 10\%iges SDS \\
\hline & 0,03 & $\%(\mathrm{w} / \mathrm{v})$ & APS \\
\hline & ad. 20,00 & $\mu l$ & TEMED \\
\hline 20 x MOPS-Laufpuffer: & 1,00 & M & MOPS \\
\hline & 1,00 & M & Tris Base \\
\hline & 0,02 & $\mathrm{M}$ & EDTA \\
\hline 20 x WB Transferpuffer: & 0,50 & M & Bicine \\
\hline & 0,02 & M & EDTA \\
\hline & 0,50 & M & Tris/HCl \\
\hline PBS Puffer: & 120,00 & $\mathrm{mM}$ & $\mathrm{NaCl}$ \\
\hline & 17,00 & $\mathrm{mM}$ & $\mathrm{Na}_{2} \mathrm{HPO}_{4}$ \\
\hline & 3,00 & $\mathrm{mM}$ & $\mathrm{KH}_{2} \mathrm{PO}_{4}, \mathrm{pH} 7,2$ \\
\hline PBST Puffer: & 0,10 & $\%(\mathrm{w} / \mathrm{v})$ & Tween 20 in PBS Puffer \\
\hline MPBST: & 5,00 & $\%(\mathrm{w} / \mathrm{v})$ & Magermilchpulver in PBST Puffer \\
\hline ECL-Substratlösung 1: & 100,00 & $\mu l$ & Tris/HCI, pH 8,0 \\
\hline & 4,40 & $\mu l$ & 90 mM p-Cumarinsäure \\
\hline & 10,00 & $\mu l$ & 250 mM Luminol \\
\hline & ad. 1,00 & $\mathrm{ml}$ & $\mathrm{H}_{2} \mathrm{O}$ \\
\hline ECL-Substratlösung 2: & 100,00 & $\mu l$ & Tris/HCI, pH 8,0 \\
\hline & 3,00 & $\mu l$ & $30 \%$ ige $\mathrm{H}_{2} \mathrm{O}_{2}$ Lösung \\
\hline & ad.1,00 & $\mathrm{ml}$ & $\mathrm{H}_{2} \mathrm{O}$ \\
\hline
\end{tabular}

E1A-Lysepuffer: $\quad$ Bei diesem Puffer wird pro $1 \mathrm{ml}$ jeweils $1 \mu \mathrm{l}$ Rase, DNase, PMSF, NP40 und Pepstatin A zugegeben

$\begin{array}{rll}50,00 & \mathrm{mM} & \text { Hepes } \\ 150,00 & \mathrm{mM} & \mathrm{NaCl} \\ 0,10 & \%(\mathrm{v} / \mathrm{v}) & \text { Igepal }\end{array}$

C1:

$\begin{array}{rll}438,14 & \mathrm{~g} & \text { Saccharose } \\ 4,06 & \mathrm{~g} & \mathrm{MgCl}_{2} \\ 4,84 & \mathrm{~g} & \text { Tris base/HCl, } \mathrm{pH} \mathrm{7,5} \\ 42,00 & \mathrm{~g} & \text { Triton X 100 } \\ \text { ad. } 1,00 & \mathrm{l} & \mathrm{H}_{2} \mathrm{O}\end{array}$

G2:

$\begin{array}{rll}76,42 & \mathrm{~g} & \text { Guanidine } \mathrm{HCl} \\ 11,17 & \mathrm{~g} & \mathrm{Na}_{2} \text { EDTA } \\ 3,63 & \mathrm{~g} & \text { Tris base/NaOH, pH 8,0 } \\ 250,00 & \mathrm{ml} & \text { 20\%ige Tween 20 Lösung } \\ 50,00 & \mathrm{ml} & 10 \% \text { ige Triton X 100 Lösung } \\ \text { ad. } 1,00 & \mathrm{l} & \mathrm{H}_{2} \mathrm{O}\end{array}$




\begin{tabular}{|c|c|c|c|}
\hline QBT: & $\begin{array}{r}750,00 \\
50,00 \\
15,00 \\
0,15\end{array}$ & $\begin{array}{l}\mathrm{mM} \\
\mathrm{mM} \\
\%(\mathrm{v} / \mathrm{v}) \\
\%(\mathrm{v} / \mathrm{v})\end{array}$ & $\begin{array}{l}\mathrm{NaCl} \\
\text { MOPS } \\
\text { Isopropanol } \\
\text { Triton X } 100 \mathrm{pH} \mathrm{7,0}\end{array}$ \\
\hline PE: & $\begin{array}{r}1,00 \\
50,00 \\
15,00\end{array}$ & $\begin{array}{l}\mathrm{M} \\
\mathrm{mM} \\
\%(\mathrm{v} / \mathrm{v})\end{array}$ & $\begin{array}{l}\mathrm{NaCl}, \mathrm{pH} 7,0 \\
\text { MOPS } \\
\text { Isopropanol }\end{array}$ \\
\hline N3 : & 3,00 & M & Kaliumacetat, pH 5,5 \\
\hline QF: & $\begin{array}{r}1,25 \\
50,00 \\
15,00\end{array}$ & $\begin{array}{l}\mathrm{M} \\
\mathrm{mM} \\
\%(\mathrm{v} / \mathrm{v})\end{array}$ & $\begin{array}{l}\mathrm{NaCl} \\
\text { Tris/HCl, pH 8,5 } \\
\text { Isopropanol }\end{array}$ \\
\hline
\end{tabular}

Qiagen Puffer P1, P2 keine Angaben vom Hersteller

\subsubsection{Ausgangsvektoren}

\section{pGEM-T}

Der pGEM-T Vektor (Promega) wurde zur Amplifikation von PCR-Fragmenten in E. coli genutzt. Da er ein überhängendes Thymin enthält, konnte er zum Ligieren von Fragmenten mit einem überhängenden Adenin verwendet werden. Als Selektionsmarker wurde Ampicillin verwendet.

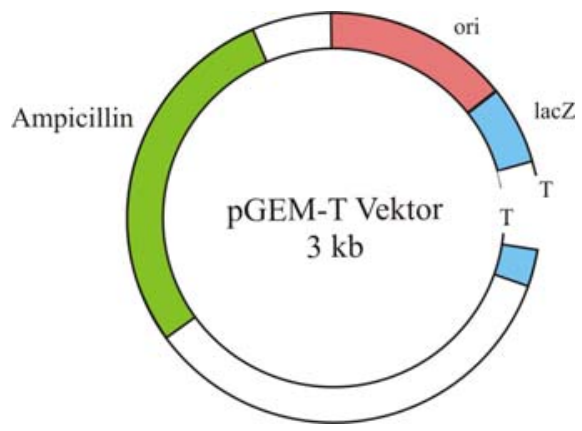
Abb. 16 pGEM-T Vektor Dieser Bakterien- expressionsvektor mit einem überhängenden Thymin wurde zur Klonierung von Fragmenten mit einem überhängenden Adenin verwendet. Selektiert konnten die Klone durch die Amicillinresistenz und das LacZ-Gen. 


\section{pCMV/Bsd}

Der pCMV/Bsd Vektor (Invitrogen) enthält als Resistenzmarker Blasticidin (Bsd) (Takeuchi et al., 1958). Dieser Vektor wurde für die Selektion auf stabile Zellklone verwendet. Die Resistenz gegen den Translationsinhibitor Blasticidin S wurde durch das Enzym Blasticidin S Desaminase von Aspergillus terreus gewährleistet (Kimura et al., 1994).

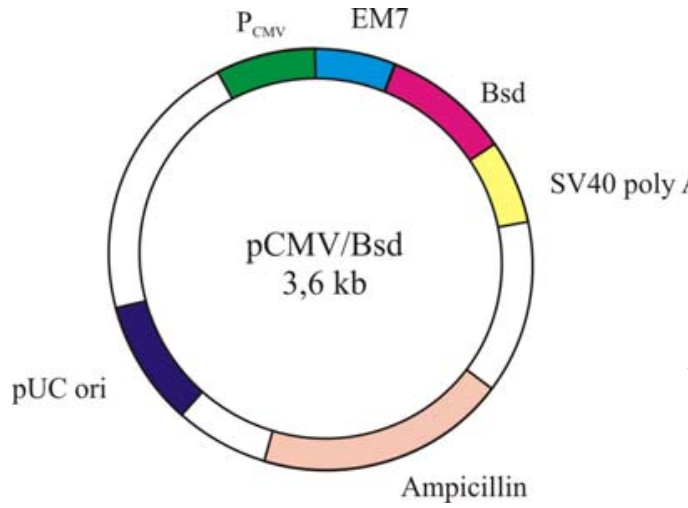

Abb. 17 pCMV/Bsd Vektor Der Vektor kann zur Selektion auf stabile eukaryontische Zellen durch eine Blasticidinresistenz verwendet werden. Zur Selektion in Bakterien wurde die Ampicillinresistenz verwendet.

\section{pTRE Tet-Off}

Der pTRE Tet-Off Vektor ist Teil eines Zwei-Komponenten-Systems zur regulierten Proteinexpression mittels Tet oder Dox durch Bindung eines tTA-Elementes. Als Selektionsmarker wurde dabei Neomycin verwendet.

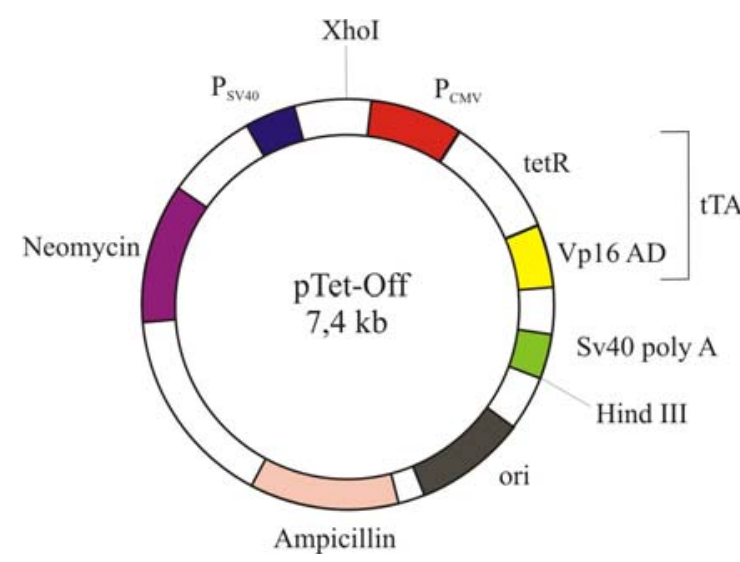

Abb. 18 pTet-Off Vektor Er ist Teil eines ZweiKomponenten-Systems zur regulierten Proteinexpression in Eukaryonten durch die Expression des tTA-Elementes, wobei Neomycin als Selektionsresistenz verwendet wird. Zur Selektion in Bakterien wurde die Ampicillinresistenz verwendet. 


\section{PTRE-FU}

Der pTet-FU Vektor wurde am DPZ von Herrn Dr. Stuke entwickelt. Dieser Vektor wurde für ein „gene targeting“ in der Maus konstruiert. Mit ihm konnten verschiedene Gene in das Mausgenom eingebracht werden. Da er über ein TRE-Element verfügte, konnten die so eingeschleusten Gene durch Bindung an ein tTA-Element gezielt an- und abgeschaltet werden.

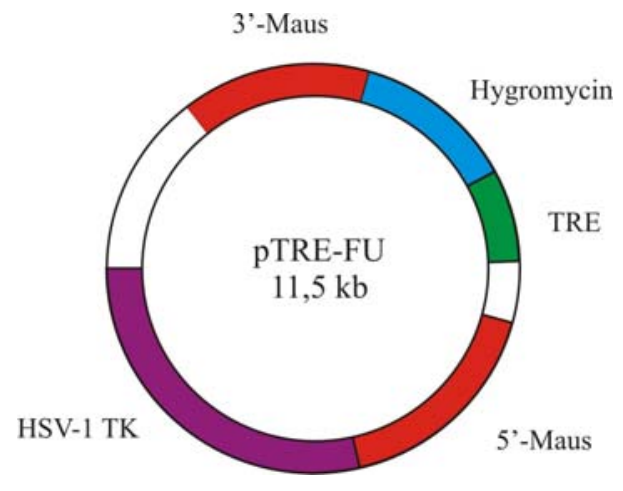

Abb. 19 pTRE-FU Vektor Dieser Vektor ist der zweite Teil des Zwei-Komponenten-Systems. Durch das TRE-Element können die dahinter liegenden Gene reguliert transkribiert und durch die Hygromycinresistenz selektiert werden.

\section{pBI-EGFP}

Der pBI-EGFP Vektor (BD Bioscience) besitzt zwei gegenläufige CMVMin Promotoren, die durch ein TRE-Element reguliert werden konnten. Dieser Fakt wurde zur An- und Abschaltung der EGFP Expression ausgenutzt.

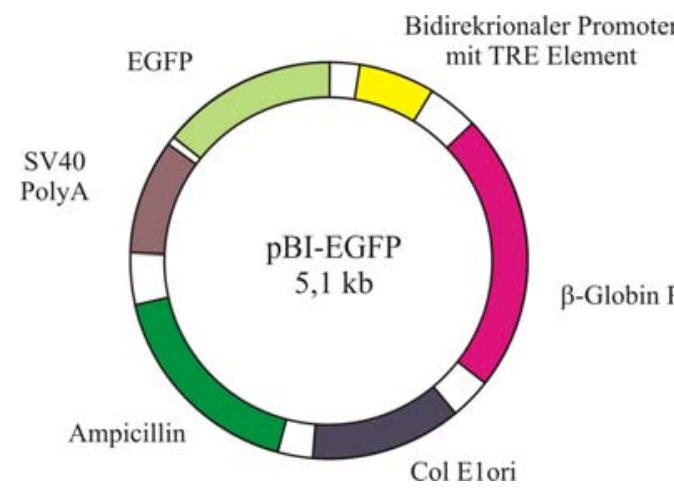

Abb. 20 pBI-EGFP Vektor Dieser Vektor exprimiert ein EGFP unter Kontrolle eines TRE-Elementes, dadurch kann es gezielt an- und abgeschaltet werden. 


\section{pRev-TRE}

Der pRev-TRE Vektor (Clontech) ist ein retroviraler Vektor in den verschiedene Gensequenzen eingebracht werden konnten. Durch ein TRE-Element waren diese ebenfalls, wie der pTRE-FU Vektor, regulierbar. Als Selektionsmarker in Eukaryonten wurde dabei Hygromycin verwendet.

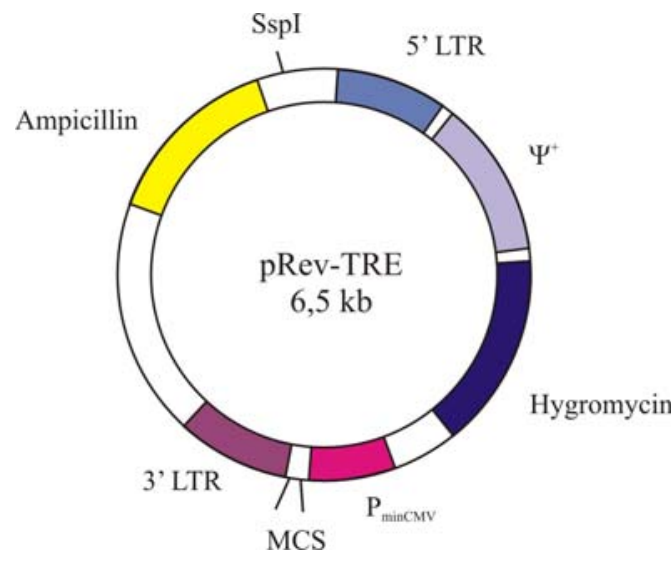

Abb. 21 pRev-TRE Vektor Dieser Vektor ist Teil eines Retrovirus. Zwischen die LTR-Regionen kann ein Gen kloniert und mit hoher Frequenz in andere Organismen integriert werden. Durch die Transfektion in die PT67 Zelllinie wird der Vektor durch das Verpackungssignal $\Psi$ in einen Retrovirus umgewandelt und aus den Zellen, ohne diese zu zerstören ausgeschleust. Durch eine anschließende Infektion mit diesem Retrovirus können stabile eukaryontische Zellen durch Selektion mit Hygromycin hergestellt werden.

\section{pUC19}

Der pUC19 Vektor (Fermentas) wurde für Testtransfektionen in E. coli verwendet (YanischPerron et al., 1985). Durch das LacZ Gen konnten Klone leicht selektiert werden.

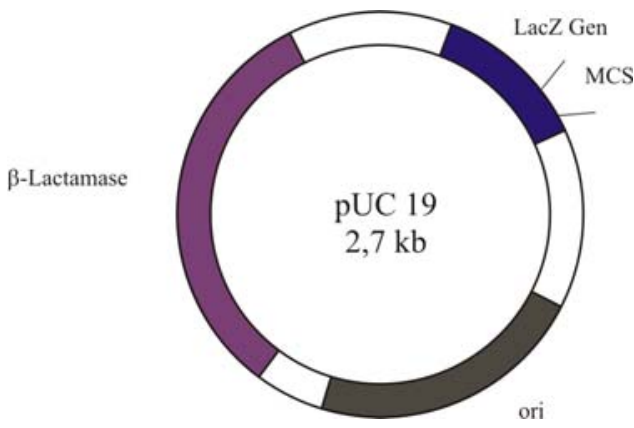

Abb. 22 pUC19 Vektor Dieser Vektor kann zur Integration von DNA-Fragmenten in die MCS des LacZ Gens genutzt und über die $\beta$-Lactamase in Bakterien selektiert werden. 


\section{pGL3}

Der pGL3 Vektor (Promega) ist ein Luziferase-Reporter-Vektor. Er wurde zur Analyse der Genexpression in transfizierten eukaryontischen Zellen verwendet.

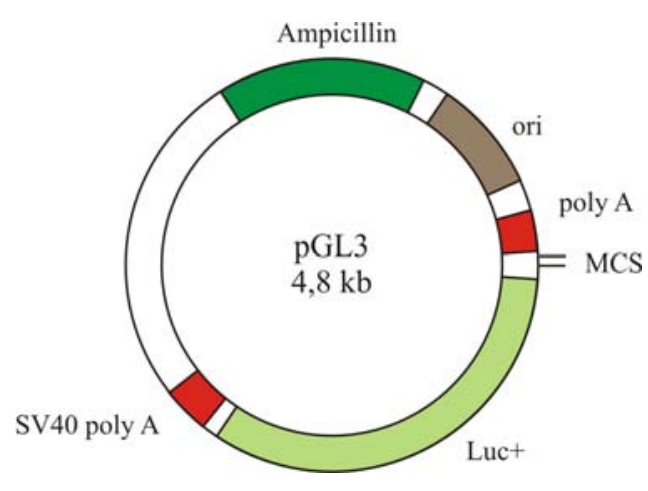

Abb. 23 pGL3 Vektor Dieser Vektor ist zur Expression von Luziferase fähig, dies kann zur Bestimmung der Luziferaseaktivität genutzt werden. 


\section{$3 \quad$ Ergebnisse}

\section{1 „In vitro“ Analyse des prnp Gens}

\subsubsection{Amplifikation des prnp Gens}

Zur Amplifikation des prnp Gens aus genomischer DNA wurde diese zuerst isoliert. Beim Menschen (Homo sapiens) und Javaneraffen (Macaca fascicularis) erfolgte dies aus dem Blut. Bei der Maus (Mus musculus) aus dem Schwanzgewebe. Die genomische DNA vom Rhesusaffen (Macaca mulatta), Bonobo (Pan paniscus), Schimpansen (Pan troglodytes), Gorilla (Gorilla gorilla), Elch (Alces alces shirasi), Rind (Bos taurus), Schaf (Ovis aries) und großen (gr.) Tümmler (Tursiops truncatus) wurde von der „German Primate Bank“ und der „German Gen Bank“ über Dr. Christian Roos bezogen. Die Amplifikation des prnp Gens der verschiedenen Spezies erfolgte mit den in der Tab. 6 dargestellten Primern. Da das prnp Gen später über eine BamHI Schnittstelle in den pTRE-FU Vektor kloniert werden sollte, wurde diese beim Primerdesign vor das Startcodon bzw. nach dem Stopcodon eingefügt.

Tab. 6 Primer zur Amplifikation des prnp Gens

\begin{tabular}{|c|c|c|}
\hline Spezies & 5' $\rightarrow$ 3' Primer & 3’ $\rightarrow$ 5' Primer \\
\hline $\begin{array}{l}\text { Mensch, } \\
\text { Javaneraffe, } \\
\text { Rhesusaffe }\end{array}$ & GCGGATCCATGGCGAACCTTGGCTGCT & GCGGATCCTCATCCCACTATCAGGAAG \\
\hline $\begin{array}{l}\text { Schimpanse, } \\
\text { Bonobo, } \\
\text { Gorilla }\end{array}$ & GCGGATCCATGGCAAACCTTGGCTGCT & GCGGATCCTCATCCCACTATCAGGAAG \\
\hline Maus & GCGGATCCATGGCGAACCTTGGCTACT & GCGGATCCTCATCCCACGATCAGGAAG \\
\hline $\begin{array}{l}\text { Elch, Rind, } \\
\text { Schaf }\end{array}$ & GCGGATCCATGGTGAAAAGCCACATAGG & GCGGATCCCTATCCTACTATGAGAAAAATG \\
\hline gr. Tümmler & GCGGATCCATGGGAAAGCTGTGTGAGCT & GCGGATCCTCAGTGCAGTAGAAGAATGC \\
\hline
\end{tabular}

Die BamHI Schnittstelle (blau) ist vor dem Start- bzw. Stopcodon (rot) dargestellt.

Mit den oben genannten Primern wurde das prnp Gen aus verschiedenen Spezies amplifiziert. Aufgrund der Schmelztemperatur der Primer wurde die theoretische Annealingtemperatur nach Rychlik (Rychlik et al., 1990) am Beispiel des Javaneraffen bestimmt. Die optimale 
Annealingtemperatur wurde anschließend mit Hilfe eines Temperaturgradienten ermittelt (siehe 2.1.5a). Bei dieser PCR wurde festgestellt, dass die optimale Annealingtemperatur für den Javaneraffen um 2 Grad höher liegt als der theoretische Wert. Mit dieser modifizierten PCR wurden alle anderen prnp Fragmente aus der jeweiligen DNA amplifiziert. Die PCR-Produkte wurden auf ein 1\%iges (w/v) Agarosegel aufgetragen und unter UV-Licht betrachtet. Bei allen Spezies war eine Bande bei einer Größe von ca. 750 Basenpaaren (bp) zu erkennen, dargestellt in der Abb. 24. Diese Bande wurde aus dem Gel isoliert und die DNA mit Hilfe eines Gelelutionskits (Qiagen) über eine Säule gereinigt (siehe 2.1.9). Das eluierte Fragment wurde anschließend in den pGEM-T Vektor kloniert. Da bei der Amplifikation ein zusätzliches Adenin an das 3'-Ende des Fragmentes angehängt wurde, konnte es mit dem überhängenden Thymin des Vektors ligiert werden (siehe 2.1.12.3). Dies war bei den meisten Fragmenten ohne weiteres möglich. Nur die Fragmente vom gr. Tümmler, Elch, Rind und Maus mussten nach der Elution noch adenyliert werden (siehe 2.1.12.4).

Die Klonierung in diesen Bakterienexpressionsvektor wurde zur Überprüfung der Sequenz und der Expression des Prion Proteins der einzelnen Spezies und in E. coli durchgeführt.

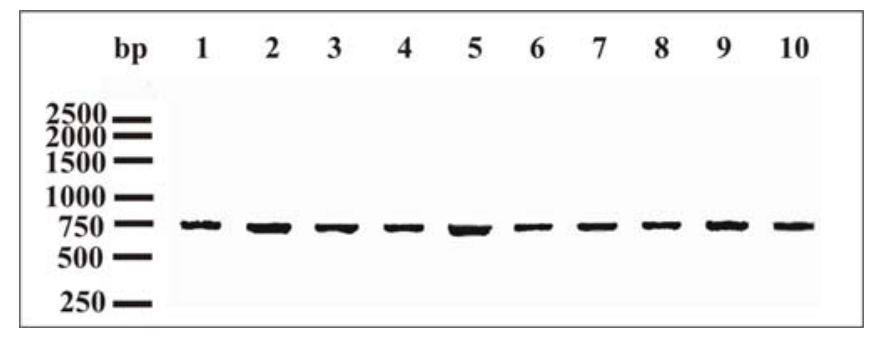

Abb. 24 PCR-Amplifikate der verschiedenen prnp Fragmente auf einem 1\%igen (w/v) Agarosegel Je 300 ng wurden von 1) Bonobo, 2) Schimpanse, 3) Gorilla, 4) Rhesusaffe, 5) Javaneraffe, 6) Rind, 7) Elch, 8) Mensch, 9) gr. Tümmler und 10) Maus aufgetragen.

\subsubsection{Sequenzierung der speziesspezifischen Prion Proteine}

Die Transformation des E. coli Stammes DH5 $\alpha$ mit den verschiedenen speziesspezifischen pGEM-T Vektoren erfolgte chemisch, mit der $\mathrm{CaCl}_{2}$-Methode (siehe 2.2.3.4) und durch Elektroporation (siehe 2.2.3.3). Dabei erwies sich die $\mathrm{CaCl}_{2}$-Methode als die Effektivere, da es bei einer Testtransformation mit dem pUC 19 Vektor zu einer Transformationseffizienz von 1 x $10^{9} \mathrm{kam}$ und bei der Elektroporation lediglich zu einer von 1 x $10^{6}$. Da das prnp Gen, in den pGEM-T Vektor zwischen das lacZ-Gen kloniert wurde, konnten positive Klone durch $\alpha$-Komplementation auf IPTG-XGal LB-Amp-Platten selektiert werden. Zum Ausschluss von 
„falsch positiven“ Klonen wurde zusätzlich eine Vektor-PCR durchgeführt (siehe 2.1.5b). Danach wurden die positiven Klone über Nacht in LB-Amp-Flüssigkulturen angezogen und das Plasmid anschließend isoliert (siehe 2.1.4). Das isolierte Plasmid wurde mit dem Enzym XmnI geschnitten. Dabei befand sich eine Schnittstelle des Enzyms auf dem Insert und die andere im Vektorrückgrat, so dass zwei Fragmente mit unterschiedlichen Größen entstehen mussten. Dieser Restriktionsfragment-Längenpolymorphismus (RFLP) wurde in einem 1\%igem (w/v) Agarosegel dokumentiert. Die Bakterienklone, die keine zwei Fragmente aufwiesen, wurden als „falsch positive“ identifiziert, die positiven Klone wurden weiter analysiert. Von den so positiv identifizierten Bakterienklonen wurde die Nukleinsäuresequenz der verschiedenen in den pGEM-T Vektor ligierten prnp Gene bestimmt. Dazu wurden jeweils 300 ng Plasmid-DNA für eine Sequenzreaktion benötigt (siehe 2.1.18). Die dabei verwendeten Sequenzprimer sind in der Tab. 7 aufgeführt. Die Primer wurden so gewählt, dass sie 30 Nukleotide vor dem Startcodon oder komplementär 30 Nukleotide nach dem Stopcodon an den DNA-Strang banden.

Tab. 7 Sequenzprimer für den pGEM-T Vektor

\begin{tabular}{ll}
\hline Primer & Basensequenz \\
\hline $5 ’, 3^{\prime}$ & GTT TTC CCA GTC ACG AC \\
3' $\rightarrow$ 5' & GGA TAA CAA TTT CAC ACA GG \\
\hline
\end{tabular}

Die Nukleotidsequenz wurde mit Hilfe des Programms pDRAW 32 (AcaClone Software) in die Aminosäurensequenz (ASS) umgewandelt. Diese wurde dann sowohl mit den bekannten Sequenzen aus der Entrez Proteinbank des NCBI als auch miteinander verglichen. Stimmten die ASS der jeweiligen Spezies überein, so wurden diese Klone weiter verwendet, anderenfalls wurde das prnp Fragment erneut amplifiziert und kloniert. Der Vergleich zwischen den verschiedenen speziesspezifischen ASS untereinander ist in der Tab. 8 dargestellt. Der Gorilla und der Bonobo entsprachen dabei dem Schimpansen und der Rhesusaffe dem Javaneraffen, deshalb wurden sie hier nicht dargestellt. 
Tab. 8 Aminosäuresequenzvergleich der speziesspezifischen Prion Proteine

\begin{tabular}{|c|c|}
\hline Mensch & _MANLGCWMLVLFVATWSDLGLCKKRPKPG_GWNTGGSRYPGQGSPGGNRYPPQGGGGW \\
\hline Javaneraffe & 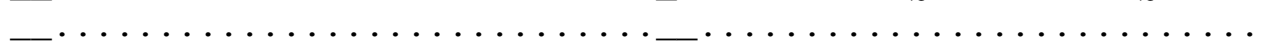 \\
\hline ise & $\ldots \ldots \ldots \ldots \ldots \ldots \ldots$ \\
\hline Maus & $\ldots$. Y.L.A. . TM.T.V. . . . . \\
\hline Elch & MVKSHI.S.I.....M...V.......G.... \\
\hline laf & 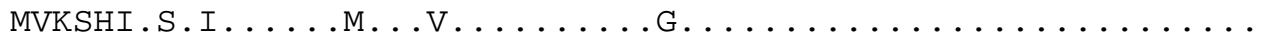 \\
\hline Rind & MVKSHI.S.I.....M...V...... \\
\hline gr. Tümmler & \\
\hline Mensch & GQPHGGGWGQPHGGGWGQPHGGGWGQPHGGG_ \\
\hline Javaneraffe & 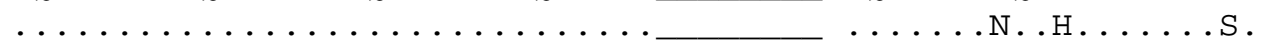 \\
\hline chimpanse & $\ldots \ldots \ldots \ldots \ldots \ldots \ldots \ldots \ldots$ \\
\hline Maus & $\ldots \ldots \ldots \ldots \ldots s \ldots \ldots s \ldots \ldots \ldots$ \\
\hline Elch & 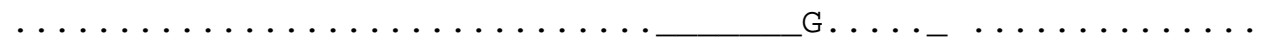 \\
\hline Schaf & $\ldots \ldots \ldots \ldots \ldots \ldots \ldots \ldots$ \\
\hline Rind & $\ldots \ldots \ldots \ldots \ldots \ldots \ldots \ldots \ldots \ldots \ldots \ldots \ldots \ldots, \ldots \ldots \ldots$ \\
\hline gr. Tümmler & $\ldots \ldots \ldots \ldots \ldots \ldots \ldots \ldots \ldots$ \\
\hline Mensch & KHMAGAAAAGAVVGGLGGYVLGSAMSRPIIHFGSDYEDRYYRENMHRYPNQVYYRPMDEY \\
\hline Javaneraffe & 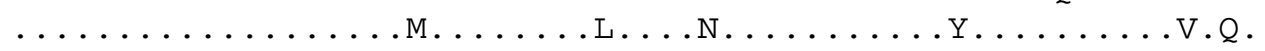 \\
\hline Schimpanse & 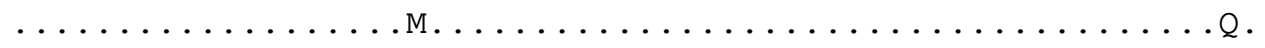 \\
\hline Maus & $\ldots \ldots \ldots \ldots \ldots \ldots \ldots$. . . . . . N.W. . . . . . . . . . Q. \\
\hline Elch & 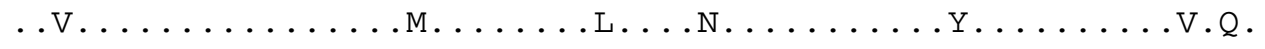 \\
\hline Schaf & $\ldots V \ldots \ldots \ldots \ldots$. . . . . . . . . . . . . . . . Y. . . . . V.H. \\
\hline Rind & $\ldots$. . . . . . . . . . . . . . . . . . . . . . . . \\
\hline gr. Tümmler & $\ldots \vee \ldots \ldots \ldots \ldots \ldots \ldots \ldots \ldots$ \\
\hline Mensch & SNQNNFVHDCVNITIKQRTVTTTTKGENFTETDVKMMERVVEQMCITQYERESQAYY_Q \\
\hline Javaneraffe & 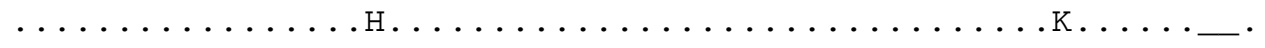 \\
\hline Schimpanse & 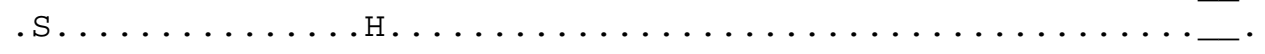 \\
\hline Maus & 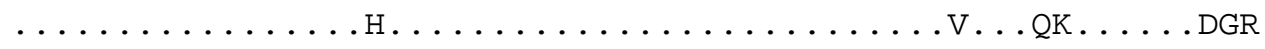 \\
\hline Elch & 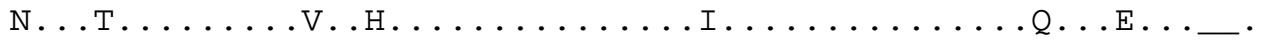 \\
\hline Schaf & $\ldots D \ldots \ldots \ldots$. . . . . . . . . . I. . . . . . . . . . \\
\hline Rind & $\ldots \ldots \ldots \ldots \ldots \ldots$ EH $\ldots \ldots \ldots \ldots \ldots$ I $\ldots$ K. . . . . . . . . \\
\hline & \\
\hline Mensch & RGSSMVLFSSPPVILLISFLIFLIVG \\
\hline Javaneraffe & $\ldots \ldots \ldots \ldots \ldots \ldots \ldots$ \\
\hline Schimpanse & $\ldots \ldots \ldots \ldots$ \\
\hline Maus &. $\mathrm{S} \ldots \ldots \ldots \ldots \ldots \ldots \ldots$ \\
\hline Elch & $\ldots$ A.VI . . . . . . . . . \\
\hline Schaf & $\ldots$ A.VI . . . . . . . . . \\
\hline $\begin{array}{l}\text { Rind } \\
\text { gr. Tümmler }\end{array}$ & $\ldots A . V I \ldots \ldots \ldots \ldots \ldots \ldots$ \\
\hline
\end{tabular}

Aus dem Aminosäuresequenzvergleich ist erkennbar, dass sich zwei Gruppen herausgebildet haben, die sich geringfügig in der Sequenz unterscheiden. Zum einen die Primaten und zum anderen der Artiodactyla. Nur die ASS der Maus und des gr. Tümmlers wiesen größere Abweichungen zu den anderen Prion Proteinen auf. Trotz dieser Unterschiede wurde festgestellt, dass sich die Prion Proteine bis auf das des gr. Tümmlers in nur max. 17 \% der Aminosäuren voneinander unterscheiden. Dies bestätigt die Aussage, dass das PrP ein hoch konserviertes Protein ist. 


\subsection{Expression und Reinigung von rekombinanten PrP aus E. coli}

Da der pGEM-T Vektor ein Bakterienexpressionsvektor ist, wurde in E. coli ein speziesspezifisches PrP durch das entsprechende prnp Fragment exprimiert. Da es zu einer Überexpression des Proteins kam, sammelte sich das PrP an und konnte aus IB gereinigt werden. Um zu sehen, welches $\operatorname{PrP}$ besonders gut exprimiert wurde, wurden die verschiedenen PrP exprimierenden Bakterienklone verglichen. Dazu wurden je $50 \mathrm{ml}$ LB-Medium mit den verschiedenen transformierten $E$. coli angeimpft und bei einer $\mathrm{OD}_{595}$ von 5 pelletiert. Anschließend wurde die Zellmembran durch Gefrierbruch und Lysozym zerstört, so dass der gesamte Zellinhalt als Proteingemisch vorlag. Von diesem Proteingemisch wurde die Konzentration gegen eine BSA-Eichreihe bestimmt, dargestellt in der Abb. 25.

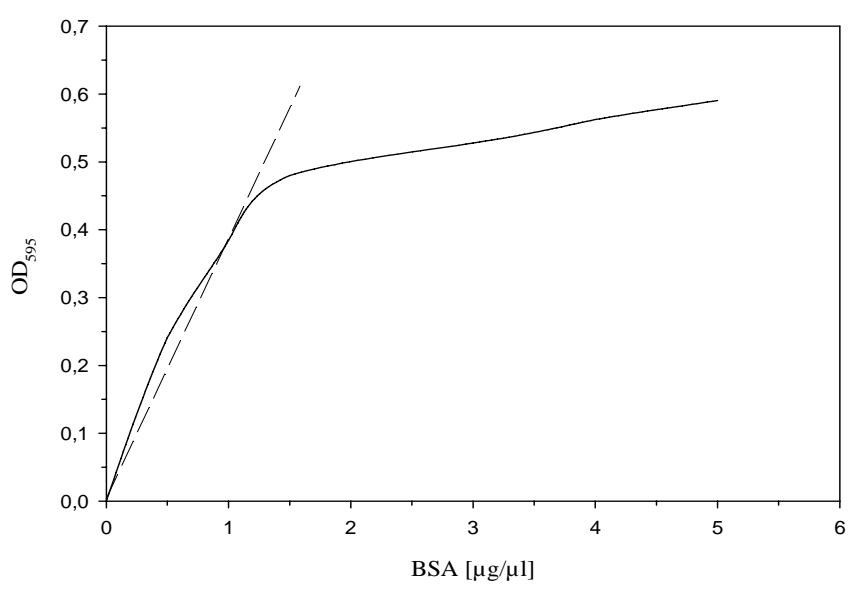

Abb. 25 BSA-Eichkurve in $\mathbf{H}_{2} \mathrm{O}$ Die lineare Regression der Eichgeraden wurde zur Bestimmung einer unbekannten Proteinkonzentration benutzt.

Die Proteinmenge ergab sich aus der linearen Regression der BSA-Eichgeraden. Die dabei verwendete Geradengleichung war folgende:

$$
y=0,32 x+0,03 \text { mit } r^{2}=0,96
$$

Zur Untersuchung der rPrP Expression in E. coli wurden je $30 \mu \mathrm{g}$ Gesamtprotein pro Geltasche auf ein SDS-Gel aufgetragen. Das Gel wurde anschließend geblottet und der WB mit dem ECL-System entwickelt. Die Expressionsmuster der verschiedenen PrP exprimierenden Bakterienklone sind in der Abb. 26 dargestellt. 

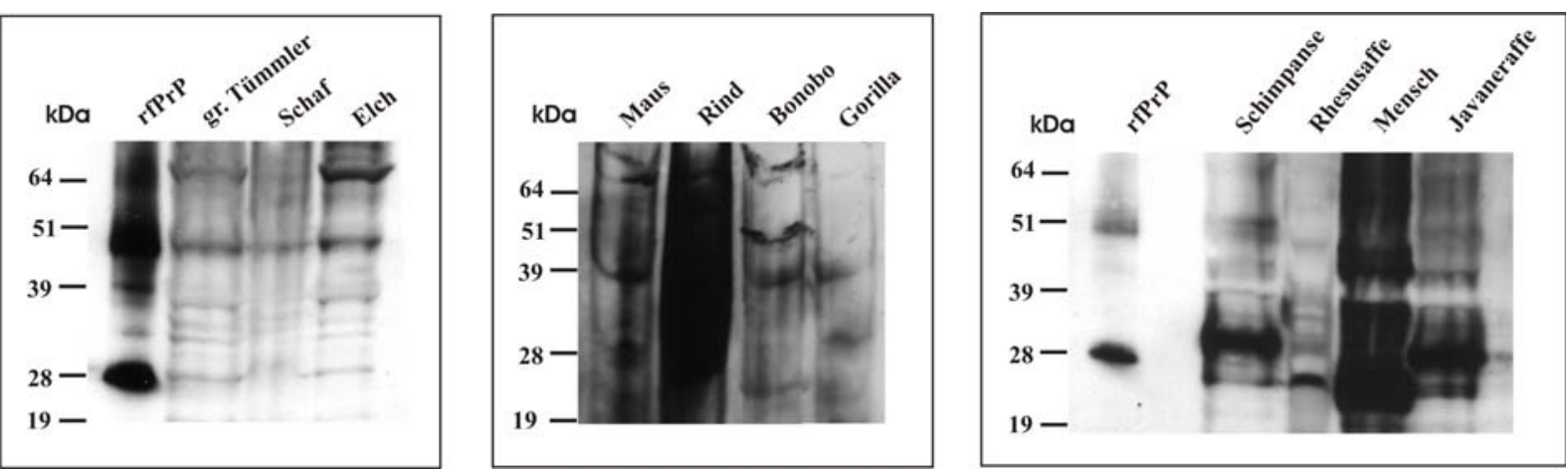

Abb. 26 Expression der verschiedenen $\mathrm{rPrP}$ in $\boldsymbol{E}$. coli Detektiert wurde das $\mathrm{rPrP}$ vom gr. Tümmler, Schaf, Elch, Maus, Rind, Bonobo, Gorilla, Schimpanse, Rhesusaffe, Mensch und Javaneraffe mit dem mAk-mix im WB. Als Vergleich wurde rekombinantes Javaneraffen $\operatorname{PrP}(\mathrm{rfPrP})$ verwendet.

Aus der Abb. 26 ist erkennbar, dass in E. coli bestimmte PrP Spezies besser exprimiert wurden als andere. Da E. coli keine Glykosylierungen durchführen kann, konnte nur die unglykosylierte Form bei $28 \mathrm{kDa}$ detektiert werden. In E. coli kommt es allerdings zur Bildung von $50 \mathrm{kDa}$ großen PrP Dimeren, diese waren bei allen Spezies vorhanden. Allerdings konnte diese Bande aufgrund der Antikörperspezifität nur unvollständig detektiert werden. Sie wurde bei allen Spezies durch eine Ponceau-Rotfärbung der NZM nachgewiesen. $\mathrm{Zu}$ den stark überexprimierenden $\mathrm{PrP}$ in E. coli gehört der Mensch, der Schimpanse, der Javaneraffe, der Rhesusaffe, das Rind und die Maus. Der Bonobo, der Gorilla, der Elch, das Schaf, und der gr. Tümmler wurden dagegen nur schwach exprimiert. Für die quantitative Reinigung wurde deshalb eine der stark überexprimierenden Spezies verwendet. Diese war der Javaneraffe, da er ebenfalls eines der meist genutzten Prionenforschungsobjekte ist.

Für die Reinigung des Prion Proteins wurden verschiedene Methoden getestet. Diese waren die einfache Lyse der Zellen durch Gefrierbruch mit Lysozym, die Ultraschallbehandlung (siehe 2.4.2.1) und mit Hilfe einer Retsch-Mühle (siehe 2.4.2.2). Das rfPrP wurde durch diese verschiedenen Methoden gereinigt und im WB aufgetragen, geblottet und durch das ECL-System detektiert, dargestellt in der Abb. 27. 


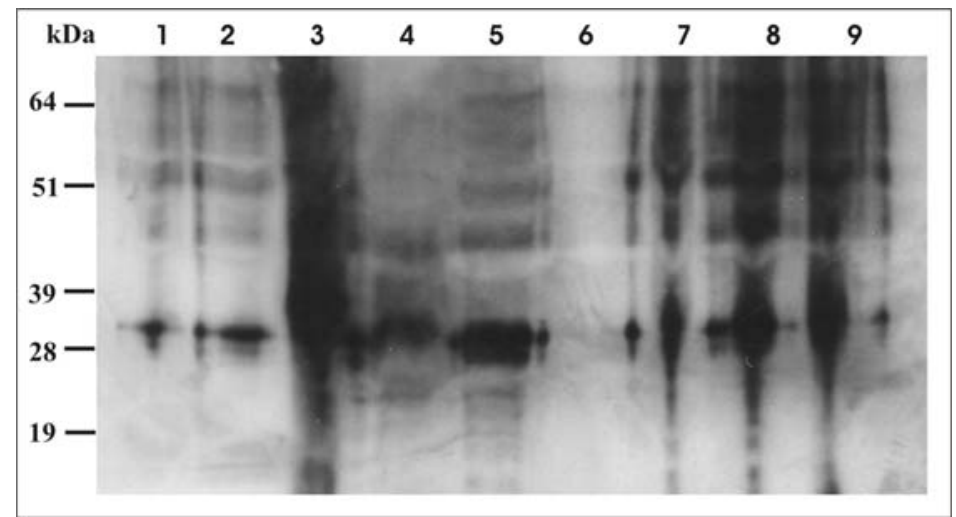

Abb. 27 Verschiedene Methoden der IB Reinigung des rfPrP aus $\boldsymbol{E}$. coli Das durch den mAk-mix im WB detektierte rfPrP wurde gereinigt durch 1) Gefrierbruch, 2) Gefrierbruch mit Lysozymzugabe, 3) $30 \mathrm{~s}$ Ultraschallbehandlung, 4) $1 \mathrm{~min}$ Ultraschallbehandlung, 5) 3 min Ultraschallbehandlung, 6) E. coli Negativkontrolle, 7) 1 min Retsch-Mühle, 8) 5 min Retsch-Mühle und 9) 10 min Retsch-Mühle.

Aus der Abb. 27 ist erkennbar, dass die Aufreinigung der IB mittels Ultraschall, die Bahnen 3 bis 5, die besten und saubersten Ausbeuten liefert. Die Ausbeuten der Retsch-Mühle, die Bahnen 7 bis 9, sind zwar ähnlich gut, allerdings ist diese Proteinaufreinigung nicht so sauber. Aus diesem Grund wurde für die weitere Aufreinigung die Ultraschallbehandlung benutzt. Dazu wurde der Javaneraffen E. coli Klon angezogen und die Reinigung wiederholt. Nachdem das Detergenz ausgewaschen war, wurde noch zweimal mit Waschpuffer die proteinhaltige Lösung gewaschen. Das Ergebnis ist in der Abb. 28 dargestellt.

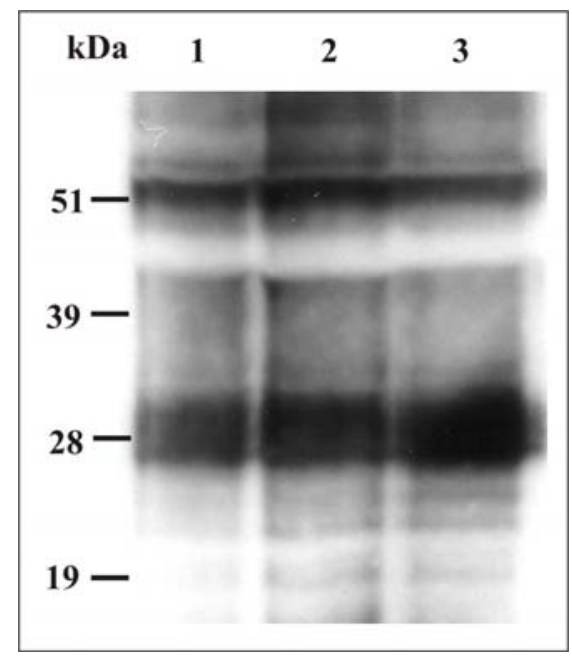

Abb. 28 Modifizierte Aufreinigung des rfPrP durch Ultraschall Mit 1) $30 \mathrm{~s}, 2) 1 \mathrm{~min}$ und 3) 3 min Ultraschallbehandlung. 
Nach der modifizierten Aufreinigung konnten keine Reinheitsunterschiede mehr zwischen den verschiedenen Zeitintervallen der Ultraschallbehandlungen festgestellt werden. Deshalb wurden alle weiteren Zellaufschlüsse jeweils für $1 \mathrm{~min}$ mit Ultraschall behandelt und nach dem modifizierten Protokoll aufgearbeitet. Bei einer so gereinigten Übernachtkultur konnten $5 \mu$ g rekombinantes PrP pro ml gewonnen werden. Neben der unglykosylierten Form wurde dabei auch das PrP Dimer isoliert und gereinigt. Das rekombinante Javaneraffen PrP (rfPrP) wurde als Positivkontrolle mitgeführt. Außerdem wurde es anderen Arbeitsgruppen zur Verfügung gestellt.

\subsection{Herstellung stabiler tTA-Expressionszelllinien}

Für die regulierte $\mathrm{PrP}^{\mathrm{C}}$ Expression im Zellkulturmodell wurden drei verschiedene Zelllinien verwendet. Diese waren die 3T3, die N2a und die $\operatorname{PrP}^{0 / 0}$ Zelllinie. Da diese Zelllinien das $\mathrm{PrP}^{\mathrm{C}}$ reguliert exprimieren sollten, wurde ein regulatorisches System benötigt. Dieses war das Tet-System. Der pTet-Off Vektor wurde als Regulationsvektor verwendet. Da von der 3T3 Zelllinie bereits eine stabil tTA exprimierende Zelllinie vorlag (3T3 L1 Tet-Off), musste diese nicht mit dem pTet-Off Vektor transfiziert werden, sondern nur die beiden Zelllinien N2a und $\mathrm{PrP}^{0 / 0}$. Dazu wurde der pTet-Off Vektor mit dem Enzym ScaI linearisiert und anschließend in die Zellen transfiziert. Dabei wurden jeweils $500 \mu \mathrm{g}$ des linearen Vektors in je $5 \times 10^{6}$ Zellen bei $0,25 \mathrm{kV}$ und $975 \mu \mathrm{F}$ elektroporiert. Nach 2 Tagen wurde mit einer Neomycinselektion begonnen.

Die N2a und die $\operatorname{PrP}^{0 / 0}$ Zelllinie erwiesen sich während der Selektion gegenüber diesem Antibiotikum als resistent. Aus diesem Grund musste ein neuer Vektor mit einem anderen Selektionsmarker konstruiert werden. Dazu wurde das tTA-Element über XhoI und HindIII aus dem pTet-Off Vektor geschnitten und in den Vektor pCMV/Bsd kloniert, dargestellt in der Abb. 29. Als Selektionsmarker in dem neuen Vektor pCMV/Bsd Tet-Off wurde Blasticidin statt Neomycin verwendet. 


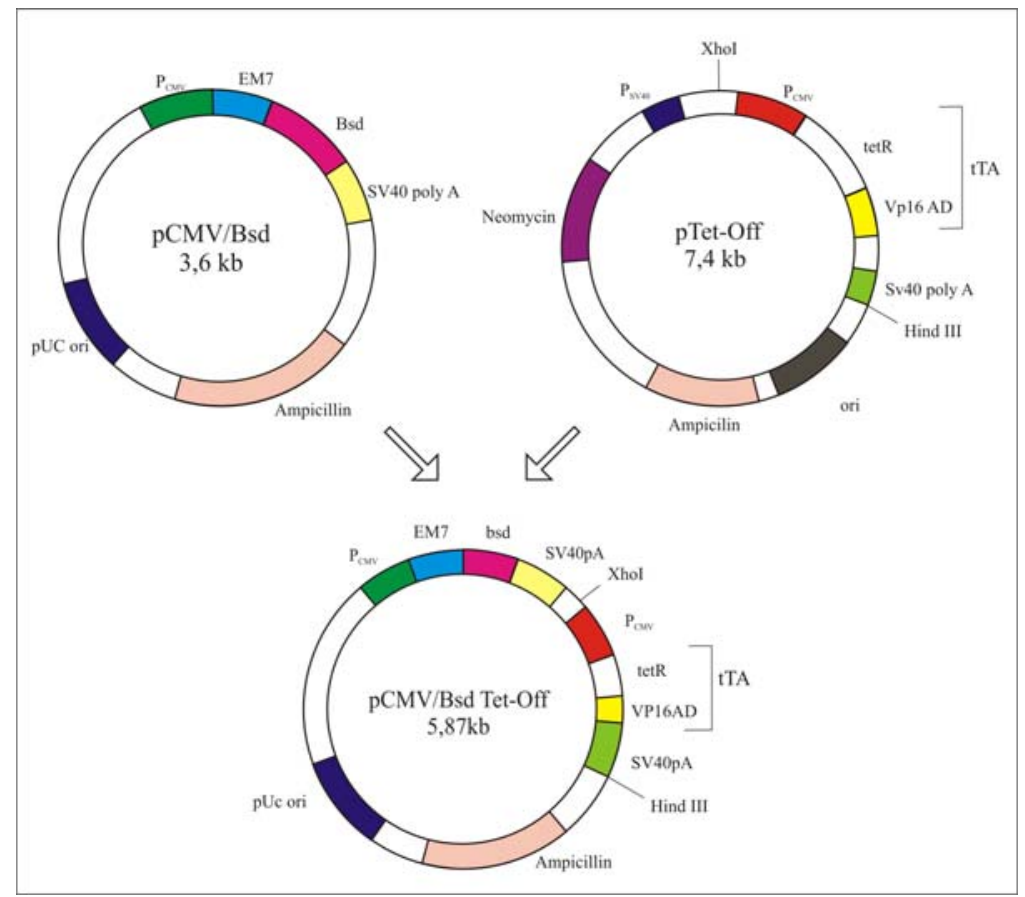

Abb. 29 Klonierungschema des pCMV/Bsd Tet-Off Vektors Der neue Vektor bestand aus einem Blasticidin (Bsd), einem Promotor $\left(\mathrm{P}_{\mathrm{CMV}}\right)$ sowie dem tTA-Element, das Teil eines ZweikomponentenRegulationssystems ist. Des Weiteren besaß der neue Vektor eine Ampicillinresistenz zur Selektion in Bakterien sowie ein Poly A Signal (SV40pA).

Der in der Abb. 29 dargestellte Vektor pCMV/Bsd Tet-Off wurde zur Herstellung stabil transfizierter Zelllinien verwendet. Die verschiedenen Zellklone wurden durch das Antibiotikum Blasticidin selektiert, dargestellt in der Abb. 30.

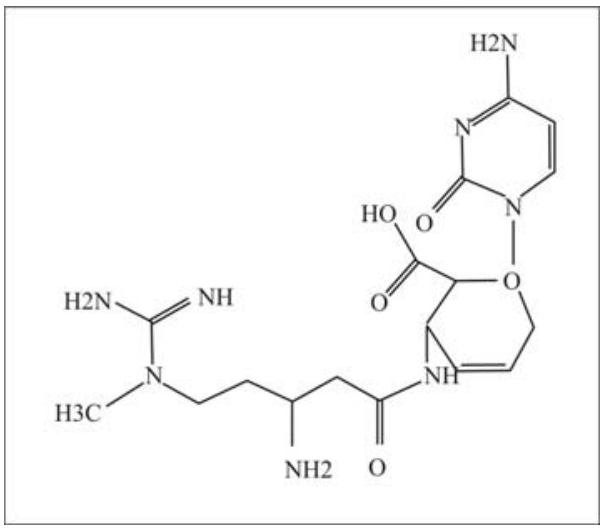

Abb. 30 Strukturformel des Blasticidins

Blasticidin erwies sich als ein guter Selektionsmarker, da man sehr schnell mit geringen Antibiotikakonzentrationen selektieren konnte. In der Abb. 31 sind die Resistenzen der nicht transfizierten Zelllinien gegenüber Blasticidin dargestellt. 



Abb. 31 Blasticidinresistenzkurven der verschiedenen Zelllinien Mit $\quad-2 \mu \mathrm{g} / \mathrm{ml}, \cdots 5$ $\mu \mathrm{g} / \mathrm{ml}$ und - - $-10 \mu \mathrm{g} / \mathrm{ml}$. Gezeigt wurde dies bei a) der $\operatorname{PrP}^{0 / 0}$ Zelllinie, b) der 3T3 Zelllinien und c) der N2a Zelllinie.

Aus den Resistenzkurven der verschiedenen Zelllinien ist ersichtlich, dass bei Zugabe von $5 \mu \mathrm{g} / \mathrm{ml}$ Blasticidin über 8 Tage hinweg keine nicht resistenten Zellen überlebten. Deshalb wurde nach der Elektroporation mit dem Transfektionsvektor pCMV/Bsd Tet-Off für die Dauer von 10 Tagen mit 5 gg/ml Blasticidin auf stabile Zellen selektiert. Danach wurden die Zellen mit $1 \mu \mathrm{g} / \mathrm{ml}$ weiter kultiviert damit der Selektionsdruck weiterhin bestand, die Zellen aber schneller wachsen konnten. Anschließend wurden von jeder Zelllinie 10 schnell wachsende Zellklone selektiert und weiter angezogen.

Diese Klone wurden auf ihre Tet-Induzierbarkeit untersucht. Dies geschah durch eine transiente Transfektion mit dem pBI-EGFP Vektor (siehe Abb. 20). Dieser besitzt als Reportergen ein „enhanced green fluorescent protein“ (EGFP) unter Kontrolle eines TRE-Elementes. Da EGFP ein fluoreszierendes Protein ist, konnten die Zellen unter dem Fluoreszenzmikroskop beobachtet und regulierbare Klone selektiert werden. Dabei wurden die Klone mit einer Wellenlänge von $488 \mathrm{~nm}$ angeregt und bei $530 \mathrm{~nm}$ beobachtet. Da die Fluoreszenzmikroskopie mit adherenten Zellen erfolgte, konnten diese Zellen nicht durch Elektroporation transfiziert werden. Sie wurden daher mittels Effectene und SuperFect 
transfiziert, da die Zellen dabei nicht von der Zellkulturplatte gelöst werden mussten. Für diese Transfektion war es allerdings notwendig, dass die optimale Konzentration von Plasmid- und Transfektionsreagenz zuvor bestimmt wurde. Die verschiedenen Konzentrationen wurden an $\operatorname{PrP}^{0 / 0}$ Zellen bestimmt und die Resultate auf die anderen Zellen übertragen. Die $\operatorname{PrP}^{0 / 0}$ Zellen wurden mit dem pGL3 Vektor (siehe Abb. 23), mit den in der Tab. 9 aufgelisteten verschiedenen Konzentrationsverhältnissen von DNA und Transfektionsreagenz transient transfiziert. Da der pGL3 Vektor Luziferase exprimiert, kam es zur Lumineszenz nach Zugabe von Luziferin. Dieses emittierte Licht konnte im Luminometer detektiert werden, dargestellt in der Abb. 32.

Tab. 9 Verhältnis der DNA zu den Transfektions-Agenzien

\begin{tabular}{ccc}
\hline \multirow{2}{*}{ Bezeichnung } & \multicolumn{2}{c}{ Verhältnis } \\
\cline { 2 - 3 } & DNA : Effectene : Enhancer & DNA : SuperFect \\
\hline 1 & $1: 0,5: 4$ & $1: 0,5$ \\
2 & $1: 1: 4$ & $1: 1$ \\
3 & $1: 1,5: 4$ & $1: 1,5$ \\
4 & $2: 1: 8$ & $2: 1$ \\
5 & $2: 2: 8$ & $2: 2$ \\
6 & $2: 3: 8$ & $2: 3$ \\
7 & $4: 2: 16$ & $4: 2$ \\
8 & $4: 4: 16$ & $4: 4$ \\
9 & $4: 6: 16$ & $4: 6$ \\
10 & $8: 4: 32$ & $8: 4$ \\
11 & $8: 8: 32$ & $8: 8$ \\
12 & $8: 0: 32$ & $8: 0$ \\
\hline
\end{tabular}

Getestet wurden die verschiedenen Verhältnisse in $\operatorname{PrP}^{0 / 0}$ Zellen mit $1=1 \mu \mathrm{l}$. 


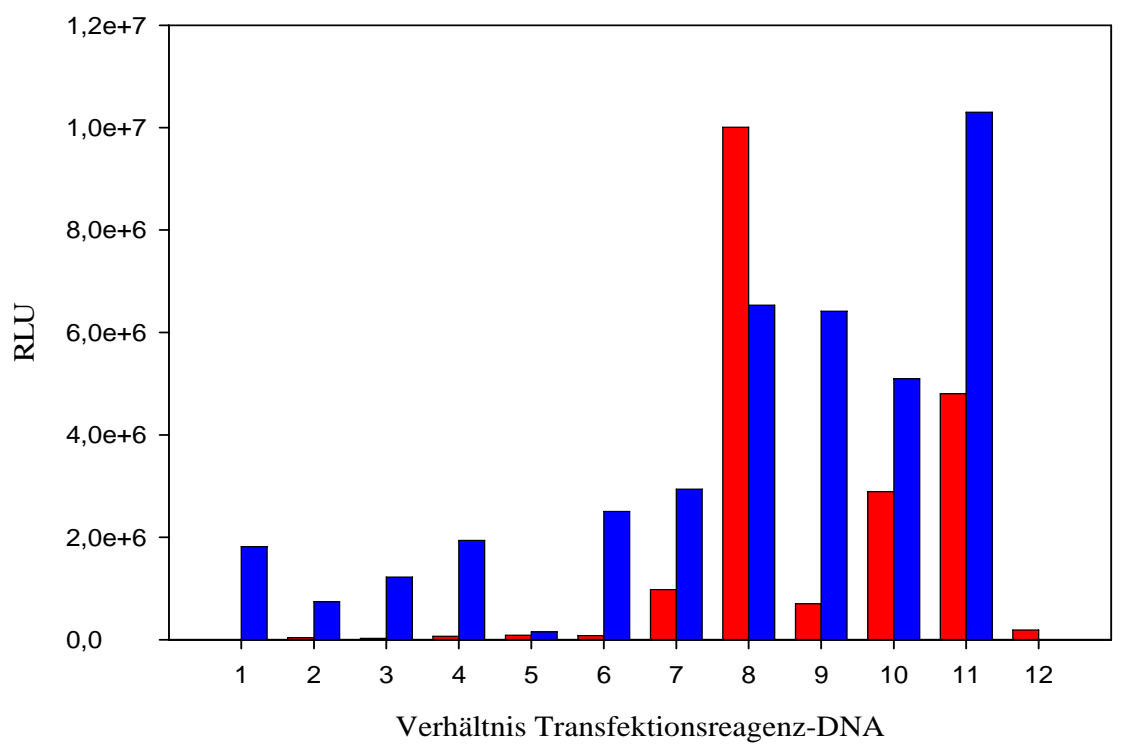

Abb. 32 Optimierung der Transfektionseffizienz Nach 24 h wurde die Luziferaseaktivität in $\operatorname{PrP}^{0 / 0}$ Zellen bestimmt. Diese wurden mit verschiedenen Mengen an pGL3 und Transfektionsagenzien (Effectene ( $\boldsymbol{\Xi})$, SuperFect ( $\boldsymbol{\Xi})$ ) transfiziert. Die relativen Mengen DNA und SuperFect bzw. Effectene mit Enhancer sind in der Tab. 9 angegeben.

Aus der Abb. 32 ist erkennbar, dass die Transfektionseffizienz mit SuperFect bei einem Verhältnis von $4 \mu \mathrm{l}$ DNA zu $4 \mu \mathrm{l}$ Transfektionsagenz gute Resultate lieferte.

Dieses Verhältnis wurde genutzt, um den pBI-EGFP Vektor in die verschiedenen pCMV/Bsd Tet-Off Zellklone der Zelllinien $\mathrm{PrP}^{0 / 0}$, N2a und 3T3 transient zu transfizieren. Anschließend wurden die so transfizierten Zellen nach $24 \mathrm{~h}$ Inkubation mit und ohne Tet unter dem Fluoreszenzmikroskop angesehen und selektiert. Diese Klone sind in der Abb. 33 dargestellt. 


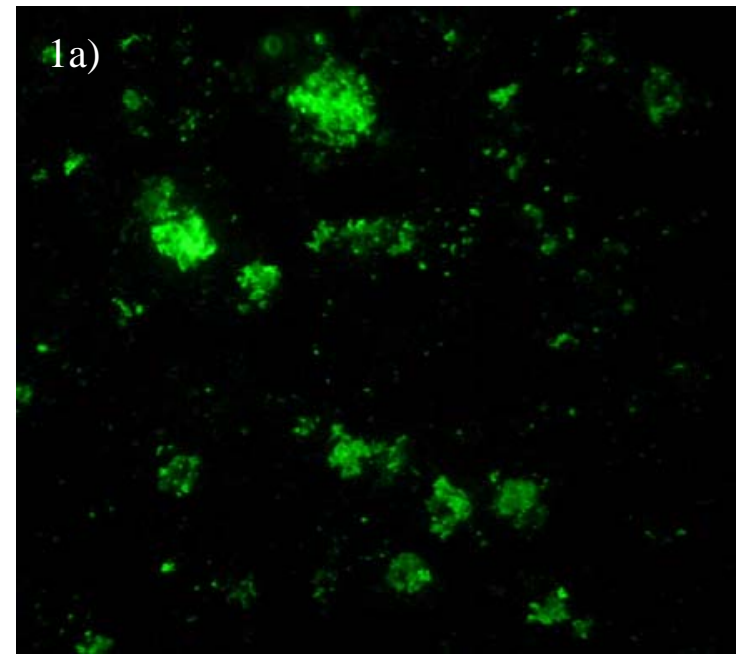

1b)
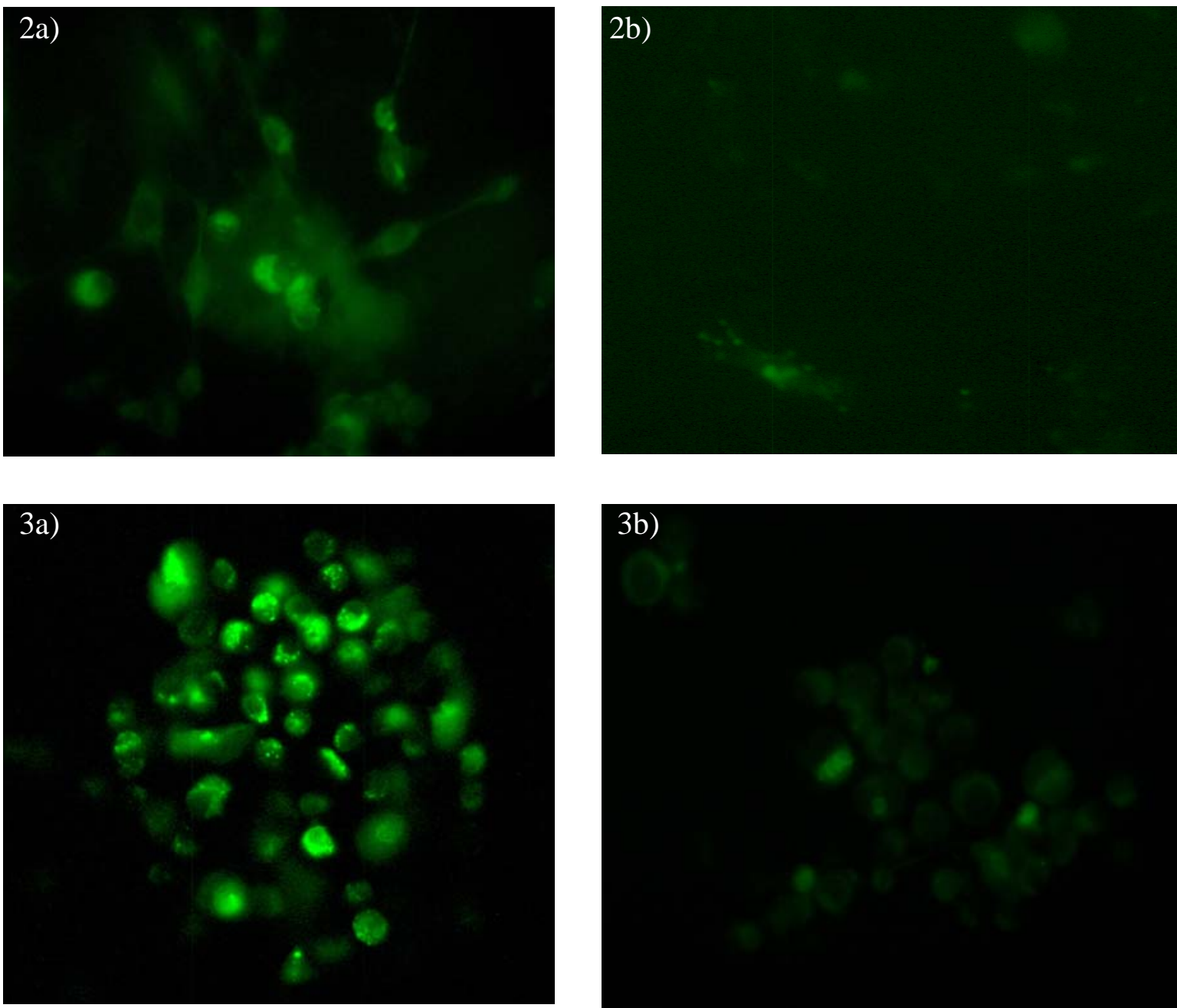

Abb. 33 Fluoreszenzmikroskopische Aufnahmen der verschiedenen Zelllinien Mit 1) $\operatorname{PrP}^{0 / 0}$ Zellen, 2) 3T3 Zellen und 3) N2a Zellen. Die Zellen in a) wurden ohne Tet kultiviert und die Zellen in b) wurden jeweils mit $50 \mu \mathrm{g} / \mathrm{ml}$ Tet kultiviert.

Aus der Abb. 33 ist zu erkennen, dass sich in den verschiedenen Zellklonen, dass durch das TRE-Element regulierte Gen mit Hilfe von Tet an- und abstellen ließ. Eine gute Regulation 
war bei den $\operatorname{PrP}^{0 / 0}$ Zellen zu beobachten, diese zeigten nach der Inkubation mit Tet die geringste Basisexpression. Dagegen war bei den anderen beiden Klonen die Basisexpression stärker ausgeprägt. Der jeweils selektierte Zellklon einer Zelllinie wurde als PrP LHABT, N2a LHABT und 3T3 LHABT bezeichnet.

Da Mycoplasmen in der Zellkultur verschiedene Krankheiten auslösen können, wurden die Zelllinien und Zellklone auf diese Kontamination in unregelmäßigen Abständen, aller 5-7 Monate, mit Hilfe der PCR untersucht (siehe 2.1.5d).

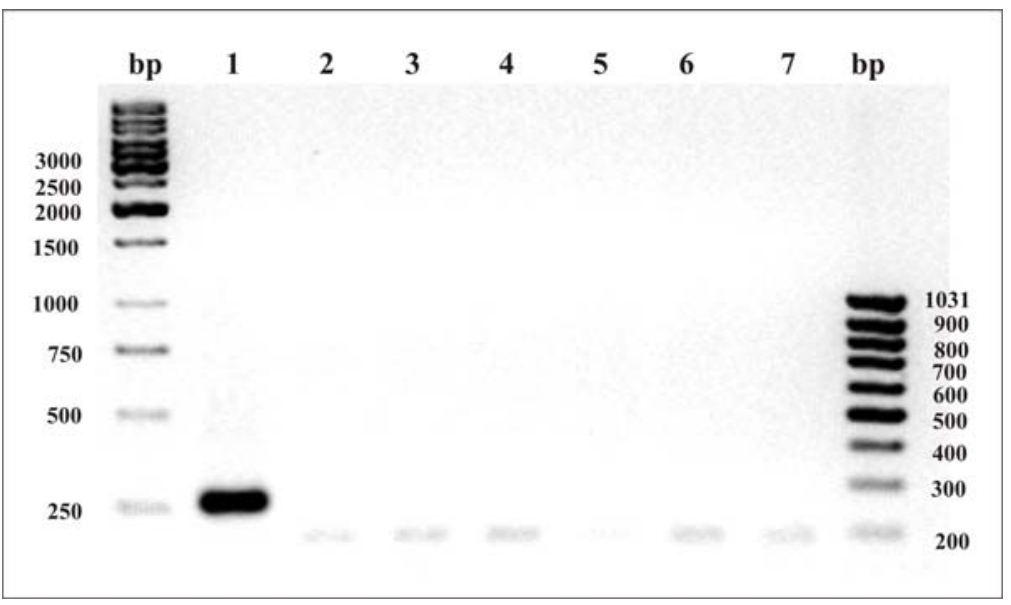

Abb. 34 Mycoplasmentest-PCR Mit 1) Positivkontrolle, 2) Negativkontrolle, 3) N2a Zellkultur, 4) $\operatorname{PrP}^{0 / 0}$ Zellkultur, 5) 3T3 Zellkultur, 6) $\mathrm{PrP}^{0 / 0}$ LHABT und 7) N2a LHABT.

Aus der Abb. 34 geht hervor, dass die Zellkulturen nicht mit Mycoplasmen infiziert waren, da nur die Positivkontrolle eine Reaktion in der PCR zeigte. Im Gegensatz dazu wies die Negativkontrolle und die verschiedenen Zellkulturen keine Reaktion auf.

\subsection{Herstellung doppelt stabiler regulierbarer $\operatorname{PrP}^{\mathrm{C}}$ exprimierender Zelllinien}

Zur Herstellung von regulierbaren $\operatorname{PrP}^{\mathrm{C}}$ Expressionszelllinien wurde das prnp Gen der verschiedenen Spezies in die verschiedenen LHABT Zellklone transfiziert. Dazu wurde das entsprechende prnp Gen aus dem pGEM-T Vektor ausgeschnitten und in verschiedene Vektoren kloniert, da zwei verschiedene Transfektionssysteme und Vektoren verwendet wurden. Zum einen wurden die Zellen mit dem „gene targeting“ Vektor pTRE-FU transfiziert und zum anderen mit dem retroviralen Vektor pRev-TRE, der über eine retrovirale Infektion in die Zellen eingeschleust wurde. Das prnp Gen war bei beiden Vektoren an ein TRE-Element gekoppelt, da es durch Tet reguliert an- und abgestellt werden sollte. Beide Vektoren besitzen einen Hygromycinmarker, weshalb nach einer Transfektion mit diesen 
beiden Vektoren die doppelt stabilen $\operatorname{PrP}^{\mathrm{C}}$ exprimierenden Zellen durch dieses Antibiotikum selektiert werden konnten. Dieses zweite Antibiotikum wurde neben Blasticidin zur Selektion verwendet. Die Strukturformel des Hygromycins ist in der Abb. 35 dargestellt. Um die Hygromycinresistenz der $\operatorname{PrP}^{0 / 0}$, N2a und 3T3 Zellen zu testen, wurden diese mit unterschiedlichen Antibiotikakonzentrationen kultiviert, dargestellt in der Abb. 36.

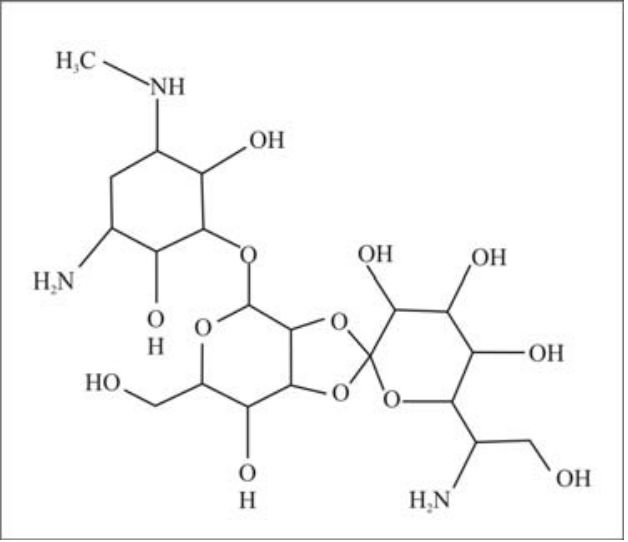

Abb. 35 Strukturformel des Hygromycins
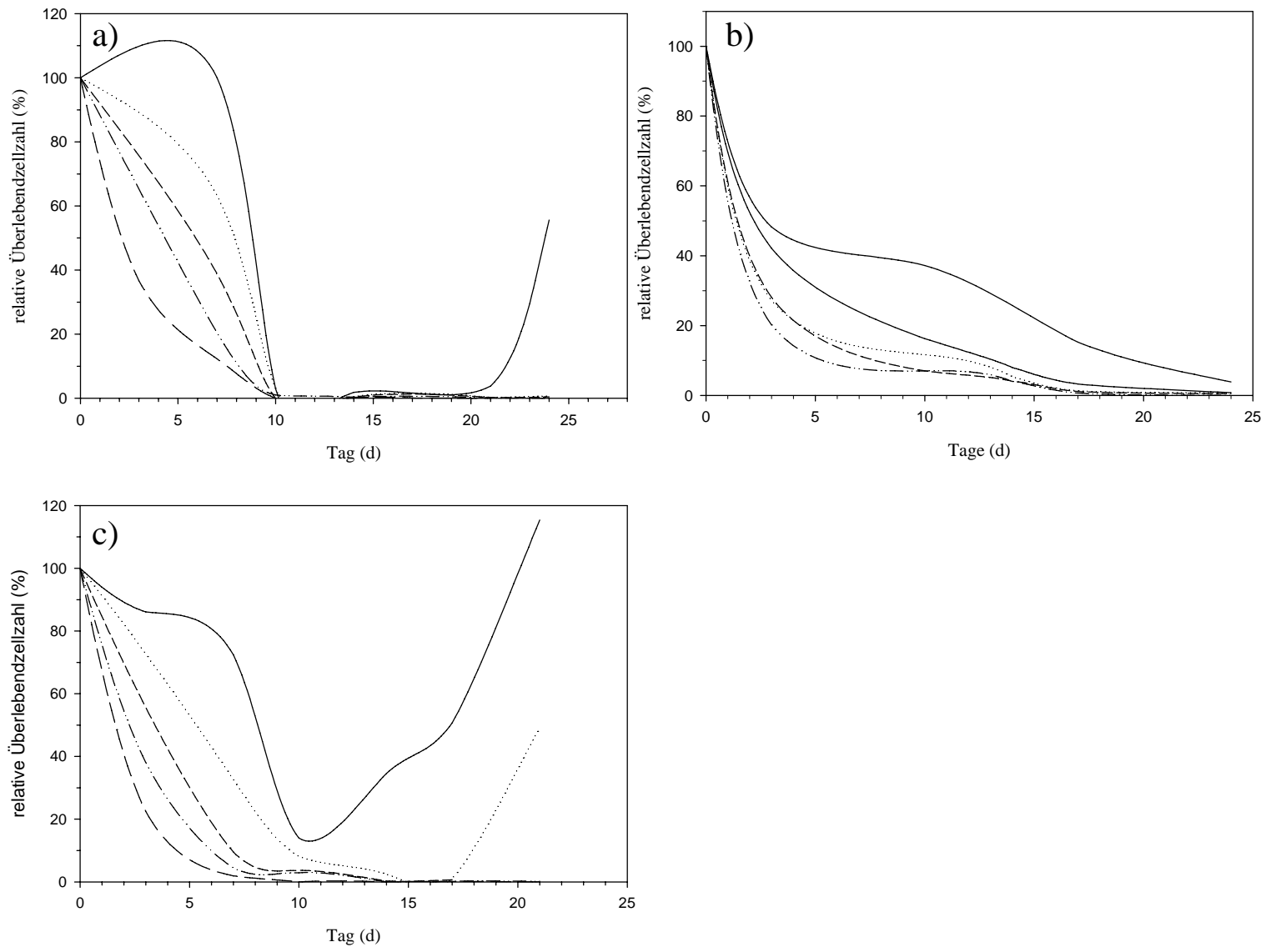

Abb. 36 Hygromycinresistenz der verschiedenen Zellklone Die Zellen wurden jeweils kultiviert mit $-50 \mu \mathrm{g} / \mathrm{ml}, \cdots 100 \mu \mathrm{g} / \mathrm{ml},--150 \mu \mathrm{g} / \mathrm{ml}, \cdots-\cdots-200$ $\mu \mathrm{g} / \mathrm{ml}$ und $-\quad-300 \mu \mathrm{g} / \mathrm{ml}$ bei a) PrP LHABT b) 3T3 LHABT und c) N2a LHABT. 
Aus den Resistenzkurven der einzelnen Zelllinien ist erkennbar, dass die Zellen, gegenüber einer Hygromycinkonzentration größer als $100 \mu \mathrm{g} / \mathrm{ml}$, nicht resistent waren. Die Absterbephase dauerte bei einer Konzentration von $150 \mu \mathrm{g} / \mathrm{ml}$ bei den PrP LHABT und N2a LHABT jeweils 11 Tage und bei den 3T3 LHABT 18 Tage. Deshalb wurden die transfizierten PrP LHABT und N2a LHABT Zellen mit $200 \mu \mathrm{g} / \mathrm{ml}$ für 15 Tage und die 3T3 LHABT für 22 Tage selektiert. Anschließend wurden die Zellen mit $50 \mu \mathrm{g} / \mathrm{ml}$ kultiviert, um den Selektionsdruck aufrecht zu erhalten und trotzdem ein schnelles Zellwachstum zu ermöglichen. Mit dieser Antibiotikakonzentration und Kultivierungszeit wurden die, auf die verschiedenen Arten transfizierten Zellen, selektiert.

\subsubsection{Herstellung doppelt stabiler $\operatorname{PrP}^{\mathrm{C}}$ exprimierender Zelllinien durch Elektroporation}

Für die stabile Transfektion durch Elektroporation wurde der pTRE-FU Vektor verwendet. In diesen wurden die verschiedenen prnp Gene aus dem pGEM-T Vektor über eine BamHI Schnittstelle kloniert, dargestellt in der Abb. 37. Dabei wurden die prnp Gene vom Rind, Menschen, Elch, Schimpansen und Javaneraffen verwendet. Danach wurde der Vektor linearisiert und $500 \mu \mathrm{g}$ in $5 \times 10^{6}$ Zellen elektroporiert mit 0,25 kV und $975 \mu \mathrm{F}$. Die Zellen PrP LHABT, 3T3 LHABT und N2a LHABT wurden mit dem Vektor pTRE-FU und dem entsprechenden prnp Gen transfiziert und anschließend durch Hygromycin auf stabile Zellen selektiert, dargestellt in der Abb. 38. 


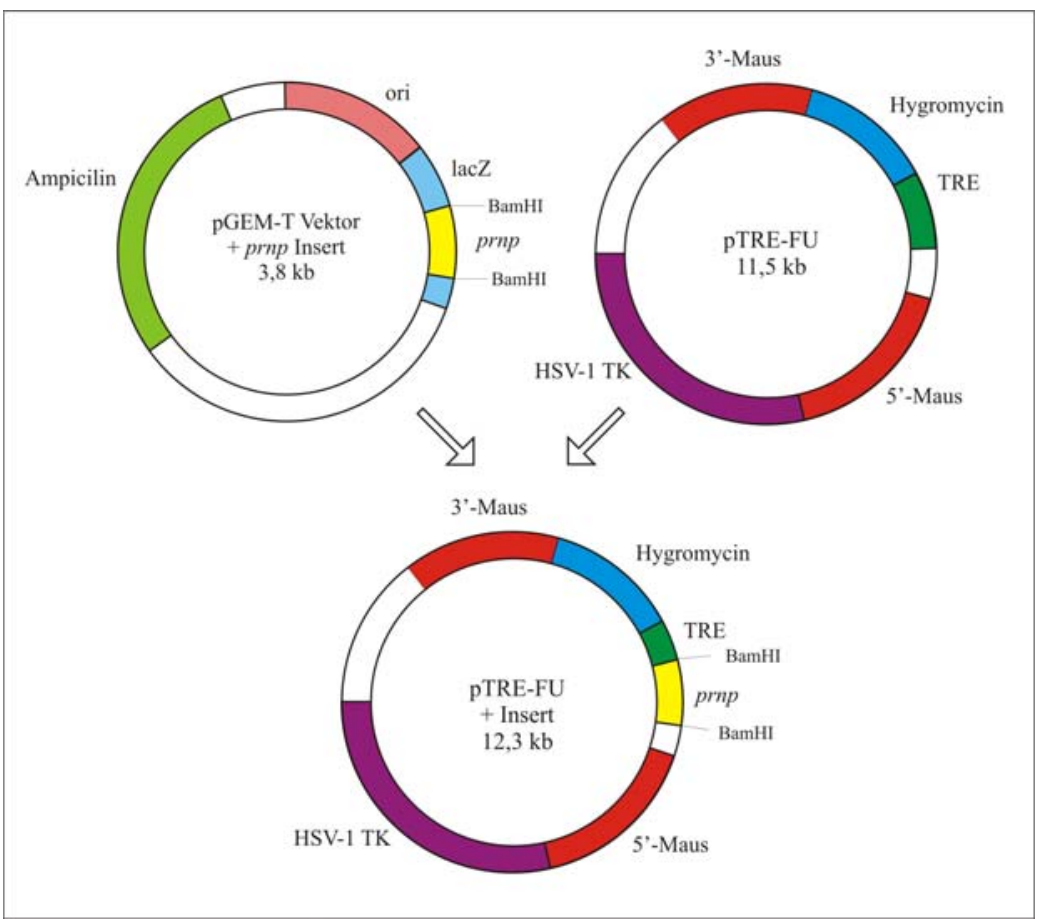

Abb. 37 Klonierung des pTRE-FU Vektors mit Insert Das prnp Gen wurde über eine BamHI Schnittstelle in den „gene targeting“ Vektor pTRE-FU kloniert. Da das Gen an ein TRE-Element gekoppelt war, konnte es reguliert an- und abgestellt werden. Die Selektion auf stabil transfizierte eukaryontische Zellen erfolgte anschließend über die Hygromycinresistenz.



Abb. 38 Stabile Transfektion durch Elektroporation Nach der Transfektion in die eukaryontischen Zellen und deren Selektion, wurde das $\operatorname{PrP}^{\mathrm{C}}$ in den verschiedenen Zellen exprimiert, auf verschiedenen Wegen nachgewiesen und isoliert. 


\subsubsection{Retrovirale Herstellung doppelt stabiler $\operatorname{PrP}^{\mathrm{C}}$ exprimierender Zellklone}

Für die stabile Transfektion durch Retroviren wurde der pRev-TRE Vektor verwendet. In diesen wurde das prnp Gen aus dem pGEM-T Vektor kloniert, dargestellt in Abb. 39. Dabei wurden die prnp Gene vom Rind, Menschen, Maus und Javaneraffen verwendet. Danach erfolgte eine Linearisierung des Vektors durch das Enzym SspI und anschließende Elektroporation in die PT67 Zelllinie. Diese produzierte die Virushüllproteine, verpackte den Vektor in einen Retrovirus und gab ihn über die Zellmembran an das Medium ab, ohne die Zellen zu zerstören. Mit diesem infektiösen Zellmedium wurden anschließend die verschiedenen LHABT Zellklone infiziert (siehe 2.3.5). Der MOI dieser Zellen betrug 1,2 cfu. Dadurch konnten die Zellen gut transfiziert und durch Hygromycin selektiert werden, dargestellt in der Abb. 40.

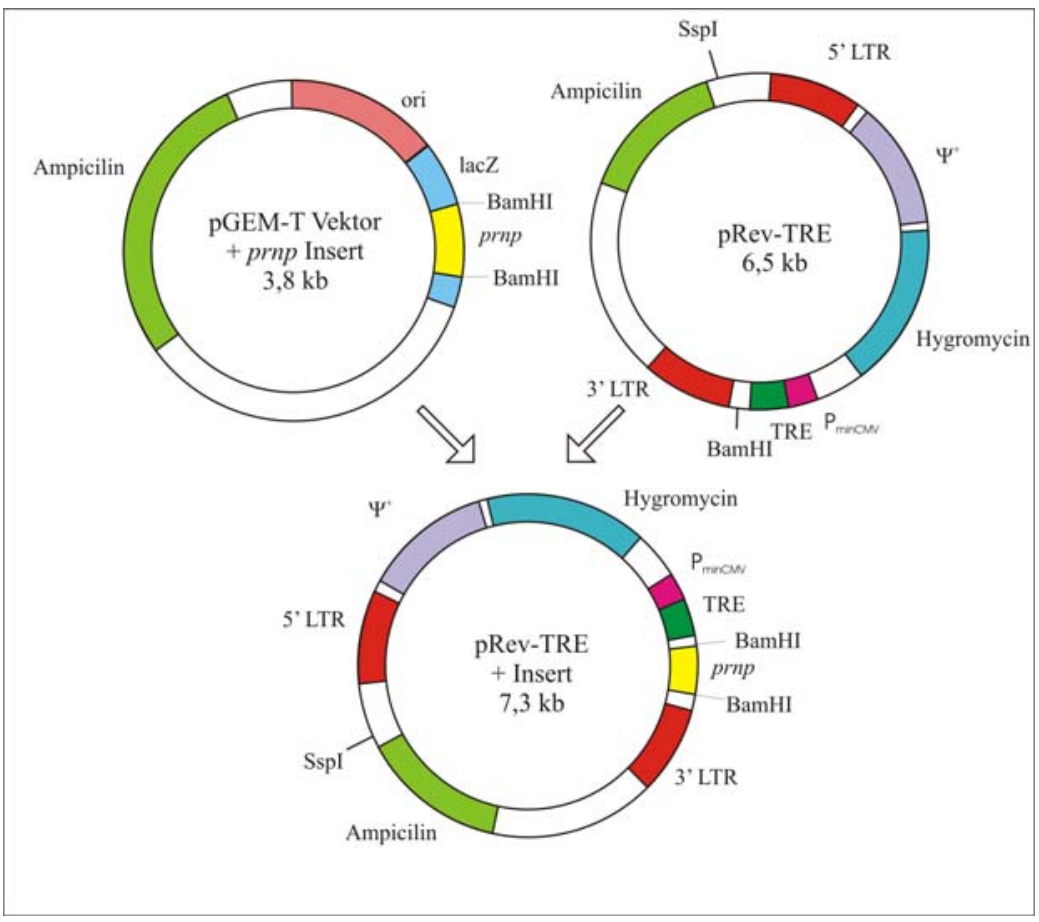

Abb. 39 Klonierung des retroviralen Expressionsvektors Der zur Transfektion benutzte retrovirale Vektor besitzt ein prnp Gen, welches über eine BamHI Schnittstelle kloniert wurde. Durch die LTR-Regionen ist die Frequenz der Transfektion sehr effizient. Da das prnp Gen an ein TRE-Element gekoppelt war, konnte es reguliert an- und abgestellt werden. Die Selektion auf stabil transfizierte eukaryontische Zellen erfolgte anschließend über eine Hygromycinresistenz. 


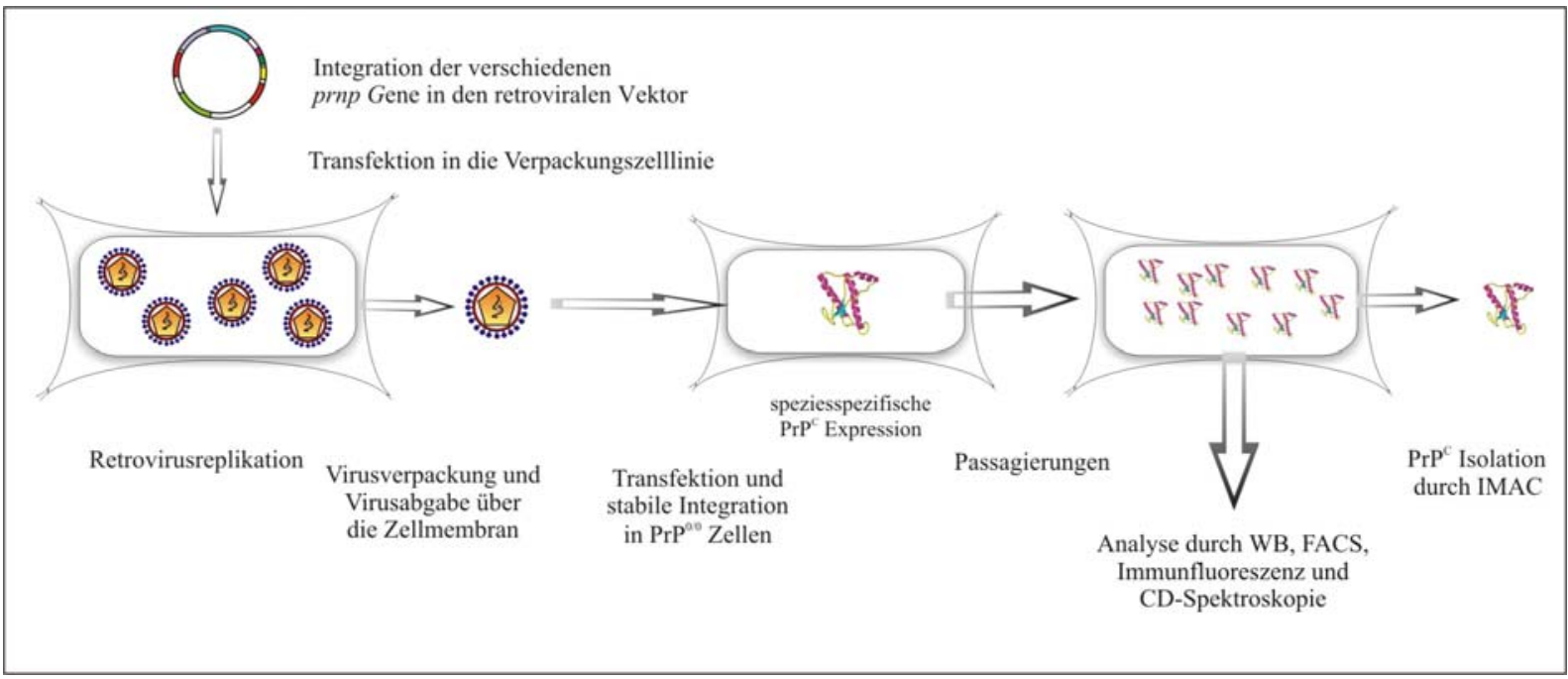

Abb. 40 Stabile Transfektion durch Retroviren Nach der Transfektion des retroviralen Vektors mit dem prnp Gen in die Verpackungszelllinie wurde ein Retrovirus produziert und an das Medium abgegeben. Mit diesem Medium wurden die Zielzellen kultiviert und anschließend selektiert mit Hilfe von Hygromycin. Das $\operatorname{PrP}^{\mathrm{C}}$ in den verschiedenen Zellen konnte exprimiert und auf verschiedenen Wegen nachgewiesen und isoliert werden.

Da bei der Transfektion durch Elektroporation mit dem pTRE-FU Vektor und anschließender Selektion bei einigen Spezies die Anzahl an positiven Klonen null war, wurden die Zellen mit Hilfe von Retroviren transfiziert. Bei einer Transfektion mit dem Javaneraffen prnp Gen, wurde ein Vergleich der Transfektionsmethoden durchgeführt. Bei der Transfektion durch einen Retrovirus und anschließender Selektion wurden 30-mal mehr Klone selektiert, als nach der Elektroporation mit dem pTRE-FU Verktor. Aus diesem Grund wurden die PrP LHABT, die N2a LHABT und die 3T3 LHABT Zellen mit Hilfe dieses Retrovirusmodells infiziert und anschließend selektiert. Da der PrP LHABT Zellklon von sich aus kein $\operatorname{PrP}^{\mathrm{C}}$ exprimiert, lag das Hauptaugenmerk der Transfektion und Selektion auf diesen Zellen.

Trotzdem wurden die anderen beiden Zellklone N2a LHABT und 3T3 LHABT mit prnp Genen transfiziert, damit ein Vergleich der verschiedenen Zelllinien vorgenommen werden konnte. Von den transfizierten Zelllinien wurden jeweils 40 Klone abgenommen und angezogen. Die 10 am schnellsten wachsenden Klone von jeder Zelllinie wurden selektiert und nach Erreichen einer Zellzahl von $1 \times 10^{6}$ im Verhältnis 1:2 gesplittet. Ein Teil wurde ohne Tet weiter kultiviert, der andere mit $50 \mu \mathrm{g} / \mathrm{ml}$ Tet. Nach 3 Tagen wurden die Zellen lysiert und das reguliert an- und abgeschaltete exprimierte $\operatorname{PrP}^{\mathrm{C}}$ im WB detektiert. Nach erfolgter Transfektion, Selektion und Detektion im WB, waren die in der Tab. 10 dargestellten stabilen regulierbaren $\operatorname{PrP}^{\mathrm{C}}$ exprimierenden Zellklone der verschiedenen Spezies in den jeweiligen Zelllinien verfügbar. 
Tab. 10 Hergestellte stabile regulierbare $\operatorname{PrP}^{\mathrm{C}}$ exprimierende Zellklone

\begin{tabular}{ccc}
\hline Zelllinie & $\begin{array}{c}\text { stabil transfizierte Zellklone } \\
\text { durch den pTRE-FU Vektor mit } \\
\text { folgenden prnp Gen }\end{array}$ & $\begin{array}{c}\text { stabil transfizierte Zellklone } \\
\text { durch den pRev-TRE Vektor mit } \\
\text { folgenden prnp Gen }\end{array}$ \\
\hline PrP $^{0 / 0}$ LHABT & Schimpanse (C1 und C4), & Javaneraffe (rF1-2), \\
& Javaneraffe (F1-1), & Mensch (rH1), Rind (rB2), \\
ET3 LHABT & Javaneraffe (F1-11), Rind (B4) & Maus (rM3) \\
N2a LHABT & Javaneraffe (F1-8), Mensch (H7) & Rind (rB3) \\
\hline
\end{tabular}

Aus der Tab. 10 geht hervor, dass 6 verschiedene Spezies reguliert das $\operatorname{PrP}^{\mathrm{C}}$ in den $\operatorname{PrP}$ LHABT Zellen exprimierten, 3 Spezies in den N2a LHABT Zellen und 2 Spezies in den 3T3 LHABT Zellen. Die durch Tet regulierbaren selektierten Zellklone, dargestellt in der Tab. 10, wurden im weiteren Verlauf der Arbeit nur noch mit ihren Abkürzungen genannt.

\subsection{Western Blot Analyse der $\operatorname{PrP}^{\mathrm{C}}$ Expression in den verschiedenen Zelllinien}

Das $\operatorname{PrP}^{\mathrm{C}}$ in Zellkultur kann auf verschiedenen Wegen nachgewiesen werden. Eine Detektion des $\operatorname{PrP}^{\mathrm{C}}$ ohne Zellaufschluss ist durch eine FACS Analyse oder Immunfluoreszenz möglich. Nach einem Zellaufschluss konnte das $\operatorname{PrP}^{\mathrm{C}}$ durch den „klassischen“ WB, bei dem 3 Banden zwischen $25 \mathrm{kDa}$ und $37 \mathrm{kDa}$ auf dem SDS-PAGE-Gel zu erkennen waren, durch eine 2DGel-Analyse und durch eine CD-Spektroskopie nachgewiesen werden.

Die Zelllyse erfolgte dabei durch den E1A-Lysepuffer (50 mM Hepes, $150 \mathrm{mM} \mathrm{NaCl,} \mathrm{0,1 \%}$ (v/v) Igepal, mit je $1 \mu \mathrm{g} / \mathrm{ml}$ RNase, DNase, PMSF und Pepstatin A). Die Bestimmung der Proteinkonzentration in den lysierten Zellen erfolgte anschließend durch lineare Regression gegen eine BSA-Eichgerade in E1A-Puffer, dargestellt in der Abb. 40 mit folgender Gleichung:

$$
y=0,42 x+0,179 \text { mit } r^{2}=0,987
$$




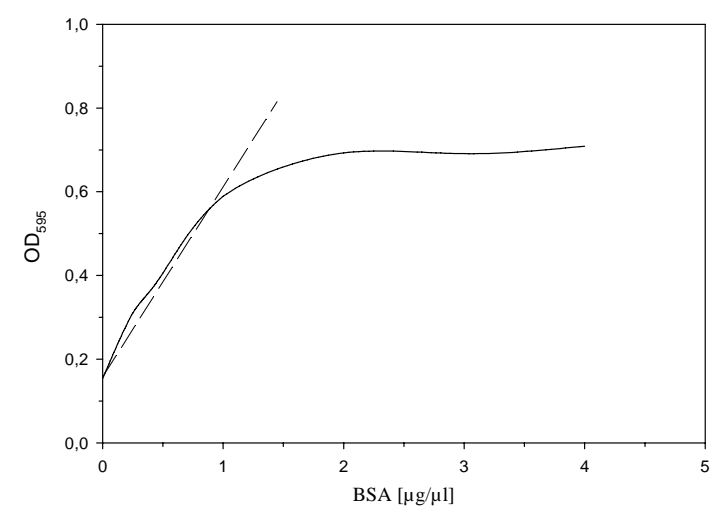

Abb. 41 Proteinbestimmung von BSA im E1A-Lysepuffer Durch die lineare Regression der BSA-Eichgerade wurde eine unbekannte Proteinmenge bestimmt.

Nach der Zelllyse und anschließender Proteinbestimmung der verschiedenen Zellklone wurden jeweils $30 \mu \mathrm{g}$ Protein pro Geltasche auf ein SDS-PAGE-Gel gegeben und danach im WB detektiert.

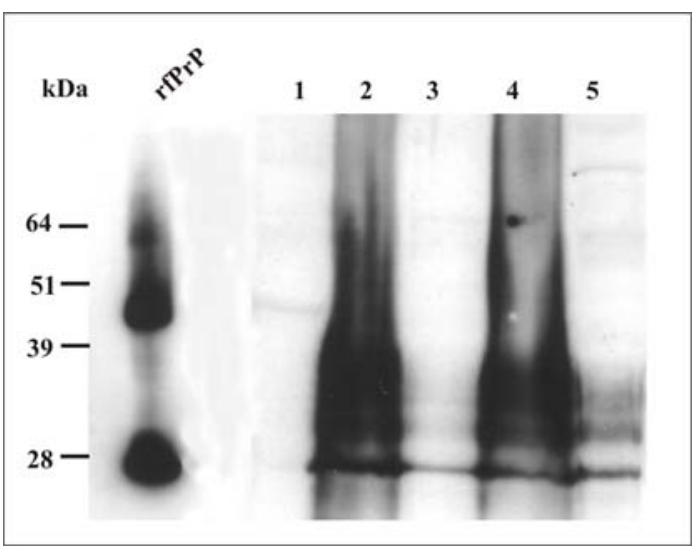

Abb. 42 WB Klonselektion der $\operatorname{PrP}^{0 / 0}$ Zelllinie Im WB sind die verschiedenen $\mathrm{PrP}^{0 / 0}$ Klone mit dem mAk-mix detektiert und gezeigt worden bei 1) PrP LHABT, 2) C1 Tet-, 3) C1 Tet+, 4) C4 Tet- und 5) C4 Tet+.

Da die $\operatorname{PrP}^{0 / 0}$ Zelllinie kein $\operatorname{PrP}^{\mathrm{C}}$ exprimiert, wurden Zellklone, die eine Basisexpression nur durch den regulierbaren Promotor, aufwiesen selektiert. Dabei zeigte sich, dass der C1 Klon eine geringere Basisexpression aufwies als der C4 Klon. Aus diesem Grund wurde dieser Klon für alle weiteren Experimente verwendet und alle Experimente wurden stellvertretend an ihm durchgeführt. Dazu gehörte unter anderem die Bestimmung des $\operatorname{PrP}^{\mathrm{C}}$ Detektionsminimums, die Abhängigkeit der $\operatorname{PrP}^{\mathrm{C}}$ Expression von der Zeit sowie von der TetKonzentration. 


\subsubsection{Detektionsminimum der $\operatorname{PrP}^{\mathrm{C}}$ Expression im WB}

Zur Bestimmung des $\operatorname{PrP}^{\mathrm{C}}$ Detektionsminimums in der Zellkultur wurde der C1 Klon ohne Tet kultiviert. Anschließend wurden die Zellen lysiert und der proteinhaltige Überstand durch den mAk-mix im WB detektiert, dargestellt in der Abb. 43.

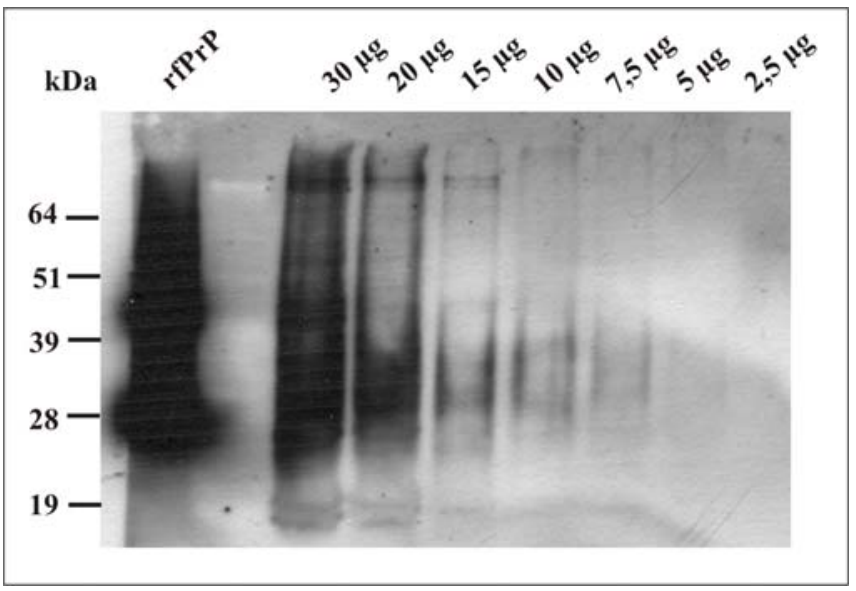

Abb. $43 \operatorname{PrP}^{\mathrm{C}}$ Detektionsminimum des C1 Klons Die $\operatorname{PrP}^{\mathrm{C}}$ Detektion durch mAk-mix wird bei 30, 20, 15, 10, 7,5, 5 und 2,5 $\mu$ g Gesamtproteinmenge im WB gezeigt.

Das $\operatorname{PrP}^{\mathrm{C}}$ konnte in dem C1 Klon bis zu einer Detektionsgrenze von 7,5 $\mu \mathrm{g}$ Gesamtproteinmenge nachgewiesen werden. Zwar sind schemenhafte Banden auch bei geringeren Konzentrationen zu erkennen, allerdings sind diese zu schwach ausgeprägt um für eine genaue Detektion verwendet werden zu können. Für weitere Detektionen wurden deshalb jeweils $30 \mu$ g Gesamtprotein nach der Lyse mit dem E1A-Puffer pro SDS-PAGE-Geltasche eingesetzt, da bei dieser Konzentration alle drei Glykosylierungsstufen des $\operatorname{PrP}^{\mathrm{C}}$ gut zu erkennen waren.

\subsubsection{Tet-Abhängigkeit der $\operatorname{PrP}^{\mathrm{C}}$ Expression}

Da die $\operatorname{PrP}^{\mathrm{C}}$ Expression durch einen Tet abhängigen Promotor unterdrückt wird, wurde die dazu notwendige Tet-Konzentration bestimmt. Dazu wurden 1 × $10^{6}$ Zellen mit verschiedenen Tet-Konzentrationen für 3 Tage kultiviert. Anschließend wurden die Zellen lysiert und jeweils $30 \mu \mathrm{g}$ Gesamtproteinmenge auf ein SDS-PAGE-Gel aufgetragen und im WB mit dem mAkmix detektiert, dargestellt in der Abb. 44. 


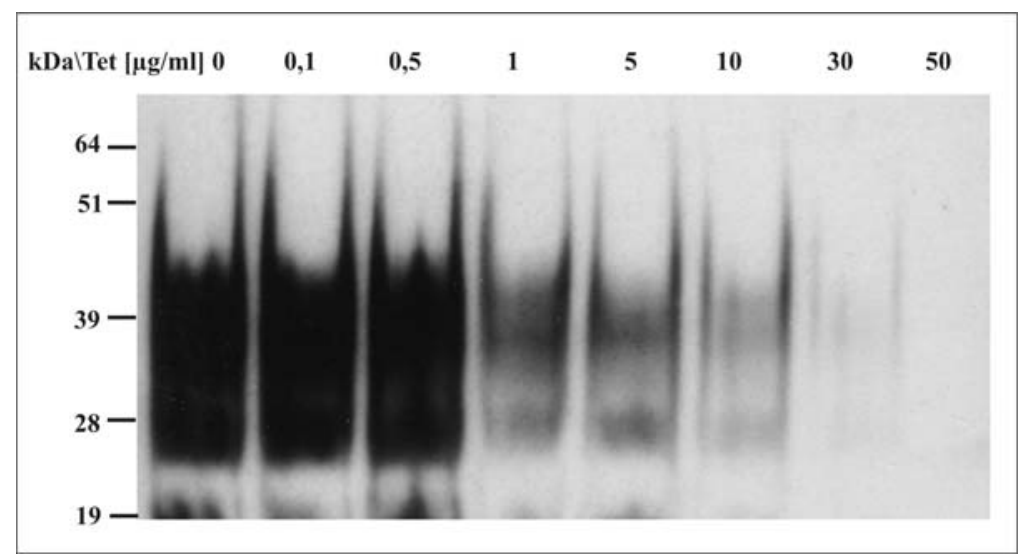

Abb. 44 Tet-Abhängigkeit des C1 Klons Der C1 Klon wurde 3 Tage mit $0,0,1,0,5,1,5,10,30$ und $50 \mu \mathrm{g} / \mathrm{ml}$ Tet kultiviert und im WB mit dem mAk-mix detektiert.

Aus der Abb. 44 ist erkennbar, dass bei einer Tet-Konzentration von $1 \mu \mathrm{g} / \mathrm{ml}$ die $\operatorname{PrP}{ }^{\mathrm{C}}$ Expression abnahm. Ab einer Konzentration von $30 \mu \mathrm{g} / \mathrm{ml}$ wurde die Expression vollständig unterdrückt. Deshalb wurde für die Suppression der Expression in den weiteren Experimenten eine Konzentration von $30 \mu \mathrm{g} / \mathrm{ml}$ Tet verwendet.

\subsubsection{Zeitabhängigkeit der $\operatorname{PrP}^{\mathrm{C}}$ Expression}

Nach der Bestimmung der Konzentrationsabhängigkeit, wurde die Zeitabhängigkeit der $\operatorname{PrP}{ }^{\mathrm{C}}$ Expression nach Tet-Zugabe bestimmt. Dazu wurden Zellkulturflaschen mit 1 x $10^{6}$ Zellen angeimpft und mit $30 \mu \mathrm{g} / \mathrm{ml}$ Tet kultiviert. Anschließend wurden in Intervallen von $12 \mathrm{~h}$ jeweils die Zellen lysiert und durch einen mAk-mix im WB analysiert. Die Zeitabhängigkeit der $\operatorname{PrP}^{\mathrm{C}}$ Expression ist in der Abb. 45 dargestellt.

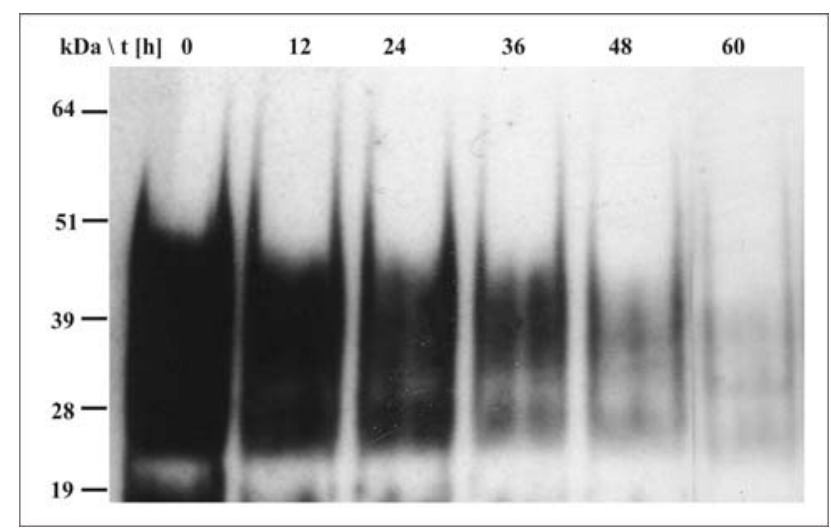

Abb. 45 Zeitabhängige $\operatorname{PrP}^{\mathrm{C}}$ Expression des C1 Klons Der C1 Klon wurde mit $30 \mu \mathrm{g} / \mathrm{ml}$ Tet kultiviert und die $\mathrm{PrP}^{\mathrm{C}}$ Expression nach 0, 12, 24, 36, 48 und $60 \mathrm{~min}$ im WB durch den mAk-mix detektiert. 
Aus der Abb. 45 ist erkennbar, dass die $\mathrm{PrP}^{\mathrm{C}}$ Expression nach $24 \mathrm{~h}$ abgenommen hatte und nach weiteren 24 h nur noch schwach detektierbar war. Nach einer Kultivierungsdauer von insgesamt 48 h sank die Expressionsintensität nicht mehr. Die restliche Detektion kann durch die Basisexpression des Tet-Promotors erklärt werden, sowie durch das $\operatorname{PrP}^{\mathrm{C}}$, das vor der TetKultivierung gebildet wurde. Durch das weitere Wachstum der Zellen wird danach nur noch das vorhandene $\operatorname{PrP}^{\mathrm{C}}$ verdünnt. Dieses kann noch nach weiteren 12 h detektiert werden.

Nach der Bestimmung der Zeitabhängigkeit und der Tet-Konzentration der $\operatorname{PrP}^{\mathrm{C}}$ Expression am Beispiel des C1 Klons, wurden diese Kultivierungszeiten für die Klone der anderen beiden Zelllinien N2a und 3T3 übernommen.

\subsection{4 $\operatorname{PrP}^{\mathrm{C}}$ Detektion in Zelllinien mit endogener $\operatorname{PrP}^{\mathrm{C}}$ Expression}

Die Klone der Zelllinien N2a und 3T3 besitzen jeweils ein endogenes $\operatorname{PrP}^{\mathrm{C}}$, welches nach der Transfektion mit dem $\operatorname{PrP}^{\mathrm{C}}$ exprimierenden Vektor ebenfalls detektiert wurde. Zum besseren Vergleich der Zellen miteinander wurden die N2a und 3T3 Zellklone mit denselben Bedingungen wie die $\operatorname{PrP}^{0 / 0}$ Zellen kultiviert. Die Zellklone wurden mit $30 \mu \mathrm{g} / \mathrm{ml}$ Tet für 2 Tage kultiviert und anschließend lysiert. $30 \mu \mathrm{g}$ des Proteingemisches wurden jeweils in eine Geltasche des SDS-PAGE-Gel gegeben und die $\operatorname{PrP}^{\mathrm{C}}$ Expression im WB durch einen mAkmix detektiert, dargestellt in der Abb. 46 und Abb. 47.

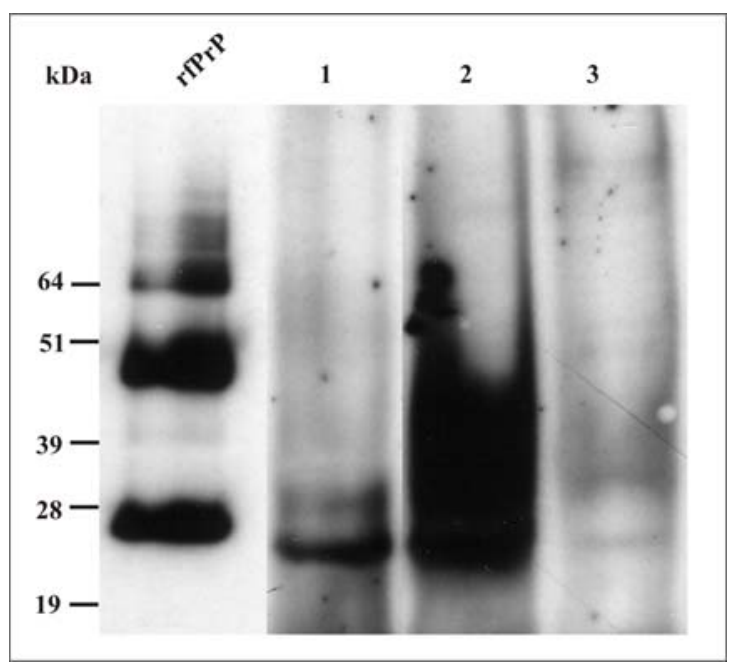

Abb. 46 WB des selektierten Klons der 3T3 Zelllinie Mit 1) 3T3 LHABT, 2) B4 Tet- und 3) B4 Tet+.



Abb. 47 WB des selektierten Klons der N2a Zelllinie Mit 1) N2a LHABT, 2) H7 Tet+ und 3) H7 Tet-

Bei den hier gezeigten Klonen exprimiert die N2a Zelllinie das humane $\operatorname{PrP}^{\mathrm{C}}$ und die 3T3 Zelllinie das bovine $\operatorname{PrP}^{\mathrm{C}}$ neben dem zelleigenen $\operatorname{PrP}^{\mathrm{C}}$. Beide Expressionen konnten durch Tet 
gesenkt werden. Das restliche detektierte $\operatorname{PrP}^{\mathrm{C}}$, ist durch die Basisexpression des TetPromotors und durch das wirtseigene $\operatorname{PrP}^{\mathrm{C}}$ zu erklären. Welches $\operatorname{PrP}^{\mathrm{C}}$ detektiert wurde, konnte allerdings nicht bestimmt werden, da die eingesetzten anti-PrP Ak nicht speziesspezifisch sind und Kreuzreaktionen mit dem $\operatorname{PrP}^{\mathrm{C}}$ von Mensch, Rind und Maus durchführten.

\subsection{Immunfluoreszenzanalyse der $\operatorname{PrP}^{\mathrm{C}}$ Expression}

Nach der Detektion des $\operatorname{PrP}^{\mathrm{C}}$ im WB wurde ein Klon von jeder Zelllinie mit und ohne Tet auf einem Deckgläschen in einer Zellkulturschale für 2 Tage kultiviert. Anschließend wurden die Zellen für eine Immunfluoreszenzmikroskopie aufgearbeitet (siehe 2.4.19). Die Aufnahmen dieser Mikroskopie sind in der Abb. 48 dargestellt. Alle untersuchten Zellklone besaßen eine Eigenfluoreszenz. Diese war nicht von der Immunfluoreszenz der jeweiligen Zellklone nach der Tet-Kultivierung zu unterscheiden und wurde deshalb hier nicht dargestellt. Die Immunfluoreszenz konnte bei den Zellklonen nur im Zytoplasma detektiert werden, da auf der Membranoberfläche keine Ak gebunden hatten.

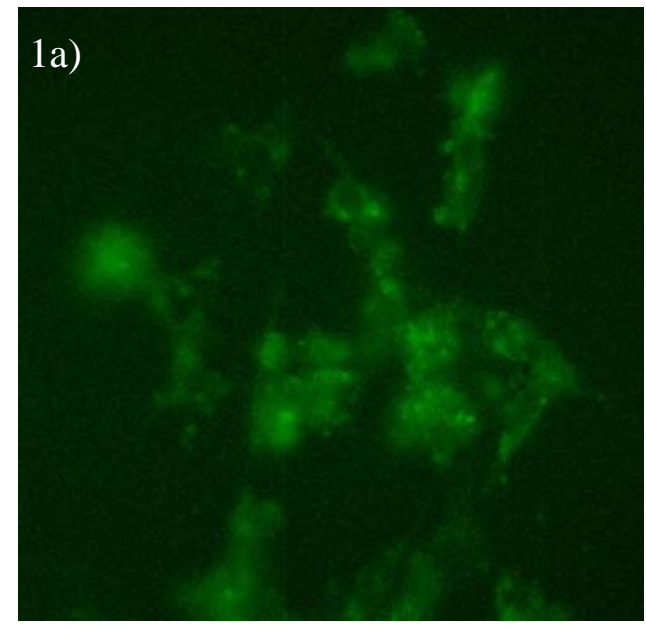

2a)

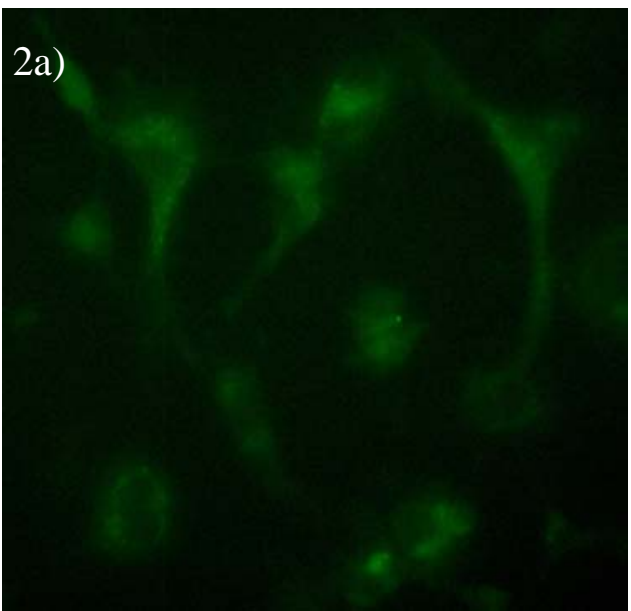

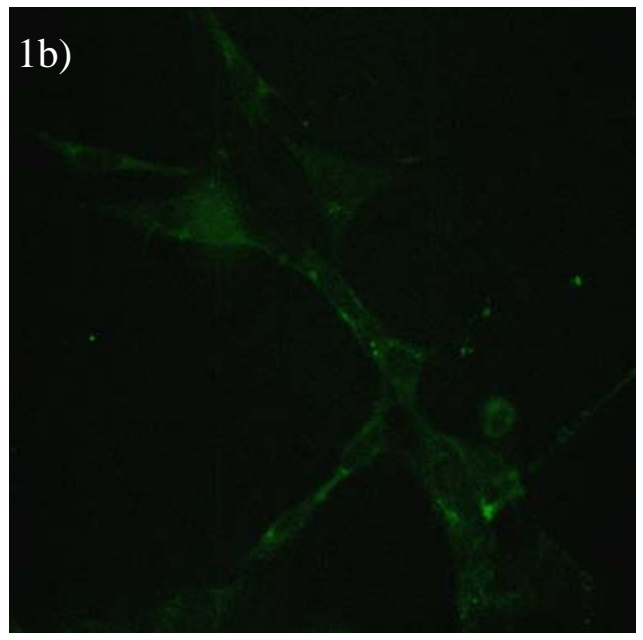

2b)

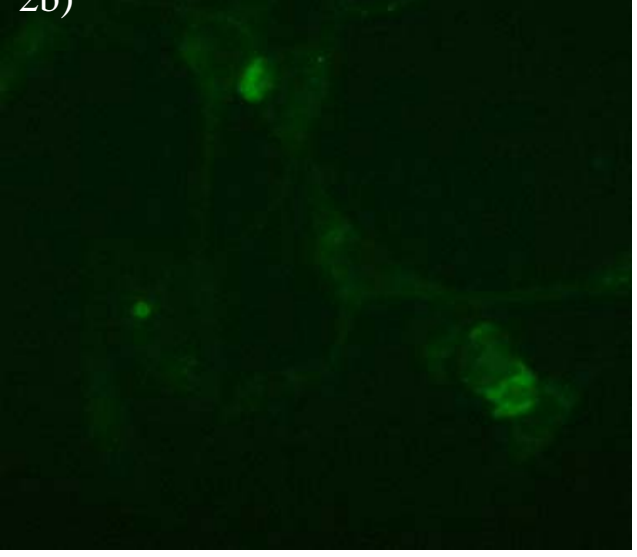





Abb. 48 Immunfluoreszenzmikroskopie der verschiedenen $\operatorname{PrP}^{\mathrm{C}}$ exprimierenden Zellklone Dargestellt ist die zytoplasmatische Detektion eines FITC gekoppelten Ziege anti-Maus Ak, der mit dem mAk-mix reagierte. Nach einer Anregung mit $488 \mathrm{~nm}$ wurde eine Emission bei $530 \mathrm{~nm}$ beobachtet bei 1) C1, 2) B4 und 3) H7. Die Zellen in a) wurden ohne Tet kultiviert und die Zellen in b) wurden jeweils mit $30 \mu \mathrm{g} / \mathrm{ml}$ Tet kultiviert.

Aus den Aufnahmen der Immunfluoreszenzmikroskopie ist erkennbar, dass bei allen Zellen eine Fluoreszenzreaktion stattgefunden hatte und das $\operatorname{PrP}^{\mathrm{C}}$ in jeder Zelle detektiert werden konnte. Der eingesetzte Primärantikörpermix in der Immunfluoreszenzmikroskopie band sich an das $\operatorname{PrP}^{\mathrm{C}}$ und ein FITC gekoppelter Sekundärantikörper reagierte mit diesem. Nach einer Anregung mit einer Wellenlänge von 488 nm kam es zu einer Emission bei 530 nm.

Diese Fluoreszenz wurde jeweils bei den Zellklonen mit und ohne Tet-Inkubation beobachtet. Bei den Zellklonen ohne Tet war eine deutliche Fluoreszenz als Reaktion auf die Anregung zu erkennen. Die Kultivierung mit Tet zeigte zwar eine Fluoreszenzreaktion, diese war aber wesentlich schwächer. Diese Fluoreszenz war auf die Eigenfluoreszenz der Zelle, die nicht unterdrückte Basisexpression des $\mathrm{PrP}^{\mathrm{C}}$ und durch unspezifische Bindungen des Primärantikörpers an andere Proteine in der Zelle, zurückzuführen. Trotz dieser Fluoreszenz konnte die Immunfluoreszenzmikroskopie verwendet werden, um die $\operatorname{PrP}^{\mathrm{C}}$ Expression in den Zellen zu beobachten, da sie geringer im Vergleich zur nicht unterdrückten Expression ist. Die deutlichste Unterscheidung der Regulation in der $\operatorname{PrP}^{\mathrm{C}}$ Expression in der Zelle wurde beim $\mathrm{PrP}^{0 / 0}$ - und beim N2a Zellklon beobachtet. Bei dem 3T3 Zellklon dagegen war eine Unterscheidung wesentlich schwerer, da die Unterschiede mit und ohne Tet nur gering waren. 


\subsection{FACS Analyse der $\operatorname{PrP}^{\mathrm{C}}$ Expression}

Da eine Immunfluoreszenzmikroskopie von allen Zellklonen möglich war, konnte die Expression des $\mathrm{PrP}^{\mathrm{C}}$ auch durch die FACS Analyse bestimmt werden. Dazu wurden jeweils 1 x $10^{6}$ Zellen aufgearbeitet (siehe 2.4.21). Zur Detektion der Fluoreszenz im FACS (LSR II) wurden die gleichen Ak wie bei der Immunfluoreszenzmikroskopie eingesetzt. Untersucht wurden dabei sowohl die jeweiligen $\operatorname{PrP}^{\mathrm{C}}$ exprimierenden Zellklone mit und ohne Tet als auch die Zellklone aus denen diese doppelt stabilen Zellen hervorgegangen waren. In der Abb. 49 sind die Ergebnisse der FACS Analyse dargestellt.
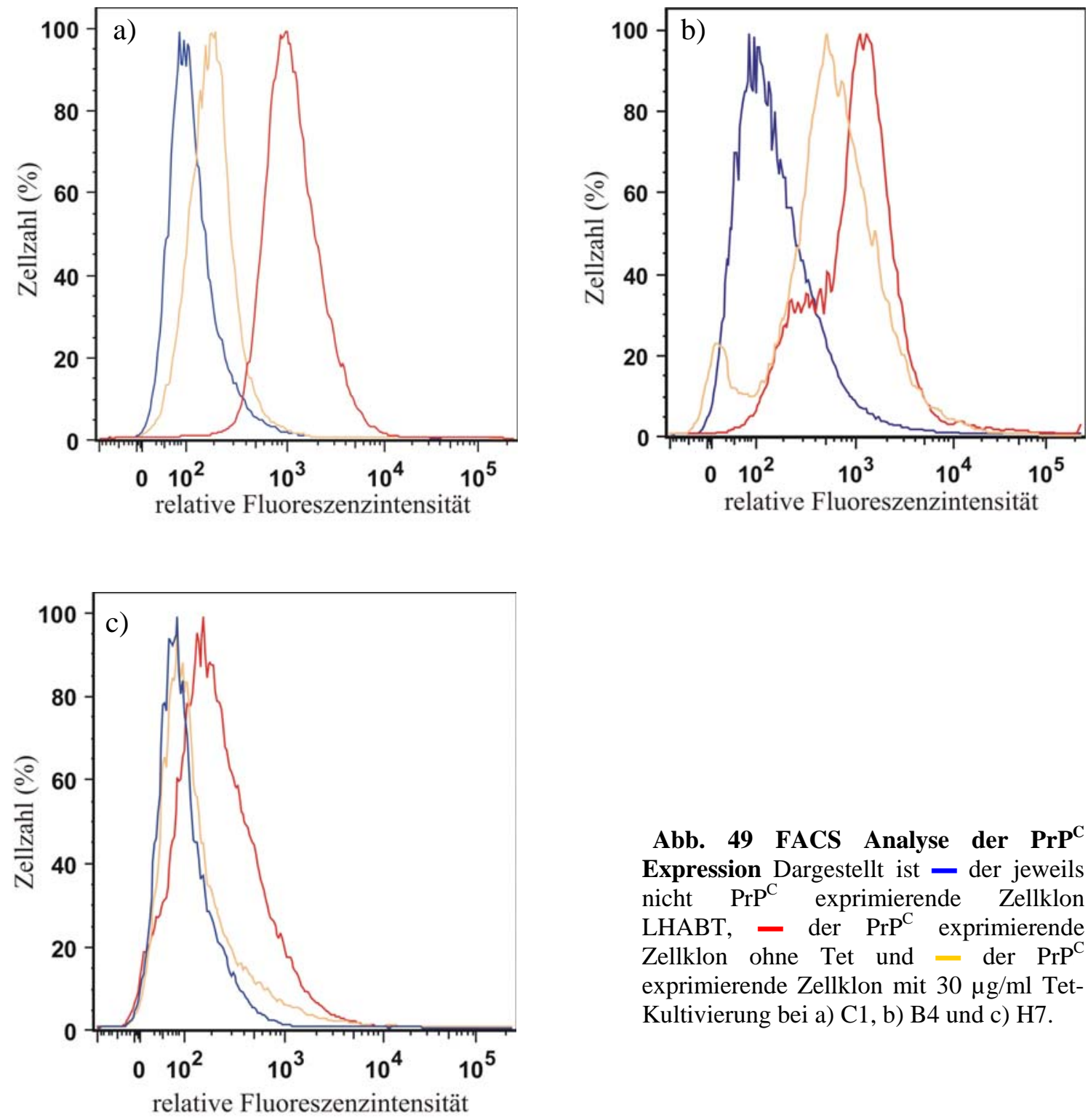

Abb. 49 FACS Analyse der $\operatorname{PrP}^{\mathrm{C}}$ Expression Dargestellt ist - der jeweils nicht $\operatorname{PrP}^{\mathrm{C}}$ exprimierende Zellklon LHABT, - der $\operatorname{PrP}^{\mathrm{C}}$ exprimierende Zellklon ohne Tet und - der $\operatorname{PrP}^{\mathrm{C}}$ exprimierende Zellklon mit $30 \mu \mathrm{g} / \mathrm{ml}$ TetKultivierung bei a) C1, b) B4 und c) H7.

Aus den FACS Messungen ist erkennbar, dass sich das $\operatorname{PrP}^{\mathrm{C}}$ in den verschiedenen Zelllinien nachweisen ließ. Ebenso, dass sich bei allen drei Zelllinien die $\operatorname{PrP}^{\mathrm{C}}$ Expression im jeweiligen 
Zellklon an- und abstellen ließ. Die dabei auftretenden Unterschiede zwischen den Zellklonen mit und ohne exprimiertem $\operatorname{PrP}^{\mathrm{C}}$ waren immer signifikant. Der Unterschied der doppelt stabilen regulierbaren $\operatorname{PrP}^{\mathrm{C}}$ exprimierenden Zellen $\mathrm{zu}$ dem Zellklon aus dem diese hervorgegangen waren, ist ebenfalls gut zu sehen.

Besonders deutlich war die Regulation der Expression durch Tet in dem $\operatorname{PrP}^{0 / 0}$ Zellklon zu erkennen. Bei diesem war der deutlichste Fluoreszenzunterschied zwischen den Zellen mit und ohne Tet-Kultivierung zu sehen. Hierbei wurde eine Differenz von einer Zehnerpotenz detektiert. Wurde dieser Zellklon mit Tet kultiviert, war die Fluoreszenzintensität fast gleich dem nicht $\operatorname{PrP}^{\mathrm{C}}$ exprimierenden $\operatorname{PrP}$ LHABT Zellklon. Die gezeigte Fluoreszenz war nur leicht erhöht, verursacht wurde dies durch die Basisexpression des Tet-Promotors.

Bei den 3T3 Zellen war eine Unterscheidung des $\operatorname{PrP}^{\mathrm{C}}$ exprimierenden Klons mit und ohne Tet-Kultivierung zum nicht exprimierenden Klon möglich. Die Fluoreszenzintensität unterschied sich zwischen der $\operatorname{PrP}^{\mathrm{C}}$ Expression und dem Klon ohne diese Expression wieder um eine Zehnerpotenz. Bei der Kultivierung mit Tet war eine wesentlich höhere Basisexpression festzustellen. Trotzdem war eine Differenzierung zur Kultivierung ohne Tet gut möglich, da diese beiden Zustände des Zellklons sich deutlich voneinander abhoben.

Bei dem N2a Zellklon war die Unterscheidung schwieriger, es zeigte sich hier nur eine 2 bis 3-fach höhere Fluoreszenz bei dem $\operatorname{PrP}^{\mathrm{C}}$ exprimierenden Zellen ohne Tet im Verhältnis zu den Ursprungszellen. Wurden die $\operatorname{PrP}^{\mathrm{C}}$ exprimierenden Zellen mit Tet kultiviert, waren keine Unterschiede zu den N2a LHABT Zellen zu sehen. Aufgrund der hier gezeigten Intensitätsunterschiede war eine Differenzierung der Zellen möglich, aber wesentlich schwieriger als bei den anderen beiden Zelllinien.

Durch die verschiedenen Fluoreszenzen konnten alle $\operatorname{PrP}^{\mathrm{C}}$ exprimierenden Zellklone ohne Tet-Kultivierung von ihren ursprünglichen Zellen abgegrenzt werden. Auch konnten die Unterschiede mit und ohne Tet-Inkubation bei allen Zellen gezeigt werden. Aus diesem Grund ist die FACS Analyse bei der weniger Zellen benötigt wurden als beim WB, besser geeignet zur schnellen Differenzierung und Selektion transfizierter gegenüber nicht transfizierter Zellen.

\subsection{Sekundärstrukturanalyse durch die CD-Spektroskopie}

Mit Hilfe der CD-Spektroskopie kann die Sekundärstruktur von Proteinen untersucht werden. Da es bei TSE-Erkrankungen zu einer Konformationsänderung des Prion Proteins kommt, ist es möglich, das $\operatorname{PrP}^{\mathrm{C}}$ und $\operatorname{PrP}^{\mathrm{Sc}}$ anhand der Sekundärstruktur zu differenzieren. Weil sich beide Isoformen in der Fähigkeit Kupfer zu binden unterscheiden, konnte eine IMAC 
durchgeführt werden um diese zu trennen. In den IMAC-Fraktionen waren neben dem $\operatorname{PrP} \mathrm{P}^{\mathrm{C}}$ oder $\mathrm{PrP}^{\mathrm{Sc}}$ noch weitere Proteine enthalten. Daher wurden diese Fraktionen zunächst bei der $\operatorname{PrP}^{0 / 0}$ Zelllinie und dem C1 Zellklon untersucht, um zu prüfen, ob eine Unterscheidung der Sekundärstruktur prinzipiell möglich war. Da lediglich die $\operatorname{PrP}^{0 / 0}$ Zellen kein endogenes $\operatorname{PrP}$ aufwiesen, wurden nur die Proteinextrakte dieser Zelllinie und deren transfizierte Klone mittels CD-Spektroskopie untersucht, weil bei dieser Zelllinie sichergestellt war, dass nur das transfizierte $\operatorname{PrP}^{\mathrm{C}}$ detektiert wurde.

Für diese Analyse wurden die Zellen mit dem E1A-Puffer lysiert. Anschließend wurde der Proteinüberstand solubilisiert (siehe 2.4.17) und durch eine IMAC in verschiedene Fraktionen aufgetrennt (siehe 2.4.16). Nach der Konzentrationsbestimmung der verschiedenen IMACFraktionen wurden jeweils $30 \mu \mathrm{g}$ auf ein SDS-PAGE-Gel aufgetragen, geblottet und mit dem ECL-System detektiert, dargestellt in der Abb. 50. Da die Kupferionen in der Elutionsfraktion die CD-Spektroskopie störten, wurden diese durch eine anschließende Dialyse entfernt (siehe 2.1.11). Die jeweiligen Vergleichsfraktionen zwischen dem C1 Zellklon und dem $\operatorname{PrP}$ LHABT Zellklon wurden anschließend mittels CD-Spektroskopie untersucht. Hierbei wurde der PrP LHABT Zellklon statt der $\operatorname{PrP}^{0 / 0}$ Zelllinie verwendet, da er ebenfalls das tTA-Element besitzt und dem C1 Klon somit ähnlicher ist.

Für die CD-Spektroskopie wurde jeweils $1 \mathrm{mg}$ der jeweiligen Proteinfraktion verwendet. Die Proteine wurden in CD-Puffer $(10 \mathrm{mM}$ Tris, $100 \mathrm{mM} \mathrm{KCl,} 320 \mathrm{mM}$ Saccharose, $10 \%$ Glycerin, 0,01 \% (v/v) NP40, pH 7,5) resuspendiert und in einer $1 \mathrm{~mm}$ Küvette gemessen. Die Resultate sind in der Abb. 51 dargestellt.



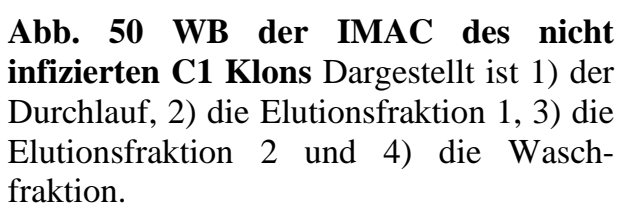
fraktion.

Aus den IMAC-Fraktionen war zu erkennen, dass im Durchlauf kein detektierbares PrP gefunden wurde. Dieses wurde nur in der Elutionsfraktion 1 in großen und in der Elutionsfraktion 2 in kleineren Mengen gefunden. 
Bei der Waschfraktion war keine definierte Bande zu erkennen, sondern nur ein Proteinschmier. Die verschiedenen Fraktionen wurden anschließend dialysiert und danach lyophillisiert. Ein Milligramm dieser Proteinlyophillisate wurde für die anschließende CDSpektroskopie eingesetzt. Da die Proteinprobe neben dem $\operatorname{PrP}^{\mathrm{C}}$ auch andere Proteine enthält, wurde neben der herkömmlichen Darstellung von $[\Theta]_{\mathrm{MRW}}$ (,,mean residue weight“) auch eine Auswertung in Bezug auf die Gesamtproteinkonzentration in mg/ml durchgeführt.
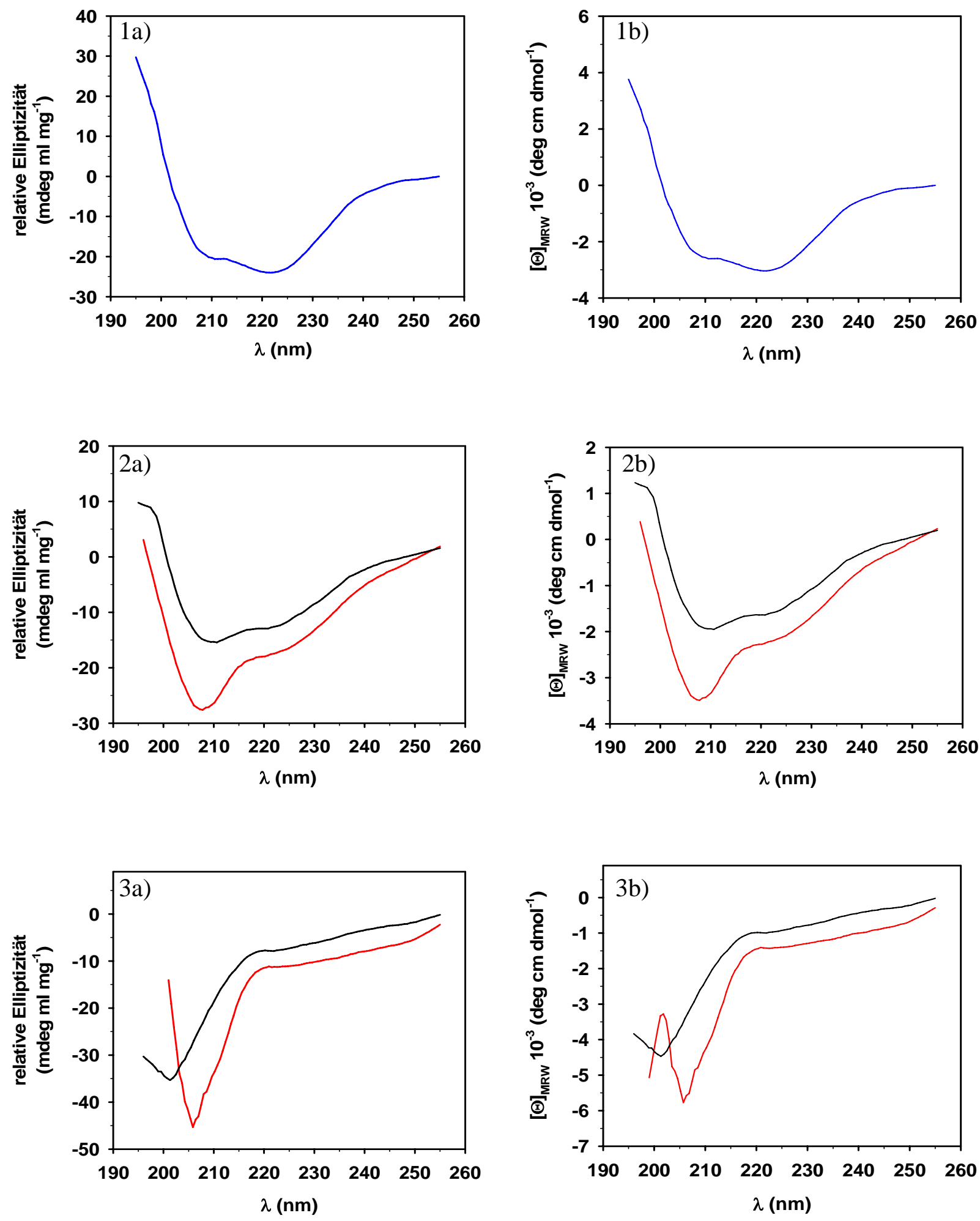



Abb. 51 CD-Spektren der IMAC-Proben Dargestellt ist bei 1) das rfPrP, 2) die Elutionsfraktion 1, 3) die Elutionfraktion 2 und 4) der Waschfraktion jeweils bezogen auf (a) die relative Elliptizität des Proteingemischs und (b) den $[\Theta]_{\mathrm{MRW}}$ Wert, bezogen auf das Prion Protein, dies ist sowohl bei dem $-\mathrm{C}$, bei dem PrP LHABT Zellklon und dem — rfPrP dargestellt.

Aus der Abb. 51 ist ersichtlich, dass das rfPrP eine deutlich helikale Struktur aufwies, die als Vergleichswert für die anderen Proteinproben verwendet werden konnte. In der Elutionsfraktion 1 zeigte der C1 Klon ein deutliches Helix-Signal im Vergleich zum PrP LHABT Zellklon. Das ist darauf zurückzuführen, dass in der C1 Probe neben den anderen Proteinen das helikale $\operatorname{PrP}^{\mathrm{C}}$ gemessen wurde. Da $\operatorname{PrP}^{\mathrm{C}}$ nicht im PrP LHABT Zellklon exprimiert wurde, wies dessen Proteinsignal auch wesentlich weniger helikale Strukturen auf (Abb. 51.2a und b). In der Elutionsfraktion 2 war der Unterschied zwischen den beiden Signalen schon nicht mehr so stark ausgeprägt (Abb. 51.3a und b). Dies kann mit dem in dieser Fraktion deutlich erhöhten Anteil denaturierten Proteins, erkennbar an dem starken negativen Signal bei ca. 200 nm, erklärt werden.

In der IMAC-Waschfraktion zeigen sich ähnliche Sekundärstrukturanteile in den beiden Proben, dass deutete darauf hin, dass kein helikales $\operatorname{PrP}^{\mathrm{C}}$ in dieser Fraktion vorhanden war. Das wurde auch durch den WB der IMAC-Fraktion bestätigt. Also mussten die CDspektroskopisch gefundenen Unterschiede auf den Signalen anderer Proteine beruhen.

Die CD-Spektren der verschiedenen IMAC-Fraktionen zeigten, dass es möglich war, die verschiedenen Klone mit und ohne $\mathrm{PrP}^{\mathrm{C}}$ Expression voneinander zu unterscheiden. Somit sollte es auch möglich sein, eine Konformationsänderung des $\operatorname{PrP}^{\mathrm{C}}$ nach einer TSE-Infektion in der Zellkultur mit dieser Methode zu unterscheiden. 


\section{K.9- und Überexpression von Proteinen in einem reguliert $\operatorname{PrP}^{\mathrm{C}}$ exprimierenden $\operatorname{PrP}^{0 / 0}$ Zellklon}

Zur Analyse von neben dem $\mathrm{PrP}^{\mathrm{C}}$ ko- oder überexprimierten Proteinen wurde eine 2D-Analyse vom C1 Zellklon und dem $\operatorname{PrP}^{0 / 0}$ LHABT Zellklon durchgeführt. Dazu wurden $1 \times 10^{6}$ Zellen lysiert und zentrifugiert. Der Überstand des Zelllysats wurde für diese Untersuchungen verwendet. Er enthielt durch den Lysepuffer zu viele Salze, die durch eine Dialyse entfernt werden mussten (siehe 2.1.11), da sie die Proteinauftrennung in der ersten Dimension störten. Für die isoelektrische Fokussierung (IEF) wurden $200 \mu$ g des gereinigten Zellüberstandes verwendet (siehe 2.4.22). Nachdem die Gele die zweite Dimension durchlaufen hatten, wurden sie durch Coomassie-Blau angefärbt. Die Gele wurden miteinander verglichen, die Spots die stärker ausgeprägt und neu dazugekommen waren, wurden ausgestochen und in einer MS Analyse identifiziert durch Dr. Olaf Jahn am MPI für experimentelle Medizin in Göttingen. Zur eindeutigen Identifizierung der Proteine wurden jeweils 5 Strips von jedem Zelllysat für die IEF aufbereitet und anschließend auf 2D-Gelen analysiert. Ein Beispiel für die Koexpression von Proteinen neben der $\operatorname{PrP}^{\mathrm{C}}$ Expression ist in der Abb. 52 durch die 2D-Bilder des C1 und PrP LHABT Klons dargestellt. Die durch die Massenspektrometrie identifizierten potenziellen Proteine für die Ko- oder Überexprimierung, wurden zusammengefasst in der Tab. 11 dargestellt.
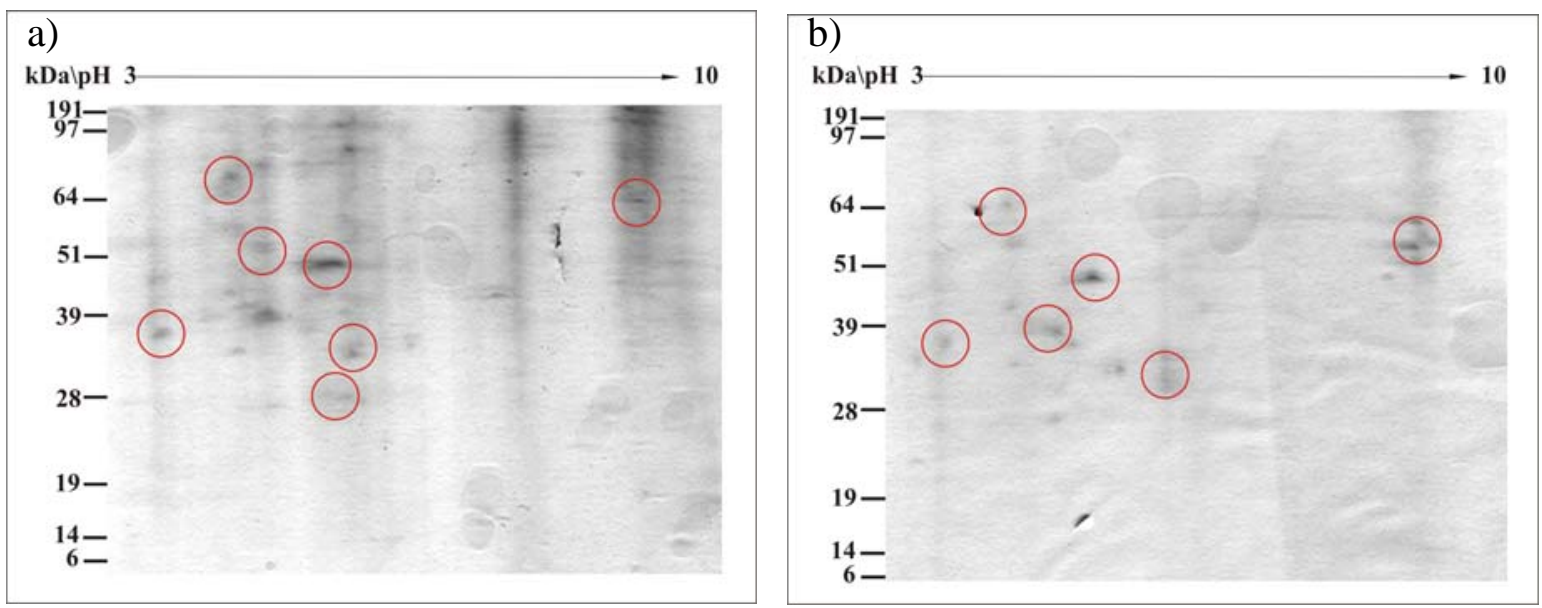

Abb. 52 2D-Gel der PrP ${ }^{0 / 0}$ Zellklone Beispiel für die zwei Zustände der Zellen bei a) C1 Zellklon mit PrP Expression und b) PrP LHABT Zellklon ohne $\operatorname{PrP}^{\mathrm{C}}$ Expression. 
Tab. 11 Zusammenfassung der identifizierten potenziellen Proteine aus der MS

\begin{tabular}{|c|c|c|c|}
\hline Protein & $\begin{array}{c}\text { Entrezeintrag } \\
\text { am NCBI }\end{array}$ & Analysemethode & $\begin{array}{l}\text { Wahrscheinlichkeit } \\
\text { der Identifizierung }\end{array}$ \\
\hline Coffin & gi 37194891 & MS/MS & sehr hoch \\
\hline Cu/Zn Superoxiddismutase & gi 226471 & MS/MS & sehr hoch \\
\hline Stathmin 1 & gi 14625464 & MS/MS & sehr hoch \\
\hline $\begin{array}{c}\text { Putative Nukleotid-Zucker- } \\
\text { Dehydrogenase }\end{array}$ & gi 19747796 & MS/MS & gering \\
\hline Lectin & gi 6678682 & MS/MS & sehr hoch \\
\hline Cholesteroloxidase & gi 24216708 & MS/MS & gering \\
\hline Calcyclin & gi 14789726 & MS/MS & gering \\
\hline Glykoprotein B & gi 4456251 & MS/MS & gering \\
\hline eingehülltes Glykoprotein & gi 6469561 & MS/MS & gering \\
\hline Enolase 1 & gi 54673814 & Fingerprint & sehr hoch \\
\hline Aldolase 1 & gi 27695278 & MS/MS & sehr hoch \\
\hline Zwei-Komponentenregulatorprotein & gi 17742346 & MS/MS & hoch \\
\hline Peroxiredoxin 6 & gi 6671549 & MS/MS & sehr hoch \\
\hline Tropomyosin 4 & gi 47682809 & MS/MS & sehr hoch \\
\hline Cc2d1a Protein & gi 20988947 & MS/MS & gering \\
\hline Acyl-Coenzym A Dehydrogenase & gi 16740777 & Fingerprint & gering \\
\hline Morc4 Protein & gi 68534224 & MS/MS & gering \\
\hline Stress-induziertes Phosphoprotein 1 & gi 14389431 & MS/MS & sehr hoch \\
\hline Profilin 1 & gi 56206029 & MS/MS & hoch \\
\hline mKIAA0357 Protein & gi 28972169 & MS/MS & hoch \\
\hline Hspd-1 Protein & gi 76779273 & MS/MS & sehr hoch \\
\hline $\begin{array}{c}\text { Voltabhängiges selektives } \\
\text { Anionkanalprotein } 1\end{array}$ & gi 10720404 & MS/MS & sehr hoch \\
\hline
\end{tabular}

Bei der Identifizierung wurden auch Proteine mit einer geringeren Wahrscheinlichkeit detektiert, dass lag daran, dass unter den identifizierten Proteinen noch weitere Proteine vorhanden waren. Besonderes häufig waren dies die Hitzeschockproteine. 


\subsection{Infektion der stabil $\operatorname{PrP}^{\mathrm{C}}$ exprimierenden Zelllinien}

Die Infektion der Zelllinien und Zellklone erfolgte nach einem abgewandelten Protokoll von S. Lehmann, 2005. Alle Zellen wurden dazu im S2 Bereich angezogen und gegebenenfalls mit Tet präkultiviert. Die Infektion und weitere Anzucht sowie die Analyse der Zellen erfolgte dann im S3 Bereich, da aufgrund der biologischen Sicherheitseinstufung von S3** nur dort mit TSE-Material gearbeitet werden durfte.

Das Schema der Infektion von Zellen mit TSE-Material ist in der Abb. 53 dargestellt. Die Zellen wurden dazu mit und ohne $30 \mu \mathrm{g} / \mathrm{ml}$ Tet kultiviert. Nach 2 Tagen wurden diese Zellen mit 1\%igem (w/v) infektiösem Rinderhirnhomogenat infiziert (siehe 2.4.15). Nach 2 weiteren Tagen wurden die Zellen für die jeweilige Analysemethode aufgearbeitet.

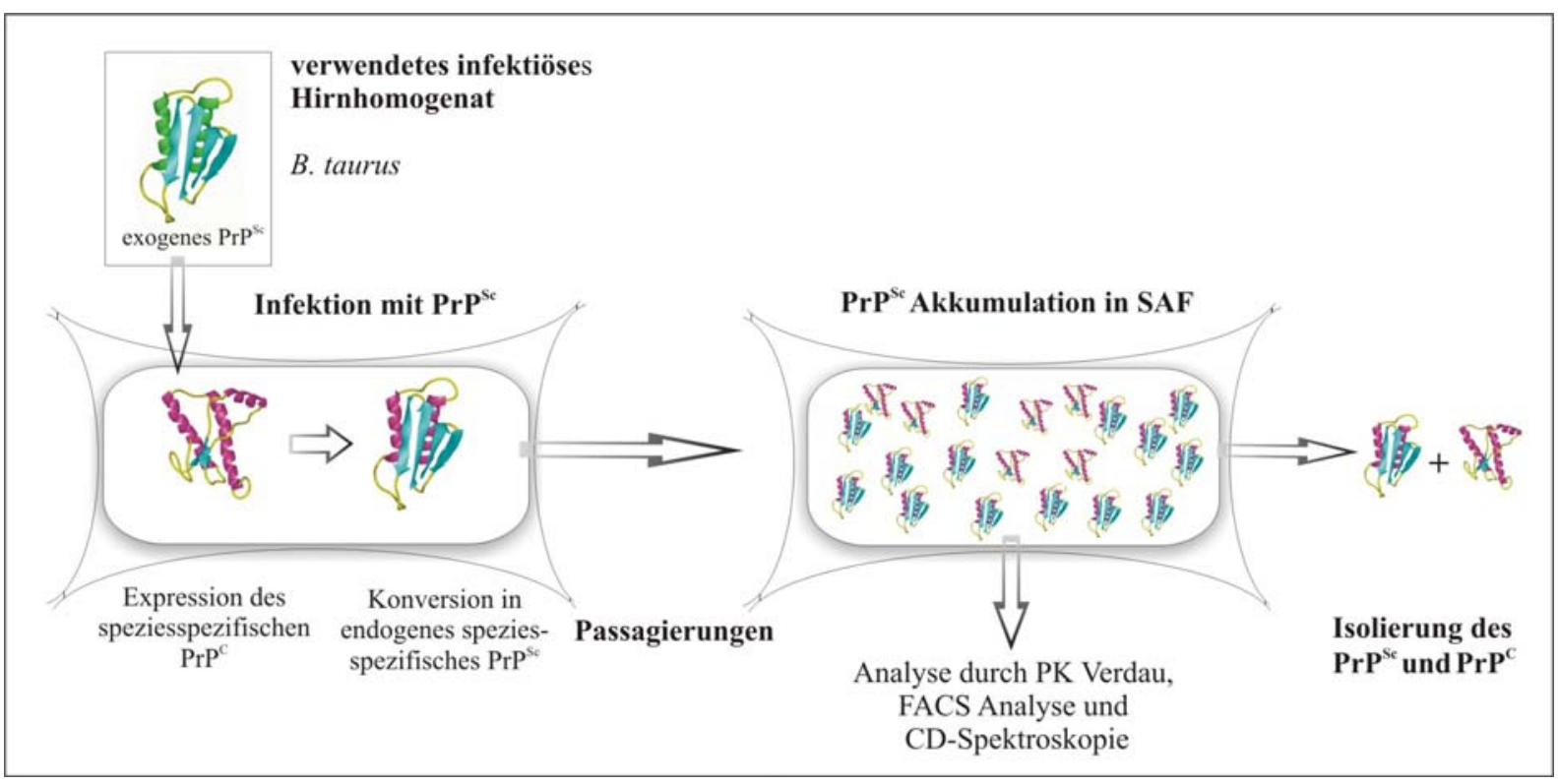

Abb. 53 Infektion einer Zelllinie mit TSE Eine $\operatorname{PrP}^{\mathrm{C}}$ exprimierende Zelllinie wurde mit $\operatorname{PrP}^{\mathrm{Sc}}$ vom Rind infiziert. Dies führte zu einer Konversion des $\operatorname{PrP}^{\mathrm{C}}$ in $\mathrm{PrP}^{\mathrm{Sc}}$ und zu dessen Replikation. Das entstandene $\mathrm{PrP}^{\mathrm{Sc}}$ konnte vom $\operatorname{PrP}^{\mathrm{C}}$ isoliert werden. Es konnte durch den PK Verdau auf dem WB und eine FACS Analyse detektiert werden. Ebenso besteht die Möglichkeit einer Unterscheidung in der CD-Spektroskopie.

\subsection{Etablierung des PK Verdaus}

Nach einem PK Verdau der beiden PrP Isoformen konnte nur noch die degradierte Form des $\operatorname{PrP}^{\mathrm{Sc}}$, das $\operatorname{PrP}^{\text {res }}$, detektiert werden. Hierzu, musste aber zuvor die Abhängigkeit von der Inkubationszeit und der PK-Konzentration bestimmt werden. Diese wurde anhand des infektiösen Rinderhirnhomogenats bestimmt. Die verwendeten Rinderhirnhomogenate 
wurden von infizierten Rindern aus England gewonnen und hatten die Referenznummern 1823 und 1990.

\subsubsection{PK-Konzentrationsabhängigkeit des PK Verdaus}

Zur Bestimmung der optimalen PK-Konzentration zum Nachweis von $\operatorname{PrP}^{\text {res }}$ wurde die Konzentration von 0 bis $500 \mu \mathrm{g} / \mathrm{ml}$ variiert. Dazu wurden $50 \mu \mathrm{g}$ 10\%iges (w/v) infektiöses Rinderhirnhomogenat mit jeweils 0, 10, 20, 100, 200 und $500 \mu \mathrm{g} / \mathrm{ml}$ PK für 60 min inkubiert. Die Reaktion wurde durch Zugabe von 0,1 M PMSF in Isopropanol abgestoppt. Anschließend wurde der Ansatz in LDS-Puffer aufgenommen und auf ein SDS-PAGE-Gel aufgetragen. Die Detektion erfolgte dann im WB, dargestellt in der Abb. 54.

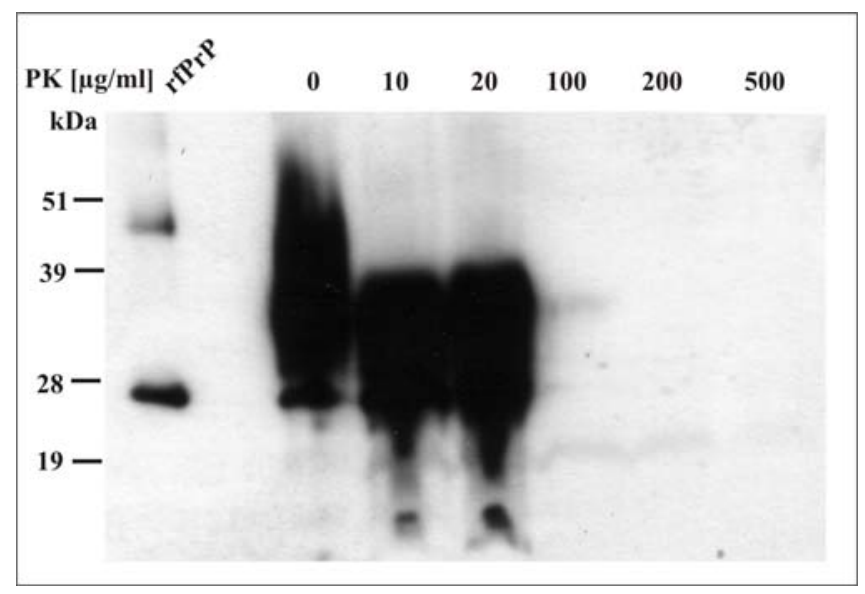

Abb. 54 Detektion von PrP ${ }^{\text {res }}$ im PK abhängigen Verdau Jeweils $50 \mu$ g eines 10\%igem (w/v) infektiösen Rinderhirnhomogenates wurden mit 0, 10, 20, 100, 200 und $500 \mu \mathrm{g} / \mathrm{ml}$ PK für 30 min inkubiert, danach wurde die Reaktion abgestoppt und PrP ${ }^{\text {res }}$ im WB mit dem mAk-mix detektiert.

Aus der Abb. 54 ist erkennbar, dass bei einer Konzentration von $10 \mu \mathrm{g} / \mathrm{ml}$ und $20 \mu \mathrm{g} / \mathrm{ml}$ eine Degradation von $\operatorname{PrP}^{\mathrm{Sc}}$ zu $\operatorname{PrP}^{\text {res }}$ stattgefunden hatte. Es war deutlich zu sehen, dass eine Verschiebung zwischen dem unverdauten $\mathrm{PrP}^{\mathrm{Sc}}$ und dem verdauten $\operatorname{PrP}^{\mathrm{Sc}}$, bei dem nur noch das $\operatorname{PrP}^{\mathrm{res}}$ zu erkennen war, auftrat. Dieses besitzt zwar ebenfalls drei Banden, allerdings hatten diese eine Größe von $19 \mathrm{kDa}$ bis $32 \mathrm{kDa}$ und nicht wie das $\operatorname{PrP}^{\mathrm{Sc}}$ oder $\operatorname{PrP}^{\mathrm{C}}$ eine Größe von $25 \mathrm{kDa}$ bis $37 \mathrm{kDa}$. Diese Verschiebung wird als „shift“ bezeichnet. Bei einer Konzentration von $100 \mu \mathrm{g} / \mathrm{ml}$ hatte dieser Abbau ebenfalls stattgefunden, allerdings war dieser weiter fortgeschritten, so dass kaum noch $\operatorname{PrP}^{\text {res }}$ zu detektieren war. Bei höheren Konzentrationen war nur noch eine schwache Bande bei 19 kDa zu erkennen. Diese war wahrscheinlich die unglykosylierte Form des $\operatorname{PrP}^{\text {res }}$, die anderen beiden glykosylierten 
Formen wurden schon zuvor durch die PK abgebaut. Da nach 30 min nur noch eine schwache Bande bei einer PK-Konzentration von $100 \mu \mathrm{g} / \mathrm{ml}$ zu detektieren war, wurde diese Konzentration zur Bestimmung der Zeitabhängigkeit des PK Verdaus verwendet.

\subsubsection{Zeitabhängigkeit des PK Verdaus}

Zur Bestimmung der Zeitabhängigkeit des PK Verdaus wurden $50 \mu \mathrm{g}$ 10\%iges (w/v) infektiöses Rinderhirnhomogenat mit $100 \mu \mathrm{g} / \mathrm{ml}$ PK inkubiert. Diese Reaktion wurde nach verschiedenen Zeitintervallen gestoppt und auf einem WB durch das ECL-System detektiert, dargestellt in der Abb. 55.

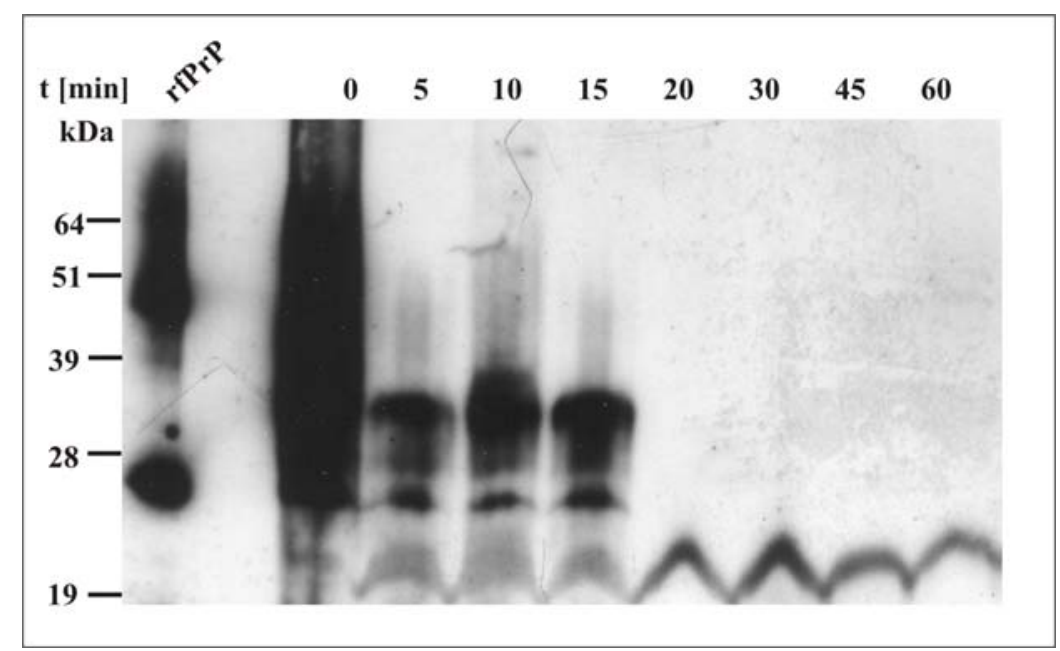

Abb. 55 Detektion von $\operatorname{PrP}^{\text {res }}$ im zeitabhängigen PK Verdau Jeweils $50 \mu$ g eines $10 \%$ igem (w/v) infektiösem Rinderhirnhomogenat wurden mit $100 \mu \mathrm{g} / \mathrm{ml}$ verdaut und nach $5,10,15,20,30,45$ und $60 \mathrm{~min}$ abgestoppt. Detektiert wurde das $\operatorname{PrP}^{\text {res }}$ mit dem mAk-mix im WB.

Aus der Abb. 55 ist erkennbar, dass schon nach 5 min das $\operatorname{PrP}^{\mathrm{Sc}} \mathrm{zu} \operatorname{PrP}^{\text {res }}$ abgebaut wurde. Die gleiche Degradation war auch nach 10 min und 15 min festzustellen. Dagegen war nach 20 min und längerer Inkubation nur noch eine schwache Bande bei 19 kDa zu sehen. Obwohl mit derselben Konzentration schon die Konzentrationsabhängigkeit bestimmt wurde, deutete dies daraufhin, dass der PK Verdau auch noch von anderen unbekannten Faktoren abhängig war. Da aber vergleichbare Werte für den PK Verdau benötigt wurden, wurde jeder weitere PK Verdau für 10 min mit einer Konzentration von 100 g/ml durchgeführt und danach gestoppt. 


\subsubsection{Detektion von $\operatorname{PrP}^{\mathrm{Sc}}$ in infizierten Zellkulturen}

Von den $\operatorname{PrP}^{0 / 0}$, N2a und 3T3 Zelllinien wurde jeweils ein nicht transfizierter LHABT Klon und ein $\operatorname{PrP}^{\mathrm{C}}$ exprimierender Klon, mit und ohne Tet wie beschrieben, inkubiert und mit 1\%igem (w/v) infektiösen Rinderhirnhomogenat infiziert (siehe 2.4.15). Nach 2 Tagen wurden diese Zellen lysiert und für einen WB aufgearbeitet. Anschließend wurde ein PK Verdau mit diesen Klonen, wenn sie die gleiche regulierbare Expression aufwiesen wie bisher beschrieben, durchgeführt, dargestellt in der Abb. 56.
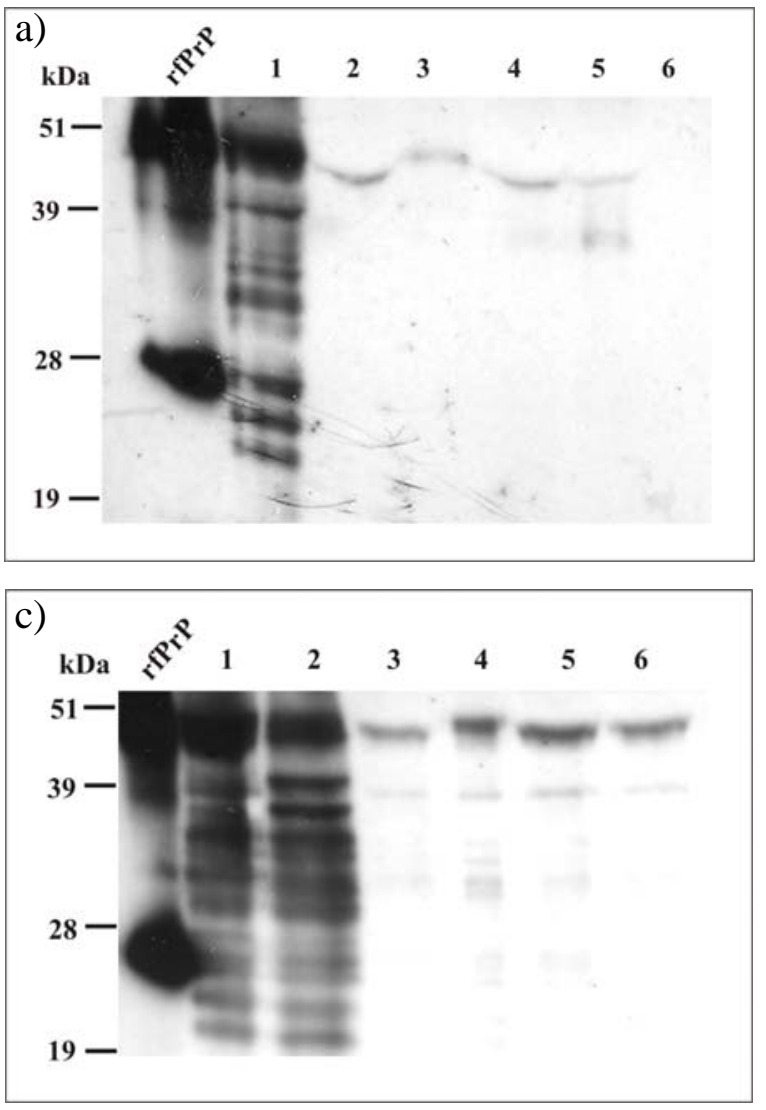



Abb. 56 PK Verdau der verschiedenen Zellklone nach BSE-Infektion Der PK Verdau wurde mit $100 \mu \mathrm{l} / \mathrm{ml}$ PK für $10 \mathrm{~min}$ durchgeführt bei den a) C1 Klone und PrP LHABT, b) B4 und 3T3 LHABT und c) H7 und N2a LHABT. Dieser wurde gezeigt bei 1) der Klon ohne Tet und BSE-Infektion, 2) der Klon mit Tet und BSE-Infektion, 3) der LHABT Klone mit BSE-Infektion, 4) der Klon ohne Tet, 5) der Klon mit Tet, 6) der LHABT Klon. Diese wurden im WB durch den mAk-mix detektiert. Als Kontrolle wurde nicht verdautes rfPrP aufgetragen.

Aus der Abb. 55 geht hervor, dass nach einem PK Verdau der $\operatorname{PrP}^{0 / 0}$ Zellen nur bei dem C1 Klon ohne Tet-Kultivierung $\operatorname{PrP}^{\text {res }}$ nach einer BSE-Infektion zu finden war. Bei den anderen Zellen waren keine Banden zu detektieren.

Bei den beiden Zelllinien, 3T3 und N2a, war neben der Infektion und Inkubation ohne Tet auch bei der Inkubation mit Tet die Detektion von $\operatorname{PrP}^{\text {res }}$ nach dem PK Verdau möglich. Bei den 3T3 Zellen war zusätzlich eine Detektion von $\mathrm{PrP}^{\text {res }}$ beim nicht transfiziertem Zellklon zu erkennen. Die dabei detektierte Menge war allerdings wesentlich geringer als bei dem $\operatorname{PrP}^{\mathrm{C}}$ überexprimierten Zellklon. Ebenfalls war bei den N2a und 3T3 Zellklonen ohne BSE noch eine schwache Bande, durch einen unvollständigen Verdau der Proteine, zu erkennen. 


\subsection{FACS Analyse der infizierten Zellklone}

Die infizierten Zellklone wurden ebenfalls für eine Immunfluoreszenzmikroskopie aufgearbeitet. Hierbei konnten aber keine wahrnehmbaren Unterschiede zwischen den mit BSE infizierten und den uninfizierten $\operatorname{PrP}^{\mathrm{C}}$ überexprimierenden Zellklonen beobachtet werden. Da sie aber auf die Anregung eine starke Fluoreszenz zeigten, wurden diese Klone mit einer FACS Analyse genauer untersucht. Dazu wurden die 1 x $10^{6}$ Zellen vom C1, B4 und H7 Klon mit und ohne $30 \mu \mathrm{g} / \mathrm{ml}$ Tet sowie ein LHABT Klon von jeder Zelllinie für 2 Tage kultiviert. Danach wurden die Zellen mit 1\%igem (w/v) infektiösem Rinderhirnhomogenat infiziert (siehe 2.4.15). Nach einem Tag wurde das Medium gewechselt und nach einem Weiteren wurden die Zellen für die FACS Analyse aufgearbeitet und im S3 Labor des PaulEhrlich Instituts in Langen untersucht.
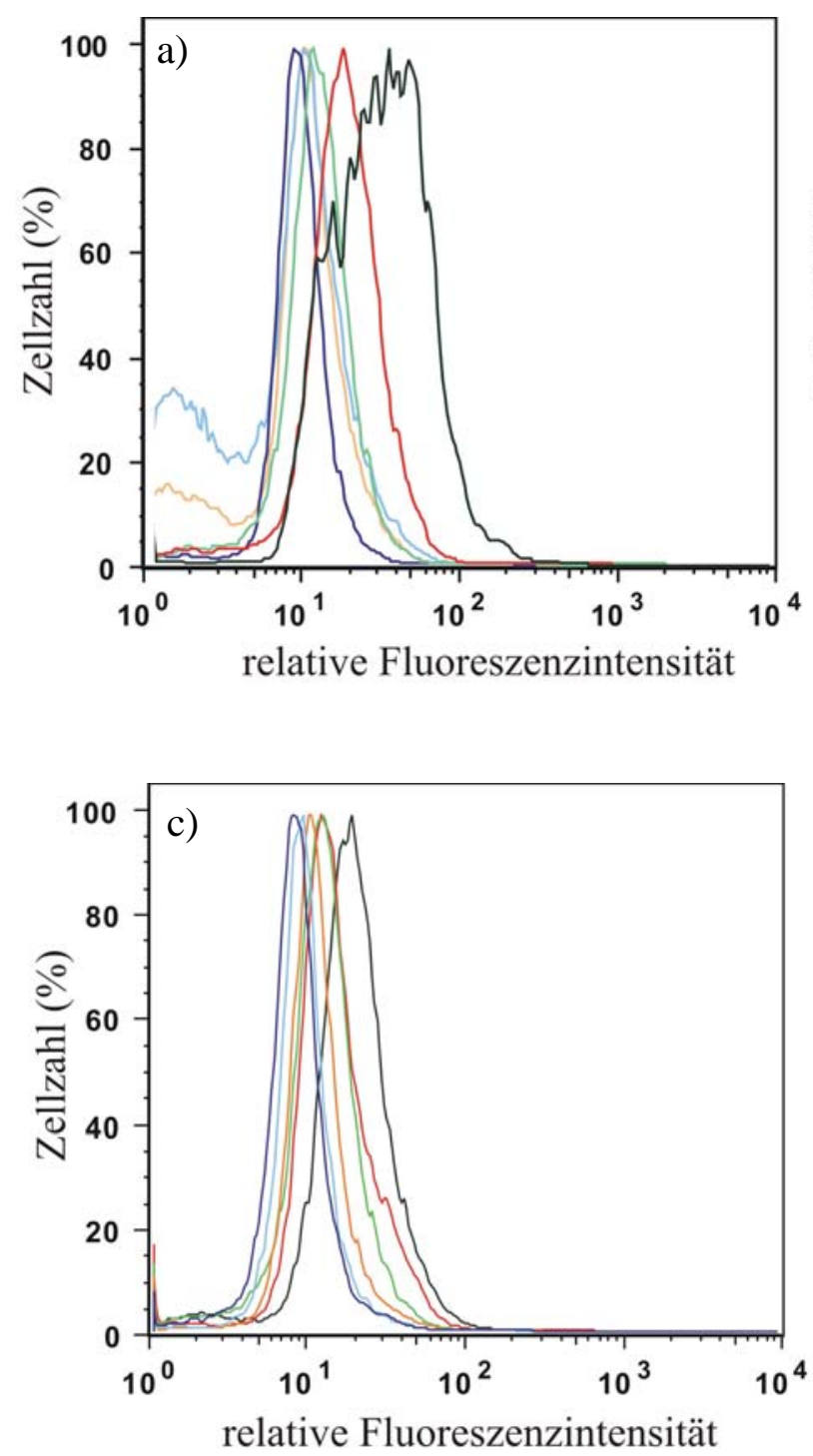



Abb. 57 FACS Analyse der Zellklone Mit a) C1, b) B4 und c) $\mathrm{H} 7$ gezeigt ist die - nicht transfizierte Zelllinie LHABT, die nicht transfizierte Zelllinie LHABT mit BSE-Infektion, - der $\operatorname{PrP}^{\mathrm{C}}$ exprimierende Zellklon ohne Tet kultiviert, - der $\operatorname{PrP}^{\mathrm{C}}$ exprimierende Zellklon mit Tet kultiviert, - der $\mathrm{PrP}^{\mathrm{C}}$ exprimierende Zellklon ohne Tet kultiviert mit BSE infiziert und - der $\mathrm{PrP}^{\mathrm{C}}$ exprimierende Zellklon mit Tet kultiviert und mit BSE infiziert. 
In der Abb. 57 ist anhand der Fluoreszenzintensitäten zu erkennen, dass sich die $\operatorname{PrP}^{\mathrm{C}}$ Expression in den Zellklonen C1, B4 und H7 durch Tet reguliert an- und abstellen ließ. Diese Resultate waren mit den in der Abb. 48 dargestellten vergleichbar. Bei den nur die Regulation nicht aber die Infektion mit BSE untersucht wurde. Die hier gezeigten Zellen hatten untereinander die gleichen Eigenschaften in Bezug auf die Basisexpression und das Regulationsvermögen der $\operatorname{PrP}^{\mathrm{C}}$ Expression. Die dargestellten Fluoreszenzintensitäten waren aber geringer als bei den in der Abb. 48 gezeigten Zellen. Dies lag daran, dass ein anderes FACS Gerät benutzt wurde und die Grundeinstellung bei den Messungen höher war, so dass die erhaltene Fluoreszenzintensität geringer ausfiel. Deshalb war ein direkter Vergleich der Intensitäten nicht möglich. Wohl aber die Verhältnisse derselben. Dies konnte auch deshalb durchgeführt werden, da die Messungen öfters am Paul-Ehrlich Institut wiederholt wurden. Dabei zeigte sich, dass die Verhältnisse die Gleichen bei den 3T3 und N2a Zellen waren. Bei den $\operatorname{PrP}^{0 / 0}$ Zellen dagegen, waren diese zwischen dem C1 Klon mit $\operatorname{PrP}^{\mathrm{C}}$ Expression und dem LHABT Klon geringer. Trotzdem waren die Unterschiede immer signifikant.

Nach einer BSE-Infektion wurde bei fast allen Zellen eine Erhöhung der Fluoreszenzintensität beobachtet, nur bei den $\mathrm{PrP}^{0 / 0}$ Zellen war diese gleich geblieben. Bei dem C1 Klon mit TetKultivierung gab es nur eine sehr geringe kaum zu detektierende Erhöhung, im Gegenansatz dazu war die Fluoreszenzstärke ohne Tet nach einer BSE-Infektion bei dem gleichen Klon wesentlich stärker ausgeprägt. Sie erhöhte sich dabei um fast das 9-fache, weshalb sie sich deutlich von den anderen unterschied.

Bei den anderen beiden Zelllinien, N2a und 3T3, war ebenfalls eine Erhöhung der Fluoreszenzintensität nach der BSE-Infektion zu messen. Dies war allerdings bei allen mit BSE infizierten Zellen der Fall. Sie erhöhte sich dabei jeweils um das 3-fache. Diese Erhöhung wurde sowohl bei einer Kultivierung mit Tet als auch bei dem LHABT Zellklon dieser beiden Zelllinien detektiert. Trotzdem waren diese Fluoreszenzen immer noch geringer als die des Zellklons ohne Tet nach einer BSE-Infektion. 
Das Prion Protein ist ein ubiquitär vorkommendes Protein. Es kann eine Erkrankung auslösen wenn es seine natürliche Konformation verändert und in eine falsch gefaltete pathogene Konformation überführt wird. Neben dieser pathogenen gibt es auch apathogene Fehlfaltungen (Abid et al., 2006). Diese werden durch Proteasen abgebaut und können nicht detektiert werden. Sie sind nur durch verschiedene Intermediate gezeigt worden. Die pathogene Isoform neigt zur Aggregation und kann durch einen PK Verdau als degradierte Form, das $\mathrm{PrP}^{\mathrm{res}}$, nachgewiesen werden. Dieser Unterschied zwischen den beiden Isoformen ist im WB zu erkennen.

Da die pathogene Isoform die gleiche Primärstruktur wie die apathogene besitzt, aber einen wesentlich höheren $\beta$-Faltblattanteil hat, können diese Isoformen anhand ihrer Sekundärstruktur unterschieden werden. Diese Konformationsänderung wurde bisher nur in Organismen beobachtet, deshalb wurden nur Bioassays zur Klärung der Fehlfaltung des Proteins und deren Auswirkungen angewandt.

Erst vor kurzem ist eine „in vitro“ Replikation des $\mathrm{PrP}^{\mathrm{Sc}}$ gelungen (Kocisko et al., 1995; Bossers et al., 2003; Breydo et al., 2005), allerdings ist nicht abzuschätzen, ob diese künstliche Form andere Organismen infizieren und in wie weit diese übertragen werden können. Aus diesem Grund wurde die Übertragung einer TSE-Infektion im Zellkulturmodell untersucht.

\subsection{Expression und Detektion des rPrP in E. coli}

Es war gelungen, das prnp Gen aus verschiedenen Spezies zu amplifizieren. Diese Gene wurden in einen Bakterienexpressionsvektor kloniert und konnten in E. coli translatiert und überexprimiert werden (Mehlhorn et al., 1996). Anschließend konnten die rPrP über IB gereinigt werden (Alvarez-Martinez et al., 2003). Die gereinigten Proteine lagen alle in ihrer unglykosylierten Form vor. Dies lag daran, dass E. coli nicht in der Lage war, die Proteine durch Glykosylierungen zu modifizieren (Legname et al., 2004). Trotzdem besitzen sie die gleichen Eigenschaften wie das $\operatorname{PrP}^{\mathrm{C}}$ (Lopez Garcia et al., 2000; Zahn et al., 2000; Hornemann et al., 2004). Allerdings kam es durch eine Aggregation von PrP Monomeren zur Bildung eines PrP Dimers (Warwicker, 2000; Sekijima et al., 2003). Diese wurde schon in anderen Organismen beschrieben (Bellinger-Kawahara et al., 1988; Priola et al., 1995). 
Diese Form kommt ebenfalls in Eukaryonten vor, dort wurde sie jedoch meistens wie entstandene Fehlfaltungen durch Proteasen abgebaut.

Da der mAk-mix bestimmte Epitope des PrP bindet, konnte eine Bande auf dem WB detektiert werden. Durch die Dimerisierung wurden aber vermutlich die Epitope des PrP blockiert, deshalb war eine Detektion des Dimers über diese Ak schlecht möglich. Da es bei einigen Prion Proteinen trotzdem im WB detektiert wurde (Meier et al., 2003), zeigte dies, dass die Epitope für den Ak nicht vollständig blockiert waren. Besonders deutlich war dieser Effekt beim Menschen, Schimpansen, Javaneraffen und Rind zu sehen, nachdem die Prion Proteine dieser Spezies aus IB gereinigt wurden.

Durch eine Ponceau-Rotfärbung konnte das Dimer allerdings bei allen Spezies detektiert werden, da diese Färbemethode eine unspezifische Interaktion eines Farbstoffes mit einem Protein ist.

\subsection{Herstellung stabiler Zelllinien}

\subsubsection{Herstellung stabil tTA exprimierender Zelllinien}

In dieser Arbeit konnten die $\operatorname{PrP}^{0 / 0}$, die N2a und die 3T3 Zellen stabil mit einem tTA-Element transfiziert werden. Durch eine Selektion mit Blasticidin wurden verschiedene stabile Klone selektiert. Anschließend wurden diese Klone mit einem pBI-EGFP Vektor, der EGFP durch ein TRE-Element reguliert exprimiert (Garni et al., 1997; Lee et al., 2006), transient transfiziert. Die Klone, bei denen sich die Expression durch Tet steuern ließ, wurden unter dem Fluoreszenzmikroskop selektiert.

Die so hergestellten und ausgesuchten Zellklone wurden als PrP LHABT, N2a LHABT und 3T3 LHABT bezeichnet und dienten als Grundlage für die Herstellung $\operatorname{PrP}^{\mathrm{C}}$ exprimierender Zellen.

Bei den hergestellten Zellklonen konnte zudem die systembedingte Basisexpression der Proteine gezeigt werden. Diese konnte auch nicht durch erhöhte Antibiotikazugabe von Tet oder Dox abgestellt werden (Robertson et al., 2002). Es führte eher dazu, dass die Zellen schneller abstarben. 


\subsubsection{Herstellung doppelt stabiler $\operatorname{PrP}^{\mathrm{C}}$ exprimierender Zellen}

Die mit dem tTA stabil transfizierten Zelllinien wurden mit verschiedenen speziesspezifischen prnp Genen transfiziert (Nakamura et al., 2003; Hirata et al., 2004). Dies geschah einerseits mit einem für ein „gene targeting“ konstruierten Vektor und andererseits durch eine retrovirale Infektion. Für die Herstellung der stabilen $\operatorname{PrP}^{\mathrm{C}}$ exprimierenden Zellen erwies sich dabei die Transfektion mittels Retroviren als die Bessere, da wesentlich mehr Klone für eine anschließende Selektion zur Verfügung standen (Menendez et al., 2006; Cenciarelli et al., 2006; Geraerts et al., 2006; Zhang et al., 2006). So konnte eine Auswahl aus einem größeren Reservoir entsprechender $\operatorname{PrP}^{\mathrm{C}}$ exprimierender Zellen getroffen werden. Bei einem Vergleich der Transfektionseffizienz der Methoden mit dem Javaneraffen prnp wurde festgestellt, dass die Effizienz des „gene targeting“ Vektor um das 30-fache geringer war. Allerdings hatte die Art der Transfektion keinen Einfluss auf die Expressionsintensität des $\operatorname{Pr} \mathrm{P}^{\mathrm{C}}$.

\section{3 $\quad \operatorname{PrP}^{\mathrm{C}}$ Expressionsanalysen}

Die Detektion der $\operatorname{PrP}^{\mathrm{C}}$ Expression konnte mit den in der Abb. 58 dargestellten Methoden durchgeführt werden.

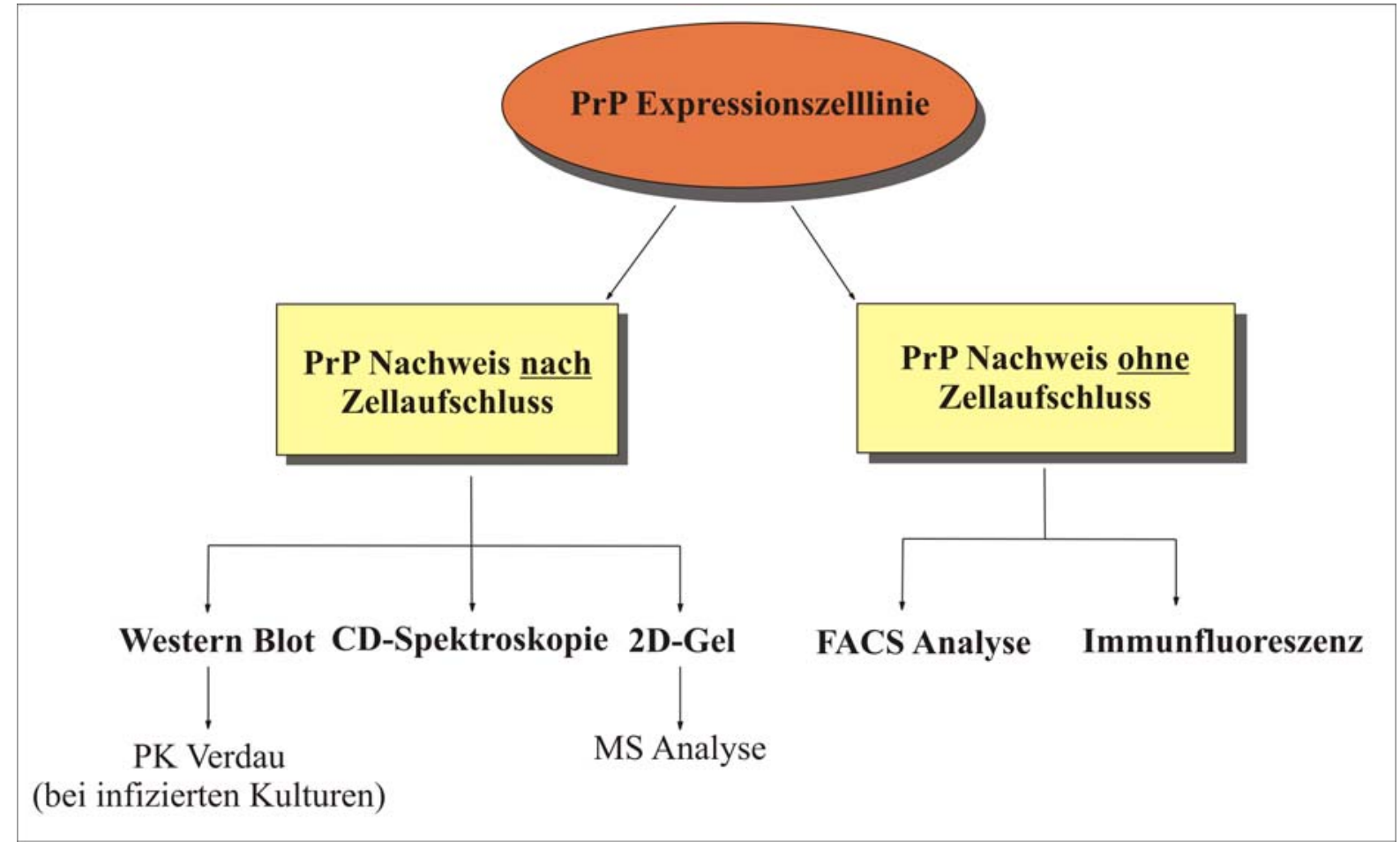

Abb. 58 Detektionsmöglichkeiten des Prion Proteins 
Die $\operatorname{PrP}^{\mathrm{C}}$ Expressionstärke variierte bei den verschiedenen Zelllinien und konnte sowohl im WB als auch mit der FACS Analyse gezeigt werden. Durch eine FACS Analyse wurde die Menge an neu gebildetem $\operatorname{PrP}^{\mathrm{C}}$ in der Zelle genau bestimmt und die Regulation durch Tet gezeigt.

Bei den transfizierten PrP „knock-out“ Zellen war die Expression am deutlichsten zu sehen, da diese Zellen zuvor kein $\operatorname{PrP}^{\mathrm{C}}$ exprimierten. Bei den transfizierten 3T3 Zellen war die Expression ca. 20-fach höher als bei den untransfizierten. Dagegen war die Expression bei transfizierten N2a Zellen nur um das 2 bis 3-fache höher. Die Expression des $\operatorname{PrP}^{\mathrm{C}}$ konnte ebenfalls in der Immunfluoreszenzmikroskopie gezeigt werden. Auch war es möglich mit Hilfe der CD-Spektroskopie, die Sekundärstrukturunterschiede eines $\operatorname{PrP}^{\mathrm{C}}$ exprimierenden transfizierten $\mathrm{PrP}^{0 / 0}$ Zellklons gegenüber der nicht transfizierten Zelllinie, nach einer Aufreinigung durch eine IMAC, zu zeigen.

\subsection{1 $\quad \operatorname{PrP}^{\mathrm{C}}$ Expressionsanalyse durch den WB}

Die Expression konnte durch den „klassischen“ WB bei allen drei Zelllinien nachgewiesen werden. Dabei waren alle drei Banden des $\operatorname{PrP}^{\mathrm{C}}$ zu erkennen (Minor et al., 2004; Stack et al., 2006; Safar et al., 2006). Es konnte sowohl die Überexpression als auch die Regulation durch Tet gezeigt werden. Bei den $\operatorname{PrP}^{0 / 0}$ Zellen wurde zudem die systembedingte Basisexpression des Tet-Systems gezeigt, die aufgrund des endogenen $\operatorname{PrP}^{\mathrm{C}}$ bei den $3 \mathrm{~T} 3$ und N2a Zellen nicht dargestellt werden konnte.

Die detektierten Expressionsstärken der hergestellten 3T3 Zellklone korrelierten dabei mit dem am DPZ bereits etablierten 3T3 Tet-Off hFFI Zellklon (Stuke et al., 2005). Dieser exprimierte das humane FFI und wurde als interner Vergleich mitbetrachtet. Dabei zeigte sich, dass nicht nur die Expressionsstärke sondern auch die Regulation der Expression vergleichbar war.

Bei der Etablierung neuer Zelllinien wurde mehr Wert auf die PrP „knock-out“ Zellklone gelegt, da bei ihnen nur das transfizierte $\operatorname{PrP}^{\mathrm{C}}$ detektiert und für weitere Experimente zur Verfügung stand (Weissmann et al., 1994; Sailer et al., 1994; Weissmann et al., 2003). Dadurch waren die Ergebnisse eindeutiger und ließen weniger Fehlinterpretationen zu. 


\subsubsection{Immunfluoreszenzmikroskopie zur Detektion der $\operatorname{PrP}^{\mathrm{C}}$ Expression}

Durch die Immunfluoreszenzmikroskopie konnte die Expression des $\operatorname{PrP}^{\mathrm{C}}$ durch Ak detektiert und im Mikroskop nachgewiesen werden (Starke et al., 2005; Dabaghian et al., 2006). Durch die Inkubation mit Tet konnte ebenfalls die systembedingte Basisexpression gezeigt werden. Dies war aber nur bei den $\operatorname{PrP}^{0 / 0}$ Zellklonen möglich, da die anderen Zelllinien jeweils ein eigenes $\operatorname{PrP}^{C}$ exprimierten und dieses ebenfalls mit den Ak reagierten. Die Intensität der Immunfluoreszenz korrelierte mit den Ergebnissen aus dem WB, das zeigte, dass die Resultate miteinander vergleichbar waren und die Immunfluoreszenzmikroskopie als Methode zur optischen Detektion von $\operatorname{PrP}^{\mathrm{C}}$ genutzt werden konnte. Allerdings mussten die betrachteten Zellklone immer zum selben Zeitpunkt und mit denselben Einstellungen untersucht werden, da durch Abnutzungserscheinungen der Fluoreszenzlampe und geringfügige Änderungen der Fluoreszenzdetektion im Detektionsprotokoll die Ergebnisse durch das Auswerteprogramm nicht immer 100\%ig übereinstimmten.

\subsection{3 $\operatorname{PrP}^{\mathrm{C}}$ Expressionsanalyse mit Hilfe der Durchflusszytometrie}

Aus den FACS Messungen war erkennbar, dass die verschiedenen Zellklone, die $\operatorname{PrP}^{\mathrm{C}}$ unter Tet reguliert exprimierten, sich von ihren nicht transfizierten Zellen deutlich unterschieden. Durch eine Kultivierung mit Tet wurde die Expression in den Klonen abgeschaltet. Dies konnte ebenfalls durch eine FACS Analyse gezeigt werden.

Die unterschiedlichen Fluoreszenzintensitäten zeigten, dass sich das $\operatorname{PrP}^{\mathrm{C}}$ in diesen Zellen reguliert an- und abschalten ließ. In den $\operatorname{PrP}^{0 / 0}$ Zellen konnte außerdem die systembedingte Basisexpression bei den Zellklonen dieser Zelllinie beobachtet werden. Bei den 3T3 und N2a Zellen konnte diese Expression ebenfalls gezeigt werden, allerdings war diese wesentlich höher, da zu dieser Fluoreszenzintensität auch noch die Fluoreszenz durch das wirtseigene $\operatorname{PrP}^{\mathrm{C}}$ der Zellen addiert wurde. Besonders deutlich war dies bei den transfizierten 3T3 Zellen durch die hohe $\mathrm{PrP}^{\mathrm{C}}$ Expressionsrate zu sehen. Bei den N2a Zellen dagegen war diese Unterscheidung schwieriger, da die Expression des transfizierten $\operatorname{PrP}^{\mathrm{C}}$ im Vergleich nur geringfügig höher war. Trotzdem konnte bei diesen Zellklonen eine Unterscheidung zwischen den nicht transfizierten Zellen und den transfizierten Zellen mit und ohne Tet-Kultivierung festgestellt werden.

Aus diesem Grund kann die FACS Analyse genutzt werden, um verschiedene transfizierte Klone gegenüber ihren Ausgangszelllinien abzugrenzen (Paltrinieri et al., 2004; Trieschmann 
et al., 2005). Auch kann diese Methode genutzt werden, um die Regulation der Expression zu zeigen. Das bei den stark überexprimierten Zellen, wie z. B. den $\operatorname{PrP}^{0 / 0}$ Zellen, einfacher war als bei geringeren Expressionsraten. Somit kann die FACS Analyse zur schnellen und einfachen Selektion von Klonen verwendet werden.

Durch die mitgeführten Negativkontrollen bei der FACS Messung wurde festgestellt, dass sich der FITC konjugierte sekundär Ak nur geringfügig an andere Isotypen und Proteine gebunden hatte. Der anti-PrP Ak dagegen hatte sich unspezifisch an andere Proteine gebunden. Das führte unter anderem zur Fluoreszenz der Zellen. Durch spezifischere Ak oder Verwendung anderer Isotypen könnte dieser Effekt verringert oder sogar verhindert werden. Da die anti-PrP Ak starke Kreuzreaktionen ausführen (Zou et al., 2004; Gregoire et al., 2005), sollte versucht werden, diese durch Inkubation in Seren, aus denen diese Ak gewonnen wurden, zu verringern.

\subsubsection{Sekundärstrukturanalyse mit Hilfe der CD-Spektroskopie}

Die Sekundärstruktur wurde nur an $\operatorname{PrP}^{0 / 0}$ Zellen gezeigt, da sie nur das gewünschte $\operatorname{PrP}^{\mathrm{C}}$ nach einer Transfektion exprimieren. Dies sollte dazu genutzt werden, um eine Konformationsänderung des $\operatorname{PrP}^{\mathrm{C}}$ nach einer Infektion mit $\operatorname{PrP}^{\mathrm{Sc}}$ nachzuweisen und um neben dem PK Verdau eine weitere Methode zum Nachweis von $\operatorname{PrP}^{\mathrm{Sc}}$ zu etablieren. Möglich ist diese Analyse, da das $\operatorname{PrP}^{\mathrm{C}}$ und $\operatorname{PrP}^{\mathrm{Sc}}$ zwar die gleiche Primärstruktur aber eine unterschiedliche Sekundär- und Tertiärstruktur besitzen (Stahl et al., 1993; Cohen et al., 1994).

Durch eine CD-Analyse der IMAC-Elutions- und Waschfraktion beim Vergleich des $\operatorname{PrP}^{\mathrm{C}}$ exprimierenden $\operatorname{PrP}^{0 / 0}$ Zellkon $\mathrm{C} 1$ und den $\mathrm{PrP}^{0 / 0}$ Zellen konnte eine deutliche Unterscheidung der einzelnen Fraktionen getroffen werden, aufgrund des erhöhten $\alpha$-Helixanteils in den Elutionsfraktionen der $\operatorname{PrP}^{\mathrm{C}}$ exprimierenden Zellen. Die Elutionsfraktionen des C1 Zellklons enthielten dabei einen deutlichen helikalen Anteil. Dieser war bei der ersten Elutionsfraktion sehr deutlich zu erkennen wogegen er bei der Zweiten geringer war, was auf einen geringeren Anteil an $\alpha$-Helices hindeutete. Der helikale Anteil ist auf das $\operatorname{PrP}^{\mathrm{C}}$ zurückzuführen, da es drei Helices besitzt (Granata et al., 2006). In der Waschfraktion waren die Signale der beiden untersuchten Klone wieder ähnlich, das zeigte, dass sich kein $\operatorname{PrP}^{\mathrm{C}}$ mehr in dieser Fraktion befand. Diese Ergebnisse wurden zusätzlich durch den WB der IMAC-Fraktionen unterstützt. In ihnen konnte gezeigt werden, dass sich in der Elutionsfraktion 1 viel $\operatorname{PrP}^{\mathrm{C}}$ und weniger in der Fraktion 2 befand, nicht aber in der Waschfraktion. 
Durch die IMAC können die bekannten Isoformen des PrP aufgrund ihrer Affinität gegenüber Kupfer (Hornshaw et al., 1995) getrennt werden. Da das $\operatorname{PrP}^{\mathrm{Sc}}$ pathogen ist und mit ihm nur im S3** Labor gearbeitet werden durfte, konnten bisher keine CD-Analysen mit dieser Isoform durchgeführt werden. Gegenwärtig laufen aber Verhandlungen mit der HeinrichHeine-Universität Düsseldorf über eine mögliche Kooperation, um diese Form analysieren zu können. Sollte dies möglich sein, müsste eine IMAC mit infizierten Zellkulturen durchgeführt werden. Das $\operatorname{PrP}^{\mathrm{Sc}}$ müsste sich dann im Durchlauf befinden, da es kein Kupfer binden kann (Wong et al., 2003; Brown 2004; Todorova-Balvay et al., 2005; Leliveld et al., 2006). Somit wäre eine Auftrennung der Isoformen möglich. In der Elution müsste sich das $\operatorname{PrP}^{\mathrm{C}}$ und im Durchlauf das $\operatorname{PrP}^{\mathrm{Sc}}$ befinden. Durch den erhöhten $\beta$-Faltblattanteil des $\operatorname{PrP}^{\mathrm{Sc}}$ müsste es sich von der Vergleichsfraktion deutlich unterscheiden lassen (Pan et al., 1993). Anschließend würden diese beiden Proteine einem $\mathrm{PK}$ Verdau unterzogen, da nur das $\operatorname{PrP}^{\mathrm{Sc}}$ resistent ist, sollten nur in dieser IMAC-Fraktion Banden auf dem WB zu erkennen sein (Caughey et al., 1997). Anschließend sollten die nicht verdauten und PK verdauten Fraktionen in der CDSpektroskopie untersucht und in Bezug auf ihre Sekundärstruktur miteinander verglichen werden. Dabei sollte sich ein deutlicher Unterschied in der Sekundärstruktur der einzelnen Fraktionen finden lassen.

\subsection{Ko- und Überexpression von Proteinen während $\operatorname{der} \operatorname{PrP}^{\mathrm{C}}$ Expression}

Durch die massenspektrometrische Analyse der 2D-Gele der $\operatorname{PrP}^{0 / 0}$ Zelllinie und eines transfizierten $\operatorname{PrP}^{\mathrm{C}}$ exprimierenden Zellklons der gleichen Zelllinie wurden verschiedene exprimierte Proteine detektiert. Dargestellt wurden diese in der Tab. 11.

Die dabei beschriebenen Proteine wurden teilweise schon in Zusammenhang mit TSEErkrankungen gebracht. Diese Proteine waren die Cu/Zn Superoxiddismutase (Dupuis et al., 2002; Freixes et al., 2005; Brown et al., 1998), das Lectin (Dragatsis et al., 1998; Herrmann et al., 2006; Mazzoni et al., 2005), das Calcyclin (Xiang et al., 2004; Volkel et al., 2001), das Glykoprotein B (Halliday et al., 2005; Zhang et al., 2003; Moroncini et al., 2004), die Enolase 1 (Poser et al., 2000; Race et al., 1995; Kropp et al.,1999), die Aldolase 1 (Strom et al., 2006) und das Stress induzierte Phosphorprotein 1 (Lopes et al., 2005).

Das Lectin (Endharti et al., 2005) und das Profilin 1 (Grumet et al., 1980) sind an der Immunabwehr beteiligt, ebenso ist das Lectin (Lasserre et al., 1999; Lu et al., 1999) für den Nervenaufbau wichtig. Weitere Proteine, die detektiert wurden, befinden sich im Gehirn, diese waren die Cholesteroloxidase (Lange et al., 1985; Raggatt et al., 1966), das Cc2d1a 
Protein (Basel-Vanagaite et al., 2005) und das voltabhängige selektive Anionkanalprotein 1 (Bres et al., 2000; Sakudo et al; 2005; Zanata et al., 2002). Durch die verstärkte oder verringerte Expression dieser Proteine kann es zu den typischen Verhaltensmustern bei TSEErkrankungen kommen. Durch weitere Analysen und Benutzung von verschiedenen „knockout“ Modellen könnte die Regulation der Expression dieser Proteine durch das PrP genauer untersucht werden.

Andere Proteine, wie die putative Nukleotid-Zucker-Dehydrogenase (Karkonen et al., 2005; Jagielski et al., 2005), sind mit verantwortlich für die Glykosierungen, den Stressabbau wie das Peroxiredoxin 6 (Strey et al., 2004) oder sind beteiligt am Membranaufbau, wie das Glykoprotein B (Kupzig et al., 2003). Eine Regulation dieser Proteine wirkt sich auf die molekularen Eigenschaften des $\operatorname{PrP}^{\mathrm{C}}$ aus. Durch eine Erhöhung oder Verringerung der Expression dieser Proteine könnte festgestellt werden, ob das $\operatorname{PrP}^{\mathrm{C}}$ seine Eigenschaften beibehält oder verliert.

Durch Proteine wie das Stathmin 1 (Kouzu et al., 2006), das Peroxiredoxin 6 (Brown et al., 2006) und Tropomyosin 4 (Lo et al., 2006; Hayashi et al., 2005) wird die Tumorbildung beeinflusst. Da das Prion Protein ebenfalls in dem Apoptosezyklus durch die Regulation des Bcl2 beteiligt ist, spielt es in diesem Zusammenhang wahrscheinlich eine Rolle in der Krebsentstehung und kann auf die Zellproliferation Einfluss nehmen.

Andere Proteine die detektiert wurden, wie das Zwei-Komponentenregulatorprotein sind durch die Transfektion in die Zelle eingebracht worden. Diese wurden für die Regulation der Expression des $\mathrm{PrP}^{\mathrm{C}}$ gebraucht und sollten, da sie von einem anderen Organismus stammten, nicht für eine mögliche Funktion des $\operatorname{PrP}^{\mathrm{C}}$ betrachtet werden.

Die hier detektierten Proteine spielen, wenn sie nicht mit dem prnp Gen in die Zelle transfiziert wurden, entweder eine Rolle im Gehirn, in der Immunabwehr, bei den Nerven oder sind an der Zellproliferation beteiligt. Wie stark dieser Einfluss der jeweiligen Proteine ist, sollte genauer untersucht werden. Dazu sollte der pH-Bereich weiter eingeengt und die Laufstrecke erhöht werden, um eventuell übereinander liegende Proteine besser auftrennen zu können. Es sollte ebenfalls ein $\mathrm{PrP}^{\mathrm{C}}$ exprimierender Klon mit Tet-Kultivierung untersucht werden, um zu bestimmen, wie stark die Überexpression einzelner Proteine ist. Die dabei identifizierten Proteine sollten durch eine zweite Methode, wie z. B. den ELISA, bestimmt und auf ihr Vorhandensein geprüft werden.

Dadurch wäre eine genauere Kenntnis über die Funktion des $\operatorname{PrP}^{\mathrm{C}}$ und seiner Signalwege möglich. Auch würden so wahrscheinlich Proteine identifiziert, die bisher nicht mit dem $\operatorname{PrP}{ }^{\mathrm{C}}$ 
in Verbindung gebracht wurden. Dies könnte neue Aufschlüsse über die Funktion des PrP liefern.

\subsection{Infektion von reguliert $\operatorname{PrP}^{\mathrm{C}}$ exprimierenden Zellklonen}

Nachdem die regulierte Expression der verschiedenen Klone untersucht worden war, wurden diese mit 1\%igem (w/v) infektiösen Rinderhirnhomogenat infiziert. Durch verschiedene Methoden konnte diese Infektion durch die Replikation des $\operatorname{PrP}^{\mathrm{Sc}}$ in den verschiedenen Zelllinien nachgewiesen werden.

\subsubsection{PrP ${ }^{\text {res }}$ Nachweis durch den Western Blot}

Das $\operatorname{PrP}^{\mathrm{res}}$ ist die degradierte Form des pathogenen $\operatorname{PrP}^{\mathrm{Sc}}$ (Pan et al., 1993), deshalb musste ein PK Verdau an infektiösem Material zum Nachweis durchgeführt werden. Das $\operatorname{PrP}^{\mathrm{C}}$ ist nicht PK resistent und war nach diesem Verdau nicht mehr detektierbar (Jendroska et al., 1991). Dieser musste, da er ein unspezifischer Verdau ist, auf jedes Material neu abgestimmt werden. Diese Abstimmung erfolgte in der vorliegenden Arbeit mit infiziertem Rinderhirnhomogenat und wurde anschließend auf die verschiedenen infizierten Zelllinien übertragen. Dabei zeigte sich, dass nach dem PK Verdau der mit BSE infizierten und $\operatorname{PrP}^{\mathrm{C}}$ exprimierenden Zellen, $\operatorname{PrP}^{\text {res }}$ nachzuweisen war. Dies konnte bei allen Zellen die $\operatorname{PrP}^{\mathrm{C}}$ exprimierten, gezeigt werden. Bei den 3T3 und N2a Zellen war dies auch bei einer Inkubation mit Tet zu erkennen. Bei den 3T3 Zellen konnte $\operatorname{PrP}^{\text {res }}$ auch an den nicht transfizierten Zellen gezeigt werden. Erklärt werden konnte dies durch das endogene wirtseigene $\mathrm{PrP}^{\mathrm{C}}$, das mit dem $\operatorname{PrP}^{\mathrm{Sc}}$ interagierte. Dadurch kam es zu einer Konformationsänderung des $\operatorname{PrP}^{\mathrm{C}}$. Das entstandene $\operatorname{PrP}^{\mathrm{Sc}}$ reicherte sich an und konnte als $\operatorname{PrP}^{\text {res }}$ im WB nach einem $\mathrm{PK}$ Verdau nachgewiesen werden. Neben dieser degradierten Form waren auf denselben Bahnen im WB auch noch die nicht degradierten Formen zu erkennen. Ob es sich dabei um $\operatorname{PrP}^{\mathrm{Sc}}$ oder $\operatorname{PrP}^{\mathrm{C}}$ handelte, konnte nicht festgestellt werden. Vermutlich handelt es sich dabei um noch nicht degradiertes $\operatorname{PrP}^{\mathrm{Sc}}$, da nach einem PK Verdau der nicht infizierten Zellen keine erkennbaren Banden auf dem WB zu detektieren waren. Detektiert werden konnten diese Formen da der Verdau unvollständig war. Wurde der PK Verdau allerdings länger durchgeführt, waren auch die detektierten Banden des $\mathrm{PrP}^{\mathrm{res}}$ nicht mehr zu erkennen, was sich auch in der Etablierung des PK Verdaus an dem infektiösen Rinderhirn zeigte. Nur durch den Einsatz spezifischer anti-PrP ${ }^{\mathrm{Sc}}$ Ak könnte das $\mathrm{PrP}^{\mathrm{Sc}}$ nachgewiesen werden, ohne das ein PK Verdau an infiziertem 
Material durchgeführt werden müsste. Da die vorhanden Ak diese Bedingung nicht erfüllten, musste der PK Verdau jedes Mal durchgeführt werden. Die PK ist allerdings eine Proteinase, die unspezifisch verschiedene Proteine verdaut. Auch schneidet sie diese an unterschiedlichen Stellen, so dass der Verdau unter gleichen Bedingungen trotzdem verschiedene Resultate liefern kann. Dies zeigt sich auch in den verschiedenen Protokollen zum Nachweis von $\operatorname{PrP}^{\text {res }}$ (Yakovleva et al., 2004; Salguero et al., 2006).

In der Literatur sind spezifische anti-PrP ${ }^{\mathrm{Sc}}$ Ak beschrieben (Korth et al., 1997; Paramithiotis et al., 2003; Curin Serbec et al., 2003), die allerdings nicht vorlagen und die zudem nur mit dem $\operatorname{PrP}^{\mathrm{Sc}}$ von Mäusen und CJD untersucht wurden. Andere Daten besagen, dass nicht speziell für das PrP selektierte Ak, dieses trotzdem detektieren können (Morel et al., 2004). Aus diesen Gründen sollte der WB infizierter Proben mit Ak vor und nach dem PK Verdau nur als ein Mittel nicht aber als Einziges zur Detektion von $\operatorname{PrP}^{\mathrm{Sc}}$ angesehen werden.

\subsection{2 $\quad \operatorname{PrP}^{\mathrm{Sc}}$ Nachweis mit Hilfe der Durchflusszytometrie}

Infizierte Kulturen wurden auch mit Hilfe der FACS Analyse untersucht. Dabei wurden die reguliert exprimierenden Kulturen mit und ohne Tet kultiviert und mit nicht transfizierten Zellen vor und nach einer Infektion mit BSE verglichen (Ratzka et al., 2001; Simak et al., 2002; Falanga et al., 2005). Dabei wurde festgestellt, dass bei allen infizierten Klonen die Fluoreszenzintensität erhöht war. Diese detektierte Fluoreszenzintensität war eine Mischung aus der Detektion des sich ständig gebildeten $\operatorname{PrP}^{\mathrm{Sc}}$ durch die Konversion des $\operatorname{PrP}^{\mathrm{C}}$ und des neu gebildeten $\operatorname{PrP}^{\mathrm{C}}$ in der Zelle. Es konnte nur eine Erhöhung des Fluoreszenzsignals detektiert, nicht aber eine Unterscheidung getroffen werden.

Bei allen $\operatorname{PrP}^{\mathrm{C}}$ exprimierenden Klonen ohne Tet-Kultivierung und mit BSE-Infektion war diese Intensität am größten. Bei den 3T3 und N2a Klonen mit Tet-Kultivierung war diese schwächer, aber nicht gleich der Intensität der Ursprungszellen. Das ist durch die Basisexpression des Tet-Systems zu erklären, die sich zur Intensität der endogenen $\operatorname{PrP}{ }^{C}$ Expression dieser Zellen addiert. Bei den untransfizierten Zellen war diese Expression noch geringer. Dagegen gut beobachtet werden konnten diese Signale bei den 3T3 Zellen und deren Klone. Bei den N2a Zellen war der Effekt, aufgrund der geringeren Überexpression, weniger deutlich ausgeprägt. Bei den $\operatorname{PrP}^{0 / 0}$ Zellen und den Klonen mit Tet-Kultivierung war dies ebenfalls zu sehen, nur dass die Intensität der Basisexpression des Tet-Systems fast gleich der Fluoreszenz der $\operatorname{PrP}^{0 / 0}$ Zellen war. Zu erklären ist das dadurch, dass diese Zellen kein endogenes $\operatorname{PrP}^{\mathrm{C}}$ exprimierten und deshalb die $\mathrm{Ak}$ auch kaum ein detektierbares Signal 
abgaben. Die abgegebenen Signale sind nur durch unspezifische Bindungen der Ak zu erklären.

In dieser Arbeit wurden nur zytoplasmatische FACS Untersuchungen dargestellt, weil eine Detektion der Proteine auf der Oberfläche nicht möglich war. Dies könnte auf die Art der Ablösung der Zellen von der Zellkulturflasche zurückzuführen sein. Durch das Abtrypsinieren wurden wahrscheinlich die Proteine oder die Epitope der Proteine auf der Oberfläche zerstört und konnten keine Bindung mehr mit den anti-PrP Ak eingehen.

Es wurde zwar versucht, neben der zytoplasmatischen Detektion des PrP auch das PrP in den Zellkernen zu detektieren, da aber die Fluoreszenzunterschiede zu gering waren, konnten keine signifikanten Signale detektiert werden. Würden die Zellkerne von der Membran und dem Zytoplasma getrennt, könnten Unterschiede in den einzelnen Fraktionen zu erkennen sein. Dies sollte sowohl vor als auch nach einer Infektion mit TSE-Material geschehen. Daraus könnte sich ein besseres Verständnis der $\operatorname{PrP}^{\mathrm{C}}$ Expression und der Konformationsänderung des $\operatorname{PrP}^{\mathrm{C}}$ ergeben.

Durch die Infektion mit BSE-Material konnte zudem gezeigt werden, dass das Schimpansen $\operatorname{PrP}^{\mathrm{C}}$ in den $\operatorname{PrP}^{0 / 0}$ Zellen zu $\operatorname{PrP}^{\mathrm{Sc}}$ umgewandelt wurde und dass es zu einer Anreicherung von $\mathrm{PrP}^{\mathrm{Sc}}$ kam. Dies konnte sowohl mit dem PK Verdau im WB als auch durch die FACS Analyse gezeigt werden. Diese Anreicherung war nur bei den transfizierten Zellen ohne Tet zu beobachten. Wurden die Zellen mit Tet kultiviert, konnte kein $\operatorname{PrP}^{\mathrm{Sc}}$ im WB als $\operatorname{PrP}^{\text {res }}$ detektiert werden. Auch waren die Signale bei diesem Klon in der FACS Analyse zu gering, um behaupten zu können, dass es zu einer Anreicherung von $\operatorname{PrP}^{\mathrm{Sc}}$ kam, trotz einer gewissen Basisexpression. Das zeigt, dass eine gewisse $\operatorname{PrP}^{\mathrm{C}}$ Konzentration vorhanden sein muss, um eine Infektion auslösen und detektieren zu können.

Die Infektiösität konnte auch beim humanen PrP in den N2a Zellen und beim bovinen PrP in 3T3 Zellen gezeigt werden. Da diese Zellen allerdings ein endogenes $\operatorname{PrP}^{\mathrm{C}}$ besaßen, konnte nicht ausgeschlossen werden, dass dieses mit dem infektiösen Agens reagiert hatte. Allerdings war zu sehen, dass bei den transfizierten Zellklonen der $\operatorname{PrP}^{\text {res }}$ Nachweis deutlicher ausfiel als bei den nicht transfizierten Zellen. Auch war nach einer Infektion mit BSE bei den Zellen ohne Tet die Detektion deutlicher ausgefallen als bei der Kultivierung mit Tet.

Das deutet darauf hin, dass das überexprimierte $\operatorname{PrP}^{\mathrm{C}}$ mit dem $\operatorname{PrP}^{\mathrm{Sc}}$ interagierte und umgefaltet wurde. Es zeigt ebenfalls an, dass durch das Zusammenspiel des transfizierten $\operatorname{PrP}^{\mathrm{C}}$ mit dem endogenen $\operatorname{PrP}^{\mathrm{C}}$ eine Konzentration überschritten war, bei der es zu einer Umfaltung des $\operatorname{PrP}^{\mathrm{C}}$ zum $\operatorname{PrP}^{\mathrm{Sc}}$ kommen kann. 
Da das $\operatorname{PrP}^{\mathrm{C}}$ von verschiedenen Spezies exprimiert wurde, deutet alles darauf hin, dass es unerheblich ist, von welcher Spezies das $\operatorname{PrP}^{\mathrm{C}}$ stammt. Das würde bedeuten, dass nur die $\operatorname{Pr} \mathrm{P}^{\mathrm{C}}$ Konzentration und nicht die Spezies des $\mathrm{PrP}^{\mathrm{C}}$ für die Initiierung der Konformationsänderung verantwortlich ist.

Somit konnte gezeigt werden, dass BSE in der Lage ist, über die Speziesbarriere hinweg, verschiedene Arten zu infizieren. Dieser Fakt wurde zwar schon in Tiermodellen nachgewiesen (Bruce et al., 1994; Gale et al., 1998), ist aber in $\operatorname{PrP}^{0 / 0}$ Zellen dieser Form zum ersten Mal gezeigt worden. Dies zeigt, dass BSE ein hohes Infektionsrisiko über die Speziesbarriere hinweg besitzt.

\subsection{Mögliche Erweiterung des neu geschaffenen Systems}

Durch die Verwendung einer weiteren oder einer nicht resistenten Zelllinie gegenüber Hygromycin oder Blasticidin kann das bisher etablierte Zellkulturmodell um eine Stufe erweitert werden. Dieses Modell kann zur Klärung von Zell-Zell-Interaktionen während einer TSE-Infektion dienen.

Dazu muss eine Zelllinie mit einem TRE-Element, wie z. B. die 3T3 Tet-Off, mit dem in dieser Arbeit verwendeten Retrovirus infiziert werden. So kann das eingeschleuste $\operatorname{Pr} \mathrm{P}^{\mathrm{C}}$ überexprimiert und mit den bekannten Methoden identifiziert werden. Durch eine anschließende Infektion mit TSE-Material kann sich das $\operatorname{PrP}^{\mathrm{C}}$ in $\operatorname{PrP}^{\mathrm{Sc}}$ umfalten.

Werden diese Zellen dann gemeinsam mit anderen $\operatorname{PrP}^{\mathrm{C}}$ exprimierenden Zellen kultiviert, wie z. B. dem C1 Klon, können durch Zugabe eines Antibiotikums z. B. Blasticidin die alten Zellen zum Absterben gebracht werden. Sollte sich dann aber immer noch $\operatorname{PrP}^{\mathrm{Sc}}$ in den Zellen nachweisen lassen, kann eine Zell-Zell-Interaktion nicht ausgeschlossen werden. Ein Schema dieses Zellkulturmodells ist in der Abb. 59 dargestellt. Durch dieses Modell können die ZellZell-Interaktionen genauer detektiert werden als bisher im Tiermodell.

Auch wäre so, durch den Einsatz verschiedener infektiöser TSE-Materialen, Übertragungsstudien von BSE auf andere $\mathrm{PrP}^{\mathrm{C}}$ Spezies als die hier beschriebenen möglich. Dadurch könnte nicht nur für BSE sondern auch für andere TSE-Agenzien, wie z. B. CWD oder Scrapie, eine Risikoabschätzung getroffen werden. 


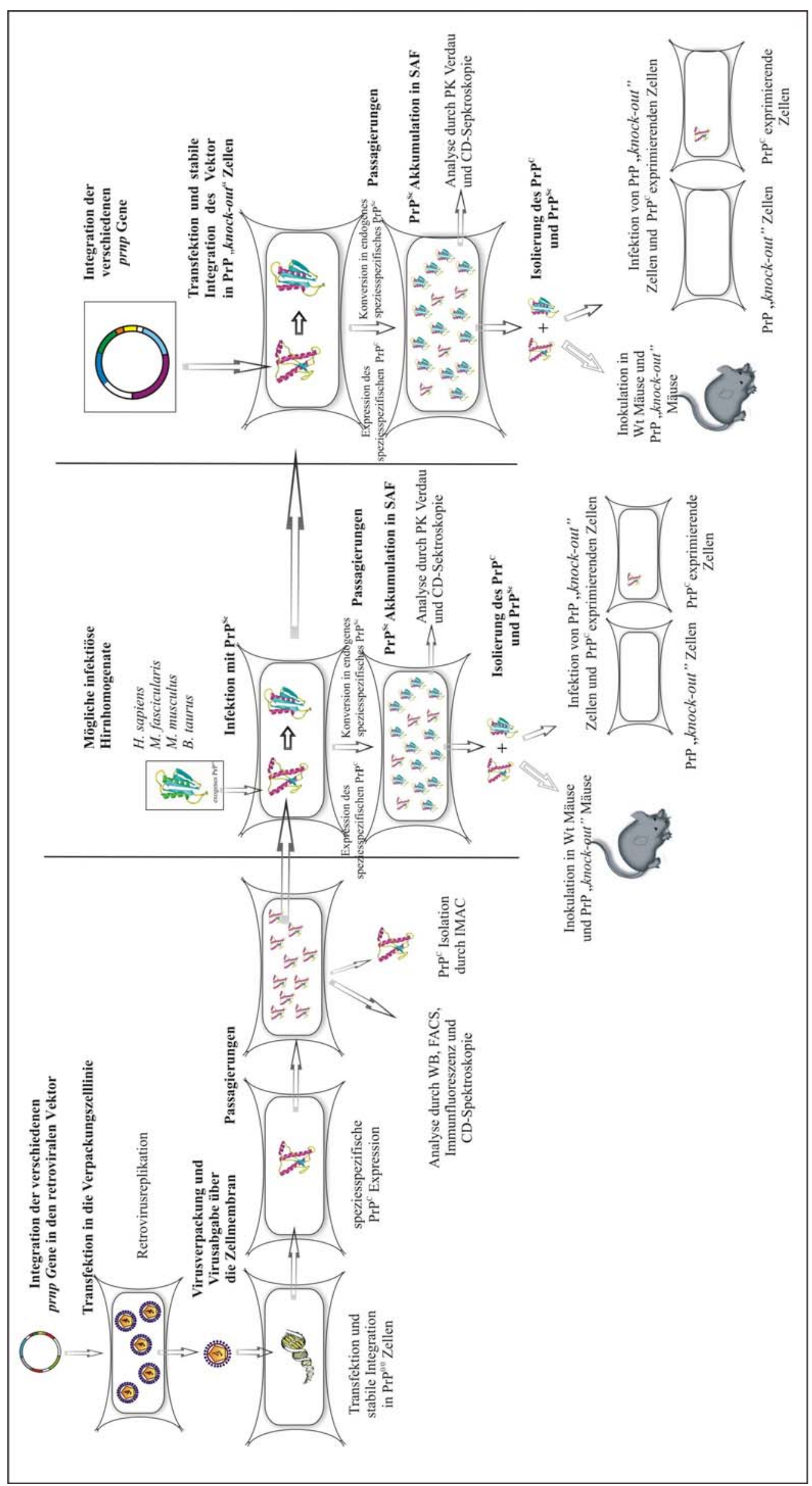



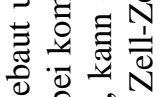

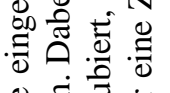


N 30


目语焉 疍

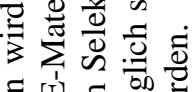
品留园:

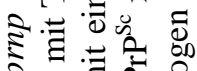

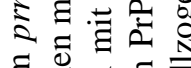
要专焉 范范 둬웜 卷芯苋

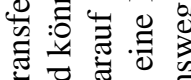

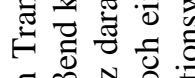

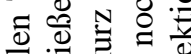

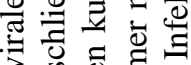

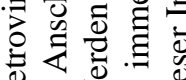
类



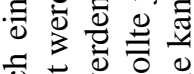

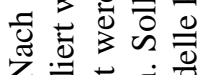
乙 象 专



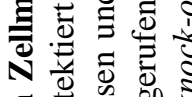

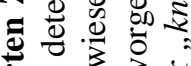

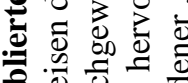
원 䒕选



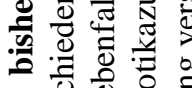

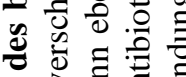
$\infty$ 资



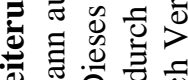

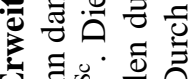

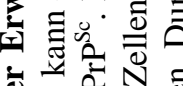

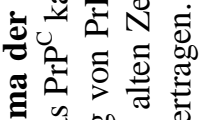

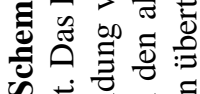



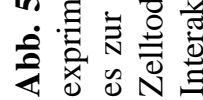


In dieser Arbeit sollten verschiedene prnp Gene stabil in eine eukaryontische Zelllinie transfiziert und das zelluläre Prion Protein überexprimiert werden. Die Expression dieses Proteins sollte dabei reguliert an- und abgeschaltet werden. Nach erfolgter stabiler und regulierbarer Expression des Proteins sollte versucht werden, eine Replikation des pathogenen Prion Proteins zu erreichen.

Deshalb wurden prnp Gene von verschiedenen Spezies amplifiziert. Zur Überprüfung ihrer Sequenz wurden diese in einen Bakterienexpressionsvektor kloniert und in E. coli exprimiert. Anschließend wurden die Sequenzen mit der Entrezdatenbank am NCBI verglichen. In E. coli konnte das PrP außerdem überexprimiert und aus IB gereinigt werden. Diese rekombinanten PrP wurden als interne Kontrollen weiterverwendet und anderen Arbeitsgruppen zur Verfügung gestellt.

Zur regulierten Expression des $\operatorname{PrP}^{\mathrm{C}}$ in Eukaryonten wurde das Tet-System verwendet. Dazu wurden 3T3, N2a und $\operatorname{PrP}^{0 / 0}$ Zellen mit einem Teil des Zwei-Komponenten-Systems stabil transfiziert. Die Regulation dieses Promotors wurde durch eine Fluoreszenzmikroskopie bestätigt. Anschließend wurden diese Zelllinien mit den verschiedenen prnp Genen stabil transfiziert. In diesen neu hergestellten Zelllinien konnte das $\operatorname{PrP}^{\mathrm{C}}$ durch Tet reguliert an- und abgestellt werden. Zudem konnte die systembedingte Basisexpression des Tet-Systems und die Expression des $\operatorname{PrP}^{\mathrm{C}}$ im WB, der Immunfluoreszenz und durch die FACS Analyse gezeigt werden.

Durch die Ausnutzung der $\operatorname{PrP}^{0 / 0}$ Zelllinie und deren Klone konnten außerdem in der CDSpektroskopie die Sekundärstrukturunterschiede gezeigt werden, bedingt durch die deutlich helikale Struktur des exprimierten $\operatorname{PrP}^{\mathrm{C}}$. Außerdem wurden in 2D-Gelen neue potenzielle Interaktionspartner des Prion Proteins gezeigt, welche bei den transfizierten und nicht transfizierten $\operatorname{PrP}^{0 / 0}$ Zellen detektiert wurden. Die dabei identifizierten Proteine spielen neben der Interaktion mit dem Prion Protein ebenfalls eine Rolle bei Krebserkrankungen und neurodegenerativen Erkrankungen. Das deutet vermutlich auf eine Verknüpfung in der Signalkaskade der Aktivierung dieser Krankheiten hin.

Die reguliert $\operatorname{PrP}^{\mathrm{C}}$ exprimierenden Zellen wurden mit BSE infiziert. Dabei kam es zu einer Konversion des $\operatorname{PrP}^{\mathrm{C}}$ in $\mathrm{PrP}^{\mathrm{Sc}}$ und dessen Anreicherung. Eine direkte Anreicherung des $\operatorname{PrP}^{\mathrm{Sc}}$ konnte als eine deutliche Erhöhung des Fluoreszenzsignals in der FACS Analyse gezeigt werden. Durch einen Proteinase K Verdau wurde das $\operatorname{PrP}^{\mathrm{Sc}}$ als degradierte Form, das $\operatorname{PrP}^{\text {res }}$, detektiert. Durch die Möglichkeit der Regulation der verschiedenen $\operatorname{PrP}^{\mathrm{C}}$ exprimierenden 
Klone wurde gezeigt, dass das $\operatorname{PrP}^{\text {res }}$ nur in den $\operatorname{PrP}^{\mathrm{C}}$ exprimierenden Zellen zu detektieren war. Besonders deutlich war dies bei den $\operatorname{PrP}^{0 / 0}$ Zellen zu sehen, da diese kein endogenes $\operatorname{PrP}^{\mathrm{C}}$ besaßen. In den anderen beiden Zelllinien, N2a und 3T3, die ein wirtseigenes endogenes nicht regulierbares $\operatorname{PrP}^{\mathrm{C}}$ besaßen, war dieser Effekt weniger deutlich ausgeprägt, da das endogene $\operatorname{PrP}^{\mathrm{C}}$ immer mit dem $\operatorname{PrP}^{\mathrm{Sc}}$ interagieren konnte.

Durch die Ausnutzung der verschieden $\operatorname{PrP}^{\mathrm{C}}$ exprimierenden Zellklone konnte gezeigt werden, dass mit BSE nicht nur Rinder sondern auch andere Spezies infiziert werden können. Somit ist BSE in der Lage, die Speziesbarriere zu überwinden.

Diese neu geschaffenen Zelllinien können als Werkzeug einer genaueren Aufklärung der Prionenerkrankungen und der Funktionen des Prion Proteins dienen. Durch die Verwendung der $\operatorname{PrP}^{0 / 0}$ Zelllinie und deren Klone für Infektionsstudien können diese teilweise gegen die bisher genutzten Bioassays ausgetauscht werden. Dadurch sind konkretere und effektivere Studien des Prion Proteins, seiner Infektionswege, Signalkaskaden sowie die Zusammenhänge mit anderen Erkrankungen möglich geworden. 
Abid K. und Soto C. (2006). The intriguing prion disorders. Cell. Mol. Life Sci., Epublished

Aguzzi A. (2006). Prion diseases of humans and farm animals: epidemiology, genetics, and pathogenesis. J. Neurochem., 97: 1726-39

Akowitz A., Sklaviadis T. und Manuelidis L. (1994). Endogenous viral complexes with long P-NA cosediment with the agent of Creutzfeldt-Jakob disease. Nucleic Acid Res., 22: 1101-07

Alvarez-Martinez M. T., Torrent J., Lange R., Verdier J. M., Balny C. und Liautard J. P. (2003). Optimized overproduction, purification, characterization and high-pressure sensitivity of the prion protein in the native $\left(\operatorname{PrP}(C)\right.$-like) or amyloid $\left(\operatorname{PrP}\left(S_{c}\right)\right.$-like) conformation. Biochim. Biophys. Acta, 1645: 228-40

Baker H. F., Ridley R. M., Wells G. A. und Ironside J. W. (1998). Prion protein immunohistochemical staining in the brains of monkeys with transmissible spongiform encephalopathy. Neuropathol. Appl. Neurobiol., 24: 476-86

Basel-Vanagaite L., Attia R., Yahav M., Ferland R. J., Anteki L., Walsh C. A., Olender T., Straussberg R., Magal N., Taub E., Drasinover V., Alkelai A., Bercovich D., Rechavi G., Simon A. J. und Shohat M. (2005). The CC2D1A, a member of a new gene family with C2 domains, is involved in autosomal recessive non-syndromic mental retardation. J. Med. Genet., 43: 203-10

Basler K., Oesch B., Scott M., Westaway D., Walchli M., Groth D. F., McKinley M. P., Prusiner S. B. und Weissmann C. (1986). Scrapie and cellular PrP isoforms are encoded by the same chromosomal gene. Cell, 46: 417-28

Belay E. D., Maddox R. A., Williams E. S., Miller M. W., Gambetti P. und Schonberger L. B. (2004). Chronic wasting disease and potential transmission to humans. Emerg. Infect. Dis., 10: $977-84$ 
Bellinger-Kawahara C., Cleaver J. E., Diener T. O. und Prusiner S. B. (1987). Purified scrapie prions resist inactivation by UV irradiation. J. Virol., 61: 159-66

Bellinger-Kawahara C. G., Kempner E., Groth D., Gabizon R. und Prusiner S. B. (1988). Scrapie prion liposomes and rods exhibit target sizes of 55,000 Da. Virology, 164: 537-41

Bennett T. P. (1967). Membrane filtration for determining protein in the presence of interfering substances. Nature, 213: 1131-2

Bertram L. und Tanzi R. E. (2005). The genetic epidemiology of neurodegenerative disease. J. Clin. Invest., 115: 1449-57

Biasimi E., Massignan T., Fioriti L., Rossi V., Dossena S., Salmona M., Forloni G., Sonetto V. und Chiesa R. (2006). Analysis of the cerebellar proteome in a transgenic mouse model of inherited prion disease reveals preclinical alteration of calcineurin activity. Proteomics, 6: 2823-34

Birkettl C. R., Hennion R. H., Bembridgel D. A., Clarkel M. C., Chree A., Bruce M. E. und Bostock C. J. (2001). Scrapie strains maintain biological phenotypes on propagation in a cell line in culture. EMBO, 20: 3351-58

Blattler T., Brandner S., Raeber A. J., Klein M. A., Voigtlander T., Weissmann C. und Aguzzi A. (1997). PrP-expressing tissue required for transfer of scrapie infectivity from spleen to brain. Nature, 389: 69-73

Bolton D. C., Meyer R. K. und Prusiner S. B. (1985). Scrapie Prp 27-30 is a Sialoglycoprotein. J. Virol., 53: 596-606

Bonifati D. M. und Kishore U. (2006). Role of complement in neurodegeneration and neuroinflammation. Mol. Immunol., 12: Epublished

Bosque P. J. und Prusiner S. B. (2000). Cultured Cell Sublines Highly Susceptible to Prion Infection. J. Virology, 74: 4377-86 
Bossers A., Rigter A., de Vries R. und Smits M. A. (2003). In vitro conversion of normal prion protein into pathologic isoforms. Clin. Lab. Med., 23: 227-47

Bradford M. (1976). A rapid and sensitive method for the quantitation of microgram quantities of protein utilizing the principles of protein-dye binding. Anal. Biochem., 72: 24854

Bradley R. und Marchant B. (eds) (1993). Transmissible Spongiform Encephalopathies. A Consultation on BSE with the Scientific Veterinary Committee of the Commission of the European Communities held in Brussels, 14-15 September 1993. Document VI/4131/94EN. European Commission, Agriculture, Brüssel, 145-159

Brandner S., Isenmann S., Raeber A., Fischer M., Sailer A., Kobayashi Y., Marino S., Weissmann C. und Aguzzi A. (1996). Normal host prion protein necessary for scrapieinduced neurotoxicity. Nature, 379: 339-43

Breydo L., Bocharova O. V., Makarava N., Salnikov V. V., Anderson M. und Baskakov I. V. (2005). Methionine oxidation interferes with conversion of the prion protein into the fibrillar proteinase K-resistant conformation. Biochemistry, 44: 15534-43

Bres V., Hurbin A., Duvoid A., Orcel H., Moos F. C., Rabie A. und Hussy N. (2000). Pharmacological characterization of volume-sensitive, taurine permeable anion channels in rat supraoptic glial cells. Br. J. Pharmacol., 130: 1976-82

Britton T. C., Al-Sarraj S., Shaw C., Campbell T. und Collinge J. (1995). Sporadic Creutzfeldt-Jakob disease in a 16-year old in the UK. Lancet, 146: 1155

Brown D. R., Schmidt B., Groschup M. H. und Kretzschmar H. A. (1998). Prion protein expression in muscle cells and toxicity of a prion protein fragment. Eur. J. Cell Biol., 75: 2937

Brown D. R. (2004). Metallic prions. Biochem. Soc. Symp., 71: 193-202

Brown D. R. und Kozlowski H. (2004). Biological inorganic and bioinorganic chemistry of neurodegeneration based on prion and Alzheimer diseases. Dalton Trans., 13: 1907-17 
Brown L. M., Helmke S. M., Hunsucker S. W., Netea-Maier R. T., Chiang S. A., Heinz D. E., Shroyer K. R., Duncan M. W. und Haugen B. R. (2006). Quantitative and qualitative differences in protein expression between papillary thyroid carcinoma and normal thyroid tissue. Mol. Carcinog., 45: 613-26

Brown P., Rau E. H., Johnson B. K., Bacote A. E., Gibbs Jr. C. J. und Gaidusek D. C. (2000). New studies on the heat resistance of hamster-adapted scrapie agent: threshold survival after ashing at 600 degrees $C$ suggests an inorganic template of replication. PNAS, 97: 3418-21

Browning S. R., Mason G. L., Seward T., Green M., Eliason G. A., Mathiason C., Miller M. W., Williams E. S., Hoover E. und Telling G. C. (2004). Transmission of prions from mule deer and elk with chronic wasting disease to transgenic mice expressing cervid PrP. J. Virol., 78: $13345-50$

Bruce M., Chree A., McConnell I., Foster J., Pearson G. und Fraser H. (1994). Transmission of bovine spongiform encephalopathy and scrapie to mice: strain variation and the species barrier. Philos. Trans. R. Soc. Lond. B. Biol. Sci., 343: 405-11

Bueler H., Fischer M., Lang Y., Bluethmann H., Lipp H. P., DeArmond S. J., Prusiner S. B., Aguet M. und Weissmann C. (1992). Normal development and behaviour of mice lacking the neuronal cell-surface PrP protein. Nature, 356: 577-82

Burns C. S., Aronoff-Spencer E., Legname G., Prusiner S. B., Antholine W. E., Gerfen G. J., Peisach J. und Millhauser G. L. (2003). Copper coordination in the full-length, recombinant prion protein. Biochemistry, 42: 6794-803

Buschmann T., Yin Z., Bhoumik A. und Ronai Z. (2000). Amino-terminal-derived JNK fragment alters expression and activity of c-Jun, ATF2, and p53 and increases H2O2-induced cell death. J. Biol. Chem., 275: 16590-96

Caughey B., Race R. E., Ernst D., Buchmeier M. J. und Chesebro B. (1989). Prion Protein Biosynthesis in Scrapie-Infected and Uninfected Neuroblastoma Cells. J. Virol., 63: 175-81 
Caughey B., Raymond G. J., Kocisko D. A. und Landsbury Jr. P. T. (1997). Scrapie Infectivity Correlates with Converting Activity, Protease Resistance, and Aggregation of Scrapie-Associated Prion Protein in Guanidine Denaturation Studies. J. Virol., 71: 4107-10

Cenciarelli C., Budoni M., Mercanti D., Fernandez E., Pallini R., Aloe L., Cimino V., Maira G. und Casalbore P. (2006). In vitro analysis of mouse neural stem cells genetically modified to stably express human NGF by a novel multigenic viral expression system. Neurol. Res., 28: 505-12

Curin Serbec V., Bresjanac M., Popovic M., Pretnar Hartman K., Galvani V., Rupreht R., Cernilec M., Vranac T., Hafner I. und Jerala R. (2004). Monoclonal antibody against a peptide of human prion protein discriminates between Creutzfeldt-Jacob's disease-affected and normal brain tissue. J. Biol. Chem., 279: 3694-8

Chandler R. L. (1961). Encephalopathy in mice produced by inoculation with scrapie brain material. Lancet, 1: 1378-79

Chesebro B., Race R., Wehrly K., Nishio J., Bloom M., Lechner D., Bergstrom S., Robbins K., Mayer L., Keith J. M. et al. (1985). Identification of Scrapie Prion Protein-Specific mRNA in Scrapie-Infected and Uninfected Brain. Nature, 315: 331-333

Choi C. J., Kanthasamy A., Anantharam V. und Kanthasamy A. G. (2006). Interaction of metals with prion protein: Possible role of divalent cations in the pathogenesis of prion diseases. Neurotoxicology, 27: 777-87

Coffin J. M., Hughes S. H. und Varmus H. E. (1997). Retrovirus. Cold Spring Harbor Laboratory Press

Come J. H., Fraser P. E. und Landsbury Jr. P. T. (1993). A kinetic model for amyloid formation in the prion diseases: Importance of seeding. PNAS, 90: 5959-63

Cotto E., Andre M., Forgue J., Fleury H. J. und Babin P. J. (2005). Molecular characterization, phylogenetic relationships, and developmental expression patterns of prion genes in zebrafish (Danio rerio). FEBS, 272: 500-13 
Cohen F. E. Principal Investigator, http://www.cmpharm.ucsf.edu/cohen

Cohen F. E., Pan K. M., Huang Z., Baldwin M., Fletterick R. J. und Prusiner S. B. (1994). Structural clues to prion replication. Science, 264: 530-31

Creutzfeldt H. G. (1920). Über eine eigenartige herdförmige Erkrankung des Zentralnervensystems. Z. Ges. Neurol. Psychiat., 57: 1-20

Cronier S., Laude H. und Peyrin J. M. (2004). Prions can infect primary cultured neurons and astrocytes and promote neuronal cell death. PNAS, 101: 12271-76

Cuillé J. und Chelle P. L. (1936). La maladie dite tremblante du mouton est-elle inoculable? Compte rendu de l'Académie des Sciences, 203: 1552-54

CWD Alliance, http://www.cwd-info.org

Cunningham A. A., Wells G. A. H., Scott A. C., Kirkwood J. K. und Barnett J. E. F. (1993). Transmissible spongiform encephalopathy in greater kudu (Tragelaphus strepsiceros). Vet. Rec., 132: 68

Dabaghian R. H., Barnard G., McConnell I. und Clewley J. P. (2006). An immunoassay for the pathological form of the prion protein based on denaturation and time resolved fluorometry. J. Virol. Methods., 132: 85-91

Davis H. E., Morgan J. R. und Yarmush M. L. (2002). Polybrene increases retrovirus gene transfer efficiency by enhancing receptor-independent virus adsorption on target cell membranes. Biophys. Chem., 97: 159-72

Dawson M., Wells G. A. H., Parker B. N. J. und Scott A. C. (1990). Primary parenteral transmission of bovine spongiform encephalopathy to the pig. Vet. Rec., 127: 338-339

Dawson M., Wells G. A. H., Parker B. N. J. und Scott A. C. (1991). Transimission studies of BSE in cattle, hamsters, pigs and domestic fowl. In: R Bradiey, M Savey, B Marchant (eds): Subacute Spongiform Encephalopathies. Commission of the European Communities. Kluwer Academic Publishers, Dordrecht, 25-32 
DeMarco M. L. und Daggett V. (2005). Local environmental effects on the structure of the prion protein. Comptes Rendus Biologies, 328: 847-62

Deslys J. P. und Picot A. (2001). Mad Cow Disease: The Risks to Humans. Dominos Flammarion Verlag

Diringer H., Braig H. R. und Czub M. (1988). Scrapie: a virus-induced amyloldosis of the brain. Ciba Found. Symp., 135: 135-45

Dragatsis I., Efstratiadis A. und Zeitlin S. (1998). Mouse mutant embryos lacking huntingtin are rescued from lethality by wild-type extraembryonic tissues. Development, 125: 1529-39

Dupuis L., Mbebi C., Gonzalez de Aguilar J. L., Rene F., Muller A., de Tapia M. und Loeffler J. P. (2002). Loss of prion protein in a transgenic model of amyotrophic lateral sclerosis. Mol. Cell Neurosci., 19: 216-24

Eigen M. (1996). Prionics or the kinetic basis of prion diseases. Biophys. Chem., 63: A1-18

Enari M., Flechsig E. und Weissmann C. (2001). Scrapie prion protein accumulation by scrapie-infected neuroblastoma cells abrogated by exposure to a prion protein antibody. PNAS, 98: 9295-99

Endo T., Groth D. und Prusiner S. B. (1989). Diversity of oligosaccharide structures linked to asparagines of the scrapie prion protein. Biochemistry, 28: 8380-88

Falanga P. B., Blom-Potar M. C., Bittoun P., Goldberg M. E. und Hontebeyrie M. (2005). Selection of ovine PrP high-producer subclones from a transfected epithelial cell line. Biochem. Biophys. Res. Commun., 340: 309-17

Fasman G. D. (1996). Circular Dichroism and the Conformational Analysis of Biomolecules. New York, Plenum Press 
Flechsig E., Hegyi I., Leimeroth R., Zuniga A., Rossi D., Cozzio A., Schwarz P., Rulicke T., Gotz J., Aguzzi A. und Weissmann C. (2003). Expression of truncated PrP targeted to Purkinje cells of PrP knockout mice causes Purkinje cell death and ataxia. EMBO, 22: 3095101

Ford M. J., Burton L. J., Morris R. J. und Hall S. M. (2002). Selective expression of prion protein in peripheral tissues of the adult mouse. Neuroscience, 113: 177-92

Foster J. D., Hope J. und Fraser H. (1993). Transmission of bovine spongiform encephalopathy to sheep and goats. Vet. Rec., 133: 339-41

Foster J. D., Hope J., McConnell I., Bruce M. und Fraser H. (1994). Transmission of bovine spongiform encephalopathy to sheep, goats, and mice. Ann. N. Y. Acad. Sci., 724: 300-3

Foster J. D., Parnham D. W., Hunter N. und Bruce M. (2001). Distribution of the prion protein in sheep terminally affected with BSE following experimental oral transmission. J. Gen. Virol., 82: 2319-26

Freixes M., Rodriguez A., Dalfo E. und Ferrer I. (2005). Oxidation, glycoxidation, lipoxidation, nitration, and responses to oxidative stress in the cerebral cortex in CreutzfeldtJakob disease. Neurobiol. Aging., 23: Epublished

Gabriel J. M., Oesch B., Kretzmar H., Scott M. und Prusiner S. B. (1992). Molekular cloning of a candidate chicken prion protein. PNAS, 89: 9097-101

Gabus C., Derrington E., Leblanc P., Chnaiderman J., Dormont D., Swietnicki W., Morillas M., Surewicz W. K., Marci D., Nandii P. und Darlix J.-L. (2001). The Prion Protein Has RNA Binding and Chaperoning Properties Characteristic of Nucleocapsid Protein NCp7 of HIV1*. J. Bio. Chem., 276: 19301-09

Gajdusek D. C. und Zigas V. (1957). Degenerative disease of the central nervous system in New Guinea. N. Engl. J. Med., 257: 974-78 
Gajdusek D. C., Gibbs Jr. C. J. und Alpers M. (1966). Experimental transmission of a kurulike syndrome to chimpanzees. Nature, 209: 794-96

Gajdusek D. C. (1977). Unconventional viruses and the origin and disappearance of kuru. Science, 197: 943-60

Gale P., Young C., Stanfield G. und Oakes D. (1998). Development of a risk assessment for BSE in the aquatic environment. J. Appl. Microbiol., 84: 467-77

Gari E., Piedrafita L., Aldea M. und Herrero E. (1997). A set of vectors with a tetracyclineregulatable promoter system for modulated gene expression in Saccharomyces cerevisiae. Yeast, 13: 837-48.

Geraerts M., Eggermont K., Hernandez-Acosta P., Garcia-Verdugo J. M., Baekelandt V. und Debyser Z. (2006). Lentiviral vectors mediate efficient and stable gene transfer in adult neural stem cells in vivo. Hum. Gene Ther., 17: 635-50

Gerstmann J. (1928). Über ein noch nicht beschriebenes Reflexphänomen bei einer Erkrankung des zerebellären Systems. W. Med. Wschr., 78: 906-08

Gibbs Jr. C. J., Gajdusek D. C., Asher D. M., Alpers M. P., Beck E., Daniel P. M. und Matthews W. B. (1968). Creutzfeldt-Jakob disease (spongiform encephalopathy): transmission to the chimpanzee. Science, 161: 388-89

Gibbs Jr. C. J., Gajdusek D. C. und Latarjet R. (1978). Unusual resistance to lonizing radiation of the viruses of kuru, Creutzfeldt-Jakob disease, and scrapie. PNAS, 75: 6268-70

Gossen M. und Bujard H. (1992). Tight control of gene expression in mammalian cells by tetracycline responsive promoters. PNAS, 89: 5547-51

Gossen M., Freundlieb S., Bender G., Muller G., Hillen W. und Bujard H. (1995). Transcriptional activation by tetracycline in mammalian cells. Science, 268: 1766-69 
Granata V., Palladino P., Tizzano B., Negro A., Berisio R. und Zagari A. (2006). The Effect of the Osmolyte Trimethylamine N-Oxide on the Stability of the Prion Protein at Low pH. Biopolymers, 82: 234-40

Gregoire S., Bergot A. S., Feraudet C., Carnaud C., Aucouturier P. und Rosset M. B. (2005). The murine B cell repertoire is severely selected against endogenous cellular prion protein. J. Immunol., 175: 6443-9

Grumet M. und Lin S. (1980). Reversal of profilin inhibition of actin polymerization in vitro by erythrocyte cytochalasin-binding complexes and cross-linked actin nuclei. Biochem. Biophys. Res. Commun., 92: 1327-34

Hadlow W. J. (1959). Scrapie and kuru. Lancet, 2: 289-90

Hadlow W. J., Kennedy R. C., Race R. E. und Eklund C. M. (1980). Virologic and neurohistologic findings in dairy goats affected with natural scrapie. Vet. Pathol., 17: 187-99

Hadlow W. J., Kennedy R. C. und Race R. E. (1982). Natural infection of Suffolk sheep with scrapie virus. J. Infect. Dis., 146: 657-64

Halliday S., Houston F. und Hunter N. (2005). Expression of PrPC on cellular components of sheep blood. J. Gen. Virol., 86: 1571-9

Hartsough G. R. und Burger D. (1965). Encephalopathy of mink. I. Epizootiologic and clinical observation. J. Infect. Dis., 115: 387-92

Hayashi E., Kuramitsu Y., Okada F., Fujimoto M., Zhang X., Kobayashi M., Iizuka N., Ueyama Y. und Nakamura K. (2005). Proteomic profiling for cancer progression: Differential display analysis for the expression of intracellular proteins between regressive and progressive cancer cell lines. Proteomics, 5: 1024-32

Heppner F. L. und Aguzzi A. (2004). Recent developments in prion immunotherapy. Curr. Opin. Immunol., 16: 594-98 
Herrmann L. M., Baszler T. V., O'Rourke K. I., Suarez C. E., Bakko M., Alverson J. und Knowles D. P. (2006). Fewer PrPc myeloid-based cells in sheep with the prion-resistant genotype. Neuroreport., 17: 125-9

Hirata R. K., Xu C., Dong R., Miller D.G., Ferguson S. und Russell D. W. (2004). Efficient PRNP gene targeting in bovine fibroblasts by adeno-associated virus vectors. Cloning Stem Cells, 6: 31-6

Hornemann S., Schorn C. und Wuthrich K. (2004). Nmr Structure of the Bovine Prion Protein Isolated from Healthy Calf Brains. EMBO, 5: 1159-64

Hornshaw M. P., McDermott J. R. und Candy J. M. (1995). Copper Binding to the NTerminal Tandem Repeat Regions of Mammalian and Avian Prion Protein. Biochem. Biophys. Res. Commun., 207: 621-29

Horwitz J. P., Chua J., Curby R. J., Tomson A. J., DaRooge M. A., Fisher B. E., Muaricio J. und Klundt I. (1964). Substrates for cytochemical demonstration of enzyme activity. Some substituted 3-indoyl- $\beta$-D-glycopyranosides. J. Med. Chem., 53: 574-5

Jagielski A. K., Podszywalow-Bartnicka P., Derlacz R. A. und Bryla J. (2005). The role of intracellular cAMP in renal gluconeogenesis in view of differential action of various cAMP analogues. Arch. Biochem. Biophys., 434: 282-8

Jahn O., Hesse D., Reinelt M. und Kratzin H. D. (2006). Technical innovations for the automated identification of gel-separated proteins by MALDI-TOF mass spectrometry. Anal. Bioanal. Chem., 386: 92-103

Jakob A. (1921). Über eigenartige Erkrankungen des Zentralnervensystems mit bemerkenswerten anatomischen Befunden. Z. Ges. Neurol. Psychiatr., 64: 147-228

Jarrett J. T. und Landsbury Jr. P. T. (1993). Seeding 'one-dimensional crystallization' of amyloid: a pathogenic mechanism in Alzheimer's disease and scrapie? Cell, 74: 1055-58 
Jendroska K., Heinzel F. P., Torchia M., Stowring L., Kretzschmar H. A., Kon A., Stern A., Prusiner S. B. und DeArmond S. J. (1991). Proteinase-resistant prion protein accumulation in Syrian hamster brain correlates with regional pathology and scrapie infectivity. Neurology, 41: 1482-90

Kaneko K., Zulianello L., Scott M., Cooper C. M., Wallace A. C., James T. L., Cohen F. E. und Prusiner S. B. (1997). Evidence for protein X binding to a discontinuous epitope on the cellular prion protein during scrapie prion propagation. PNAS, 94: 10069-74

Kanu N., Imokawa Y., Drechsel D. N., Williamson R. A., Birkett C. R., Bostock C. J. und Brockes J. P. (2002). Transfer of scrapie prion infectivity by cell contact in culture. Curr. Biol., 12: 523-30

Karkonen A., Murigneux A., Martinant J. P., Pepey E., Tatout C., Dudley B. J. und Fry S. C. (2005). UDP-glucose dehydrogenases of maize: a role in cell wall pentose biosynthesis. Biochem. J., 391: 409-15

Kikuchi Y., Kakeya T., Sakai A., Takatori K., Nakamura N., Matsuda H., Yamazaki T., Tanamoto K. und Sawada J. (2004). Propagation of a protease-resistant form of prion protein in long-term cultured human glioblastoma cell line T98G. J. Gen. Virol., 85: 3449-57

Klebe R. J. und Ruddle F. H. (1969). Neuroblastoma: Cell culture analysis of a differentiating stem cell system. J. Cell Biol., 43: 69A

Klose J. und Spielmann H. (1975). Gel isoelectric focusing of mouse lactate dehydrogenase: heterogeneity of the isoenzymes A4 and X4. Biochem. Genet., 13: 707-20

Korth C. Stierli B., Streit P., Moser M., Schaller H., Fischer R., Schulz-Schaeffer W., Kretzschmar H., Raeber A., Braun U., Ehrensperger F., Hornemann S., Glockshuber R., Riek R., Billeter M. Wuthrich K. und Oesch B. (1997). Prion (PrPSc)-specific epitope defined by y monoclonal antibody. Nature, 390: 74-77 
Kocisko D. A., Come J. H., Priola S. A., Chesebro B., Raymond G. J., Lansbury P. T. und Caughey B. (1995). Cell-free formation of protease-resistant prion protein. Nature, 370: 4714

Kouzu Y., Uzawa K., Koike H., Saito K., Nakashima D., Higo M., Endo Y., Kasamatsu A., Shiiba M., Bukawa H., Yokoe H. und Tanzawa H. (2006). Overexpression of stathmin in oral squamous-cell carcinoma: correlation with tumour progression and poor prognosis. Br. J. Cancer, 94: 717-23

Kramer M. L., Kratzin H. D., Schmidt B., Romer A., Windl O., Liemann S., Hornemann S. und Kretzschmar H. (2001). Prion protein binds copper within the physiological concentration range. J. Biol. Chem., 20: 16711-19

Krasemann S., Groschup M., Harmeyer S., Hunsmann G. und Bodemer W. (1996). Generation of monoclonal antibodies against human prion proteins in PrP0/0 mice. Mol Med., 2: 725-34

Krasemann S., Groschup M., Hunsmann G. und Bodemer W. (1996). Induction of antibodies against human prion proteins $(\operatorname{PrP})$ by DNA-mediated immunization of $\operatorname{Pr} P^{0 / 0}$ mice. $\mathrm{J}$. Immunol. Methods., 199: 109-18

Kretzschmar H. A., Stowring L. E., Westaway D., Stubblebine W. H., Prusiner S. B. und DeArmond S. J. (1986). Molecular cloning of a human prion protein CDNA. DNA, 5: 315-24

Kretzschmar H. A., Giese A., Brown D. R., Herms J., Keller B., Schmidt B. und Groschup M. (1997). Cell death in prion disease. J. Neural. Transm. Suppl., 50: 191-210

Kropp S., Zerr I., Schulz-Schaeffer W. J., Riedemann C., Bodemer M., Laske C., Kretzschmar H. A. und Poser S. (1999). Increase of neuron-specific enolase in patients with Creutzfeldt-Jakob disease. Neurosci. Lett., 261: 124-6

Kupzig S., Korolchuk V., Rollason R., Sugden A., Wilde A. und Banting G. (2003). Bst2/HM1.24 is a raft-associated apical membrane protein with an unusual topology. Traffic, 10: 694-709 
Laemmli U. K. (1970). Clevavage of structural proteins during the assembly of the head of bacteriophage T4. Natur, 227: 680-5

Landazuri N. und Le Doux J. M. (2006). Complexation with chondroitin sulfate $C$ and Polybrene rapidly purifies retrovirus from inhibitors of transduction and substantially enhances gene transfer. Biotechnol. Bioeng., 93: 146-58

Lange Y. und Steck T. L. (1985). Cholesterol-rich intracellular membranes: a precursor to the plasma membrane. J. Biol. Chem., 260: 15592-7

Lasmezas C. I., Comoy E., Hawkins S., Herzog C., Mouthon F., Konold T., Auvre F., Correia E., Lescoutra-Etchegaray N., Sales N., Wells G., Brown P. und Deslys J. P. (2005). Risk of oral infection with bovine spongiform encephalopathy agent in primates. Lancet, 365: 781-83

Lasserre C., Colnot C., Brechot C. und Poirier F. (1999). HIP/PAP gene, encoding a C-type lectin overexpressed in primary liver cancer, is expressed in nervous system as well as in intestine and pancreas of the postimplantation mouse embryo. Am. J. Pathol., 154: 1601-10

Leblanc P., Baas D. und Darlix J.-L. (2004). Analysis of the Interactions Between HIV-1 and the Cellular Prion Protein in a Human Cell Line. J. Mol. Biol., 337: 1035-51

Lee S., Agah R., Xiao M., Frutkin A. D., Kremen M., Shi H. und Dichek D. A. (2006). In vivo expression of a conditional TGF-beta1 transgene: no evidence for TGF-beta1 transgene expression in SM22alpha-tTA transgenic mice. J. Mol Cell. Cardiol., 40: 148-56

Lee Y. H., You J. O. und Peng C. A. (2005). Retroviral transduction of adherent cells in resonant acoustic fields. Biotechnol. Prog., 21: 372-6

Legname G., Baskakov I. V., Nguyen H. O., Riesner D., Cohen F. E., DeArmond S. J. und Prusiner S. B. (2004). Synthetic mammalian prions. Science, 305: 673-6

Lehmann S. und Harris D. A. (1997). Blockade of glycosylation promotes acquisition of scrapie-like properties by the prion protein in cultured cells. J. Biol. Chem., 272: 21479-87 
Lehmann S. (2005). Prion propagation in cell culture. Methods Mol. Biol., 299: 227-34

Leffers K. W., Schell J., Jansen K., Lucassen R., Kaimann T., Nagel-Steger L., Tatzelt J. und Riesner D. (2004). The structural transition of the prion protein into its pathogenic conformation is induced by unmasking hydrophobicsites. J. Mol. Biol., 344: 839-53

Leliveld S. R., Dame R. T., Wuite G. J., Stitz L. und Korth C. (2006). The expanded octarepeat domain selectively binds prions and disrupts homomeric prion protein interactions. J. Biol. Chem., 281: 3268-75

Li K. et al. (1989). Ferri-dye collodial iron binding followed by perls'reaction for the staining of proteins transferred from sodium dodecylsulfate gels to nitrocellulose and positively charged nylon membranes. Anal. Biochem., 153: 18-22

Li K. W., Geraerts W. P., van Elk R. und Joosse J. (1989). Quantification of proteins in the subnanogram and nanogram range: comparison of the aurodye, ferried and India ink staining methods. Anal. Biochem., 145: 315-21

Lindl T. (2000). Zell und Gewebekultur. 4. überarbeitete und erweiterte Auflage, Spektrum Akademischer Verlag, Heidelberg; Berlin.

Lopez Garcia F., Zahn R., Riek R. und Wuthrich K. (2000). Nmr Structure of the Bovine Prion Protein. PNAS, 97: 8334-39

Lopes M. H., Hajj G. N., Muras A. G., Mancini G. L., Castro R. M., Ribeiro K. C., Brentani R. R., Linden R. und Martins V. R. (2005). Interaction of cellular prion and stress-inducible protein 1 promotes neuritogenesis and neuroprotection by distinct signalling pathways. J. Neurosci., 25: 11330-39

Endharti A. T., Zhou Y. W., Nakashima I. und Suzuki H. (2005) Galectin-1 supports survival of naive T cells without promoting cell proliferation. Eur. J. Immunol., 35: 86-97 
Lo W. Y., Tsai M. H., Tsai Y., Hua C. H., Tsai F. J., Huang S. Y., Tsai C. H. und Lai C. C. (2006). Identification of over-expressed proteins in oral squamous cell carcinoma (OSCC) patients by clinical proteomic analysis. Clin. Chim. Acta., 30: Epublished

Lu Y. und Lotan R. (1999). Transcriptional regulation by butyrate of mouse galectin-1 gene in embryonal carcinoma cells. Biochim. Biophys. Acta, 1444: 85-91

Lugaresi E., Medori R., Baruzzi P. M., Cortelli P., Lugaresi A. und Tinuper P. (1986). Fatal familiar insomnia and dysautonomia, with selective degeneration of thalamic nuclei. N. Engl. J. Med., 315: 997-1003

Lupi O., Dadalti P., Cruz E. und Sanberg P. R. (2006). Are prions related to the emergence of early life? Med. Hypotheses., 28: Epublished

Marcos Z., Bodegas M. E., Sesma M. P. und Guembe L. (2005) Characterization of PrPcimmunoreactive cells in monkey (Macaca fascicularis) gastrointestinal tract. Ann. N. Y. Acad. Sci., 1040: 387-90

Marsh R. F., Kincaid A. E., Bessen R. A. und Bartz J. C. (2005). Interspecies transmission of chronic wasting disease prions to squirrel monkeys (Saimiri sciureus). J. Virol., 79: 13794-96

Mazzoni I. E., Ledebur Jr. H. C., Paramithiotis E. und Cashman N. (2005). Lymphoid signal transduction mechanisms linked to cellular prion protein. Biochem. Cell Biol., 83: 644-53

McKenzie D., Bartz J. C. und March R. F. (1996). Transmissible mink encephalopathy. Seminars in Virology, 7: 201-06

McKinley M. P., Bolton D. C. und Prusiner S. B. (1983). A protease-resistant protein is a structural component of the scrapie prion. Cell, 35: 57-62

Menendez P., Wang L., Cerdan C. und Bhatia M. (2006). Retroviral transduction of hematopoietic progenitors derived from human embryonic stem cells. Methods Mol. Biol., 331: 201-20 
Mehlhorn I., Groth D., Stockel J., Moffat B., Reilly D., Yansura D., Willett W. S., Baldwin M., Fletterick R., Cohen F. E., Vandlen R., Henner D. und Prusiner S. B. (1996). High-level expression and characterization of a purified 142-residue polypeptide of the prion protein. Biochemistry, 35: 5528-37

Meier P., Genoud N., Prinz M., Maissen M., Rulicke T., Zurbriggen A., Raeber A. J. und Aguzzi A. (2003). Soluble dimeric prion protein binds $\operatorname{Pr}(\mathrm{Sc})$ in vivo and antagonizes prion disease. Cell, 113: 49-60

Miller A. D. und Chen F. (1996). Retrovirus packaging cells based on 10AI murine leukemia virus for production of vectors that use multiple receptors for cell entry. J. Virol., 70: 5564-71

Miller M. W. und Williams E. S. (2004). Chronic wasting disease of cervids. Curr. Top. Microbiol. Immunol., 284: 193-214

Minor P., Newham J., Jones N., Bergeron C., Gregori L., Asher D., van Engelenburg F., Stroebel T., Vey M., Barnard G. und Head M. (2004). WHO Working Group on International Reference Materials for the Diagnosis and Study of Transmissible Spongiform Encephalopathies. Standards for the assay of Creutzfeldt-Jakob disease specimens. J. Gen. Virol., 85: 1777-84

Mitsuiki S., Hui Z., Matsumoto D., Sakai M., Moriyama Y., Furukawa K., Kanouchi H. und Oka T. (2006). Degradation of $\operatorname{PrP}(\mathrm{Sc})$ by keratinolytic protease from Nocardiopsis sp. TOA1. Biosci. Biotechnol. Biochem., 70: 1246-48

Morel N., Simon S., Frobert Y., Volland H., Mourton-Gilles C., Negro A., Sorgato M. C., Créminon C. und Grassi J., (2004). Selective and efficient immunoprecipitation of diseaseassociated form of the prion protein can be mediated by nonspecific interactions between monoclonal antibodies and scrapie-associated fibrils. J. Bio. Chem., 279: 30143-49

Moroncini G., Kanu N., Solforosi L., Abalos G., Telling G. C., Head M., Ironside J., Brockes J. P., Burton D. R. und Williamson R. A. (2004). Motif-grafted antibodies containing the replicative interface of cellular PrP are specific for PrPSc. PNAS, 101: 10404-9 
Moudjou M., Frobert Y., Grassi J. und La Bonnardiere C. (2001). Cellular Prion Protein Status in Sheep: Tissue-Specific Biochemical Signatures. J. Gen. Virol., 82: 2017-24

Mullis K. B. und Faloona F. A. (1987). Specific synthesis of DNA in vitro via a polymerasecatalysed chain reaction. Methods Enzymol., 155: 335-50

Nakamura Y., Sakudo A., Saeki K., Kaneko T., Matsumoto Y., Toniolo A., Itohara S. und Onodera T. (2003). Transfection of prion protein gene suppresses coxsackievirus B3 replication in prion protein gene-deficient cells. J. Gen. Virol., 84: 3495-502

Narang H. (1996). The Nature of the scrapie agent: the virus theory. Proc. Soc. Exp. Biol. Med., 212: 208-24

Neuhoff V. (1985). Clear background and highly sensitive protein staining with Coomassie Blue dyes in polyacrylamide gels: A systematic analysis. Electrophoresis, 6: 427-48

Nunziante M., Gilch S. und Schatzl H. M. (2003). Prion Diseases: From Molecular Biology to Intervention Strategies. Chembiochem., 4: 1268-84

Oesch B., Westaway D., Walchli M., McKinley M. P., Kent S. B., Aebersold R., Barry R. A., Tempst P., Teplow D. B., Hood L. E. et al. (1985). A Cellular Gene Encodes Scrapie Prp 2730 Protein. Cell, 40: 735-46

Oidtmann B., Simon D., Holtkamp N., Hoffmann R. und Baier M. (2003). Identification of cDNAs from Japanese pufferfish (Fugu rubripes) and Atlantic salmon (Salmo salar) coding for homologues to tetrapod prion proteins. FEBS, 538: 96-100

Paltrinieri S., Comazzi S., Spagnolo V., Rondena M., Ponti W. und Ceciliani F. (2004). Bovine Doppel (Dpl) and prion protein ( $\mathrm{PrP})$ expression on lymphoid tissue and circulating leukocytes. J. Histochem. Cytochem., 52: 1639-45

Pan K.-M., Baldwin M., Nguyen J., Gasset M., Serban A., Groth D., Mehlhorn I., Huang Z., Flettericks R. J., Cohen F. E. und B. Prusiner S. B. (1993). Conversion of a-helices into ,fsheets features in the formation of the scrapie prion proteins. PNAS, 90: 10962-66 
Paramithiotis E., Pinard M., Lawton T., LaBoissiere S., Leathers V. L., Zou W. Q., Estey L.A., Lamontagne J., Lehto M. T., Kondejewski L. H., Francoeur G. P., Papadopoulos M., Haghighat A., Spatz S. J., Head M., Will R., Ironside J., O'Rourke K., Tonelli Q., Ledebur H. C., Chakrabartty A. und Cashman N. R. (2003). A prion protein epitope selective for the pathologically misfolded conformation. Nat. Med., 9: 893-9

Parry H. B. (1983). Recorded occurrence of scrapie from 1750. In Oppenheimer Dr. ed. Scrapie disease in sheep. London: Academic Press, 31-59

Paquet S., Sabuncu E., Delaunay J. L., Laude H. und Vilette D. (2004). Prion Infection of Epithelial Rov Cells Is a Polarized Event. J. Virol., 78: 7148-52

Poser S., Zerr I., Schroeter A., Otto M., Giese A., Steinhoff B. J. und Kretzschmar H. A. (2000). Clinical and differential diagnosis of Creutzfeldt-Jakob disease. Arch. Virol. Suppl., 16: $153-9$

Prinz M., Heikenwalder M., Junt T., Schwarz P., Glatzel M., Heppner F. L., Fu Y. X., Lipp M. und Aguzzi A. (2003). Positioning of follicular dendritic cells within the spleen controls prion neuroinvasion. Nature, 425: 957-62

Priola S. A., Caughey B.,Wehrly K. und Chesebro B. (1995). A 60-kDa prion protein (PrP) with properties of both the normal and scrapie-associated forms of PrP. J. Biol. Chem., 270: 3299-305

Prusiner S. B., Groth D. F., Cochran S. P., Masiarz F. R., McKinley M. P. und Martinez H. M. (1980). Molecular properties, partial purification, and assay by incubation period measurements of the hamster scrapie agent. Biochemistry, 19: 4883-91

Prusiner S. B. (1982). Novel proteinaceous infectious particles cause scrapie. Science, 216: $136-44$

Prusiner S. B. (1991). Molecular biology of prion diseases. Science, 252: 1515-22

Public Health Agency of Canada, http://www.phac-aspc.gc.ca/cjd-mcj/gfx/bse-vcjd-ukgraph_e.gif 
Race R. E., Priola S. A., Bessen R. A., Ernst D., Dockter J., Rall G. F., Mucke L., Chesebro B. und Oldstone M. B. (1995). Neuron-specific expression of a hamster prion protein minigene in transgenic mice induces susceptibility to hamster scrapie agent. Neuron, 15: 1183-91

Raggatt P. R. und Whitehouse M. W. (1966). Substrate and inhibitor specificity of the cholesterol oxidase in bovine adrenal cortex. Biochem. J., 101: 819-30

Ratzka P., Schroter A., Cepek L., Henkel K., Wiltfang J., Kretzschmar H. A., Prange H., Poser S. und Otto M. (2001). Unaltered apoptotic behaviour of mononuclear cells from patients with sporadic Creutzfeldt-Jakob disease. J. Neurol., 248: 690-4

Riek R., Hornemann S., Wider G., Billeter M., Glockshuber R. und Wuthrich K. (1996). NMR structure of the mouse prion protein domain $\operatorname{PrP}(121-321)$. Nature, 6587: 180-82

Robertson A., Perea J., Tolmachova T., Thomas P. K. und Huxley C. (2002). Effects of mouse strain, position of integration and tetracycline analogue on the tetracycline conditional system in transgenic mice. Gene, 282: 65-74

Rogers M., Yehiely F., Scott M. und Prusiner S. B. (1993). Conversion of truncated and elongated prion proteins into the scrapie isoform in cultured cells. PNAS, 90: 3182-86

Rosenthal E. (2006). Inquiries in Britain Uncover Loopholes in Drug Trials. The New York Times, 3. August

Rychlik W., Spencer W. J. und Rhoads R. E. (1990). Optimization of the annealing temperature for DNA amplification in vitro. Nucl. Acids Res., 18: 6409-12

Sabuncu E., Petit S., Le Dur A., Lai T. L., Vilotte J. L., Laude H. und Vilette D. (2003). PrP Polymorphisms Tightly Control Sheep Prion Replication in Cultured Cells. J. Virol., 77: 2696-700 
Safar J., Ceroni M., Piccardo P., Liberski P. P., Miyazaki M., Gajdusek D. C. und Gibbs C. J. Jr. (1990). Subcellular Distribution and Physicochemical Properties of Scrapie-Associated Precursor Protein and Relationship with Scrapie Agent. Neurology, 40: 503-08

Safar J. G., Geschwind M. D., Deering C., Didorenko S., Sattavat M., Sanchez H., Serban A., Vey M., Baron H., Giles K., Miller B. L., DeArmond S. J. und Prusiner S. B. (2005). Diagnosis of human prion disease. PNAS, 102: 3501-06

Safar J. G., Kellings K., Serban A., Groth D., Cleaver J. E., Prusiner S. B. und Riesner D. (2005). Search for a prion-specific nucleic acid. J. Virol., 79: 10796-806

Safar J. G., Wille H., Geschwind M. D., Deering C., Latawiec D., Serban A., King D. J., Legname G., Weisgraber K. H., Mahley R. W., Miller B. L., DeArmond S. J. und Prusiner S. B. (2006). Human prions and plasma lipoproteins. PNAS, 103: 11312-7

Saiki R. K., Scharf S., Faloona F., Mullis K. B., Horn G. T., Erlich H. A. und Arnheim N. (1985). Enzymatic amplification of beta-globin genomic sequences and restriction site analysis for diagnosis of sickle cell anemia. Science, 230: 1350-54

Sailer A., Bueler H., Fischer M., Aguzzi A. und Weissmann C. (1994). No propagation of prions in mice devoid of PrP. Cell, 77: 967-8

Sakaguchi S., Katamine S., Nishida N., Moriuchi R., Shigematsu K., Sugimoto T., Nakatani A., Kataoka Y., Houtani T., Shirabe S., Okada H., Hasegawa S., Miyamoto T. und Noda T. (1996). Loss of cerebellar Purkinje cells in aged mice homozygous for a disrupted PrP gene. Nature, 380: 528-31

Sakudo A., Lee D. C., Li S., Nakamura T., Matsumoto Y., Saeki K., Itohara S., Ikuta K. und Onodera T. (2005). PrP cooperates with STI1 to regulate SOD activity in PrP-deficient neuronal cell line. Biochem. Biophys. Res. Commun., 328: 14-19

Salguero F. J., Diaz-San S. F., Brun A., Cano M. J. und Torres J. M. ( 2006). Comparison of three monoclonal antibodies for use in immunohistochemical detection of bovine spongiform encephalopathy protease-resistant prion protein. J. Vet. Diagn. Invest., 18: 106-9 
Sambrook J., Fritsch E. F. und Maniatis T. (1989). Molecular cloning: A laboratory manual. Cold Spring Harbor Laboratory Press, New York

Sanger F., Nicklen S. und Coulson A. R. (1977). DNA sequencing with chain-terminating inhibitors. PNAS, 74: 5463-67

Satoh J. und Yamamura T. (2004). Gene expression profile following stable expression of the cellular prion protein. Cell Mol. Neurobiol., 24: 793-814

Scharf S. J., Hirn G. T. und Erlich H. A. (1986). Direct cloning and sequence analysis of enzymatically amplified genomic sequences. Science, 233: 1076-78

Schatzl H. M., Da Costal M., Taylor L., Cohen F. E. und Prusiner S. B. (1995). Prion Protein Gene Variation Among Primates. J. Mol. Biol., 245: 362-74

Scheibel T. (2004). Amyloid formation of a yeast prion determinant. J. Mol. Neurosci., 23: $13-22$

Sekijima M., Motono C., Yamasaki S., Kaneko K. und Akiyama Y. (2003). Molecular dynamics simulation of dimeric and monomeric forms of human prion protein: insight into dynamics and properties. Biophys J., 85: 1176-85

Shumyatsky G. P., Malleret G., Shin R. M., Takizawa S., Tully K., Tsvetkov E., Zakharenko S. S., Joseph J., Vronskaya S., Yin D., Schubart U. K., Kandel E. R. und Bolshakov V. Y. (2005). Stathmin, a gene enriched in the amygdala, controls both learned and innate fear. Cell, 123: 697-709

Simak J., Holada K., D'Agnillo F., Janota J. und Vostal J. G. (2002). Cellular prion protein is expressed on endothelial cells and is released during apoptosis on membrane microparticles found in human plasma. Transfusion, 42: 334-42

Simonic T., Duga S., Strumbo B., Asselta R., Ceciliani F. und Ronchi S. (2000). CDNA Cloning of Turtle Prion Protein. FEBS, 469: 33-38 
Stack M., Jeffrey M., Gubbins S., Grimmer S., Gonzalez L., Martin S., Chaplin M., Webb P., Simmons M., Spencer Y., Bellerby P., Hope J., Wilesmith J. und Matthews D. (2006). Monitoring for bovine spongiform encephalopathy in sheep in Great Britain, 1998-2004. J. Gen. Virol., 87: 2099-107

Stahl N., Borchelt D. R., Hsiao K. und Prusiner S. B. (1987). Scrapie prion protein contains a phosphatidylinositol glycolipid. Cell, 51: 229-40

Stahl N., Baldwin M. A., Teplow D. B., Hood L., Gibson B. W., Burlingame A. L. und Prusiner S. B. (1993). Structural studies of the scrapie prion protein using mass spectrometry and amino acid sequencing. Biochemistry, 32: 1991-2002

Starke R., Harrison P., Mackie I., Wang G., Erusalimsky J. D., Gale R., Masse J. M., Cramer E., Pizzey A., Biggerstaff J. und Machin S. (2005). The expression of prion protein $(\operatorname{Pr} P(C))$ in the megakaryocyte lineage. J. Thromb. Haemost., 3: 1266-73

Stewart R. S., Piccardo P., Ghetti B. und Harris D. A. (2005) Neurodegenerative illness in transgenic mice expressing a transmembrane form of the prion protein. J. Neurosci., 25: 3469-77

Strey C. W., Spellman D., Stieber A., Gonatas J. O., Wang X., Lambris J. D. und Gonatas N. K. (2004). Dysregulation of stathmin, a microtubule-destabilizing protein, and up-regulation of Hsp25, Hsp27, and the antioxidant peroxiredoxin 6 in a mouse model of familial amyotrophic lateral sclerosis. Am. J. Pathol., 165: 1701-18

Strom A., Diecke S., Hunsmann G. und Stuke A. W. (2006). Identification of prion protein binding proteins by combined use of far-Western immunoblotting, two dimensional gel electrophoresis and mass spectrometry. Proteomics, 6: 26-34

Stuke A. W. und Strom A. (2005). Tetracycline-regulated highly inducible expression of the human prion protein in murine 3T3 cells. Protein Expression and Purification, 39: 8-17

Ullmann A., Jacob F. und Monod J. (1967). Charakterization by in vitro complementation of a peptide corresponding to an operator-proximal segment of the beta-galactosidase structural gene of Escherichia coli. J. Mol. Biol., 24: 339-43 
Takahashi M., Ogino T. und Baba K. (1969). Estimation of relative molecular length of DNA by electrophoresis in agarose gel. Biochim. Biophys. Acta, 174: 183-87

Tang M. X., Redemann C. T. und Szoka Jr. F. C. (1996). In vitro gene delivery by degraded polyamidoamine dendrimers. Bioconjugate Chem., 7: 703-14

Taraboulos A., Scott M., Semenov A., Avrahami D., Laszlo L. und Prusiner S. B. (1995). Cholesterol depletion and modification of $\mathrm{COOH}$-terminal targeting sequence of the prion protein inhibit formation of the scrapie isoform. J. Cell Biol., 129: 121-32

Telling G. C., Scott M., Mastrianni J., Gabizon R., Torchia M., Cohen F. E., DeArmond S. J. und Prusiner S. B. (1995). Prion propagation in mice expressing human and chimeric PrP transgenes implicates the interaction of cellular PrP with another protein. Cell, 83: 79-90

Thompsett A. R., Abdelraheim S. R., Daniels M. und Brown D. R. (2005). High affinity binding between copper and full-length prion protein identified by two different techniques. J. Biol. Chem., 280: 42750-8

Tobler I., Gaus S. E., Deboer T., Achermann P., Fischer M., Rülicke T., Moser M., Oesch B., McBride P. A. und Manson J. C. (1996). Altered circadian activity rhythmus and sleep in mice devoid of prion protein. Nature, 380: 639-42

Todorova-Balvay D., Simon S., Creminon C., Grassi J., Srikrishnan T. und Vijayalakshmi M. A. (2005). Copper binding to prion octarepeat peptides, a combined metal chelate affinity and immunochemical approaches. J. Chromatogr. B. Analyt .Technol. Biomed. Life. Sci., 818: $75-82$

Todaro G. J. und Green H. (1963). Quantitative studies of the growth of mouse embryo cells in culture and their development into established lines. Cell Biol., 17: 299-313

Trieschmann L., Navarrete Santos A., Kaschig K., Torkler S., Maas E., Schatzl H. und Bohm G. (2005). Ultra-sensitive detection of prion protein fibrils by flow cytometry in blood from cattle affected with bovine spongiform encephalopathy. BMC. Biotechnol. 4: 5-26 
Vey M., Pilkuhn S., Wille H., Nixon R., DeArmond S. J., Smart E. J., Anderson R. G., Taraboulos A. und Prusiner S. B. (1996). Subcellular colocalization of the cellular and scrapie prion proteins in caveolae-like membranous domains. PNAS, 93: 14945-49

Volkel D., Zimmermann K., Zerr I., Lindner T., Bodemer M., Poser S. und Schwarz H. P. (2001). C-reactive protein and IL-6: new marker proteins for the diagnosis of CJD in plasma? Transfusion, 41: 1509-14

Xiang W., Windl O., Wunsch G., Dugas M., Kohlmann A., Dierkes N., Westner I. M. und Kretzschmar H. A. (2004). Identification of differentially expressed genes in scrapie-infected mouse brains by using global gene expression technology. J. Virol., 78: 11051-60

Warwicker J. (2000). Modeling a prion protein dimer: predictions for fibril formation. Biochem. Biophys. Res. Commun., 278: 646-52

Weissmann C. und Flechsig E. (2003). PrP knock-out and PrP transgenic mice in prion research. Br. Med. Bull., 66: 43-60

Weissmann C., Bueler H., Fischer M., Sailer A., Aguzzi A. und Aguet M. (1994). PrPdeficient mice are resistant to scrapie. Ann. N. Y. Acad. Sci., 724: 235-40

Weissmann C., Bueler H., Fischer M., Sauer A. und Aguet M. (1994). Susceptibility to scrapie in mice is dependent on PrPC. Philos. Trans. R. Soc. Lond. B. Biol. Sci., 343: 431-33

Weiss B., Jacquemine-Sablon T. R., Fareed G. C. und Richardson C. C. (1968). Further purification and properties of polynucleotid ligase from E. coli infected with bacteriophage T4. J. Biol. Chem., 243: 4543-55

Wells G. A. H., Scott A. C., Johnson C. T., Gunning R. F., Hancock R. D., Jeffery M., Dawson M. und Bradley R. (1987). A novel progressive spongiform encephalopathy in cattle. Vet. Rec., 121: 419-420 
Wells G. A., Dawson M., Hawkins S. A., Green R. B., Dexter I., Francis M. E., Simmons M. M., Austin A. R. und Horigan M. W. (1994). Infectivity in the ileum of cattle challenged orally with bovine spongiform encephalopathy. Vet. Rec., 135: 40-41

Wells G. A., Hawkins S. A., Austin A. R., Ryder S. J., Done S. H., Green R. B., Dexter I., Dawson M. und Kimberlin R. H. (2003). Studies of the transmissibility of the agent of bovine spongiform encephalopathy to pigs. J. Gen. Virol., 84: 1021-31

Wells G. A. H., Spiropoulos J., Hawkins S. A. C., Ryder S. J. (2005). Pathogenesis of experimental bovine spongiform encephalopathy (BSE): preclinical infectivity in tonsil and observations on the distribution of lingual tonsil in slaughtered cattle. Vet. Rec., 156: 401-07

Wilesmith J. W., Wells G. A. H., Cranwell M. P. und Ryan J. M. B. (1988). Bovine spongiform encephalopathy: epidemiological studies. Vet. Rec., 123: 638-44

Wilesmith J. W., Ryan J. B. und Atkinson M. J. (1991). Bovine spongiform encephalopathy: epidemiological studies on the origin. Vet. Rec., 128: 199-203

Williams E. S. und Young S. (1980). Chronic wasting disease of captive mule deer: $a$ spongiform encephalopathy. J. Wildl. Dis., 16: 89-98

Williams E. S. und Young S. (1982). Spongiform encephalopathy of rocky mountain elk. J. Wildl. Dis., 18: 465-71

Windl O., Dempster M., Estibeiro P. und Lathe R. (1995). A Candidate Marsupial Prp Gene Reveals Two Domains Conserved in Mammalian Prp Proteins. Gene, 159: 181-86

Wong B. S., Li R., Sassoon J., Kang S. C., Liu T., Pan T., Greenspan N. S., Wisniewski T. und Brown D. R. (2003). Sy MS. Mapping the antigenicity of copper-treated cellular prion protein with the scrapie isoform. Cell Mol. Life Sci., 60: 1224-34

Wu C., Pang W. und Zhao D. (2006). Amino acid sequence of the Amur tiger prion protein. Virus Res., 121: 93-6 
Wyatt J. M., Peardon G. R., Smerdon T. N., Gruffydd-Jones T. J., Wells G. A. H. und Wilesmith J. W. (1991). Naturally occurring scrapie-like spongiform encephalopathy in five domestic cats. Vet. Rec., 129: 233-36

Yakovleva O., Janiak A., McKenzie C., McShane L., Brown P. und Cervenakova L. (2004). Effect of protease treatment on plasma infectivity in variant Creutzfeldt-Jakob disease mice. Transfusion, 44: 1700-5

Zahn R., Liu A., Luhrs T., Riek R., von Schroetter C., Lopez Garcia F., Billeter M., Calzolai L., Wider G. und Wuthrich K. (2000). Nmr Solution Structure of the Human Prion Protein. PNAS, 97: 145-50

Zanata S. M., Lopes M. H., Mercadante A. F., Hajj G. N., Chiarini L. B., Nomizo R., Freitas A. R., Cabral A. L., Lee K. S., Juliano M. A., de Oliveira E., Jachieri S. G., Burlingame A., Huang L., Linden R., Brentani R. R. und Martins V. R. (2002). Stress-inducible protein 1 is a cell surface ligand for cellular prion that triggers neuroprotection. EMBO, 21: 3307-16

Zeidler M., Stewart G. E., Barraclough C. R., Bateman D. E., Bates B., Burn B. J., Cholchester A. C., Durward W., Fletcher N. A., Hawkins A. C., Mackenzie J. M. und Will R. G. (1997). New variant Creutzfeldt-Jakob disease: Neurological features and diagnostic tests. Lancet, 350: 903-07

Ziegler J., Sticht H., Marx U. C., Muller W., Rosch P. und Schwarzinger S. (2003) CD and NMR studies of prion protein $(\operatorname{PrP})$ helix 1. Novel implications for its role in the PrPC->PrPSc conversion process. J. Biol. Chem., 278: 50175-81

Zhang Y., Spiess E., Groschup M. H. und Burkle A. (2003). Up-regulation of cathepsin B and cathepsin L activities in scrapie-infected mouse Neuro2a cells. J. Gen. Virol., 84: 2279-83

Zhang X. und Godbey W. T. (2006). Viral vectors for gene delivery in tissue engineering. Adv. Drug. Deliv. Rev., 58: 515-34

Zou W. Q., Zheng J., Gray D. M., Gambetti P., Chen S. G. (2004). .Antibody to DNA detectsscrapie but not normal prion protein. PNAS, 101: 1380-5 


\section{Danksagung}

Ich danke Herrn Prof. Oliver Einsle vom GZMB, in Göttingen und Frau Prof. Frauke Melchior, Leiterin der Biochemie I der Medizin an der Georg-August Universität Göttingen, für die Übernahme des 1 . Referenten und des 2. Referenten.

Ich danke Herrn Prof. Gerhard Hunsmann dafür, dass ich meine Doktorarbeit in der Abteilung Virologie und Immunologie des Deutschen Primatenzentrums, Mitglied der Leibnitz Gesellschaft anfertigen durfte.

Herrn Dr. Andreas Stuke und seiner Arbeitsgruppe am Deutschen Primatenzentrums danke ich für die Betreuung während der Anfertigung meiner Doktorarbeit.

Herrn Dr. Olaf Jahn von der Arbeitsgruppe Proteomics in der Abteilung Molekulare Neurobiologie am Max-Planck Institut für experimentelle Medizin, Göttingen, danke ich für die massenspektrometrischen Untersuchungen meiner ausgewählten 2D-Spots.

Herrn Dr. Edgar Holznagel und Frau Dipl. Ing. (FH) Barabara Yutzy, vom Primatenzentrum des Paul-Ehrlich-Instituts, Langen, danke ich für Möglichkeit der Durchführung der Messung von infizierten Proben im FACS Gerät.

Herrn PD. Dr. Sighard Sopper und Herrn Dipl. Biochem. Reiner Schulte aus der Abteilung Virologie und Immunologie des Deutschen Primatenzentrums danke ich für die Unterstützung bei der Durchführung und Auswertung der FACS Analysen.

Dr. Christian Roos, von der Arbeitsgruppe Primatengenetik am Deutschen Primatenzentrum, danke ich für die Beschaffung der DNA verschiedener Spezies, die Sequenzierung der amplifizierten Fragmente und für die Beratung bei der Interpretationen der Sequenzen.

Ich danke meinem ehemaligen Komillitonen Herrn Dipl. Biochem. Knut Kölbel, von der Abteilung Enzymologie der Biochemischen Fakultät der Martin-Luther Universität HalleWittenberg, für die CD-Spektroskopischen Untersuchungen ausgewählter Proteinproben. 
Herrn Dr. Jörg Kahle, von der Abteilung Molekularbiologie am Zentrum für Biochemie und Molekulare Zellbiologie an der Georg-August Universität Göttingen, danke ich für die Möglichkeit der Durchführung meiner Fluoreszenz- und Immunfluoreszenzmikroskopie Untersuchungen.

Meiner Familie und meinen Freunden danke ich für die Unterstützung während der Zeit die ich in Göttingen verbracht habe, um meine Doktorarbeit anzufertigen. 


\section{Lebenslauf:}

$\begin{array}{ll}\text { Name: } & \text { Lars Heinig } \\ \text { Ausbildung: } & \text { Dipl. Biochemiker } \\ \text { Geburtsdatum: } & \text { 29. April 1978 } \\ \text { Geburtsort: } & \text { Karl-Marx-Stadt; jetzt Chemnitz }\end{array}$

\section{Bildungshintergrund}

04/03 - 09/06 Anfertigung der Doktorarbeit am Deutschen Primatenzentrum in der Abt. Virologie und Immunologie bei Prof. Hunsmann mit Thema: „Ex vivo " Replikation des pathogenen Prion Proteins.

05/06 - 05/06 Wissenschaftliche Hilfskraft am Albrecht von Haller Institut der GeorgAugust Universität Göttingen bei Prof. R. Tischner

02/03 - 03/03 Wissenschaftlicher Mitarbeiter in der Abteilung Hämatologie am Klinikum der Johann Wolfgang Goethe-Universität Frankfurt am Main bei Prof. Hoelzer mit dem Thema: Modulatoren der Chromatinstruktur als therapeutische Strategie bei soliden Tumoren und hämatologischen Neoplasien.

04/00 - 06/00 Forschungsgruppenpraktikum in am Institut für Physiologische Chemie an der Martin-Luther-Universität Halle-Wittenberg bei Prof. Braun mit dem Thema: Charakterisierung von Mox2 Mutanten bei Mäuseembryonen.

07/99 - 09/99 Ferialpraktikant bei Boeringer Ingelheim Wien, Österreich

03/99-07/99 Studentische Hilfskraft an der Martin-Luther-Universität Halle-

\section{Studium} Wittenberg, im Fachbereich Biochemie / Biotechnologie

$10 / 97-11 / 02$

Studium der Biochemie / Biotechnologie an der Martin-LutherUniversität Halle-Wittenberg

Diplomarbeit im Fachbereich Biochemie / Biotechnologie, in der Arbeitsgruppe Biosensoren bei PD Dr. U. Spohn mit dem Thema: Amperometrische Pyruvatsensoren auf der Basis nanoporöser Schichten.

\section{Grundwehrdienst}

11/96 - 08/97 Grundwehrdienst in Regensburg

\section{Schule}

09/92 - 08/96

Gottfried - Leibniz - Gymnasium, Chemnitz

Abschluss: Allgemeine Hochschulreife

$09 / 84-08 / 92$

Georgi - Dimitroff - Oberschule, Chemnitz 


\section{Konferenzbeiträge:}

2003:

Heinig L., Strom A. und Stuke A. W. „Cell lines over expressing prnp genes of different species to characterise homo- and heterologous prions" Prion diseases: from basic RESEARCH to intervention CONCEPTS, München, Deutschland

Heinig L., Motzkus D. und Stuke A. W. "Regulation of PrP expression to characterise prions from several species” Prion 2004 First International Conference of the European Network of Excellence NeuroPrion, Pasteur Institut, Paris, Frankreich

Heinig L. und Stuke A. W. "Regulated prion protein expression for prion conversion monitoring” Prion 2005 Between fundamentals and society’s needs Düsseldorf, Deutschland

\section{Kurse:}

„Schutz und Vermarktung von Forschungsergebnissen am DPZ“ Ascenion, Göttingen, Deutschland 
Glück entsteht oft durch

Aufmerksamkeit in kleinen Dingen.

Unglück oft durch

Vernachlässigung kleiner Dinge.

Chinesische Weisheit 